The Finnish Environment

\title{
ENVIRONMENTAL
} PROTECTION

Pirkko Kauppila and Saara Bäck (eds)

\section{The state \\ of Finnish coastal waters in the 1990s}

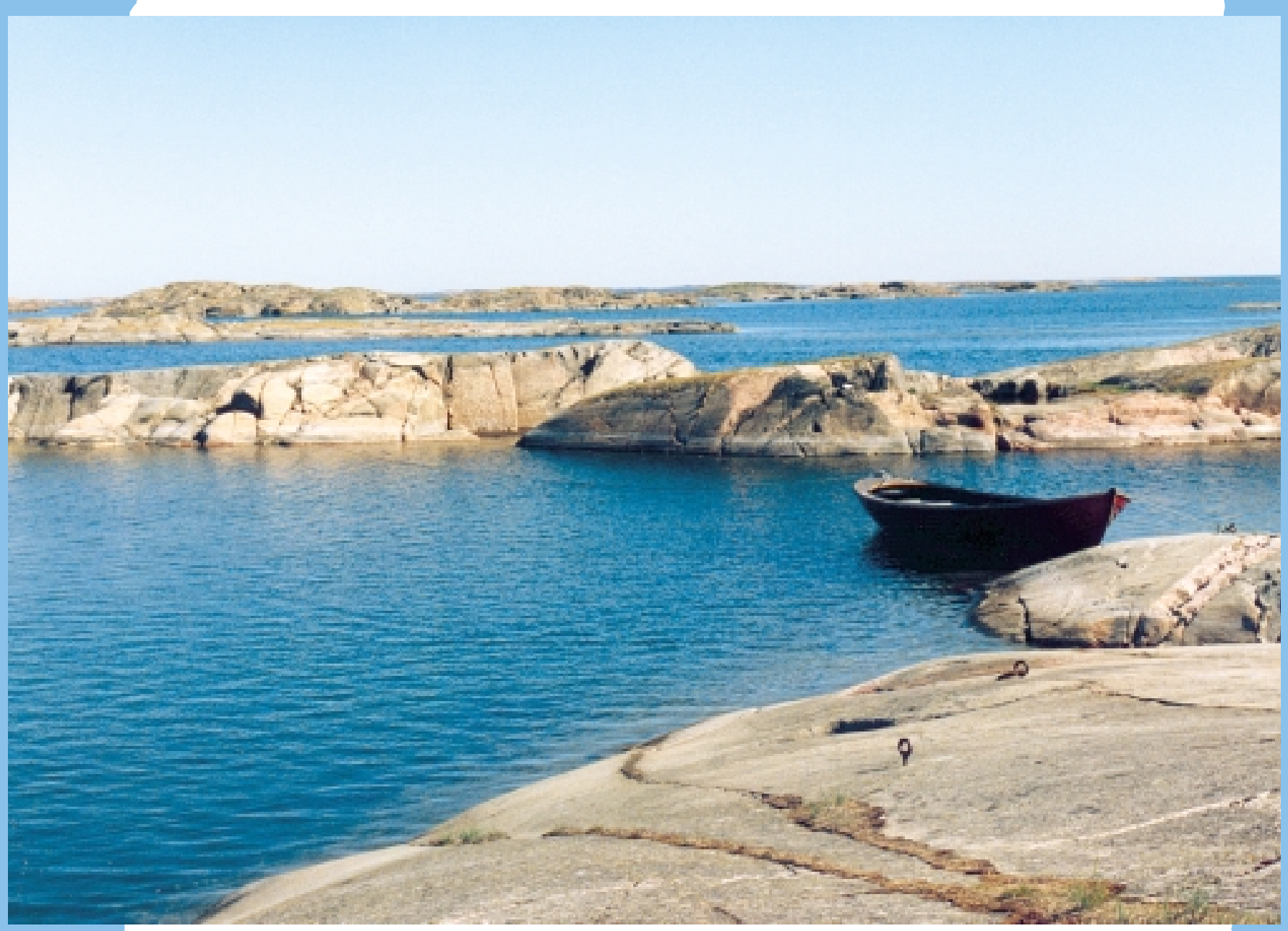




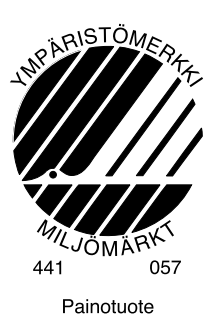

The publication is also available in the internet

http://www.vyh.fi/palvelut/julkaisu/elektro/fe472/fe472.htm

ISBN 952- I I-0878-9

ISSN 1238-73|2

Maps: Maanmittauslaitos, permission no 7/MYY/0

Cover photo: Pirkko Kauppila

Page-layout: DTPage Oy

Printinghouse: Vammalan Kirjapaino Oy, 200I

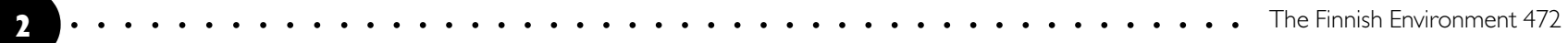


The status of Finnish coastal waters is an important environmental issue. Especially the shallow coastal zone is in many respects sensitive to pollution and eutrophication. The long term loading of nutrients and harmful substances of the catchment areas have had deteriorating effects in many ways. Finally the loading reaches coastal waters and affects the coastal zone. Water protection measures based on sound assessment information are urgently needed. Improvement of the ecological status of coastal waters and conservation of coastal areas are also required by the EU Water Policy Directive and the Habitats directive as well as by many international agreements, such as the HELCOM convention, the Ramsar convention and the Convention on biodiversity.

Numerous scientific articles and areal reports deal with Finnish coastal waters. However, only some reports provide the reader with general view of coastal water quality such as HELCOM periodic assessments of the state of the marine environment of the Baltic Sea.

This report is the second national effort to compile information on the changes in water quality in Finnish coastal waters. In addition to nutrients and harmful substances, monitoring data of phytoplankton and macrozoobenthos are also evaluated. Moreover, the available data on phytobenthos changes originated from separate research projects and it was evaluated. The report covers the years from the the early 1980s to the late 1990s. In addition to international, national and administrative requirements, the report also focus on providing information on coastal water state for the public.

The assessment is mainly based on the coastal monitoring data produced by the Finnish Environment Institute (FEI). The physical and chemical monitoring data in open sea areas originated from the Finnish Institute of Marine Research (FIRM). The section on fish catches was delivered by the Finnish Game and Fisheries Research Institute. Numerous scientific arcticles and reports were evaluated to assess the changes in phytobenthos because monitoring data for phytobenthos was not available. Additionally, local pollution control studies were utilized in order to obtain additional information on zoobenthos and harmful substances in polluted water areas.

The editors are grateful to the group of the collegues both in FEI and FIRM for their contributions to the report. We would like to express our warmest thanks to Sirkka Vuoristo who finialised the figures of this report, Petri Porvari for his participation to GIS-work, Antti-Räike and Anna-Maija Beloff who participated in compiling the data, Kati Manni, Petri Ekholm, Jussi Vuorenmaa and Jouni Lehtoranta for their contributions to the text for "information boxes". The English language was revised by Michael Bailey. We thank Doc. Matti Perttilä in FIRM and Teija Kirkkala in the Southwest Finland Environment Centre for their valuable comments on the manuscript. 


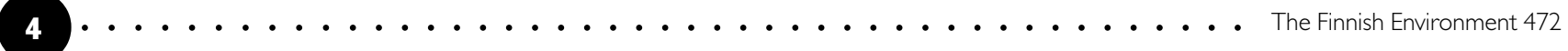




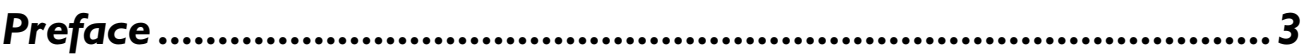

I Introduction ................................................................................. 7

1.1 Content and purpose of this report ...................................................... 7

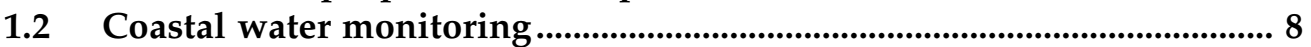

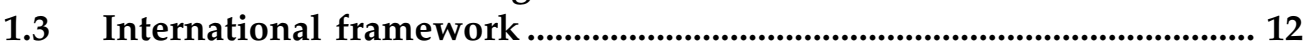

2 Main characteristics of Finnish coastal waters..................... I I3

3 Loading of pollutants ........................................................ I5

3.1 Nutrient loading and its source apportionment .......................................... 15

3.2 Trends in the nutrient loads in 1985-1998 ............................................. 22

3.3 Loading of organic matter and its trends in 1985-1997 ........................... 27

3.4 Loading of harmful substances .................................................................. 27

$4 \quad$ Hydrography and oxygen conditions.........................................30

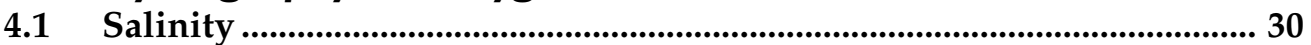

4.2 Oxygen ......................................................................................................... 35

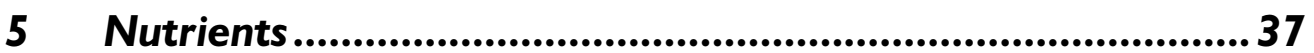

5.1 Spatial distribution of phosphorus and nitrogen ..................................... 37

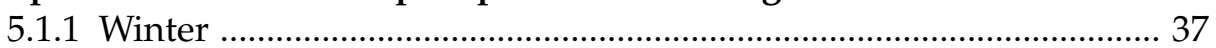

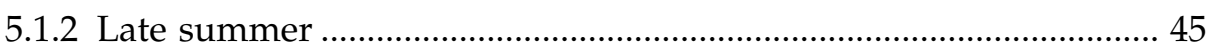

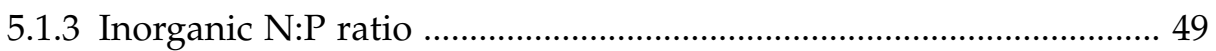

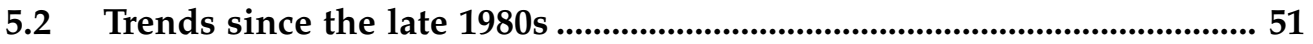

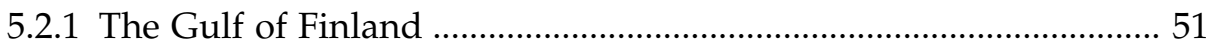

5.2.2 The Archipelago Sea ............................................................................ 51

5.2.3 The Bothnian Sea and the Bothnian Bay ............................................ 58

6 Changes in phytoplankton .......................................................6I

6.1 Areal distribution of phytoplankton chlorophyll $a$..............................61 61

6.2 Seasonal variations of phytoplankton ........................................................64

6.3 Long term changes in phytoplankton ......................................................66

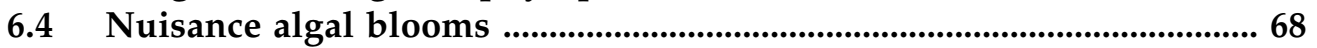

$7 \quad$ Changes in phytobenthos .......................................................... 7 I

7.1 Species composition of macroalgae ................................................................ 71

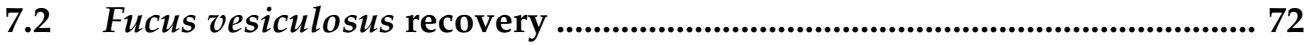

7.3 Soft bottom vegetation .................................................................................. 73

7.4 Mass occurrence of macroalgae .................................................................... 74

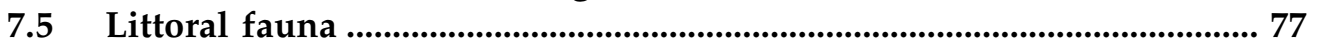

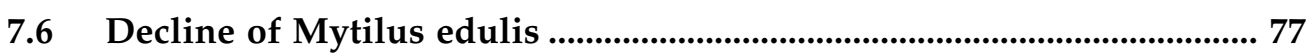

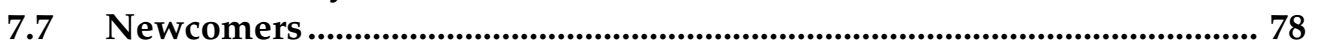

8 Changes in zoobenthic communities ........................................ 79

8.1 The Bothnian Bay ...................................................................................... 79

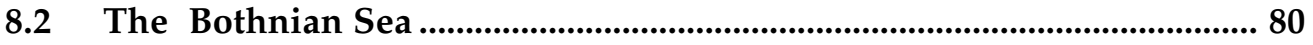

8.3 The Turku area in the Archipelago Sea ...................................................... 82 


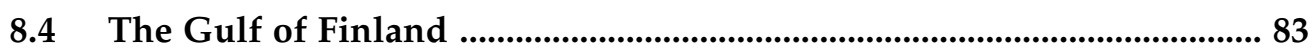

8.5 Zoobenthos trends in a reference area in Tvärminne ............................... 85

8.6 General zoobenthos trends in the Finnish coastal waters ....................... 86

$9 \quad$ Fish stocks and fisheries ..................................................89 89

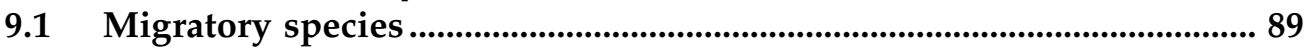

9.2 Limnic species .............................................................................................. 89

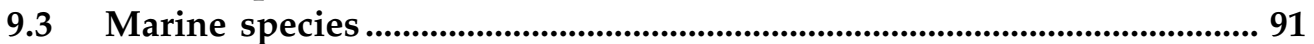

9.4 Direct harmful effects on fishery ............................................................... 92

10 Harmful substances ................................................................ 94

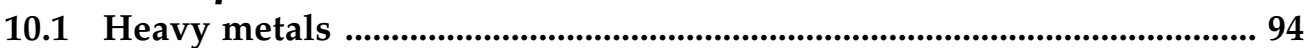

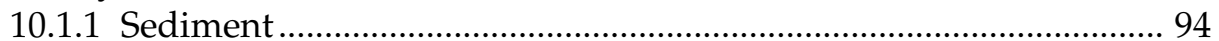

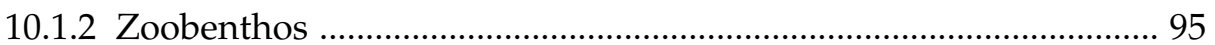

10.1.3 Hg in fish .................................................................................... 96

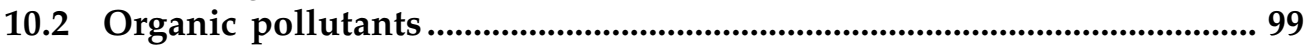

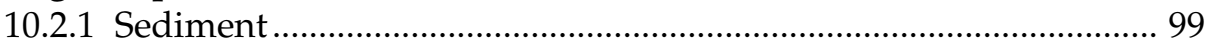

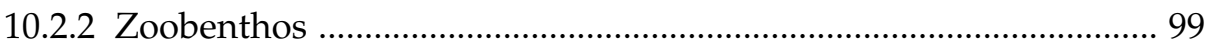

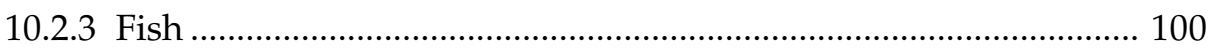

10.3 Oil and other contaminants from the petrochemical industry ............ 104

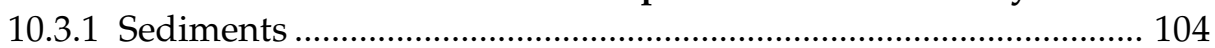

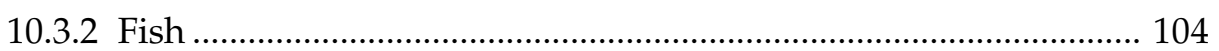

I I Classification of coastal water quality .............................. I 05

Summary in English and in Finnish ............................................ 109

References................................................................... I 22

Documentation pages ................................................................. I I32 


\section{I.I Context and purpose of this assessment report}

The ecological status of coastal waters has been and still is in most European countries an important environmental issue. The long term point-source loading of watercourses, especially by nutrients, as well as the indirect effects of increasing demand for different land use e.g agriculture and building activities in catchment areas and the construction of watercourses have had deteriorating effects in many ways. Ultimately the loading reaches coastal waters and affects the coastal zone. Especially the shallow Finnish coastal zone is in many respects sensitive to pollution and eutrophication. Widespread deterioration of the ecological status of surface waters and nutrient loading into coastal waters throughout Europe was highlighted by the European Environment Agency (EEA) in "Europe Environment report" in 1999, "the Dobris +3 " -report, Environmental signals 2000 and in a report of Nutrients in European ecosystems.

On the other hand, the increasing demands for cleaner and more utilisable water quality and healthy ecosystem functions are a frequently expressed concern everywhere and at all levels in Europe. Water protection measures based on sound ecological information are urgently needed in all countries. Improvement of the ecological status of coastal waters and conservation of coastal areas are also required by the EU Water Policy Directive and the Habitats directive as well as by many international agreements, such as the HELCOM convention, the Ramsar convention and the Convention on biodiversity.
This report is the second national effort to compile monitoring information on the changes in water quality in Finnish coastal waters. In addition to nutrients and harmful substances, monitoring data of phytoplankton and macrozoobenthos are also evaluated. Moreover, the available data on phytobenthos changes originated from separate research projects and it was evaluated. The report covers the years from the the early 1980 s to $1998 / 2000$.

The objectives of the report are to

- calculate the loading of nutrients and harmful substances originating from different sources - assess the effects of loading on chemical and biological water quality in different coastal areas

- assess changes in the state of coastal waters during the 1990s and reasons for the changes

- evaluate phytobenthos and macrozoobenthos as a measure of the state of coastal waters - $\quad$ evaluate changes in fish populations and fisheries.

The report is based on the results of different monitoring programmes, loading statistics and studies concerning the state of Finnish coastal water areas. In this report data and information have been collected using the national data bases in which the monitoring data is stored and maintained. In the case of macrozoobenthos the information is mainly based on the results of the recipient control studies. The information on harmful substances is based on national monitoring, recipient control data and on specific studies. In order to obtain the relevant data on phytobenthos, available published reports and scientific articles were evaluated. 


\section{I.2 Coastal water monitoring}

The Finnish national monitoring project includes:

- Physical/chemical monitoring of the coastal waters

- Biological monitoring of macrozoobenthos and phytobenthos

- Monitoring of material inputs to the Baltic Sea by Finnish rivers

- Monitoring of harmful substances in biota.

Objectives of the monitoring programme are:

- to produce information on the quality and loading of the Finnish coastal waters, and on the state of the biological communities, for use by the national ad- ministration for research and also by the international community and monitoring programmes for decision-making in environmental control

- $\quad$ to study spatial and temporal variations in the state of water areas and to investigate factors influencing them

- to provide background data for use in other investigations concerning brackish water problems

- $\quad$ to record the levels and changes in concentrations of harmful substances in water, sediments and biota.

\section{Organisation of coastal monitoring}

The Finnish Environment Institute (FEI) coordinates the national coastal water-monitoring programme. Region-

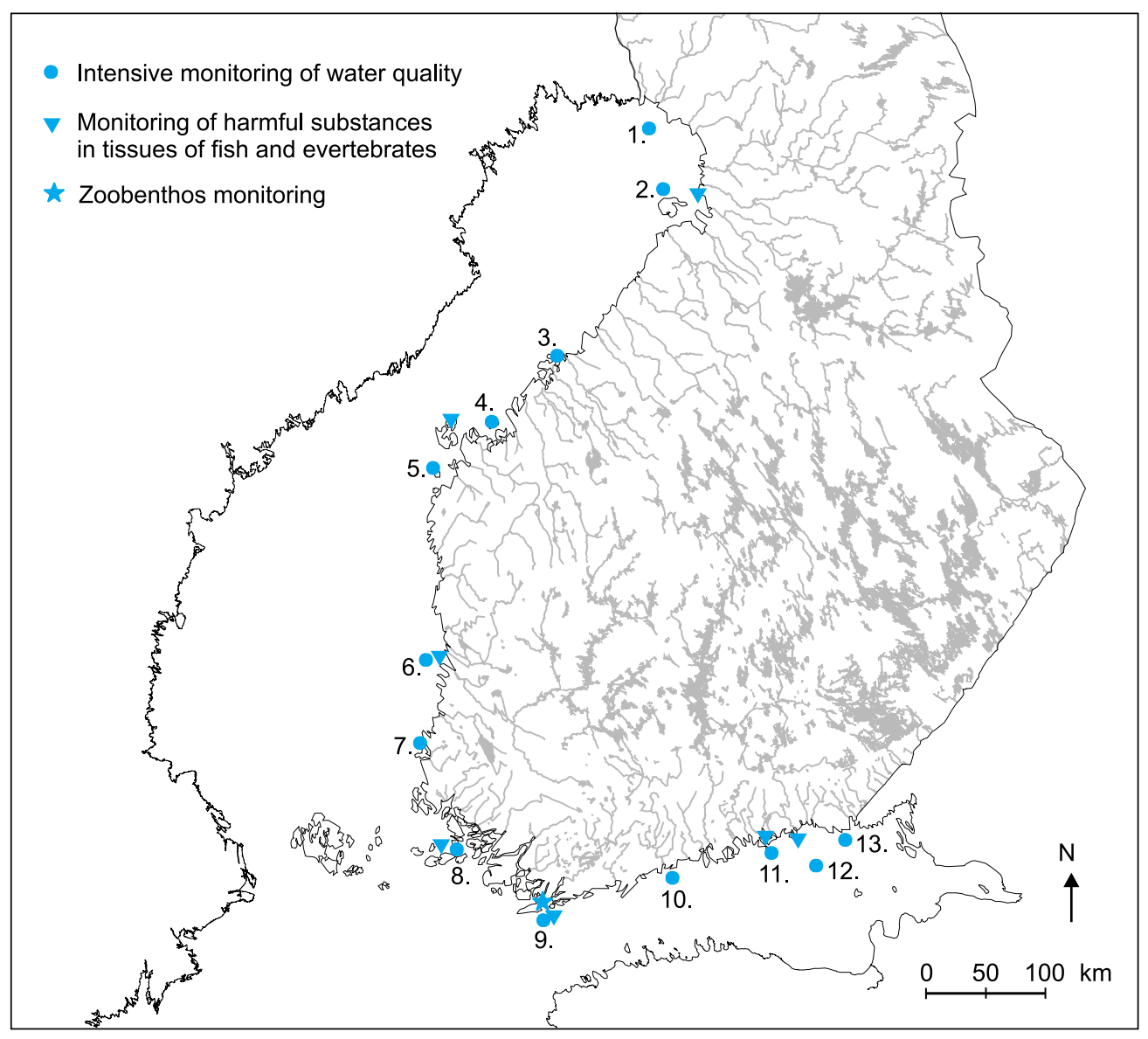

Fig. I. I. Intensive monitoring stations of the Finnish coastal waters: Pohjantähti (I), Hailuoto (2), Repskär (3), Storbodan (4), Bergö (5), Repo-saari (6), Truutinpauha (7), Seili (8), Längden (9), Länsi-Tonttu (I0), Ängsön (II), Haapasaari (I2) and Huovari (13). 


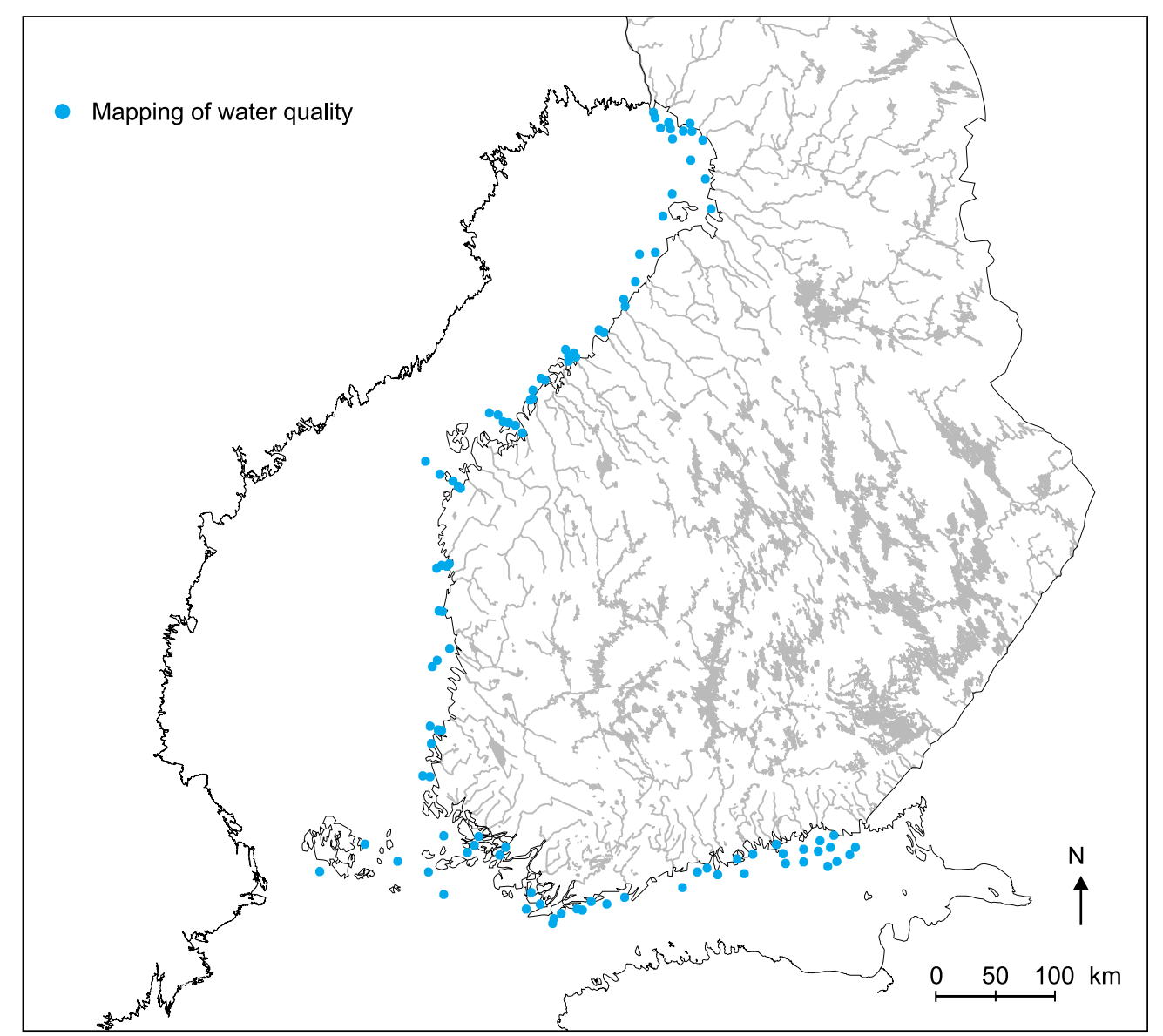

Fig. I.2. Coastal monitoring stations in Finnish coastal waters.

al Environmental Centres (RECs) carry out field observations and sampling. The analyses are performed mainly by the laboratories of the RECs, but in some cases by the Research Laboratory of FEI. The results are kept in the Water Quality database (PIVET) of the Finnish Environment Institute. The zoobenthos monitoring is carried out in co-operation with the Finnish Institute of Marine Research (FIMR) and the University of Helsinki. The samples for the monitoring of harmful substances are taken by the RECs and analysed by the Research Laboratory, University of Jyväskylä. Both FEI and the RECs are responsible for reporting.

\section{Geographical coverage}

The national network of coastal monitoring stations covers the entire area of Finnish territorial waters. Thirteen in- tensive stations are situated in the outer archipelago waters, not directly influenced by wastewater (Fig. 1.1). The distance between individual stations may be some hundreds of kilometres. Two principles have been followed when locating the stations: 1) the station should represent a large coastal water body which is quite clean and 2) sampling must be possible without unreasonable efforts.

The other 94 coastal stations are located more or less evenly throughout the territorial zone (Fig 1.2). Most of them are at sites not directly influenced by wastewater. It is planned that this program, together with local pollution monitoring based on the Water Act and supervised by the RECs, and the open sea monitoring carried out by FIMR, will provide a basis for evaluation of water quality throughout the full range from the vicinity of pollution sources to open sea areas. 


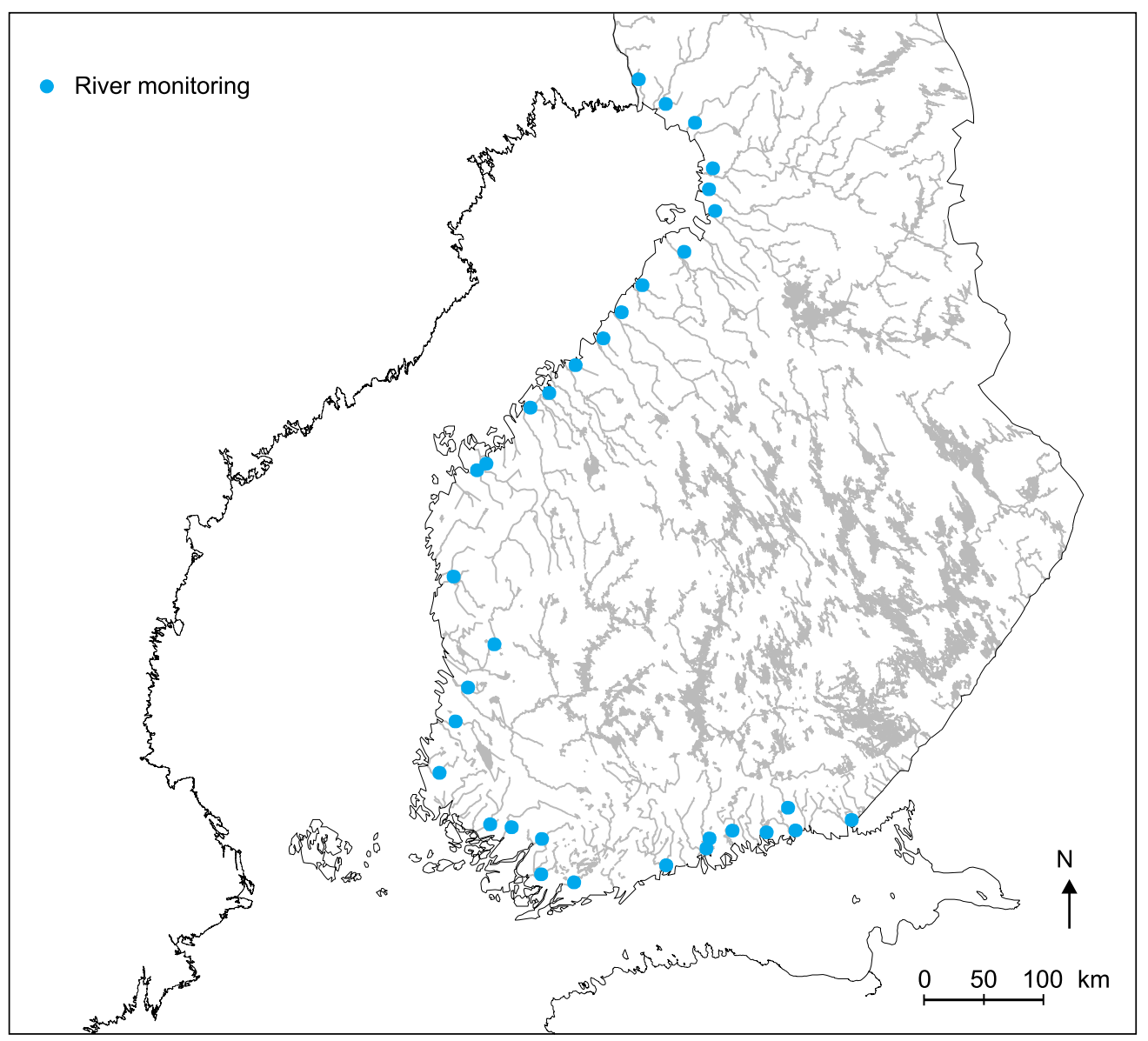

Fig. I.3. Monitoring stations of river loading.

National monitoring of zoobenthos is carried out at two stations which are located in Tvärminne on the SW coast of Finland, where local pollution is very low (Fig 1.1). The strategy is to analyse natural fluctuations in populations of the most important benthic species. These provide background information for evaluating trends in zoobenthos in polluted areas, which is included in recipient control monitoring programmes. Biological material is collected at eight areas along the Finnish coast. The areas represent both polluted and clean areas.

Regarding the coverage in the riverine monitoring, the whole area gathering the rain waters to rivers must be taken into account. The catchment area of Finnish coastal waters totals about $250000 \mathrm{~km}^{2}$, of which monitored rivers comprise about 90\% (Fig. 1.3).
However, the river Vuoksi Basin is not included in this figure because it discharges via Russia to the Gulf of Finland. The areas of large river basins (more than $10000 \mathrm{~km}^{2}$ ) account for $75 \%$ of the total catchment area whereas the reminder comprises coastal rivers with catchment areas less than $5000 \mathrm{~km}^{2}$.

\section{Current sampling frequency}

The thirteen intensive stations are sampled 16 to 20 times per year. The strategy is to follow the annual cycle of the water ecosystem of the main water bodies. The other 94 stations are sampled only twice a year, at times when the water body is in steady state in February/March and in July to September; biological variables are measured only in the open water period. This makes it possible, with the aid of the other 
programmes, to obtain a comprehensive areal picture of water quality.

National zoobenthos monitoring has continued annually at the two fixed stations in Tvärminne since 1964, but the first records from exactly the same points are available even from the 1920s and the late 1930s. This is the oldest biological time series in the Baltic Sea. Samples are taken twice a year. The autumn records reflect actual population quantities and the spring samples allow estimating of production capacities. National phytobenthos monitoring started in 1999 in seven localities and the programme was expanded with two new locations in 2000.

The river discharge monitoring covers 30 main rivers (Fig. 1.3). The monitoring was started in 1970 for nutrients and organic matter and in 1982 for heavy metals. However, comparable and reliable analyses for heavy metals were not available until the introduction of ICP (Inductively Coupled Plasmamass Spectrometry) in 1994. Since 1985 the sampling has been arranged according to the variation in the water flow of each river, sampling frequency of water quality variables usually being 12 times per year. Water flow is measured daily from each of the rivers. The annual material loads via rivers are obtained by multiplying the mean monthly concentrations by the monthly flow and summing up the monthly loads.

Monitoring of harmful substances has shown that trends in concentrations of harmful substances in biota develop very slowly. This fact and the heavy costs of analysing organic compounds have resulted in the present frequency of sampling. Samples are taken in autumn and analysed annually by a rolling system of three years: benthic specimens are sampled in the first year, coastal fish in the second and open sea fish in the third year.

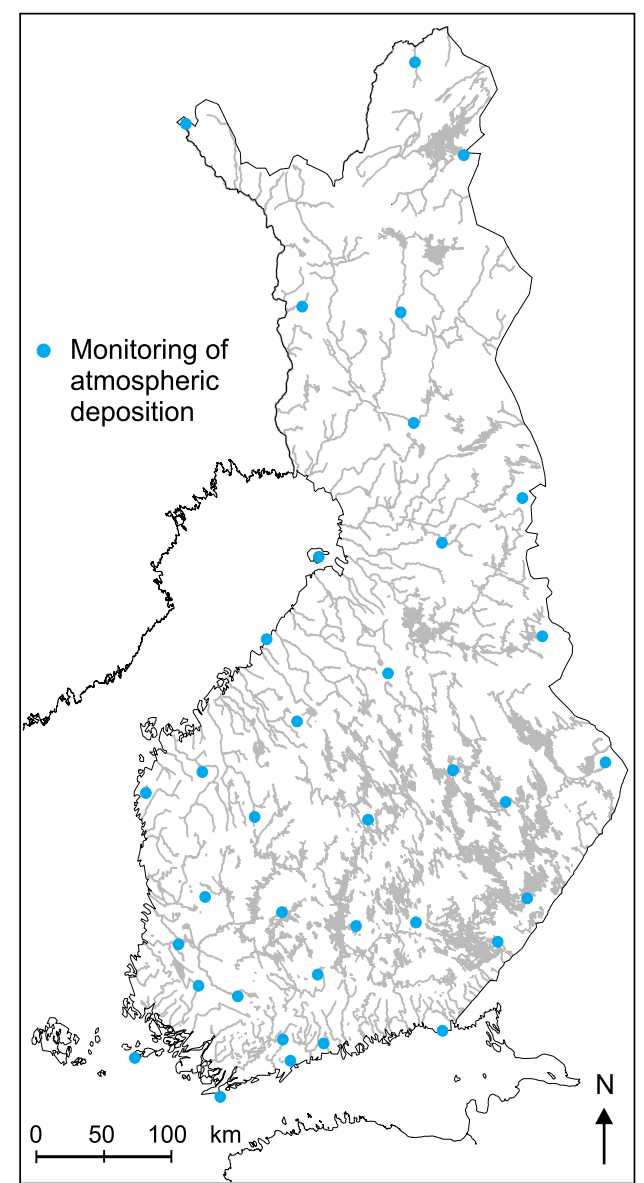

Fig. I.4. Monitoring stations of atmospheric deposition.

Atmospheric deposition on lakes is measured from thirty background stations which are located in the river catchment areas (Fig. 1.4). Nutrient concentrations are analysed from integrated monthly samples of rain water. Precipitation measurements are obtained from the Finnish Meteorological Institute. Atmospheric deposition on lakes is calculated by multiplying specific deposition by the surface area of lakes.

In Finnish coastal monitoring, the methods are adapted from HELCOM guidelines with some exceptions, e.g. chlorophyll $a$ which is analysed using Finnish standard methods. 


\section{Variables measured}

Physico/chemical variables

Temperature, Conductivity, Salinity, Oxygen concentration and \%-saturation, $\mathrm{pH}$, Turbidity, Solid substances, Colour, Tot-N, $\mathrm{NO}_{3}+\mathrm{NO}_{2}, \mathrm{NH}_{4}-\mathrm{N}$, Tot$\mathrm{P}, \mathrm{PO}_{4}-\mathrm{P}, \mathrm{SiO}_{2}, \mathrm{Fe}, \mathrm{OrgC} / \mathrm{TOC}$.

\section{Biological variables}

Chlorophyll $a$, Phytoplankton species composition and biomass, Zoobenthos species composition, abundance and biomass. Macroalgae species composition, coverage and depth ranges.

\section{Harmful substances}

$\mathrm{Hg}, \mathrm{Cd}, \mathrm{Cu}, \mathrm{Pb}, \mathrm{Zn}, \mathrm{Cr}, \mathrm{Mn}, \mathrm{Co}$, Chlorinated hydrocarbons, Chlorinated phenols, Anisols and veratrols, Toxaphene, EOX, extractable organic halogens, $\mathrm{PAH}$, polyaromatic hydrocarbons, Dioxins and furans, Coplanary PCBs.

\section{Quality assurance}

Many laboratories involved in the coastal monitoring have accreditated their analytical methods. In the area of coastal and open sea monitoring, FIMR (Finnish Institute of Marine Research) has accreditated also sampling. Accreditation, based on internationally agreed criteria, is an instrument to provide confidence in the technical competence, impartiality and integrity of the bodies. Personal certification of the individuals in charge of sampling is in progress according to international recommendations and will soon be completed (Niemi et al. 2000). The aim is that in the near future all the laboratories involved in sampling and analysis of data will have certified individuals in charge of sampling and accreditated methods in analytical work.

\section{I.3 International framework}

HELCOM monitoring is well established and has been operated since 1979 when physical, chemical and biological variables were first measured. Under the new revised Helsinki Convention in 1992 the obligation of monitoring of coastal waters was included, and countries are obliged to report the data to the Commission. The Environmental Committee is conducting a harmonised coastal monitoring programme (CMP) which also includes the monitoring of Baltic Sea Protected Areas (BSPA). The coastal monitoring programme is completed and it includes a programme description and technical annexes. All the different programmes should be integrated into a common structure and therefore the Cooperative Monitoring in the Baltic Marine Environment COMBINE was established in 1999. The aims of COMBINE monitoring are to identify and quantify anthropogenic discharges and activities in the Baltic Sea, against the background of the natural variations in the system, and to identify and quantify changes in the environment occurring as a result of regulatory actions. 


\section{Main characteristics of}

\section{Finnish coastal waters}

When considering the marine water masses near the Finnish coast, the Baltic Sea can be divided into two major bodies, the Gulf of Finland and the Gulf of Bothnia. The Gulf of Finland is a direct extension of the Baltic Proper, and the combined effects of the large fresh water inflow to the eastern end and the water exchange with the Baltic proper lead to strong salinity gradients. In the long term, on a basin-wide scale, the overall water circulation in the Gulf of Finland is anti-clockwise, resulting in a westward transport along the Finnish coast. Locally the currents are determined by the coastal morphometry, wind conditions, water level changes and freshwater inputs.

The Gulf of Bothnia (including the Bothnian Bay, Bothnian Sea, Åland Sea and Archipelago Sea) has two major basins and two larger archipelago areas in the northern and southeastern parts (Fig. 2.1). The northern (Bothnian Bay) and southern basin (Bothnian Sea) are separated by a shallow sill, the Northern Quark. Inflow of freshwater from numerous rivers and from precipitation causes relatively low salinity of the area.

Table I. Division of sea areas with their catchment area expressed as $\mathrm{km}^{2}$.

\begin{tabular}{lrc}
\hline Area & Total & Finnish area \\
\hline Gulf of Finland & 412900 & $\begin{array}{l}54000 \\
\text { (without Vuoksi) }\end{array}$ \\
Archipelago Sea & 9000 & 9000 \\
Bothnian Sea & 215910 & 39300 \\
Bothnian Bay & II3 620 & 146000 \\
\hline Total & & 248300 \\
\hline
\end{tabular}

The remarkable feature of the northern Baltic Sea is its relatively wide annual seawater temperature range. The Baltic is a cold sea and its temperature varies between 0 and $20^{\circ} \mathrm{C}$. Freezing, ice cover and the duration of the ice depend mainly on the meteorological conditions, and may vary considerably in different years. The Bothnian Bay is normally completely covered by ice by January. Generally, complete ice coverage also occurs in the coastal zone down to the Åland Sea and along the Gulf of Finland. The ice in the coastal zones is normally stationary. The thickness of the ice in the Bothnian Bay is about $50-80 \mathrm{~cm}$ and it may occur for 150-180 days, for more than 100 days with a maximum thickness of $50 \mathrm{~cm}$ at the southern border of the Gulf of Bothnia, and for 30-40 days $(25-30 \mathrm{~cm})$ in the Gulf of Finland. The salinity of the seawater varies between 4 and 5 psu seasonally. Surface waters may become rather warm in summer, temperatures of $16-17{ }^{\circ} \mathrm{C}$ being frequent in August over large areas of the Baltic, while in shallow bays temperature of $20^{\circ} \mathrm{C}$ may occasionally be reached.

There is no tide in the Baltic Sea and irregular fluctuations in the Baltic water level occur mainly in response to the changes in barometric conditions and associated changes in wind force and direction. An underlying seasonal pattern exists. In general, water level follows the pattern of being low in spring (March-April) and rising gradually, being highest in autumn. In some years, water level is high in spring and decreases in summer for a short period of time. Later in the autumn water level rises. 


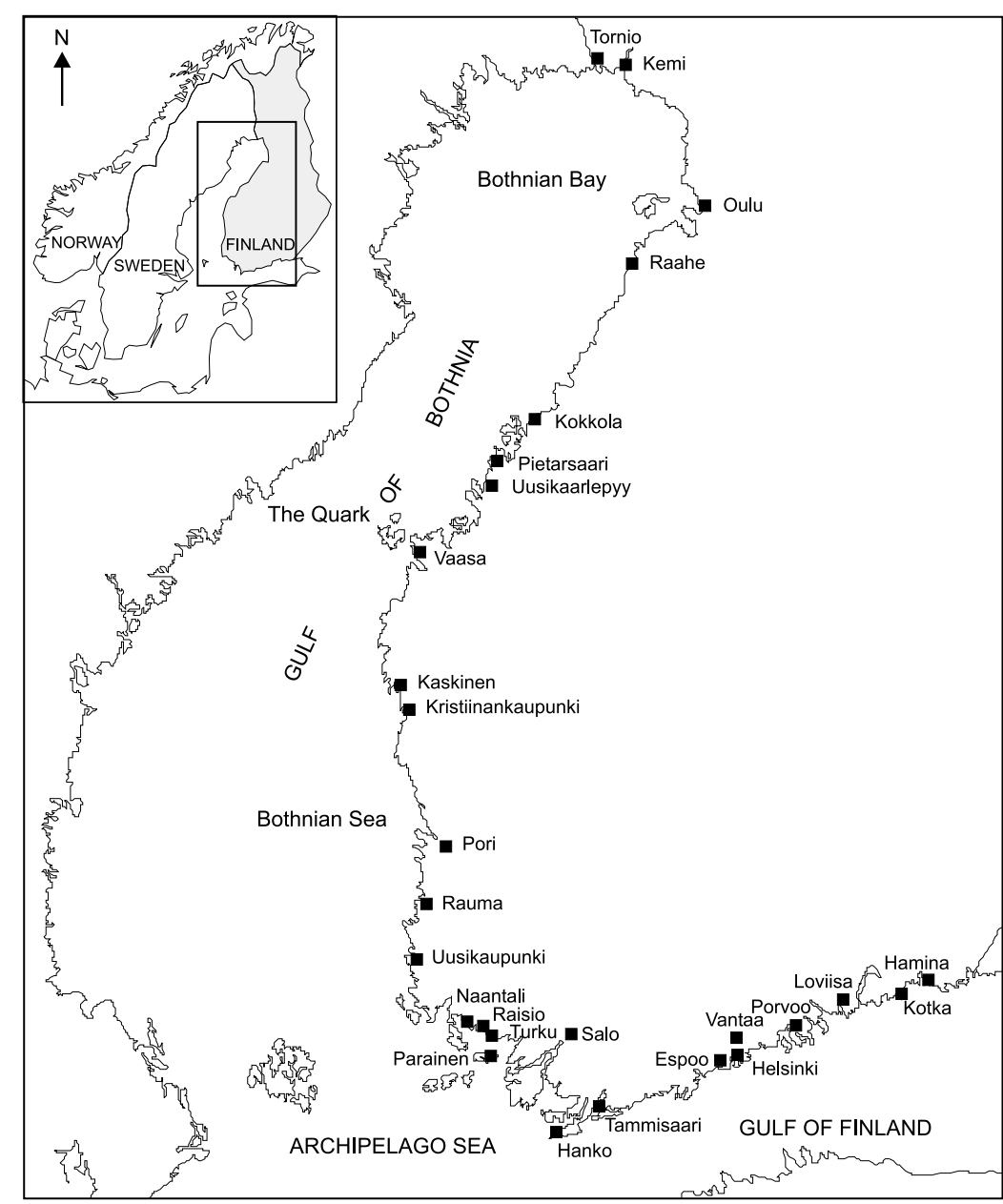

Fig. 2.I. The sea areas around Finland and locations of the main municipal and industrial centers on the Finnish coast.
Permanent salinity stratification is the dominant feature of the Baltic hydrography. The freshwater input causes surface water to be less saline than the deeper and bottom waters derived from the subsurface flows. The surface layer is separated from the deeper water by the halocline. However, there is no permanent salinity stratification in the Gulf of Bothnia. Surface salinity varies from over $6 \mathrm{psu}$ in the western parts to around $3 \mathrm{psu}$ in the eastern regions of the Finnish part of the Gulf of Finland. The South coast of Finland is an upwelling area because the more saline Atlantic water after a saline water pulse will eventually surface by the southern coast of Finland. In a small scale, upwelling can occur also locally. Westerly or northerly winds push coastal waters away from the shore and draw deeper waters to the surface. This local upwelling can be detected as cooling of the surface waters and as increased nutrient and salinity values.

The shoreline length of the Finnish mainland is ca. $6000 \mathrm{~km}$. However, this would increase to almost 46000 $\mathrm{km}$ if the fragmented archipelago were included. Finland has ca. 73000 islands and 52600 of these are small, less than one hectare in size. The most islandrich sea area is the Archipelago Sea, in with 22000 islands and a total shore $12000 \mathrm{~km}$. A mosaic of islands and skerries of varying size dominate the Finnish coastal area. The coastline mainly consists of bedrock, although inner parts of the archipelagoes and bays are sheltered enough for the deposition of fine material. On the shores of the islands underwater rock does not reach a great depth and forms only a narrow zone on which attached algae can grow. 
Pirkko Kauppila, Markku Korhonen, Heikki Pitkänen, Kaarle Kenttämies, Seppo Rekolainen and Pekka Kotilainen

\section{I Nutrient loading and its source apportionment}

During 1991-1996, Finnish coastal waters received annually on an average $4090 \mathrm{t}$ of $\mathrm{P}$ and $74000 \mathrm{t}$ of $\mathrm{N}$ from or via the Finnish territory (Table 3.1). The fluxes varied considerably from year to year depending mainly on hydrological conditions. In the periods of high runoff, nutrients are abundantly leached from soil, which increases the loads originating from diffuse sources and natural leaching. The greatest nutrient loads (4 $600 \mathrm{t}$ of $\mathrm{P}$ and $97000 \mathrm{t}$ of $\mathrm{N}$ ) in the decade were received in 1992 and smallest (3 $100 \mathrm{t}$ of $\mathrm{P}$ and $65000 \mathrm{t} \mathrm{N}$ ) in 1997.

The total fluxes of nutrients originated from various sources: diffuse and point-sources, atmosphere and natural leaching. Agriculture was the main anthropogenic source of loading, accounting for one third of the total fluxes of $\mathrm{P}$ and $\mathrm{N}$ respectively (Table 3.1, Figs. 3.3, 3.4). In the catchment of the Archipelago Sea, its contribution was even higher: ca. $50 \%$ of the nutrient loading. However, in summertime the direct eutrophying effect of agricultural load was not so pronounced because under normal hydrological conditions nutrient leaching from the lakepoor catchments of small agricultural rivers mainly occurs during spring and August (Pitkänen 1994).

Point-source loading (industry, municipalities and fish farming) was responsible for 15 and $20 \%$ of the total fluxes of $\mathrm{P}$ and $\mathrm{N}$ respectively (Table 3.1, Figs. 3.3, 3.4). In the catchment of the Gulf of Finland, municipalities were the main source of $\mathrm{N}$ load, accounting for ca. $40 \%$ of the total fluxes and $85 \%$ of the point source load of $\mathrm{N}$ (Figs. 3.4, 3.5). However, in 1998 the municipal load of $\mathrm{N}$ in the capital region reduced to half from its level in 1997, due to the introduction of enhanced denitrification in the sewage treatment plants (Pesonen 1999). This decreased the total point-source load of $\mathrm{N}$ to the Gulf of Finland by ca. $30 \%$. Industry, especially pulp and paper industry, was the main source of the $\mathrm{P}$ load ( $46 \%$ of point source loading) in the Bothnian Bay (Fig.3.5).

The contribution of the nutrient load from fish-farming was significant only in the catchment of the Archipelago Sea, where it accounted about 15 and $10 \%$ of the inputs of $\mathrm{P}$ and $\mathrm{N}$ respectively (Table 3.1, Figs 3.3, 3.4). This contribution becomes more pronounced when considering only the point-sources: more than 70 and 30\% of the loads of $\mathrm{P}$ and $\mathrm{N}$ were originated from fish-farming (Figs. 3.5, 3.6). In summertime, the contribution of pointsource loading is usually more important than diffuse loading (Pitkänen 1994). Moreover, the eutrophying effect is further increased by the facts that practically the whole load enters the sea area during the growing season and nearly all of the load is bioavailable for the growth of algae (Pitkänen 1994).

The P load from scattered dwellings clearly exceeded the municipal load, while its contribution for N fluxes remained insignificant. Scattered dwellings accounted about $10 \%$ of the total fluxes of $P$ in the Finnish coastal catchment, where about 570000 inhab- 


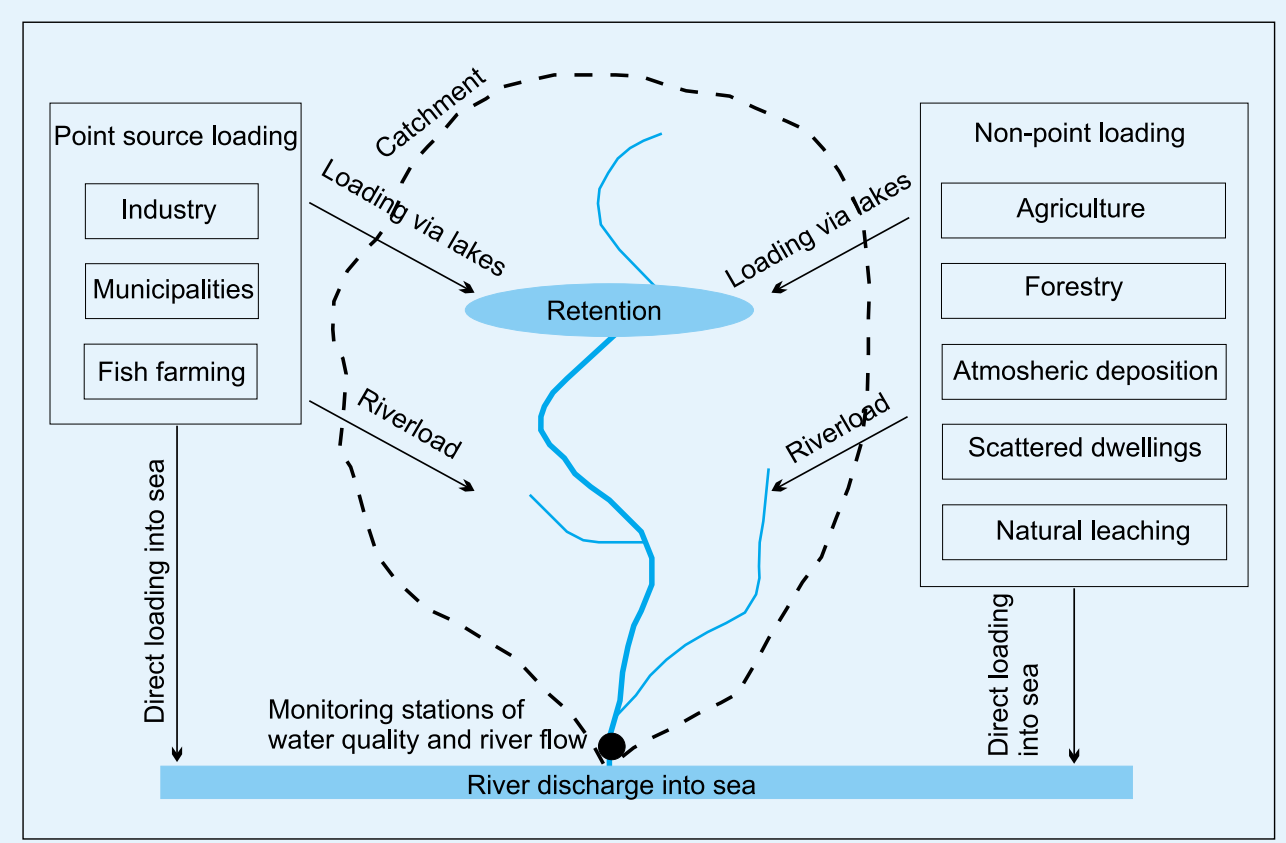

Fig. 3.I. Scematic representation of loading by different sources entering Finnish coastal waters directly or via rivers.

\section{Sources of loading}

Nutrients entering into Finnish coastal waters, directly from the coast or via rivers, originate from various sources (Fig. 3.1). The point source loading consists of the effluents from industry, municipalities and fishfarms (Figs. 2.1, 3.2), while diffuse loading originates from non-point sources: mainly agriculture, forestry, scattered dwellings, atmospheric deposition and natural leaching. Nutrient loads via rivers are assumed to be carried unchanged into the coastal waters in lake-poor river basins (Pitkänen 1994, Rekolainen et al. 1995). In lake-rich river basins such as in the Rivers Kymijoki, Kokemäenjoki and Oulujoki retention of nutrients must be taken into account.

\section{Budget calculations}

In budget calculations, annual nutrient fluxes into Finnish coastal waters from different sources were gained by the means of the data base system of VEPS developed by FEI for the estimation and control of nutrient loads into watercourses. VEPS is an a up to date Management and Assessment system for water pollution. VEPS can be used to easily obtain information about nutrient loading, its quantity and sources. The VEPS system has an easy to use user interface, and it has been developed to help researchers of the Finnish Environmental Administration. The VEPS system uses the data base system of HERTTA which includes the point sources database, the surface water quality database and the hydrological da- tabase. In addition, VEPS uses assessments which are based on mathematical models. The assessment methods have been developed simultaneously with the systems technical implementation. Using the available data VEPS assesses the sources, quantity and temporal variability of nutrient loads into surface waters. VEPS also calculates nutrient fluxes of monitored rivers and divides it into different sources. The division is based on the assessment of the quantity of the nutrient load in the catchment area. In large catchment areas VEPS takes retention into account.

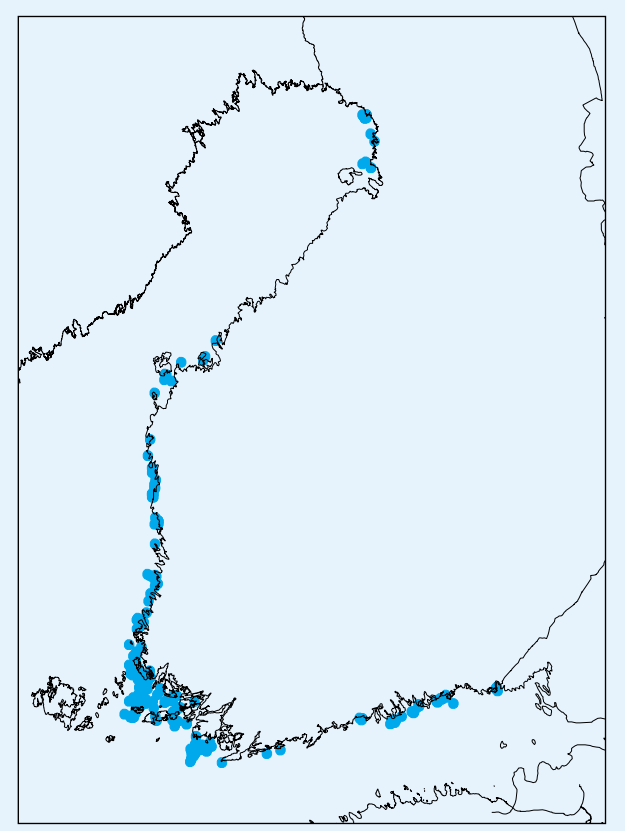

Fig. 3.2. Locations of fish farms in Finnish coastal waters in 1998. 


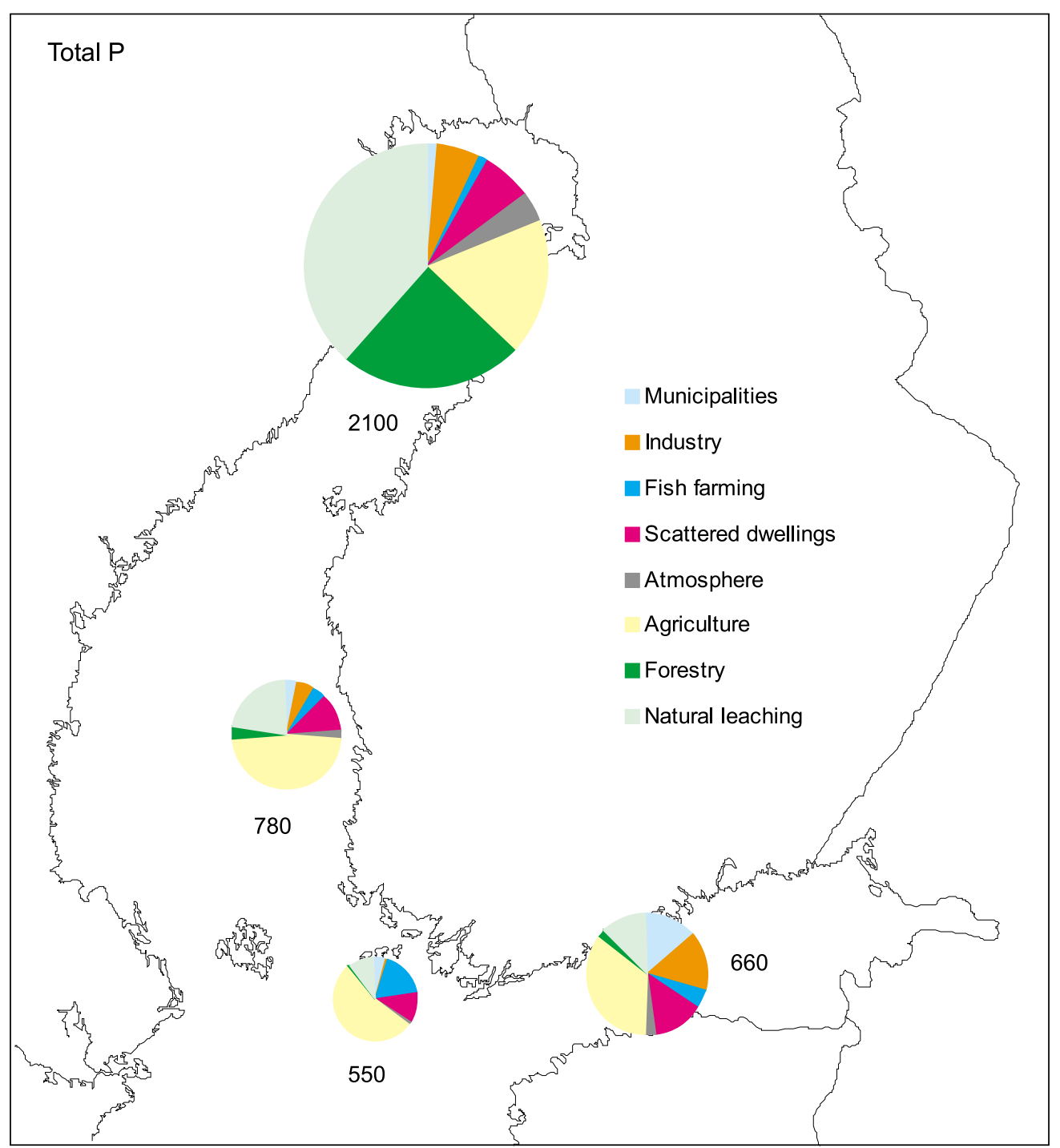

Fig. 3.3. Total load of $P\left(t a^{-1}\right)$ from different sources into Finnish coastal waters in I99I1996. Note that nutrient loads from Russia and Estonia to the Gulf of Finland and the loads from Sweden to the Gulf of Bothnia have not been included in these calculations.

itants lived in year around in houses not connected to public sewerage systems (Table 3.1, Fig. 3.3). In the catchment of the Bothnian Bay, the greater load was mainly due to weaker equipment for lavatory wastes compared to that in the other main catchments.

The contribution of forestry, as well as natural leaching, increased from south to north (Table 3.1). In the catchment of the Bothnian Bay, forestry was the main source of anthropogenic $\mathrm{P}$ load, accounting for nearly $25 \%$ of the total P fluxes (Fig. 3.3). Forestry was mainly practised in the upper parts of the catchments. Due to the small lake percentage of the water- courses in the northern Finland, the retention of nutrients leaching from forestry soil was generally small. However, nutrient leaching from soil is promoted by the great percentage of wetlands. Considering forestry operations, remedial drainage was the greatest single source of nutrient leaching in the catchment of the Bothnian Bay (Kenttämies and Vilhunen 1999).

The proportion of forestry practices as a source of nutrient loading was greatest to the Bothnian Bay, but fairly insignificant to the other sea areas regarding to both N and P. During 19911996, the mean annual input originating from forestry practices was about 


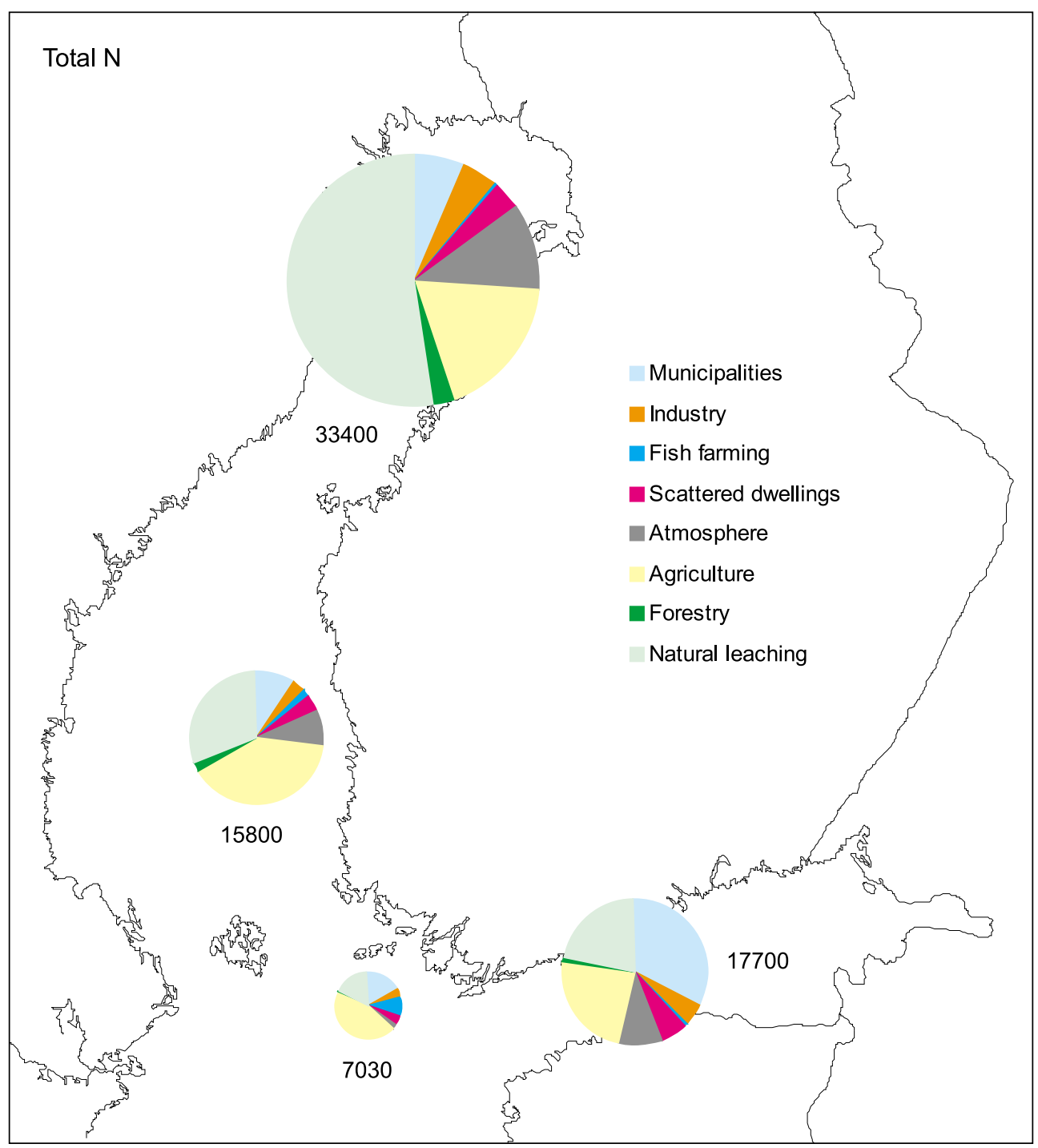

Fig. 3.4. Total load of $N\left(t a^{-1}\right)$ from different sources into Finnish coastal waters in I99I1996. Note that nutrient loads from Russia and Estonia to the Gulf of Finland and the loads from Sweden to the Gulf of Bothnia have not been included in these calculations.

$400 t$ of $P$ and $3370 t$ of $N$ (Table 3.2). Phosphorus loading decreased during that time but the same trend was not found in nitrogen figures. The main reason for this is the almost total ceasing of phosphorus fertilization in the late 1980s. Instead, the main nitrogen loaders, drainage and felling, have remained on the stable level.

The atmospheric nutrient deposition on lake surface accounted $3 \%$ of the $\mathrm{P}$ and $10 \%$ of the $\mathrm{N}$ inputs (Table 3.1, Figs. 3.3 and 3.4). Natural leaching contributed about one third of the total fluxes of nutrients to Finnish coastal waters, being smallest in the catchment of the Archipelago Sea (ca.10 and
$20 \%$ of the total fluxes of $\mathrm{P}$ and $\mathrm{N}$ ) and greatest in the catchment of the Bothnian Bay (ca. 40 and $50 \%$ of the total fluxes of $\mathrm{P}$ and $\mathrm{N}$ ).

Table 3.2. The estimated mean total phosphorus and total nitrogen loads $\left(\mathrm{t} \mathrm{a}^{-1}\right)$ from forestry practices on catchments into coastal waters in 1991-1996 (Kenttämies and Vilhunen 1999).

\begin{tabular}{lrc}
\hline Main catchments & $\begin{array}{l}\text { Total nitrogen } \\
\mathrm{t} \mathrm{a}^{-1}\end{array}$ & $\begin{array}{l}\text { Total phosphorus } \\
\mathrm{t} \mathrm{a}^{-1}\end{array}$ \\
\hline Bothnian Bay & 2152 & 273 \\
Bothnian Sea & 515 & 54 \\
Archipelago Sea & 81 & 7.5 \\
Gulf of Finland & 622 & 66 \\
Total & 3370 & 400.5 \\
\hline
\end{tabular}



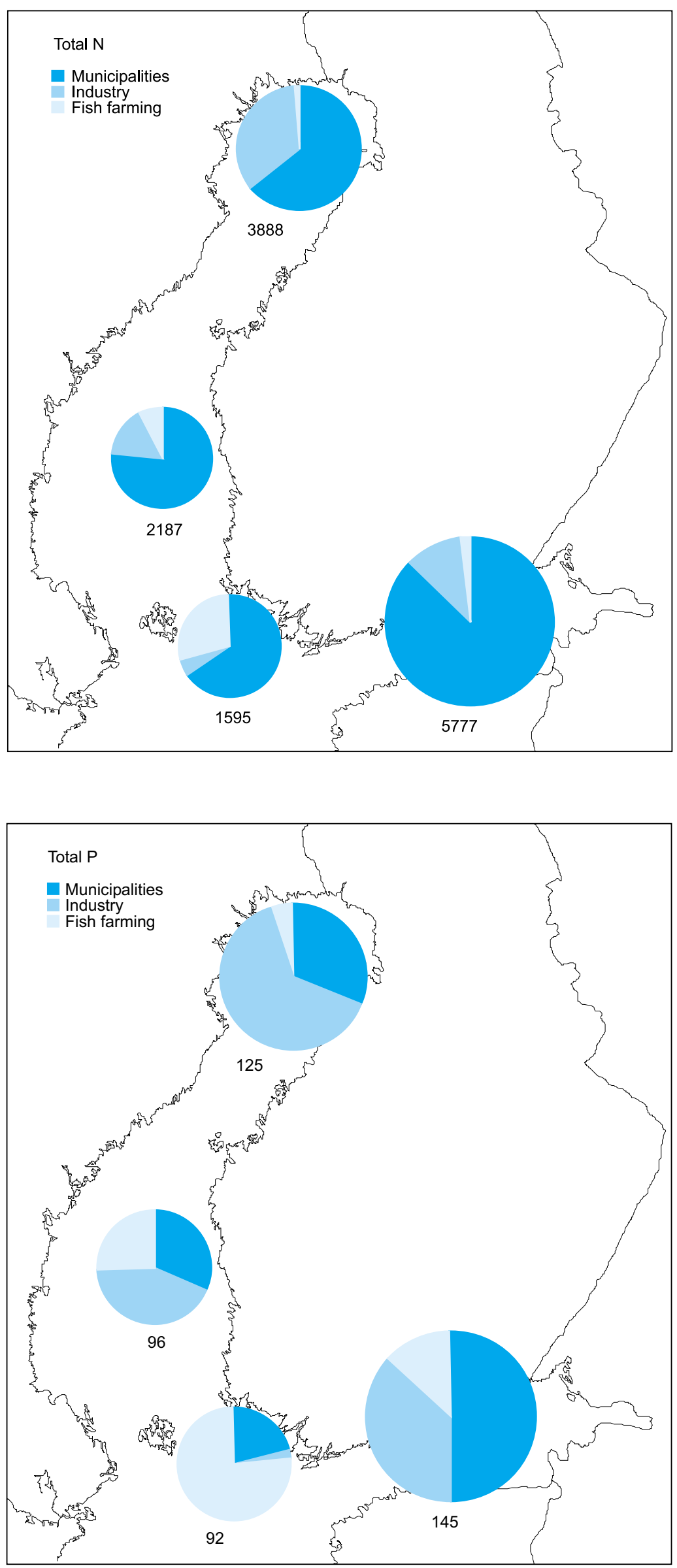

Fig. 3.5. Point-source loading of $N\left(t a^{-1}\right)$ into Finnish coastal waters by sources in 1997. Note that nutrient loads from Russia and Estonia to the Gulf of Finland and the loads from Sweden to the Gulf of Bothnia have not been included in these calculations.

Fig. 3.6. Point-source loading of $P\left(t a^{-1}\right)$ into Finnish coastal waters by sources in 1997. Note that nutrient loads from Russia and Estonia to the Gulf of Finland and the loads from Sweden to the Gulf of Bothnia have not been included in these calculations. 
Table 3.I. Loads of $P$ and $N\left(t a^{-1}\right)$ to Finnish coastal waters in 1986-90, 199|-96 and 1997. Note the difference in estimating diffuse load in 1986-90 and in 1991-1996/1997. Regarding the load calculations for the period of 1986-90 by Pitkänen (1994), the contributions of forestry, atmospheric inputs and natural leaching are included in the calculations of background load while the load from scattered dwellings is included in the calculations of agricultural load. The correction factor presented by Mäkinen (1998) for the nutrient loads from fish-farming ${ }^{(1)}$ was taken into account for the period of 1995-96/97. The uncorrected values ${ }^{(2)}$ have presented here only to show the trend of nutrient load from fish-farming.

\begin{tabular}{|c|c|c|c|c|c|c|}
\hline \multirow[t]{2}{*}{ Coastal region } & \multicolumn{2}{|c|}{$1986-90$} & \multicolumn{2}{|c|}{$199 \mid-1996$} & \multicolumn{2}{|c|}{1997} \\
\hline & $P$ & N & $P$ & N & $P$ & N \\
\hline \multicolumn{7}{|l|}{ Gulf of Finland } \\
\hline municipalities & 160 & 5286 & 93 & 5809 & 72 & 5038 \\
\hline industry + traffic & 137 & 738 & 104 & $805+24$ & 54 & 627 \\
\hline fish-farming ${ }^{2}$ & 17 & 112 & 15 & 104 & 10 & 70 \\
\hline fish-farming ${ }^{\prime}$ & . & . & 29 & 165 & 19 & 112 \\
\hline agriculture & 309 & 5140 & 235 & 4240 & . & . \\
\hline forestry & . & . & 15 & 220 & . & . \\
\hline scattered dwellings & . & . & 86 & 920 & . & . \\
\hline atmosphere & . & . & 17 & 1640 & . & . \\
\hline natural leaching & . & . & 84 & 3890 & . & . \\
\hline background & 264 & 8627 & . & . & . & . \\
\hline total & 887 & 19903 & 664 & 17705 & 461 & 13796 \\
\hline \multicolumn{7}{|l|}{ Archipelago Sea } \\
\hline municipalities & 39 & 1088 & 30 & 1315 & 20 & 1032 \\
\hline industry & 1.3 & 189 & 5 & 191 & 2 & 86 \\
\hline fish-farming ${ }^{2}$ & 56 & 410 & 51 & 386 & 40 & 298 \\
\hline fish-farming ${ }^{\prime}$ & . & . & 94 & 623 & 92 & 477 \\
\hline agriculture & 379 & 4050 & 297 & 3090 & . & . \\
\hline forestry & . & . & 4 & 40 & . & . \\
\hline scattered dwellings & . & . & 60 & 330 & . & . \\
\hline atmosphere & . & . & 2 & 150 & . & . \\
\hline natural leaching & . & . & 57 & 1290 & . & . \\
\hline background & 105 & 1332 & . & . & . & . \\
\hline total & 580 & 7069 & 550 & 7030 & 511 & 7734 \\
\hline \multicolumn{7}{|l|}{ Bothnian Sea } \\
\hline municipalities & 46 & 1223 & 28 & 1616 & 30 & 1662 \\
\hline industry & 115 & 503 & 43 & 473 & 41 & 360 \\
\hline fish-farming ${ }^{2}$ & 19 & 147 & 17 & 136 & 13 & 103 \\
\hline fish-farming ${ }^{\prime}$ & . & . & 34 & 212 & 25 & 165 \\
\hline agriculture & 433 & 5770 & 360 & 6110 & . & . \\
\hline forestry & . & . & 32 & 320 & . & . \\
\hline scattered dwellings & . & . & 85 & 620 & . & . \\
\hline atmosphere & . & . & 22 & 1420 & . & . \\
\hline natural leaching & . & & 177 & 5010 & . & . \\
\hline background & 437 & 10004 & . & & . & . \\
\hline total & 1050 & 17647 & 782 & 15781 & 653 & 16789 \\
\hline
\end{tabular}




\begin{tabular}{|c|c|c|c|c|c|c|}
\hline \multirow[t]{2}{*}{ Coastal region } & \multicolumn{2}{|c|}{$1986-90$} & \multicolumn{2}{|c|}{$1991-1996$} & \multicolumn{2}{|l|}{1997} \\
\hline & $P$ & $\mathrm{~N}$ & $P$ & N & $P$ & $\mathrm{~N}$ \\
\hline \multicolumn{7}{|l|}{ Bothnian Bay } \\
\hline municipalities & 76 & 2113 & 37 & 2209 & 39 & 2495 \\
\hline industry & 182 & 1713 & 115 & 1518 & 80 & $|35|$ \\
\hline fish-farming ${ }^{2}$ & 4.5 & 35 & 4 & 32 & 3 & 26 \\
\hline fish-farming ${ }^{\prime}$ & . & & 8 & 51 & 6 & 42 \\
\hline agriculture & 565 & 9040 & 377 & 6220 & . & . \\
\hline forestry & . & . & 506 & 860 & . & . \\
\hline scattered dwellings & . & . & 139 & 1100 & . & . \\
\hline atmosphere & . & . & 92 & 3870 & . & . \\
\hline natural leaching & . & & 815 & 17550 & . & . \\
\hline background & $|50|$ & 21443 & . & & . & . \\
\hline total & 2329 & 34344 & 2090 & 33378 & 1798 & $3 / 112$ \\
\hline \multicolumn{7}{|l|}{ Total } \\
\hline municipalities & 321 & 9710 & 188 & 10949 & 175 & 9332 \\
\hline industry + traffic & 435 & 3143 & 268 & $2987+24$ & 164 & 2286 \\
\hline fish-farming ${ }^{2}$ & 97 & 704 & 89 & 669 & 86 & 665 \\
\hline fish-farming ${ }^{\prime}$ & . & & 165 & 1043 & 163 & 1063 \\
\hline agriculture & 1686 & 24000 & 1270 & 19660 & . & . \\
\hline forestry & . & . & 559 & 1440 & . & . \\
\hline scattered dwellings & . & . & 370 & 2970 & . & . \\
\hline atmosphere & . & . & 133 & 7080 & . & . \\
\hline natural leaching & . & & 1133 & 27740 & . & . \\
\hline background & 2307 & 41406 & . & & . & . \\
\hline total & 4846 & 78963 & 4086 & 73903 & 3424 & 69430 \\
\hline
\end{tabular}

Footnote: Nutrient loads from fish-farms were estimated by mass balance calculations based on the amount and nutrient content of the feed, the amount of produced fish and the type of the plant. $\mathrm{On}$ the basis of the recent information on the amounts of feed sold and the weighted means of the nutrient contents of feeds in 1995 and 1996, the loading of phosphorus would be $90 \%$ and the loading of nitrogen $60 \%$ greater than was originally reported by fish farms (Mäkinen 1998).

\subsection{Trends in the nutrient loads in 1985-98}

The average annual nutrient fluxes to Finnish coastal waters in the 1990s were smaller than in the late 1980s (Table 3.1, Fig. 3.7). This is partly due to smaller water flows to the sea areas and partly due to changes in loading from different sources (Figs. 3.7-3.10). The total load of $\mathrm{N}$ decreased by $10 \%$ from the level of the late 1980s, which is simply explained by the smaller water flow in the 1990s because the point-source loading of $\mathrm{N}$ actually slightly increased during that time. The decline in the load of P by about $16 \%$ was mainly due to water protection measures in industry and municipalities. However, in the Archipelago Sea no clear change in nutrient fluxes could be observed, mainly due to equal level of runoff between the two study periods.

As for $\mathrm{P}$, the municipal and industrial load has decreased by $60 \%$ since the mid 1980s, mainly due to more efficient purification of waste waters (Fig. 3.8). The reduction of the municipal load actually started already in the 1970s after the introduction of Fe/ Al precipitation in the purification plants. The next strong decrease in the load of $\mathrm{P}$ in the early 1990s was due to the introduc- 


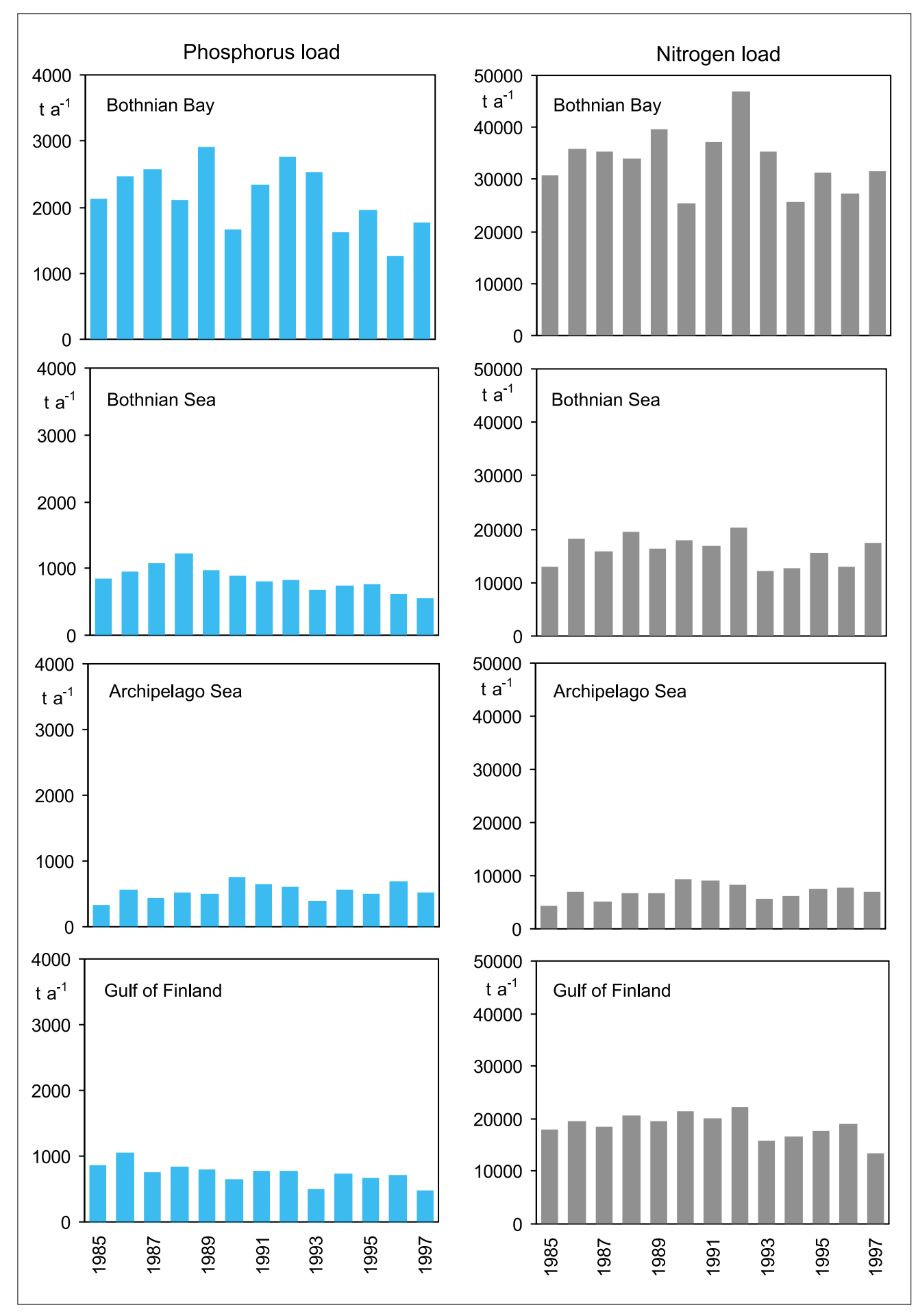

Fig. 3.7. Trends of point-source loads of $N$ and $P$ into Finnish coastal waters in 1985-1997.

tion of active sludge method in pulp and paper industry, and the centralization of municipal waste water treatment, especially in the Helsinki region.

Regarding point sources, the total loads of $\mathrm{N}$ decreased by $10 \%$ since the peak in the early 1990s (Fig. 3.8). How- ever, the direction and the slope of the trend varied in each main catchment: In the Gulf of Finland, Archipelago Sea and Bothnian Sea the reductions were 15,22 and $28 \%$ respectively, and the level of the mid 1980s was achieved again in 1996-97. On the contrary, in 


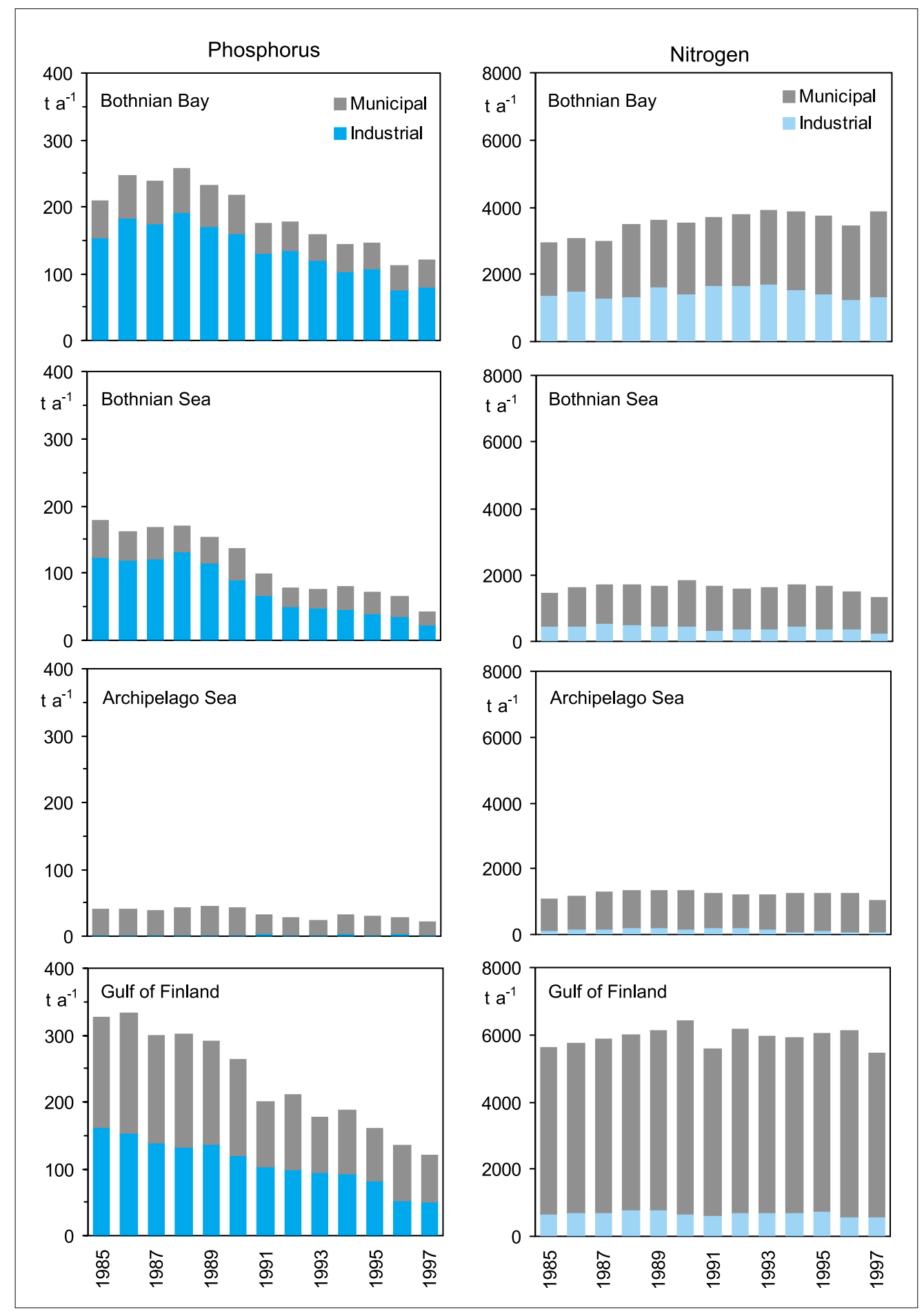

Fig. 3.8. Trends of the total fluxes of $N$ and $P$ into Finnish coastal waters in 1985-1997.

the Bothnian Bay the load has even increased (24\%) since the mid 1980s although this trend levelled off in the late 1990s. The increase in the 1980s (and in the Bothnian Bay also in the early 1990s) was mainly due to municipal loading. This, in turn, resulted from the increase in the number of households connected to sewer systems. The reduction in the 1990s was mainly due to centralization of municipal treatment and better control in the treatment plants of pulp and paper industry. 

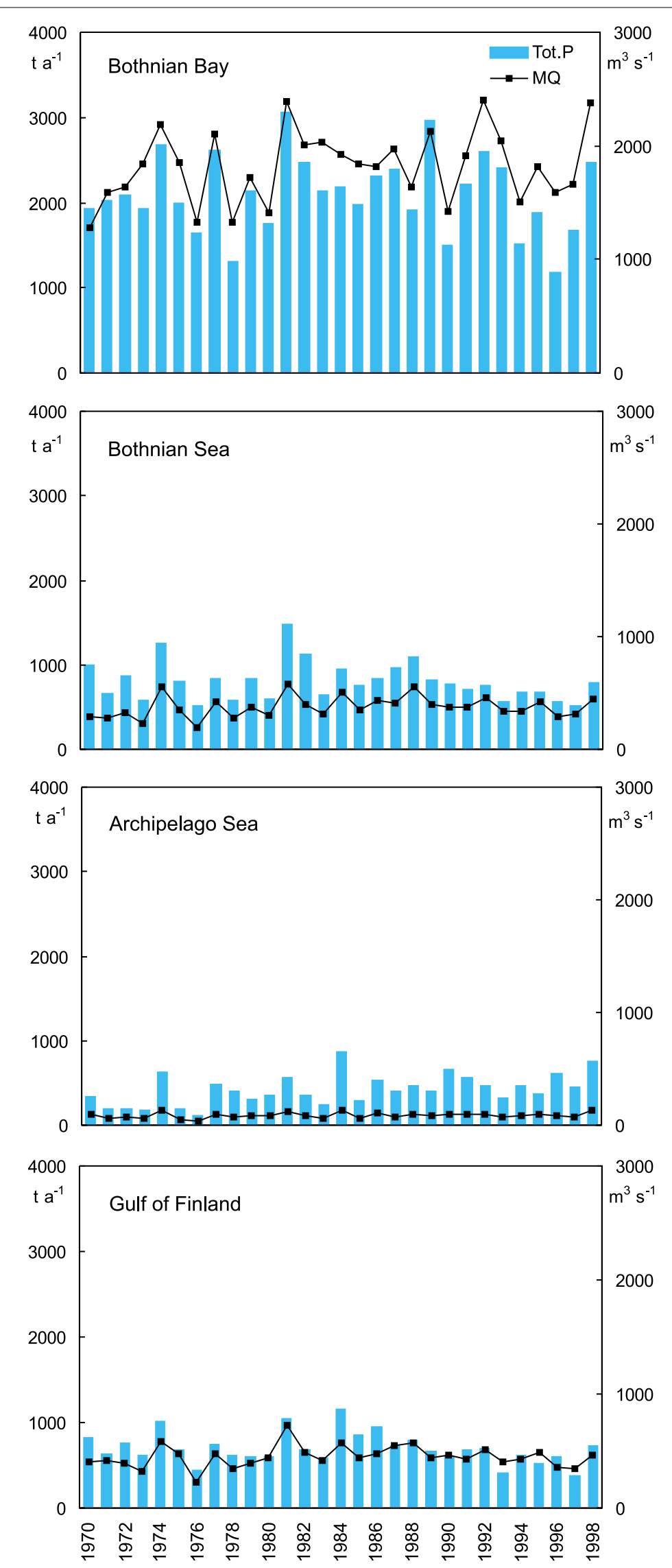

Fig. 3.9. Mean annual water flows $\left(M Q, m^{3} s^{-1}\right)$ and riverine fluxes of $P$ into Finnish coastal waters in 1970-1998.
The increase in the loading of $\mathrm{N}$ and $\mathrm{P}$ from fish farming by more than $70 \%$ since the mid 1980s was a consequence from the intensified production of rainbow trout in cages. However, the load started to reduce in the early 1990s partly due to diminished production, and partly due to protection measures by optimazing the content of feed, and organizing feeding. By 1997 it had decreased by $30 \%$ from the level of the early 1990s.

The potential load (retention in lakes not included) from forestry practices in the catchment area of the Baltic Sea had a decreasing trend in phosphorus leaching but fairly stable level in nitrogen load. The main cause to this is almost the total ceasing of phosphorus fertilization in late 1980s. Instead, the main nitrogen loaders, drainage and felling, have remained on the stable level.

Targets set in Ministry Declaration in 1988 for decreasing industrial and municipal loading of $\mathrm{P}$ to Finnish coastal waters was succeeded in the 1990s. On the contrary, the load of $\mathrm{N}$ from agriculture, municipalities and industry were not remarkably declined. A new target has been set to decrease the load of nutrients by about $50 \%$ from all sources of nutrient loading by the year 2005.

\section{Control of agricultural pollution}

Before Finland joined the European Union (EU) and accepted its Common Agricultural Policy (CAP), its environmental policy and management of agriculture were mostly based on information and education by agricultural and environmental authorities and extension services. Only limited financial incentives were available for farmers, mostly directed towards investments for manure storage. No direct legislation existed for controlling agricultural pollution, except an environmental tax added to fertilizer prices for a few years in the 1990s, which led to a reduction in fertilizer use. 
A massive financial incentive programme in accordance with the EU's AgriEnvironmental Support Scheme was launched in Finland in 1995, when Finland joined the EU. Through this programme, farmers are paid to adopt environmentally sound management practices. In 1998, more than $80 \%$ of Finnish farmers participated in the programme. Briefly, to be eligible for support, farmers must simultaneously achieve the following on their farms:

- Farm environmental management plans must be prepared.

- The maximum levels of fertilization plus manure application must not be exceeded.

- Manure must be appropriately stored and may not be spread on frozen soil or on snow.

- Livestock density may not exceed 1.5 livestock units ha ${ }^{-1}$.

- Buffer strips (1-3 m in width) must be established on the sides of main ditches and watercourses.

- Pesticide spraying devices must be tested by an authorized agency, and pesticides may be applied only by a person who has been trained in their use.

- At least $30 \%$ of arable land must be covered by crops or crop residues (reduced tillage techniques) during the winter in southern Finland.

Implementation of the EU's Agri-Environmental Support Scheme in Finland has led to significant changes in agricultural practices resulting in more environmentally sustainable agriculture. The implementation of the Nitrate Directive in Finland sets upper dose limits for chemical fertilizer and manure spreading, and also time limits for manure spreading (no spreading allowed on frozen soil or on snow cover); however, the undertakings according to the directive are less demanding than the requirements of the Finnish Agri-Environmental Scheme. With more than $80 \%$ of Finnish farmers participating in the scheme, it can be expected that only a minor general reduction in nitrate losses can be achieved via implementation of the Nitrate Directive. However, it may have local impact in areas with intense animal husbandry.
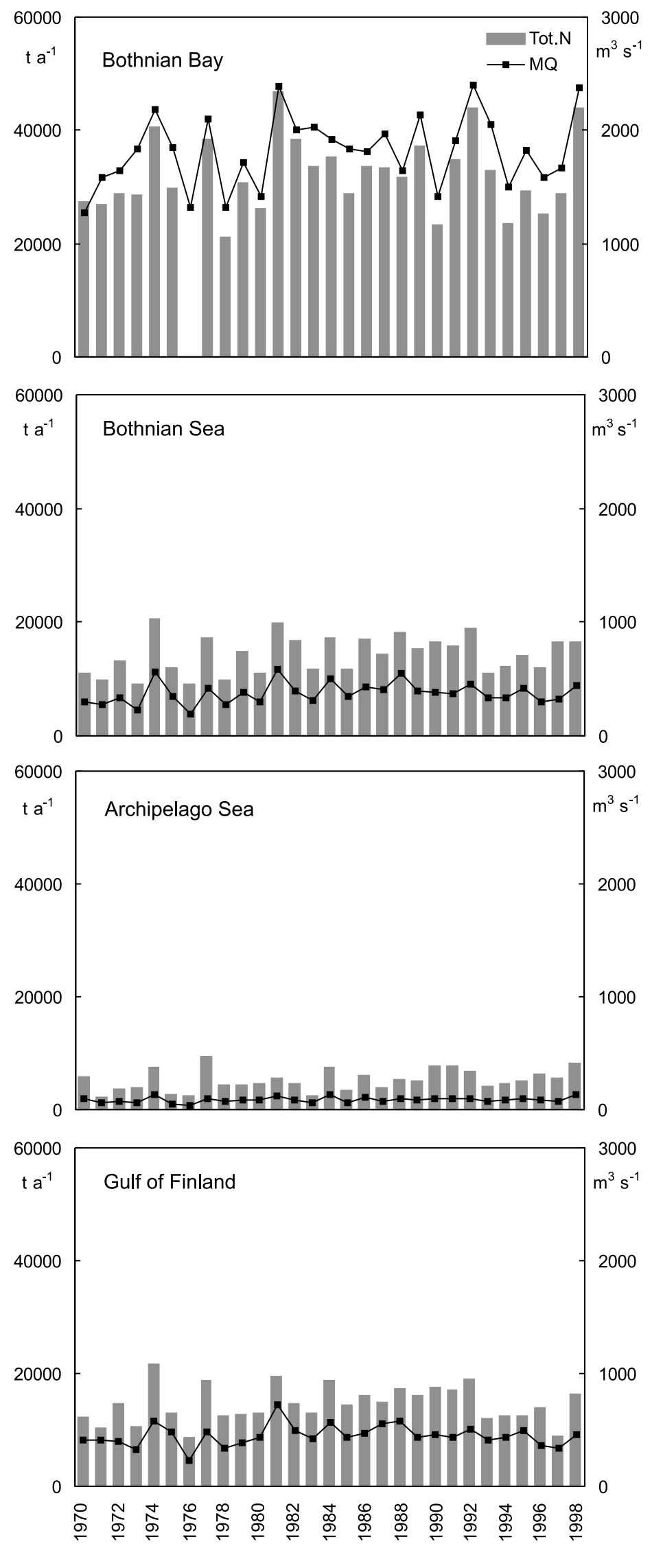

Fig. 3. I0. Mean annual water flows $\left(\mathrm{MQ}, \mathrm{m}^{3} \mathrm{~s}^{-1}\right)$ and riverine fluxes of $N$ into Finnish coastal waters in 1970-1998. 


\section{Atmospheric deposition}

All the pollutants that are released into atmosphere must at some time return to the earth again. This can occur in two ways: gaseous and particle-borne substances can be transferred directly to the ground, to water surfaces or to vegetation, while substances scavenged by cloud or rain drops reach the earth's surface in precipitation. The first is called dry deposition and the second wet deposition.

Atmospheric deposition of inorganic nitrogen consists of oxidised nitrogen (NOx) and reduced nitrogen (ammonium, $\mathrm{NHx}$ ). Agricultural activities are the predominant source of ammonium deposition while most of nitrogen oxides emissions are generated in the combustion of fossil fuels (e.g. as exhaust gas of traffic).

In the mid 1990s, one third of total deposition of ammonium and 15\% of that of nitrogen oxides to Finnish area originated from Finnish sources (Ministry of the Environment 1998). The main part of deposition was gained by long range transport from other European countries, Russia being responsible for below $10 \%$ of the nitrogen deposition to Finland. The predominant contributors of nitrogen deposition to the Baltic sea area are Germany, Poland, Denmark and Sweden (Bartnicki et al., 1998). Finnish emissions contribute $16 \%$ of nitrogen deposition to the Gulf of Bothnia and 10\% of nitrogen deposition to the Gulf of Finland. About half of total atmospheric nitrogen deposition to the Gulf of Bothnia and Gulf of Finland comes from outside the Baltic countries.

Modelling calculations of atmospheric deposition to the Baltic Sea suggest that nitrogen deposition has decreased by about 20\% from 1986 to 1996 (Bartnicki et al.,1998). This is mainly due to the general decline in nitrogen emissions in areas contributing to deposition to the Baltic sea, most notably in Germany, Poland, Denmark, Estonia, Latvia and Lithuania (Tarrason and Schaug, 1999). Nitrogen emissions in Finland and Sweden have not dropped considerably during the period 1986-1996. In the Russian Federation the reported emissions of reduced nitrogen have decreased by $40 \%$ but simultaneously the emissions of oxidised nitrogen have increased, the net effect being a $16 \%$ decrease in total nitrogen emissions.

\section{The natural or background leaching of $\mathbf{N}$ and $\mathbf{P}$}

The background load is a figure for the natural leaching from a catchment area that is not affected by human activities (HELCOM 1998). All anthropogenic nutrient sources, both point and diffuse ones, have to be separated from natural leaching. Typical anthropogenic diffuse sources of nutrients are scattered dwellings, agriculture, forestry and anthropogenic part of airborne nutrient load. The estimation of natural leaching is based on specific coefficients obtained from the monitoring programmes of small drainage basins (Kauppi 1979, Rekolainen 1989).

The natural leaching of nitrogen and phosphorus from pristine, untouched terrestrial ecosystems is not very well known, even if its importance in the source apportionment of total nutrient load of rivers is large, especially in the northern rivers. Special problems arise when calculations are needed about the natural leaching from fields, because little is known of the quality of their original, past ecosystems. The majority of contemporary fields in Finland are supposed to represent forest types on fine textured, nutrient rich soils before taking into cultivation. However, about the third of fields are former sea or lake bottom soils or peatlands (Kähäri et al. 1987) without any forested phases in the past time.

The airborne load of nitrogen and phosphorus are not easily separable from natural leaching, and may increase the "natural" background level. For example in 1995 annual precipitation of inorganic nitrogen was about $1000 \mathrm{~kg} \mathrm{~km}^{-2} \mathrm{a}^{-1}$ in the south and 200 to $300 \mathrm{~kg} \mathrm{~km}^{-2} \mathrm{a}^{-1}$ in the northern Finland (Barret and Berge 1996). Total phosphorus deposition was about from 8 to $12 \mathrm{~kg} \mathrm{~km}^{-2} \mathrm{a}^{-1}$ in the southern Finland and from 3 to $6 \mathrm{~kg} \mathrm{~km}^{-2} \mathrm{a}^{-1}$ in the northern Finland (Järvinen and Vänni 1997). The high inorganic nitrogen loads during snow melt time in spring clearly show the importance of airborne loading (Anderson and Lepistö 1998). However, contemporary calculations of background load do not separate airborne load and natural leaching. The share of natural and anthropogenic nutrients in precipitation are uncertain, too, and in calculations only wet and dry deposition right on lake or sea surfaces are included. 


\subsection{Loading of organic} matter and trends in

\section{| 985-97}

In 1997, the point source load of organic matter (measured as $\mathrm{BOD}_{7}$ ) to Finnish coastal waters was $17600 \mathrm{t}$, which load was mainly discharged to the Bothnian Sea and the Gulf of Finland (Table 3.3). Industry, woodpro-cessing industry, was responsible nearly $80 \%$ of the load. The decrease in the load of organic matter by more than $70 \%$ since the mid 1980s was due to the introduction of active sludge method in woodprocessing industy.

\subsection{The loading of harmful substances}

Several harmful contaminants enter Finnish coastal waters as effluents from industry, as diffuse loads, and via the atmosphere. The groups of compounds that the most attentation is given in this report are PCBs, DDTs, chlorinated pesticides, polychlorinated dioxins and furanes (PCDD/Fs), polyaromatic hydrocarbons (PAHs) and heavy metals $(\mathrm{Hg}, \mathrm{Cd}, \mathrm{Zn}, \mathrm{Pb}, \mathrm{Cr}$ and $\mathrm{Cu}$ ). Many of the harmful organic compounds originate from incomplete combustion

Table 3.3. Point source load of organic matter $\left(\mathrm{BOD}_{7}, \mathrm{t} \mathrm{a}^{-1}\right)$ to the Finnish coastal waters in 1986-90, 1991-96 and 1997.

\begin{tabular}{|c|c|c|c|}
\hline & $\begin{array}{l}\mathrm{BOD}_{7} \\
1986-90\end{array}$ & $1991-1996$ & 1997 \\
\hline \multicolumn{4}{|l|}{ Gulf of Finland } \\
\hline municipalities & $|275|$ & 6588 & 3661 \\
\hline industry & 2841 & 1858 & 1576 \\
\hline total & 15592 & 8445 & 5237 \\
\hline \multicolumn{4}{|l|}{ Archipelago Sea } \\
\hline municipalities & 159 & 75 & 63 \\
\hline industry & 835 & 692 & 759 \\
\hline total & 994 & 767 & 822 \\
\hline \multicolumn{4}{|l|}{ Bothnian Sea } \\
\hline municipalities & 11888 & 2772 & 2655 \\
\hline industry & 1348 & 1405 & 1057 \\
\hline total & 13235 & 4177 & 3712 \\
\hline \multicolumn{4}{|l|}{ Bothnian Bay } \\
\hline municipalities & 20224 & 9137 & 6507 \\
\hline industry & 1393 & 1336 & 1273 \\
\hline total & 21618 & 10473 & 7780 \\
\hline \multicolumn{4}{|l|}{ Total } \\
\hline municipalities & 45023 & 18572 & 12886 \\
\hline industry & 6417 & 5290 & 4665 \\
\hline Total & 51439 & 23862 & |755| \\
\hline
\end{tabular}


(PAHs, dioxins), the disposal and disintegration of old condensators, transformers or other electrical equipment (PCBs), or are side products of chemical processes (PCDD/Fs). After the ban on PCBs and DDTs in Scandinavia, the input of these organochlorines into the northern Baltic Sea has declined, but not altogether stopped.

Over a lengthy period of time the sea areas surrounding Finland have been loaded with metals, chiefly from metallurgical industry, chemical industries and mines. Taking into account the development of industry it may be assumed that this load was at its heaviest in the 1960s. For the first time there was concern about the danger these emissions represented to the environment. Though the measurement of emissions at this time was sparse, it can still be estimated that the load of mercury, cadmium, lead and arsenic has decreased by at least 95\% to the Gulf of Bothnia during the last 20 years (Encell-Sarkola et al. 1989). This means that the situation today is much better than even ten years ago. On the other hand, it must be remembered that a lot of heavy metals and other persistent hazardous compounds have been deposited and stored in the Finnish coastal area, which is also evident in the elevated concentrations in sediment and biota.

The direct load from industries through waste water is not the only input of heavy metals into the sea environment. Heavy metals find their way into the sea environment through municipalities, by river transportation (Table 3.4) and by deposition from the atmosphere.

The pulp and paper industry has historically been considered a significant contributor of pollutants to the environment. The bleaching of pulp with chlorine can produce a great number of chlorinated organic compounds. From the end of the 1970s, the public concern about the potential hazard of the discharge of chlorinated or- ganic compounds has led to dramatic changes in the processes in pulp mills. The use of elementary chlorine as a bleaching agent has been replaced by chlorine oxide, or other oxygen containing chemicals such as molecular oxygen, ozone or peroxide. In addition, sewage treatment has been improved considerably, with the installations of external treatment plants of different designs. Finally most plants have decreased their waste-water emissions by increased closure of the processes (Owens and Lehtinen, 1995).

\section{Hot spots}

In the hot spot list, specified by HELCOM Convention in 1992 to decrease deteriorating effluents to the Baltic for recovering the ecologically healthy balance of the sea, 8 out of 134 sites were located in the Finnish catchment. By now, the number of hot spots in Finland has decreased to 3 sites, the remaining representing agricultural runoff in the Archipelago Sea, fishfarming in the Archipelago Sea and Åland Sea and metal industry in the Bothnian Sea.

\section{Accumulation of pollutants in biota}

Pollutants are usually spread over vast areas by currents and hence the immediate effect on the biota is often small due to the large dilution factor. The direct effects of toxic organic pollutants, or heavy metals, in the sea may remain unnoticed for a long time until becoming apparent when top predators such as seals or salmon are affected.

Not only the top predators, but also filtering organisms such as the common mussel (Mytilus edulis), are able to accumulate large quantities of heavy metals. Toxic effects in this mussel are usually discerned as histopathological changes but may also result in death if exposure is long enough. Since the common mussel is a popular food for flatfish, cod and eider, which in their turn are consumed by humans, heavy metals may very well end up accumulated in humans. 
Table 3.4. The total load of heavy metals $\left(\mathrm{t} \mathrm{a}^{-1}\right)$ into Finnish coastal waters in 1995.

\begin{tabular}{|c|c|c|c|c|}
\hline Contaminant & rivers & municipalties & industries & total \\
\hline \multicolumn{5}{|l|}{ Gulf of Finland } \\
\hline Mercury & 0.07 & 0.01 & 0.0 & 0.08 \\
\hline Cadmium & 0.13 & 0.006 & 0.0 & 0.136 \\
\hline Chromium & 17 & . & 0.005 & 17 \\
\hline Copper & 27 & 1.53 & 0.039 & 28.6 \\
\hline Lead & 6 & 0.29 & 0.034 & 6.3 \\
\hline Zinc & 89 & 6.38 & 0.067 & 95 \\
\hline \multicolumn{5}{|l|}{ Archipelago Sea } \\
\hline Mercury & 0.04 & 0.007 & 0.0 & 0.011 \\
\hline Cadmium & 0.16 & 0.004 & 0.0 & 0.16 \\
\hline Chromium & 14 & . & 0.003 & 14 \\
\hline Copper & 14 & 0.36 & 0.099 & 14.4 \\
\hline Lead & 4.3 & 0.11 & 0.075 & 4.3 \\
\hline Zinc & 75 & 2.07 & 0.011 & 77 \\
\hline \multicolumn{5}{|l|}{ Bothnian Sea } \\
\hline Mercury & 0.09 & 0.002 & 0.02 & 0.11 \\
\hline Cadmium & 0.8 & 0.001 & 0.07 & 0.15 \\
\hline Chromium & 26 & . & 14.4 & 40.4 \\
\hline Copper & 2.6 & 0.26 & 0.95 & 3.8 \\
\hline Lead & II & 0.05 & 1.51 & 12.5 \\
\hline Zinc & 192 & 1.07 & 38 & 231 \\
\hline \multicolumn{5}{|l|}{ Bothnian Bay } \\
\hline Mercury & 0.56 & 0.002 & 0.02 & 0.58 \\
\hline Cadmium & I.I & 0.002 & 0.08 & I.I \\
\hline Chromium & 41 & . & 3.44 & 44.4 \\
\hline Copper & 42 & 0.38 & 0.16 & 41.5 \\
\hline Lead & 10 & 0.07 & 0.01 & 10.1 \\
\hline Zinc & 200 & 1.64 & 7.7 & 209 \\
\hline \multicolumn{5}{|l|}{ Total } \\
\hline Mercury & 0.76 & 0.021 & 0.04 & 0.78 \\
\hline Cadmium & 2.19 & 0.013 & 0.15 & 1.42 \\
\hline Chromium & 98.0 & . & 17.8 & 115.8 \\
\hline Copper & 85.6 & 2.19 & 1.25 & 88.3 \\
\hline Lead & 31.3 & 0.52 & 1.63 & 33.2 \\
\hline Zinc & 556 & II.2 & 45.8 & 612 \\
\hline
\end{tabular}




\section{Hydrography and \\ oxygen conditions}

Heikki Pitkänen, Pirkko Kauppila and Yki Laine

\section{I Salinity}

\section{Horizontal distribution}

The surface and bottom open sea salinities showed the typical increasing gradient in the Gulf of Bothnia from the Bothnian Bay (2 to $4 \mathrm{psu}$ ) via the Bothnian Sea (5 to $6 \mathrm{psu}$ ) to the Archipelago Sea ( 6 to $6.5 \mathrm{psu}$ ) and in the Gulf of Finland from the east (4 to $5 \mathrm{psu}$ ) to the west (5 to 6.5 psu, Fig. 4.1). In the Gulf of Finland, the wintertime salinities were about 0.5 psu higher than the summer ones, reflecting the high freshwater flow from the River Neva (Fig. 4.2). In the Gulf of Bothnia, the seasonal variations in surface salinity were small, except in the NE Bothnian Bay, which showed very low wintertime salinities $(<1 \mathrm{psu})$ over an area of about $2000 \mathrm{~km}^{2}$ due to the concentration of river waters just below the ice cover.

\section{Vertical stability}

The general hydrography of the Baltic Sea causes the well known vertical salinity stratification for the Gulf of Finland. The salinity difference between the mixed surface layer and the nearbottom waters was up to 3 psu in summer and 2 psu in winter (Figs. 4.2 and 4.3). In the Gulf of Bothnia the vertical stability is much weaker: in the present data practically no difference was observed in winter, whereas mean differences up to 1 psu were detected in the summer data. Due to the influx of saline water from the North Sea to the Baltic Sea in 1993, the vertical density stratification has strengthened in the Gulf of Finland since 1995.

Very strong wintertime stratifications (vertical differences up to $5 \mathrm{psu}$ ) were observed especially in larger estuaries (Kymijoki, Karjaanjoki, Uskelanjoki, Paimionjoki, Kokemäenjoki and Kyrönjoki) as well as in the whole NE Bothnian Bay, which indicates very poor vertical mixing and an extensive spread of river water as a separate layer immediately below the ice in these areas. 
Salinity

summer, bottom

psu

\begin{tabular}{|l|l}
\hline & $<1$ \\
$\square$ & $1-2$ \\
$\square$ & $2.1-3$ \\
$\square$ & $3.1-4$ \\
$\square$ & $4.1-5$ \\
$\square$ & $5.1-6$ \\
$\square$ & \\
\hline
\end{tabular}
Tornio

Kemi
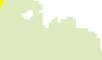

- Kokkola

Pietarsaari

-Oulu

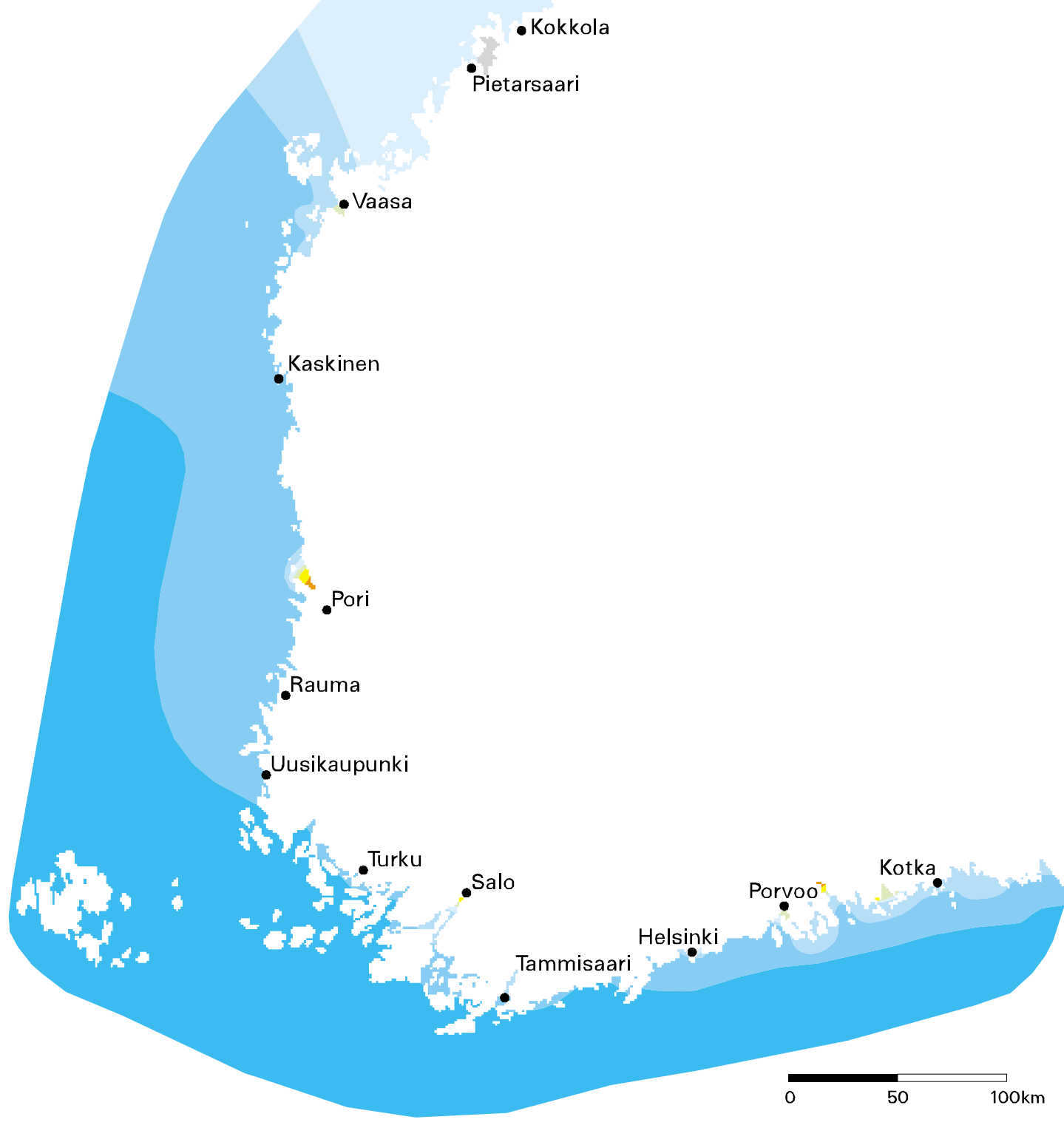

Fig. 4.I. Mean bottom layer values for salinity in summers I99I-1996. 


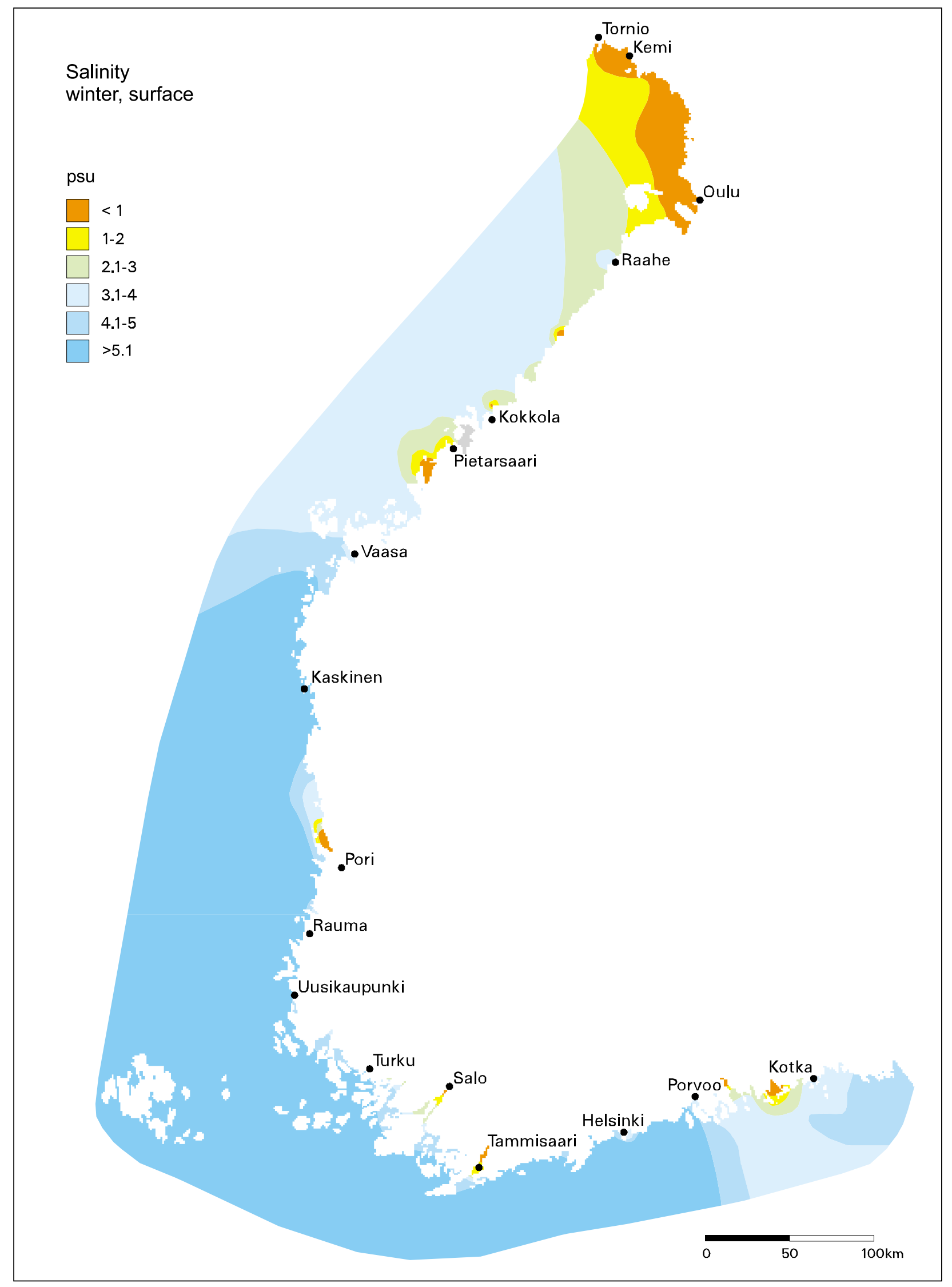

Fig. 4.2. Mean surface values for salinity in winters 199I-1996. 
Salinity

winter, bottom

psu

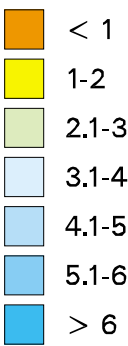

- Raahe

3.1-4

1-5

1- 6

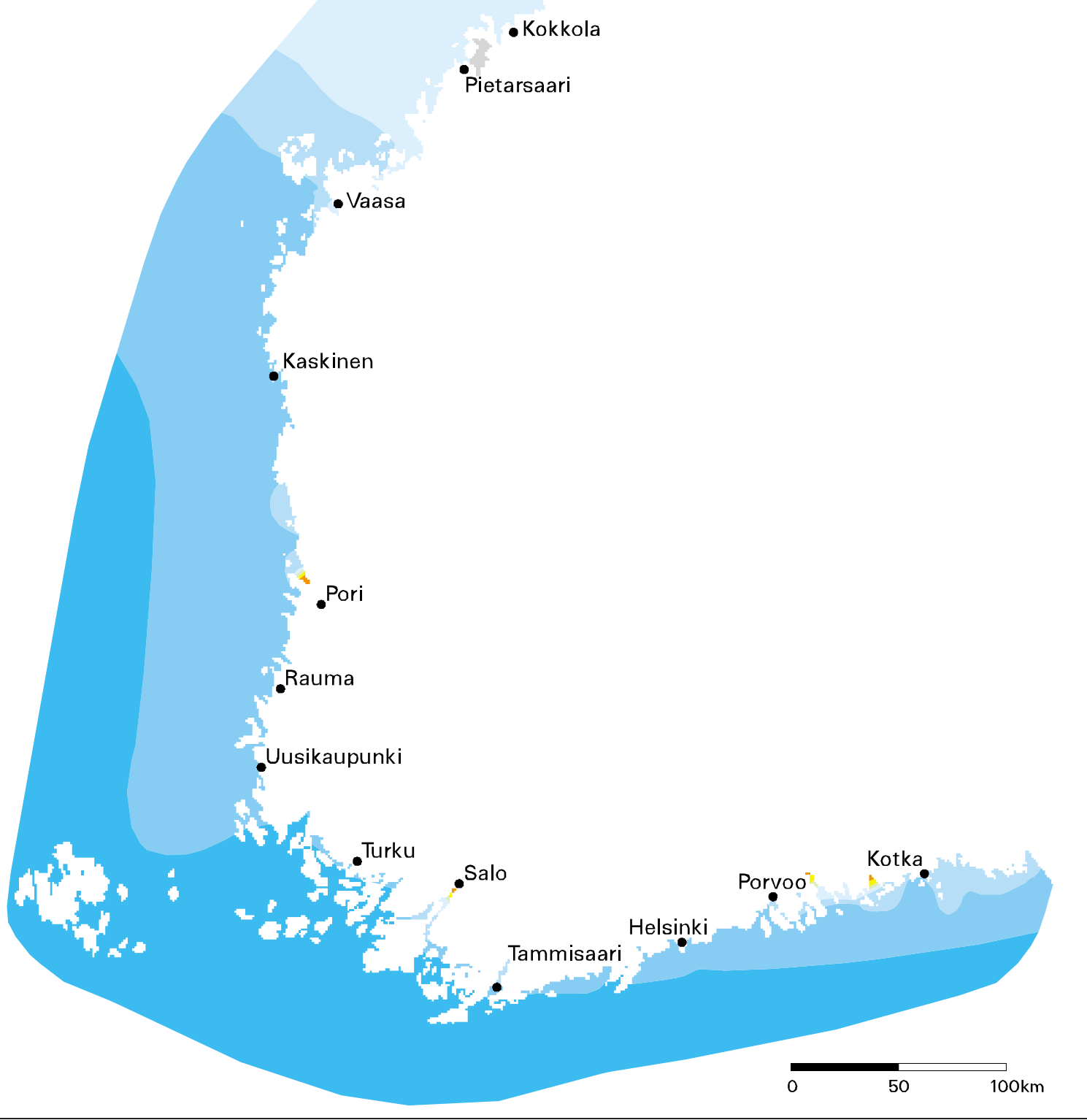

Fig. 4.3. Mean bottom layer values for salinity in winters 199I-1996. 


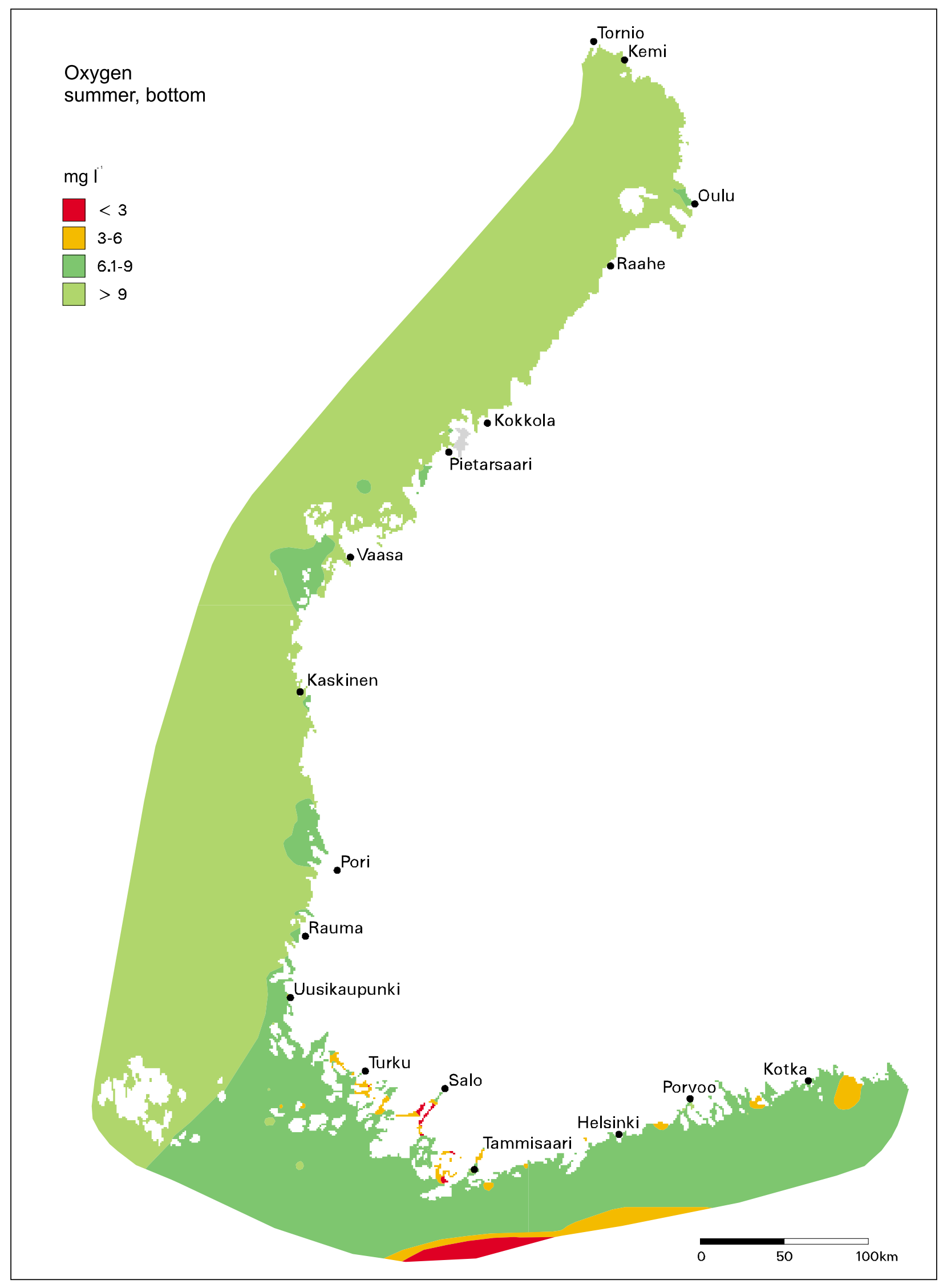

Fig. 4.4. Mean bottom layer values for oxygen in summers 199I-1996. 


\subsection{Oxygen}

In winter, the oxygen conditions have been good in the whole open sea area and also in most parts of the coastal waters. Reduced saturation values (below $70 \%$ ) were observed only in some deep parts of the open Gulf of Finland and in very restricted coastal areas (mostly small bays or estuaries). In summer the conditions were clearly poorer especially in the deep open Gulf of Finland, where mean saturation values from 30 to $60 \%$ were common. In the coastal waters mean values below $50 \%$ were obtained for several coastal basins and estuaries both in the Gulf of Finland and in the Archipelago Sea (Fig. 4.4).

The oxygen conditions of the 1990s were generally, both in winter and in summer, better than those of the earlier assessment period (1979-83), mainly due to weakened salinity stratification and decreased loading of organic matter $\left(\mathrm{BOD}_{7}\right)$ from the coast. However, despite the decreased loading and vertical stability in the Gulf of Finland, the conditions there were at least as poor as ten years earlier. In certain enclosed basins, oxygen concentrations were even lower than in the 1980s indicating some kind of cumulative effects of loading in these areas. In the eastern Gulf of Finland in the coastal basins the conditions have been particularly poor since the mid 1990s. In the open Gulf this can be explained (in addition to autochtonous production caused by large nutrient inputs) by the inflow of saline water which entered the Gulf in 1995.

\section{Anoxic bottoms}

Due to the increased sedimentation and decomposition of organic matter, oxygen will be used up and anoxic conditions can occur in the water column and especially in the bottom layers. Shortage of oxygen and therefore increase in the production of hydrogen sulphide in the sediment has negative effects on the fauna and flora. Bottomdwelling animals suffer and fish either die or escape the affected area and increased nutrient concentrations also cause changes in aquatic vegetation. Several semi- enclosed bottom areas with reduced sediment surface have been detected in the coastal Gulf of Finland in the late 1990s (Fig. 4.5). The reason for the phenomenon is partly antrophogenic (external loading) and partly natural (coastal topography, physical stratification). Longer timeseries reviel that locally reduced bottoms and internal loading have caused eutrophication at least since the 1970s.

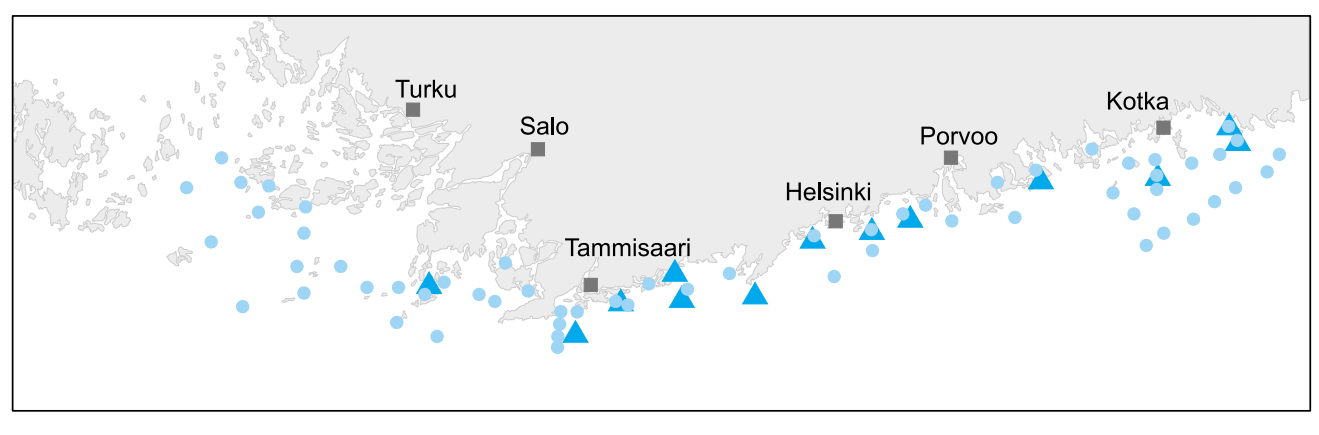

Anoxic bottom sediments

- Sampling site

Fig. 4.5. Anoxic bottom sediments in the Gulf of Finland in August 2000. 


\section{Internal nutrient loading}

Normally it is assumed that loading is socalled external loading, which can be defined as loading into the ecosystem from outside e.g. via rivers, from the atmosphere or from sewage treatment plants. However, in the Baltic Sea the phenomenon of internal loading may occur. This is defined as loading taking place inside the aquatic ecosystem, e.g. release of phosphorus from bottom sediment to the water column in anoxic conditions. Nitrogen and phosphorus are sedimented as particulate matter on the surface of the bottom. However, all sedimented nutrients are not buried into the sediment. After mineralization and chemical processes, parts of the nutrients are changed into dissolved forms, which are transported from the sediment back to water. These bioavailable dissolved inorganic nutrients originating from sediment constitute part of the new biological production occurring in the euphotic zone of water.

\section{The importance of iron} in phosphorus binding and as a buffer for hydrogen sulfide in marine sediments

The classic model explaining release of phosphate from sediment to water is based on the Fe cycle in the sediment. Solid Fe(III) oxides are reduced to dissolved Fe(II) ions and after this reduction Fe bound phosphate is released to interstitial water of the sediment. When reduced dissolved $\mathrm{Fe}(\mathrm{II})$ is transported to the oxic sediment surface it is oxidized back to Fe(III) oxides, which have a high capacity to bind phosphate. Thus these precipitated Fe(III) oxides can effectively prevent phosphate from entering the euphotic layer of water. Another important function of sediment $\mathrm{Fe}(\mathrm{III})$ oxides is to block toxic hydrogen sulphide $\left(\mathrm{H}_{2} \mathrm{~S}\right)$ entering from sediment to water. In this oxidation-reduction reaction $\mathrm{Fe}(\mathrm{III})$ oxides are reduced and $\mathrm{H}_{2} \mathrm{~S}$ is oxidized to sulfate $\left(\mathrm{SO}_{4}\right)$. 


\section{I Spatial distributions of phosphorus and nitrogen}

\section{I.I Winter}

The late winter concentration distributions of both total and inorganic $\mathrm{N}$ and $\mathrm{P}$ indicate the trophic conditions and sources of nutrients around the Finnish coast due to the negligible activity of primary producers (Figs. 5.1a,b; 5.2; $5.3 a, b ; 5.4 a, b)$. The winter level of inorganic nutrients also directly controls the level of the spring algal bloom. This means that in the Gulf of Finland where the nutrient levels are highest, the spring bloom of phytoplankton, as well as the summertime productivity, is also most pronounced, whereas in the P-limited Bothnian Bay both the concentrations of $\mathrm{P}$ and the general productivity during the growth period are lowest.

Both in the Gulf of Finland and in the Gulf of Bothnia, clear west-east and south-north gradients prevail, whereas in almost all loaded coastal regions an open sea - coast gradient can be found. In the Gulf of Bothnia the open sea gradient for both total and inorganic $\mathrm{P}$ is, in contrast to $\mathrm{N}$, from north to south due to the effective chemical precipitation of $\mathrm{P}$ with iron compounds in the Bothnian Bay (cf. Voipio 1969). This leads to low concentrations of bioavailable $\mathrm{P}$ in this sea area despite the voluminous nutrient inputs from several large rivers (Fig. 3.6).

A clear west-east gradient in $\mathrm{N}$ and $\mathrm{P}$ compounds is observable both in the open sea and in Finnish coastal waters outside local loading sources, due to the strong nutrient loading to the easternmost Gulf from the River
Neva and St. Petersburg and due to the estuarine hydrography of the Gulf. However, the east-west gradient has weakened in the 1990s, possibly due to decreased loading from the River Neva.

Some clear changes in the open sea nutrient distributions can be found between the present period of study (1991-98) and 1979-83, the period of the previous corresponding report (Pitkänen et al. 1987). The most extensive is the increase in the level of $\mathrm{P}$ in the open Bothnian Sea, whereas in the eastern Gulf of Finland a decrease of ca. 20\% has taken place in the average level of $\mathrm{TP}$, probably reflecting the decreased load from the River Neva - St. Petersburg region in Russia (Pitkänen et al. 1997).

In coastal waters, the most striking changes between the early 1980s and the 1990s were the increase in the area of TN concentrations exceeding $500 \mathrm{mg} \mathrm{m}^{-}$ ${ }^{3}$ in the middle and inner Archipelago Sea and in parts of the coastal Bothnian Bay. Regarding the changes in $\mathrm{P}$ distribution, the area of TP concentrations exceeding $40 \mathrm{mg} \mathrm{m}^{-3}$ has decreased off the larger point-source loaders in the Bothnian Sea (Uusikaupunki, Rauma, Pori, Kaskinen, Vaasa), most probaly due to the decreases in the municipal and industrial (pulp and paper industry) loading of $P$ to these coastal water areas (Figs. 3.8).

The winter distributions of both TN and DIN clearly reflect the inputs from rivers and larger towns as the main coastal sources of $N$. Due to the permanent ice cover in coastal waters in February-March, water areas with elevated concentrations (more than 500 mg TN mg m $\mathrm{m}^{-3}$ or $200 \mathrm{mg}^{\mathrm{DIN}} \mathrm{mg} \mathrm{m}^{-3}$ ) in the surface layer extended further 


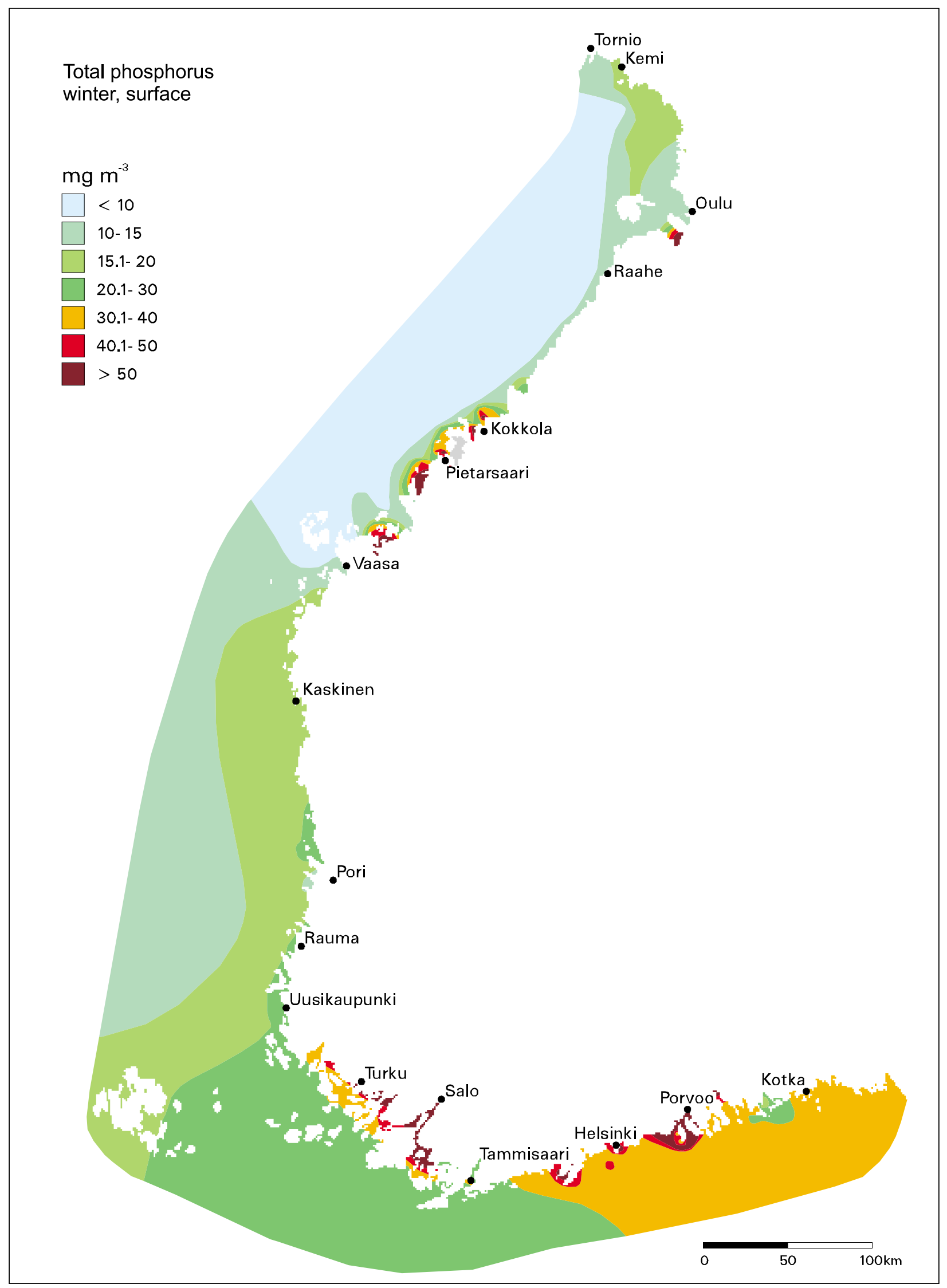

Fig. 5. Ia. Mean surface values for total phosphorus in winter 199I-1996. 
Total phosphorus

winter, bottom
$\mathrm{mg} \mathrm{m}^{-3}$
$\square<10$
10-15
15.1- 20
20.1-30
30.1-40
40.1- 50
$>50$
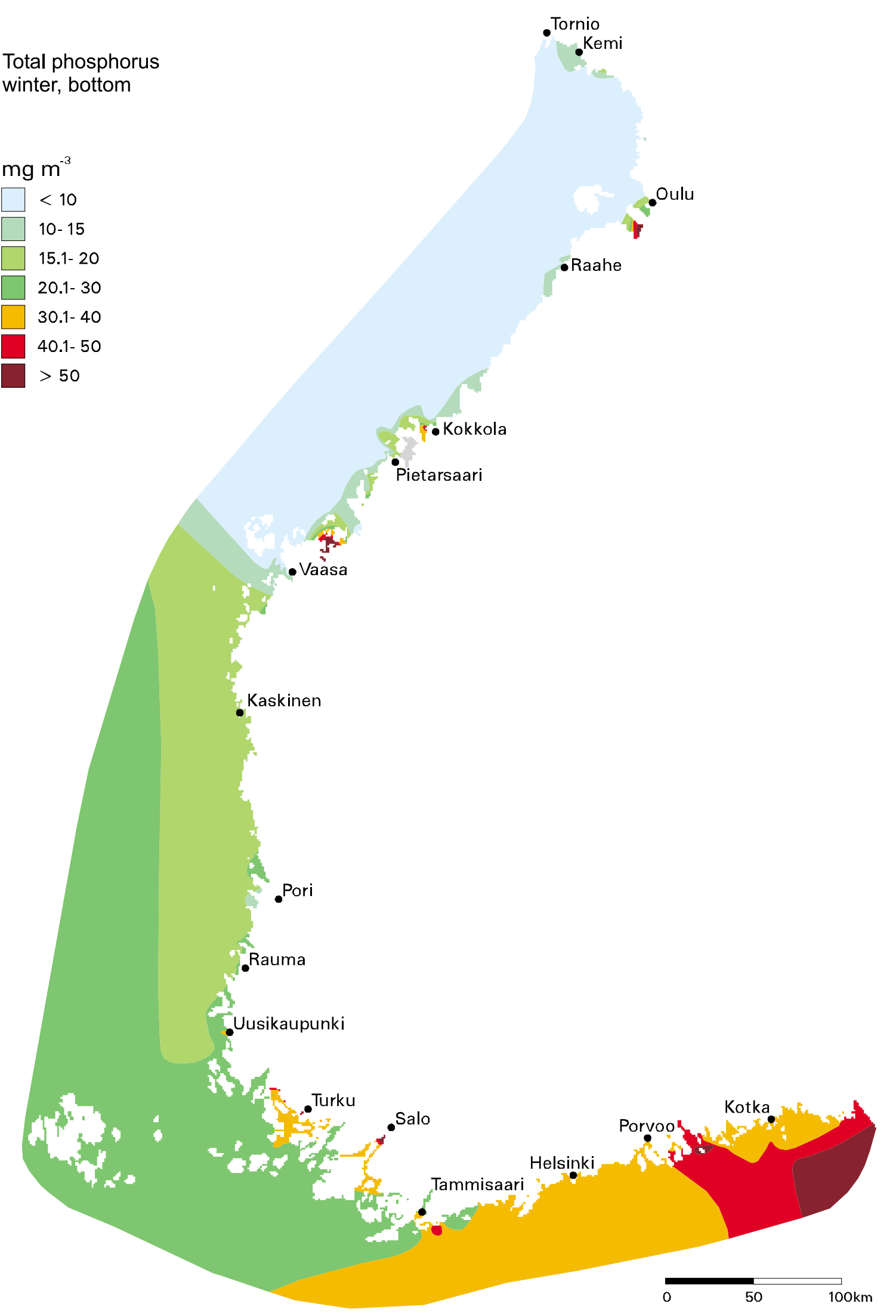

Fig. 5. Ib. Mean bottom layer values for total phosphorus in winter 199I-1996. 


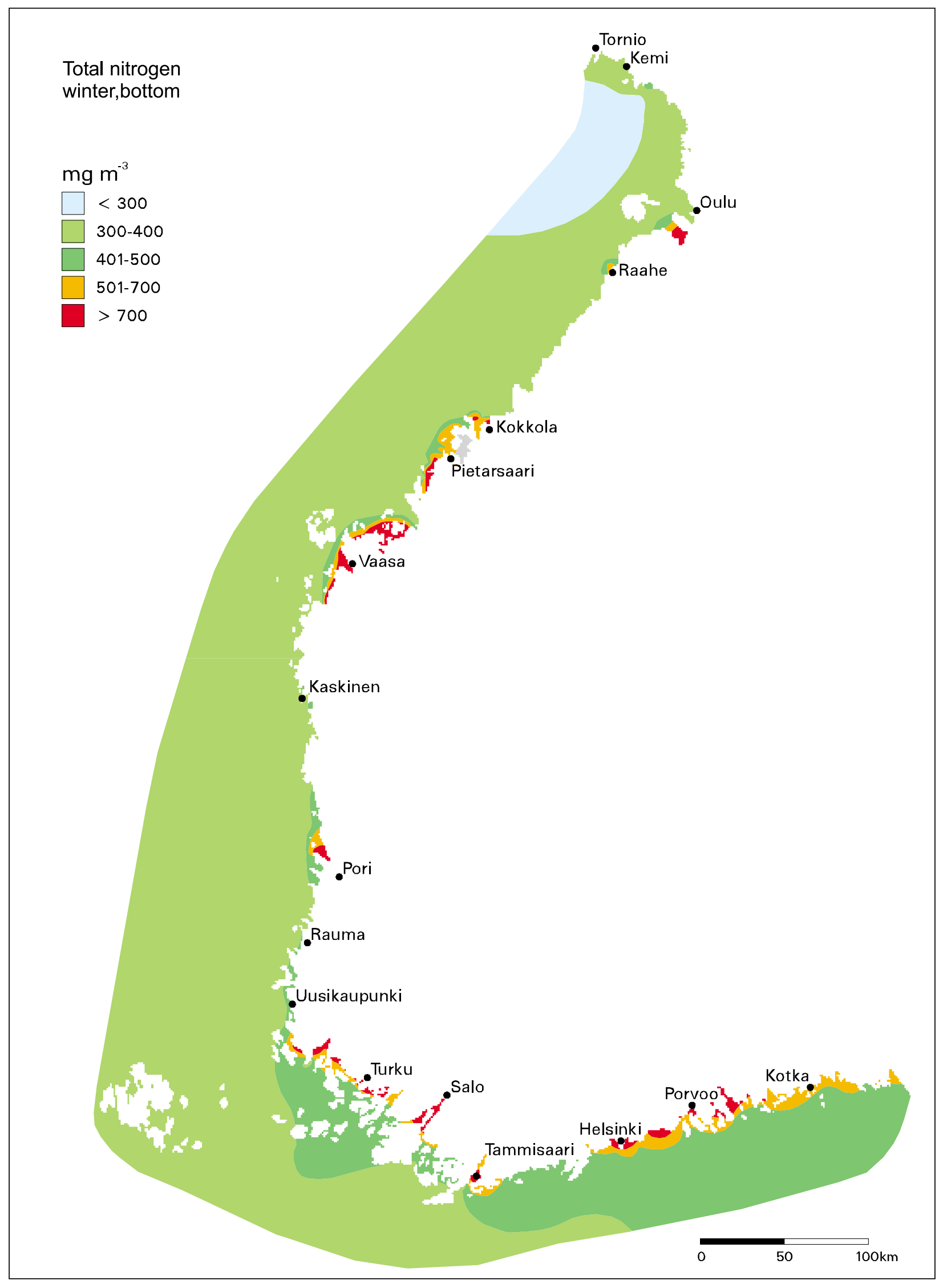

Fig. 5.2. Mean bottom values for total nitrogen in winter 199I-1996. 


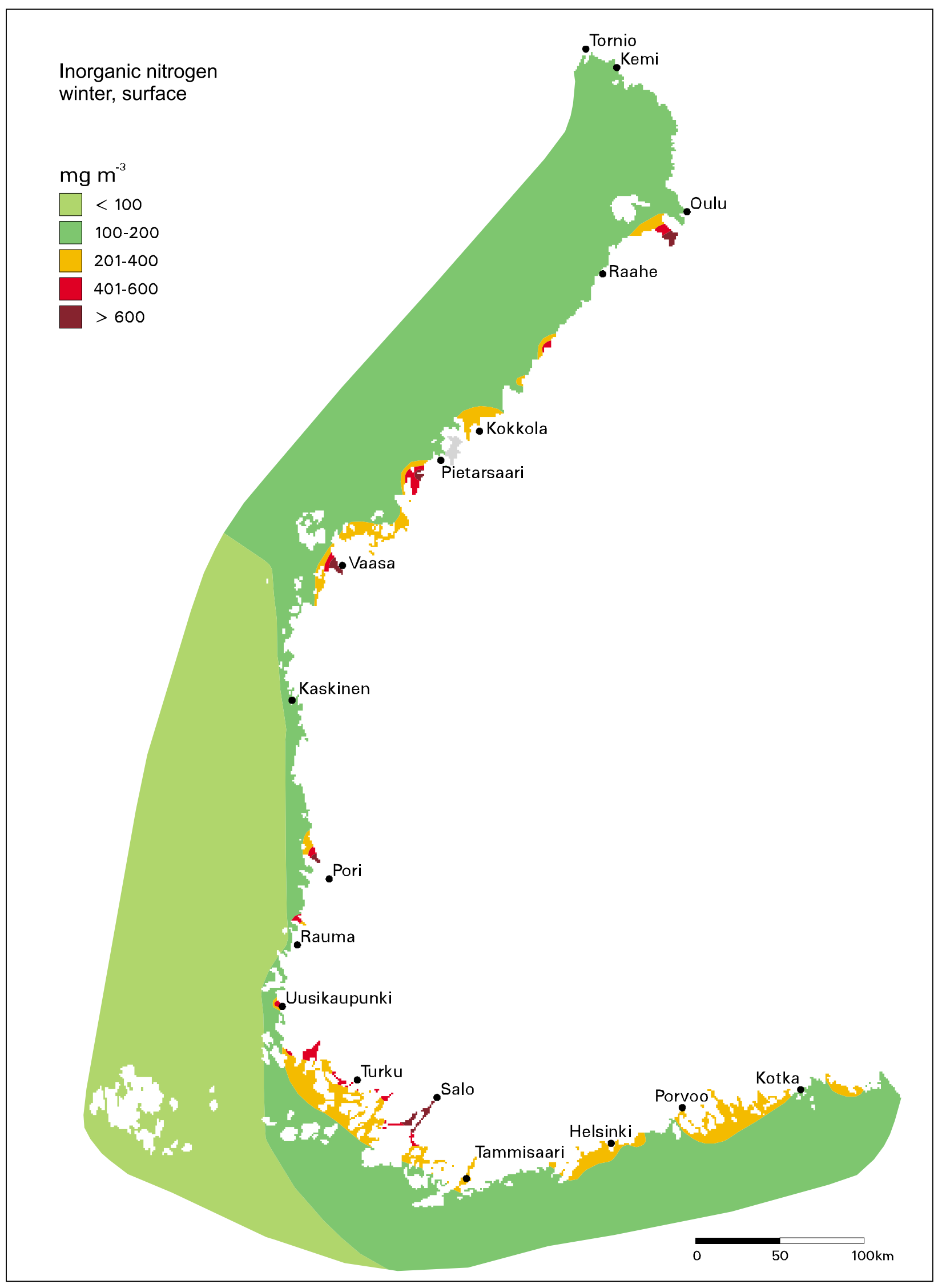

Fig. 5.3a. Mean surface values for inorganic nitrogen in winter 1991-1996. 


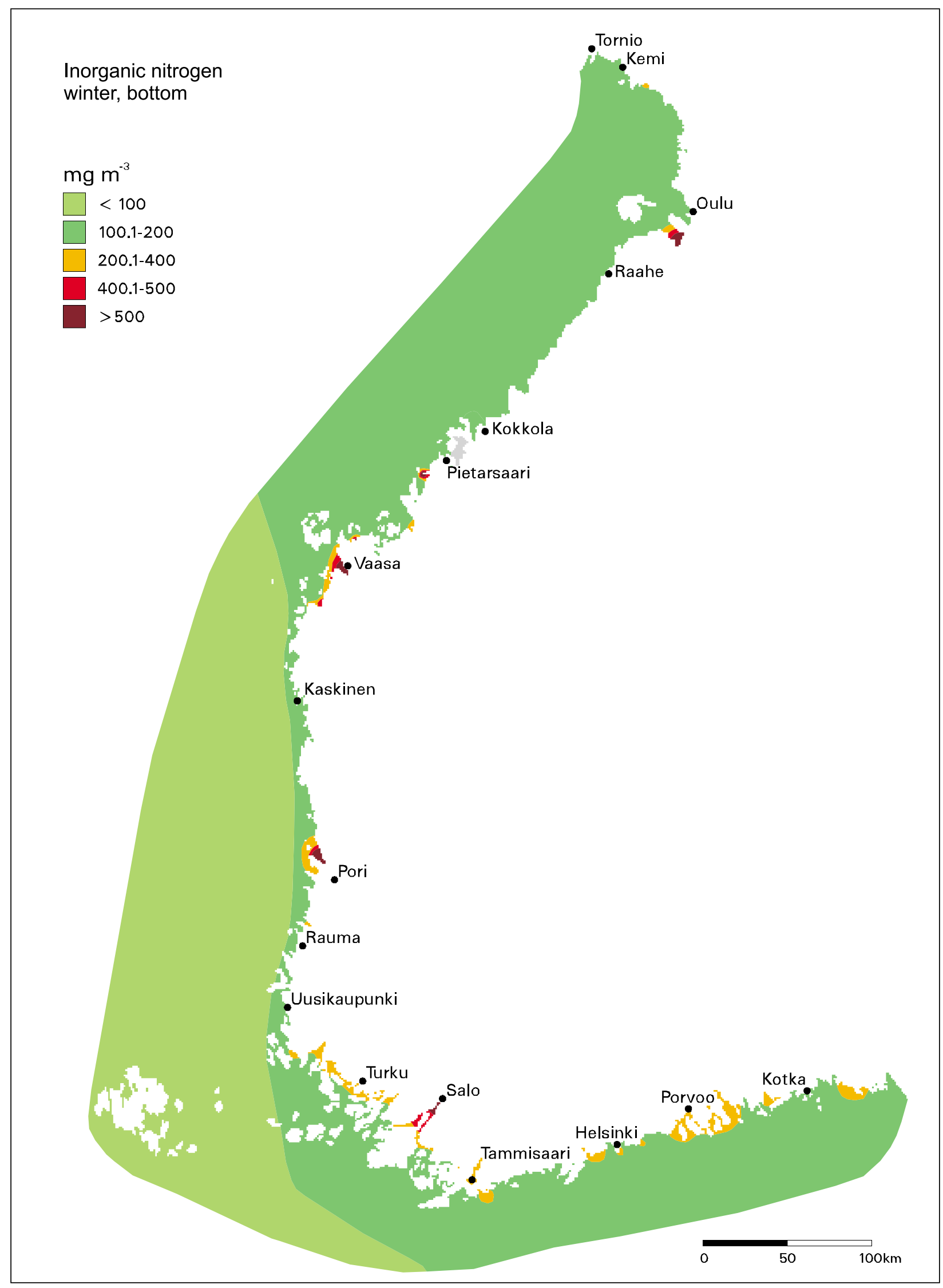

Fig. 5.3b. Mean bottom layer values for inorganic nitrogen in winters 199/-1996. 


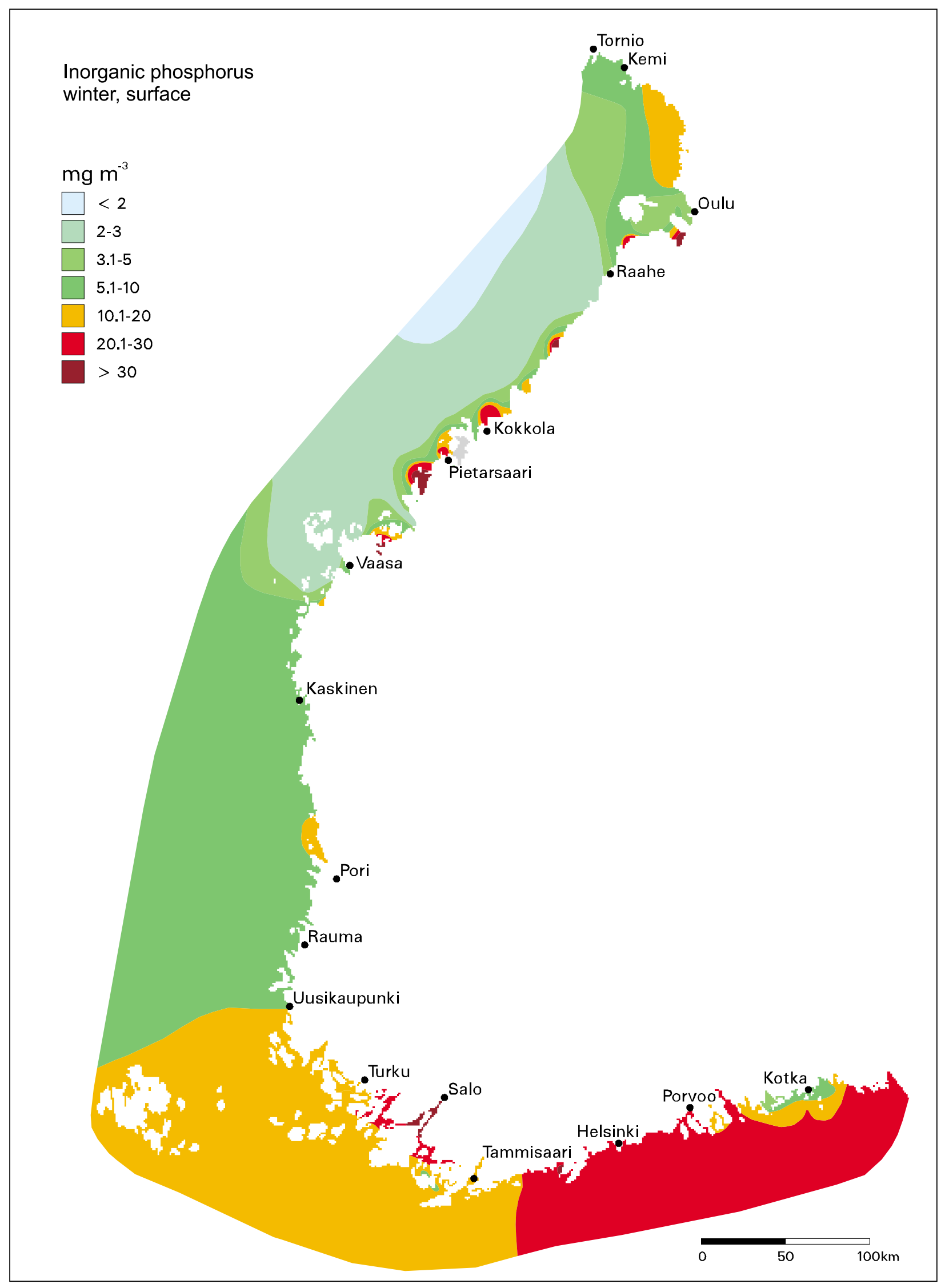

Fig. 5.4a. Mean surface values for inorganic phosphorus in winters 199I-1996. 


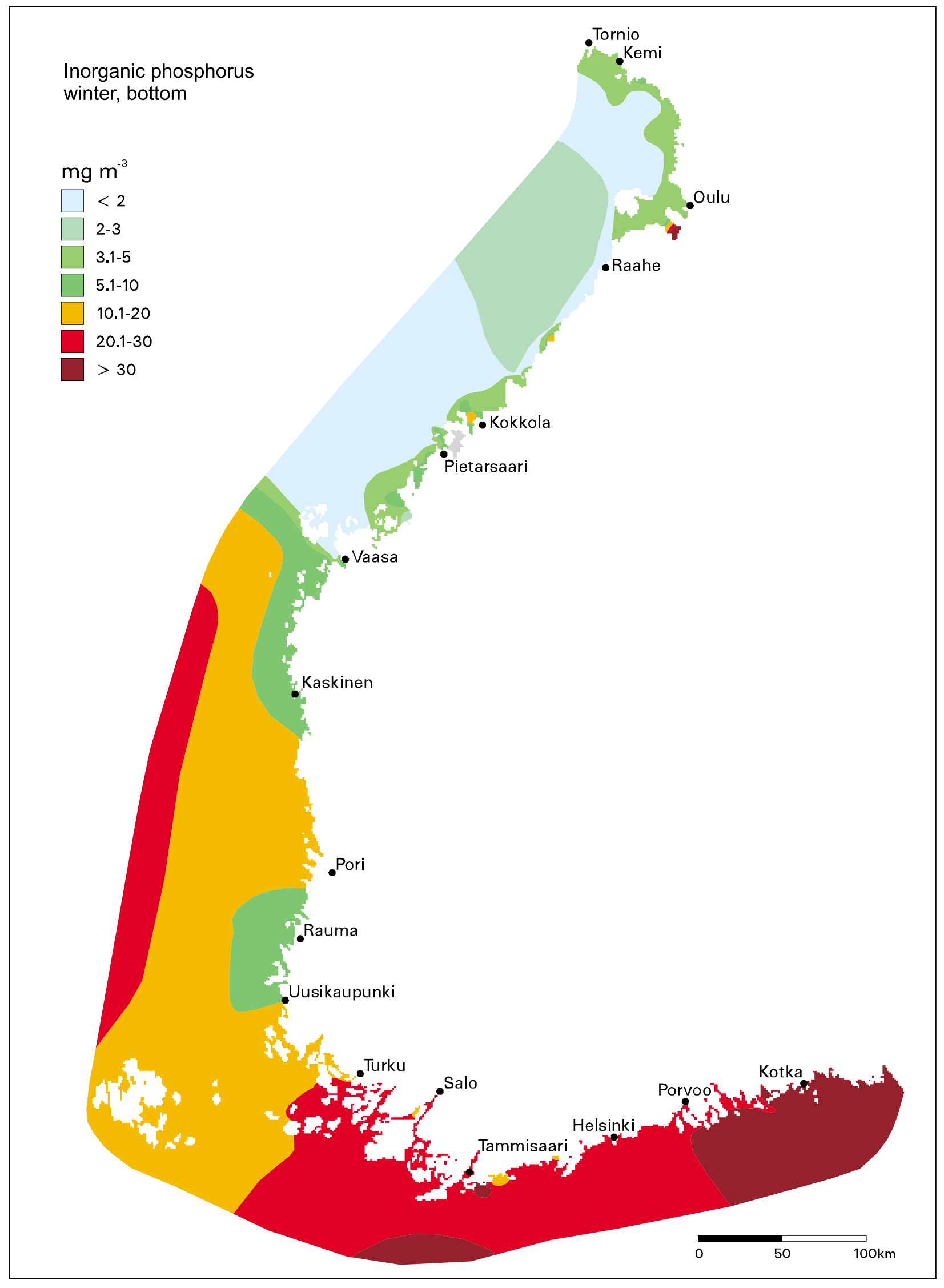

Fig. 5.4b. Mean bottom layer values for inorganic phosphorus in winters 199I-1996. 
outwards from the coast than in the near-bottom waters. A similar, but clearly weaker (due to the fixing by primary producers) effect can also be seen in the summer distributions of $\mathrm{N}$. The reason for these phenomena is that river water is lighter than brackish coastal water and especially in winter the mixing of the two water layers is limited because of the lack of wind shear stress (cf. Alasaarela 1980).

\section{I.2 Late summer}

The late summer period (July-September in the present study) represents conditions when the growth of algae is usually nutrient (N, P) limited (cf. Tamminen et al. 1996). Thus the surface concentrations of both inorganic $\mathrm{N}$ and $\mathrm{P}$ were usually low in the open sea areas (Figs. $5.5,5.6$ ), generally near or below the detection limits of the analytical methods (here $2 \mathrm{mg} \mathrm{m}^{-3}$ for phosphate-P and $5 \mathrm{mg} \mathrm{m}^{-3}$ for both ammonium- and nitrate-N).

In the coastal waters, the values were in many places at an elevated level due to the continuous inputs from rivers and coastal point-sources. Typically, the areas of increased values of DIN and DIP are much smaller in summer than in winter due to the effective fixing of nutrients by primary producers in summer and, on the other hand, the undisturbed spreading of nutrientrich river waters under the ice in winter. In shallow coastal waters lacking a permanent thermocline (e.g. smaller bays), the nutrient concentrations and productivity are elevated by the upward vertical transport of benthic and near-bottom nutrients.

Clearly elevated concentrations (more than $10 \mathrm{mg}$ DIP and/or $50 \mathrm{mg}$ DIN m ${ }^{-3}$, Fig. 5.5, 5.6) were observed only in restricted areas in the estuaries of the rivers Kyrönjoki, Kokemäenjoki, Uskelanjoki, Porvoonjoki and Pernajanjoki. According to current data a large part of the inner and middle Archipelago Sea showed increased phosphate concentrations ( 3 to $5 \mathrm{mg} \mathrm{P} \mathrm{m}^{-3}$ ). In the whole
Bothnian Bay, inorganic $\mathrm{N}$ varied between 50 and $100 \mathrm{mg} \mathrm{N} \mathrm{m}^{-3}$ due to the clearly P-restricted primary production (Alasaarela 1980) and the accumulation of the extra bioavailable $\mathrm{N}$ in the water mass. Thus the Bothnian Bay rather resembles lakes in this respect.

During the 1990s internal loading of nutrients caused an increase in the levels of both TP and DIP in the Gulf of Finland, although external loading to the Gulf decreased during the same period. The reason for this was an extensive anoxia at the sediment-water interface in vast areas, especially in the eastern Gulf in 1996 (Pitkänen and Välipakka 1997). Oxygen problems have also been observed in smaller scale in the coastal waters of the Gulf of Finland (Fig. 4.5).

It is possible that the increased level of $\mathrm{P}$ in the southern and southwestern Archipelago Sea is connected to the corresponding increase in the Gulf of Finland, because due to the general anti-clockwise circulation system, waters outflowing from the Gulf of Finland tend to turn towards the Archipelago Sea (Helminen et al. 1998).

Regarding phosphorus, the general distribution of near-bottom nutrient reserves in summer largely resembles that of wintertime values: lowest in the Bothnian Bay and highest in the Gulf of Finland (Fig 5.7). In the case of nitrogen the situation is somewhat different due to the strong accumulation of $\mathrm{N}$ in the P-limited Bothnian Bay. As a result, $\mathrm{N}$ concentrations increase from the Bothnian Sea to the Bothnian Bay, while in the Gulf of Finland there is a clear west-east gradient towards the Neva Estuary.

The reasons for the deep water $\mathrm{P}$ distribution are obvious: the main process transferring nutrients from the euphotic surface layer to the aphotic nearbottom layer is the sedimentation of plankton detritus (e.g. Heiskanen 1998). Thus both in the open and coastal Gulf of Finland (DIP up to $100 \mathrm{mg} \mathrm{P} \mathrm{m}^{-3}$ ), high winter concentrations lead to intensive vernal primary production and subsequent sedimentation of dead algae. 


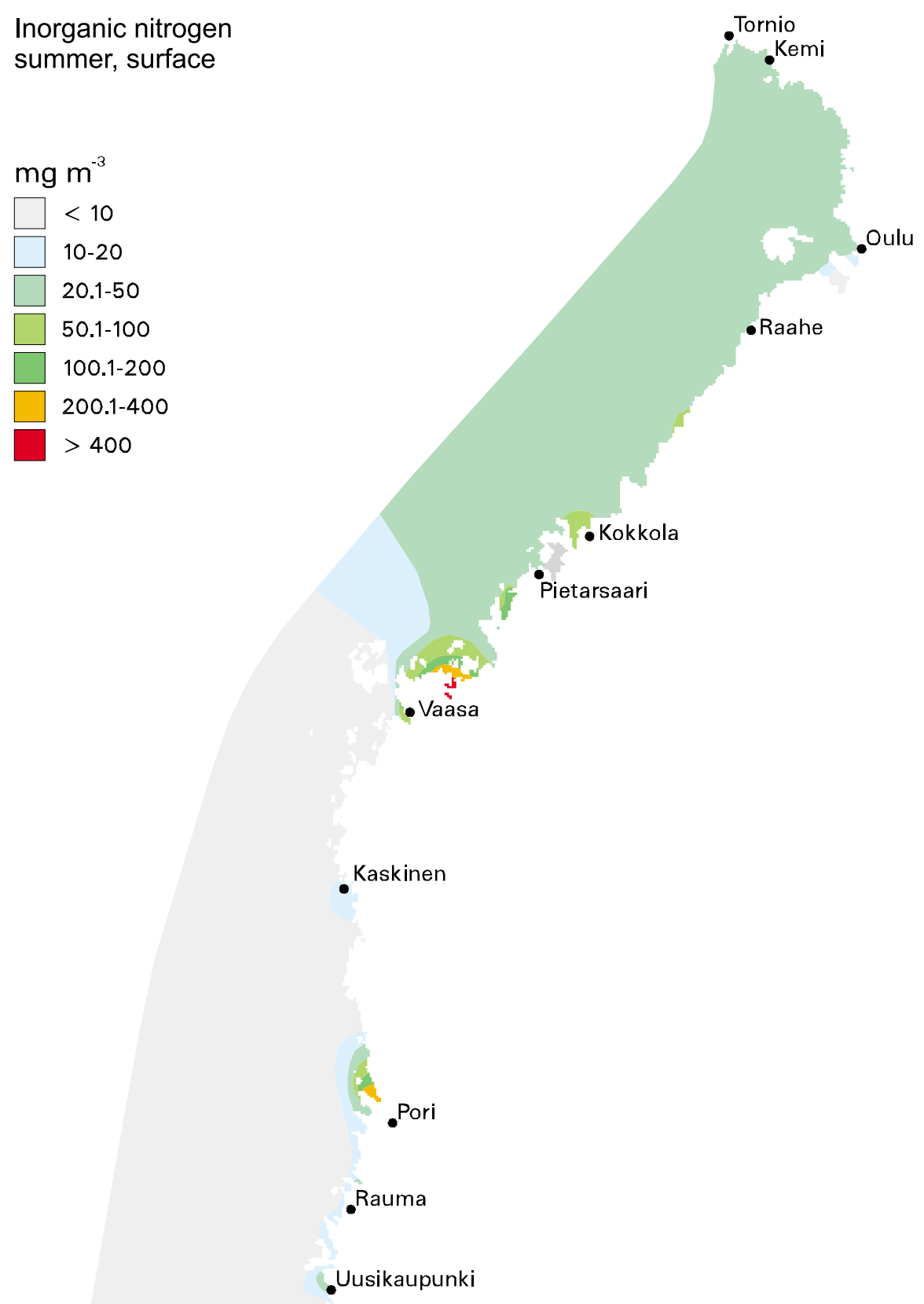

Kaskin Salo

Kotka.

Helsinki

Tammisaari

-

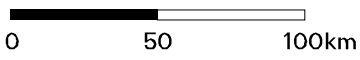

Fig. 5.5. Mean surface values for inorganic nitrogen in summers 1991-1996. 


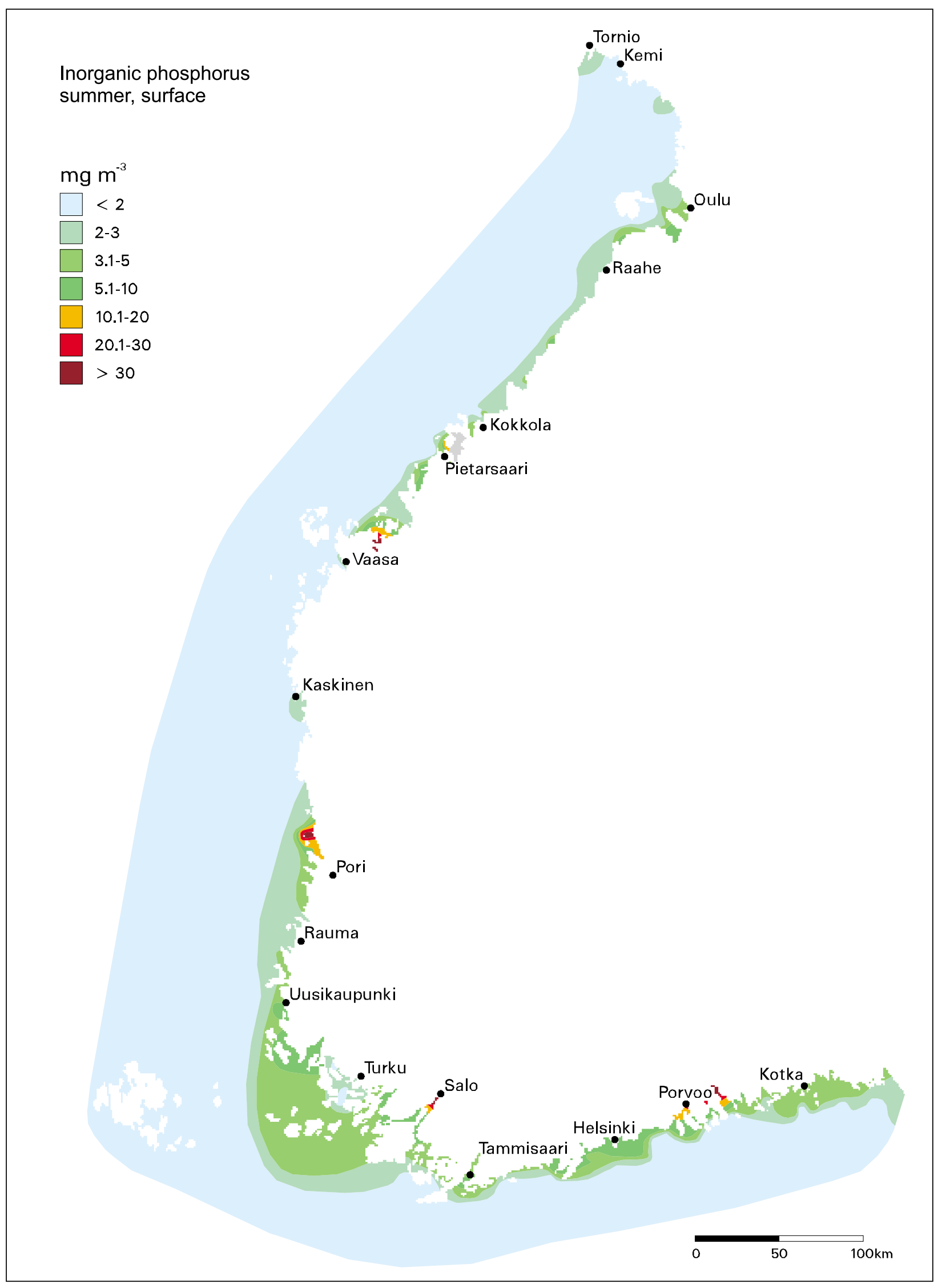

Fig. 5.6. Mean surface values for inorganic phosphorus in summers 1991-1996. 


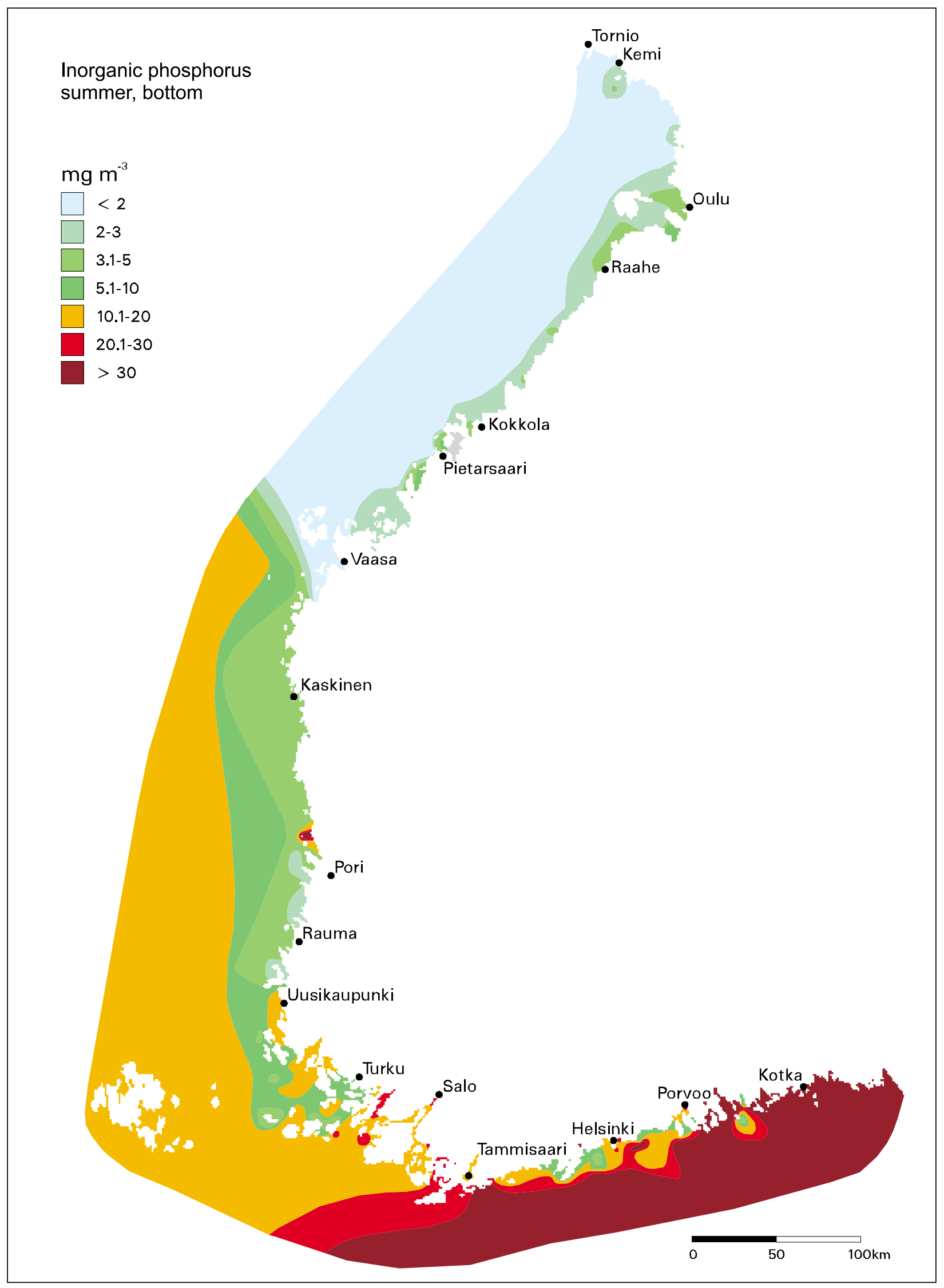

Fig. 5.7. Mean bottom layer values for inorganic phosphorus in summers 1991-1996. 
Furthermore the $\mathrm{P}$ values are elevated by internal loading, which is also partly caused by the high sedimentation of organic matter.

In the coastal waters, highest deep water values of both $\mathrm{N}$ and $\mathrm{P}$ were recorded in certain semi-enclosed basins and estuaries in the coastal Gulf of Finland and in the Archipelago Sea. Typical for the distribution in some coastal areas, excluding the Bothnian Bay, was that in contrast to surface values, the near-bottom concentrations increased from the coastline towards the outer coastal waters, where the main sedimentary basins are located.

\section{Bioavailable nutrients and the $\mathrm{N}: P$ ratio}

The estimation of nutrient loading is most often based on the fluxes of total amounts of nutrients. In the receiving waters, algae and other primary producers readily use only a part of the nutrients, whereas some nutrient forms may become available slowly or may be entirely inert. Generally, nutrients in dissolved form are more readily available than those in particulate form. Thus to efficiently abate eutrophication, the load reduction measures should be targeted towards bioavailable nutrients rather than total nutrients.

Calculating the ratio of inorganic (totally bioavailable) $\mathrm{N}$ and $\mathrm{P}$ concentrations $\left(\mathrm{NH}_{4}+\right.$ $\mathrm{NO}_{3}+\mathrm{NO}_{2}-\mathrm{N} / \mathrm{PO}_{4}-\mathrm{P}$ ) helps us to make (usually approximate) conclusions on the potential controlling roles of these two nutrients in the eutrophication process. According to Forsberg et al. (1978), nitrogen is the main limiting factor when the ratio is below 5, whereas phosphorus limits primary production when the ratio is higher than 12 . According to Ryther and Dunstan (1971) nitrogen limitation is more likely when the ratio is below 10 and phosphorus limitation when the ratio is higher than 10 . It must be remembered that judgements based on nutrient concentration ratios are based on momentaneous concentrations and can thus produce only very tentative conclusions in cases when both DIN and DIP are low. In cases where clearly measurable values of either DIN or DIP are continuously present during the growth period the judgement is easy and reliable. In cases where elevated values of both nutrients are present (usually in inner river estuaries) some other factor, e.g. light availability, controls primary production.

\section{I.3 Inorganic N/P ratio}

The wintertime distribution of DIN: DIP indicates a clear P-controlled spring production in the Bothnian Bay and generally in river estuaries, due to the high N:P ratio of river water (e.g. Alasaarela 1980, Pitkänen 1994) and also to effective P precipitation in the Bothnian Bay (Voipio 1969). In the Bothnian Bay and in the easternmost Finnish waters of the Gulf of Finland the ratio indicated co-limitation of $\mathrm{N}$ and $\mathrm{P}$, whereas in the western Gulf of Finland and in the outer Archipelago Sea N appeared to be the primary controlling factor of the spring bloom. During the 1990s the conditions have changed especially in the middle and western Gulf of Finland, where the controlling role of $\mathrm{N}$ became stronger, probably due to the intensified internal loading which has a low N:P ratio. In the Archipelago Sea the role of $\mathrm{N}$ as the primary controlling factor has also increased (cf. Kirkkala et al. 1998).

The situation is largely the same according to the late summer data (Fig. 5.8). However, on the basis of inorganic concentrations the middle Gulf of Finland also seemed to be co-limited and the estuarine and archipelagic areas of potential $\mathrm{P}$ limitation were smaller compared with conditions before the spring bloom. Good correspondence can be found between the present results and the experimental results on nutrient limitation obtained by Tamminen (1990), Kivi et al. (1993), Pitkänen and Tamminen (1995) and Tamminen and Kivi (1996). During the later half of the 1990s summer concentrations around $10 \mathrm{mg}$ $\mathrm{m}^{-3}$ of free DIP were measured from the mixed surface layer in the middle and western Gulf, indicating clear N control of primary production. This extra pool of DIP disappeared in the summer of 1999, when the formation of blue-green algal blooms was also less prominent than during the warm summer of 1997. 


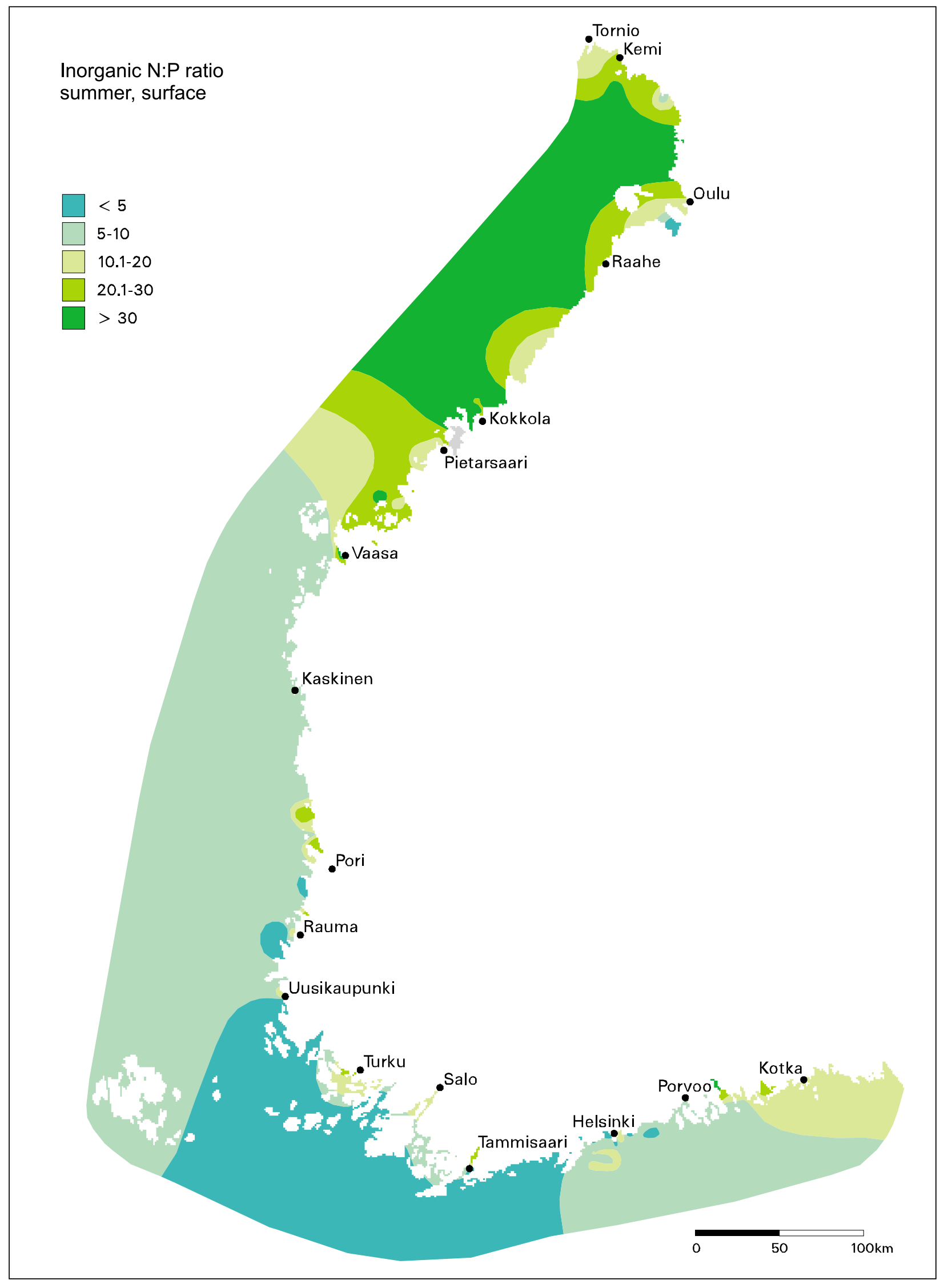

Fig. 5.8. Mean ratio of inorganic N/P in surface layer in summers I99I-1996. 


\subsection{Trends since the late 1980 s}

\subsection{The Gulf of Finland}

A typical behaviour for the concentrations of $\mathrm{N}$ in the Gulf of Finland in the 1970s and the 1980s was an average increase regarding both winter and summer data (Figs. 5.9a,b; 5.10a,b; $5.11 \mathrm{a}, \mathrm{b} ; 5.12 \mathrm{a}, \mathrm{b})$. This was evident in the open sea values, which approximately doubled in the surface layer of the Gulf during the 1970s and the 1980s (Perttilä et al. 1996). In the coastal waters the development was very similar, although the trend was less steep in the eastern Gulf. As the concentrations of $P$ in the surface layer did not markedly change, and showed even some uncertain decrease in the eastern Gulf at the same time, the inorganic N:P-ratio gradually increased.

During the 1990s the development was the opposite: $\mathrm{N}$ concentrations slowly started to decrease, while P concentrations started to increase due to the intensified internal loading. The decreasing trends of $\mathrm{N}$ in both the open sea (Perttilä et al. 1996) and in coastal waters in the 1990s were most probably connected with the decrease of $\mathrm{N}$ loading by over $30 \%$ to the Gulf of Finland during the decade, while the increase of $\mathrm{P}$, despite the decreased external loading (see section 3), was due to the strong increase of internal $\mathrm{P}$ loading in the mid 1990s (Figs. 5.9a,b; 5.10a,b, Pitkänen and Välipakka 1997). Thus the nutrient limitation clearly shifted more pronouncedly towards $\mathrm{N}$ control during the 1990s (cf. Kivi et al. 1993, Tamminen et al. 1996). The most striking sign of this was the increase of unfixed DIP in the outer coastal waters in July-August 1997-98 (Figs. $5.11 \mathrm{a}, \mathrm{b} ; 5.12 \mathrm{a}, \mathrm{b})$, causing strong blooms of Nodularia spumigena in the warm summer of 1997.

\subsubsection{The Archipelago Sea}

In the 1990s, eutrophication proceeded in the Archipelago Sea (Bonsdorff et al. 1997b, Kirkkala 1998). However, increasing nutrient trends can be discerned only for phosphate- and total P, while DIN decreased (Figs. 5.13a, b,c,d). In the 1970s and the 1980s, increasing trends for both $\mathrm{P}$ and $\mathrm{N}$ concentrations were evident (Pitkänen et al. 1987, Kirkkala 1998) and could at least partly be explained by intensified agriculture and fish-farming. However, in coastal areas off larger towns $P$ concentrations showed decreasing trends, due to the introduction of $\mathrm{P}$ precipitation at the municipal treatment plants.

In the middle Archipelago Sea, a drastic increase of phosphate-P from 10 to $30 \mathrm{mg} \mathrm{P} \mathrm{m}^{-3}$ in the summertime nearbottom concentrations took place during the late 1980s and the 1990s. At the same time the deep water oxygen concentrations continuously decreased and reached 6-7 $\mathrm{mg} \mathrm{l}^{-1}$ (ca. 50\% saturation, Fig. 5.13d) in 1997. These phenomena indicate increased sedimentation of organic detritus caused by increased primary production and /or possible anoxia and internal loading at the sediment-water interface. Simultaneously, an increase of $\mathrm{P}$ was also evident in the summertime surface concentrations.

The middle Archipelago Sea is mainly limited by nitrogen during the mid- and late summer months, although the situation can oscillate between control by nitrogen and phosphorus (Tamminen et al. 1996). The generally increased DIP and decreased DIN according to the wintertime data indicate that the development further strengthened towards the end of the 1990s. The results of Kirkkala et al. (1998) based on total nutrients from the middle and southern Archipelago Sea also support reasons to similar conclusions.

A possible factor in the observed development is the increased flow of P from the Gulf of Finland (cf. Helminen et al. 1998), where P concentrations strongly increased in the late 1990s (Fig. 5.10a). Factors affecting in the same direction are the possibly increased benthic outflux of $\mathrm{P}$ and/or increased sedimentation of organic matter. 
Fig. 5.9a. Surface values for total $N$, inorganic $N(D I N)$, total $P$, inorganic $P$ (DIP), salinity and oxygen at Huovari in the eastern Gulf of Finland in winter 1979-1998. See Fig. I.I for the location of the station.

Fig. 5.9b. Bottom values for total $N$, inorganic $N(D I N)$, total $P$, inorganic $P(D I P)$, salinity and oxygen at Huovari in the eastern Gulf of Finland in winter 1979-1998.
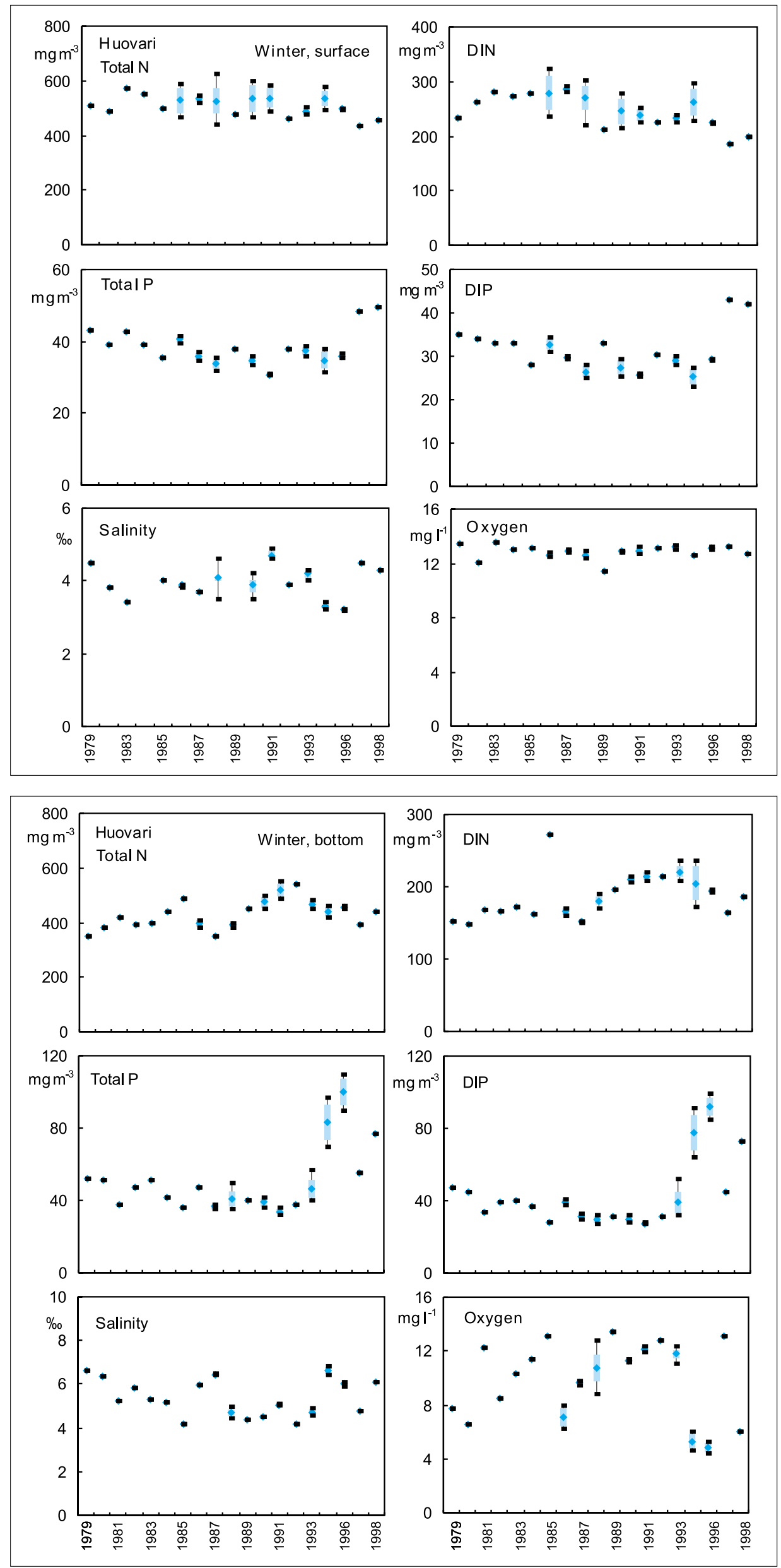


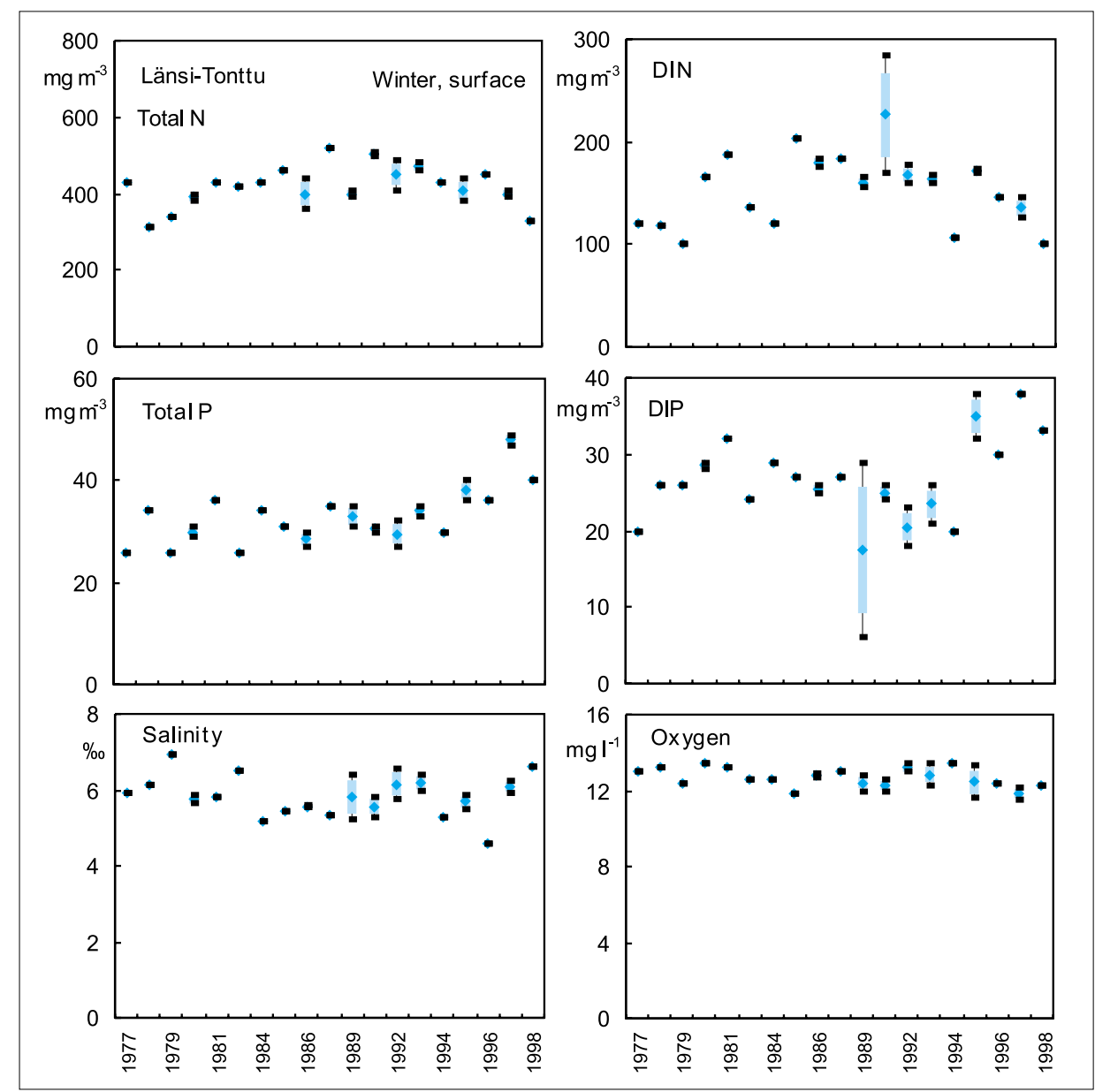

Fig. 5. 10a. Surface and bottom values for total $N$, inorganic $N(D I N)$, total $P$, inorganic $P(D I P)$, salinity and oxygen at Länsi-Tonttu off the coast of Helsinki in winter 1979-1998.

See Fig. I.I for the location of the station.

Fig. 5. IOb. Bottom values for total $N$, inorganic $N(D I N)$, total $P$, inorganic $P(D I P)$, salinity and oxygen at LänsiTonttu off the coast of Helsinki in winter 1979-1998.

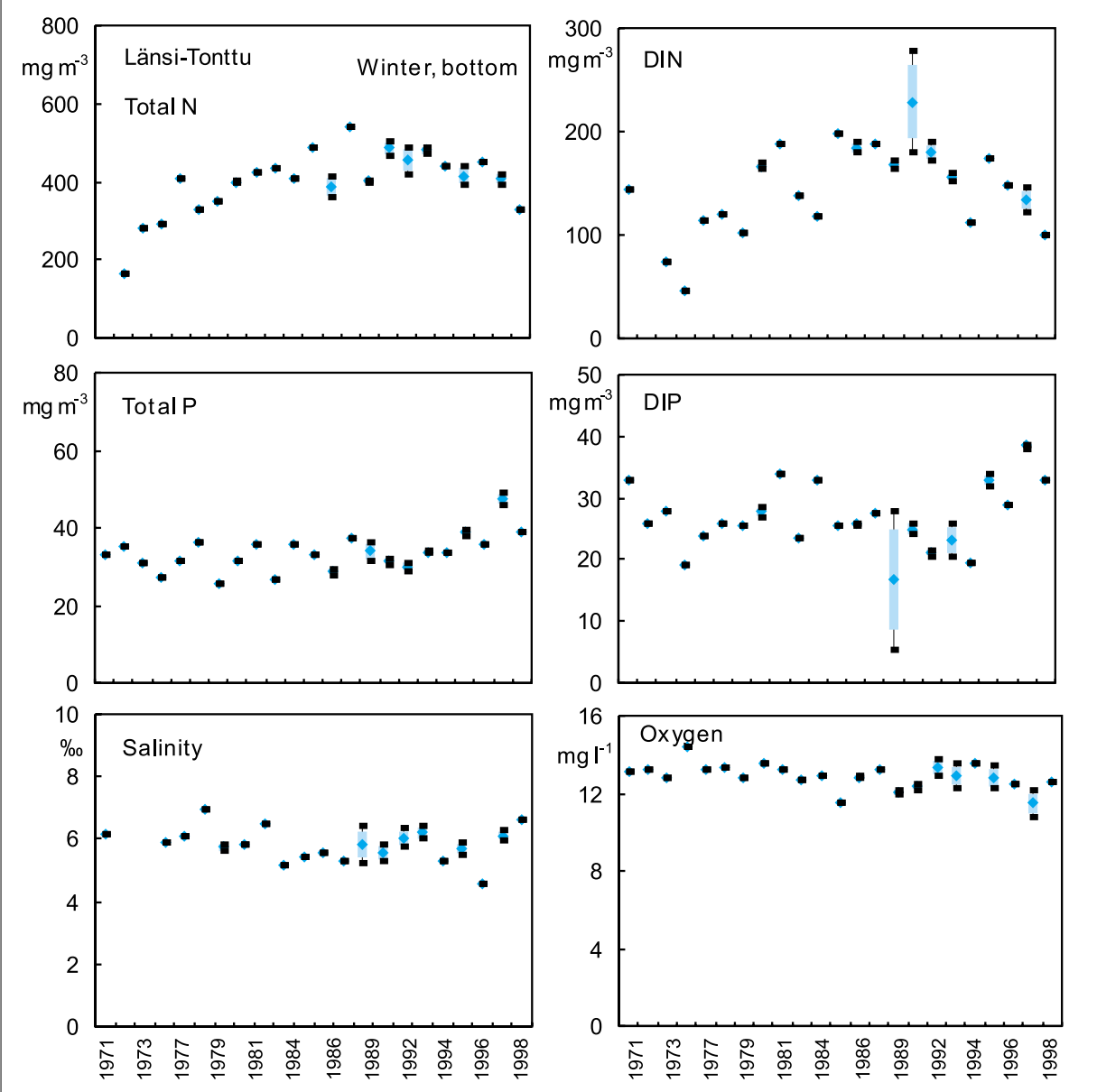

The Finnish Environment 472 
Fig. 5. I la. Surface values for total $N$, inorganic $N(D I N)$, total $P$, inorganic $P(D I P)$, salinity and oxygen at Huovari in the eastern Gulf of Finland in summers 1979-1998.

Fig. 5. I lb. Bottom values for total $N$, inorganic $N(D I N)$, total $P$, inorganic $P(D I P)$, salinity and oxygen at Huovari in the eastern Gulf of Finland in summers 1979-1998.
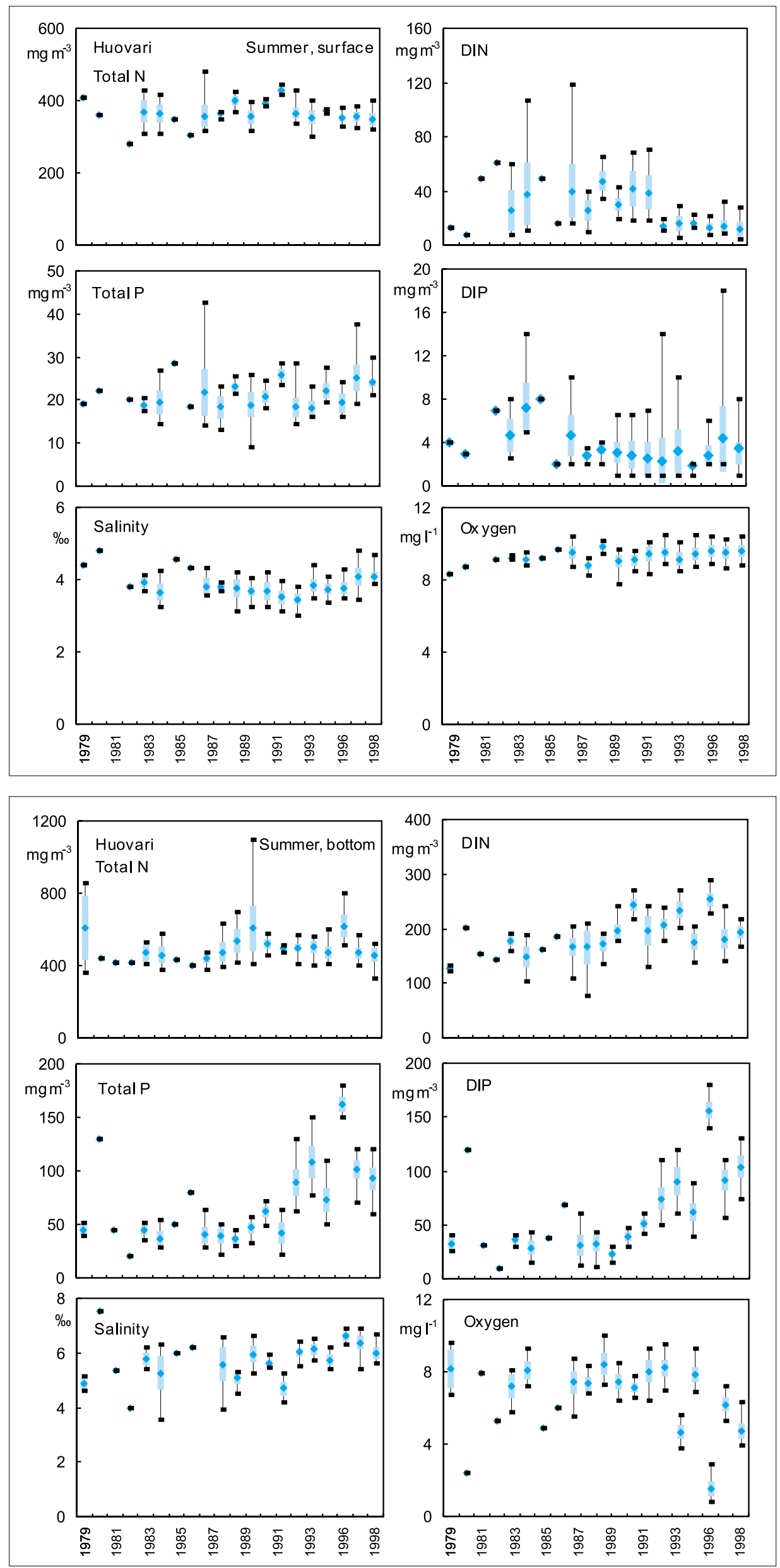

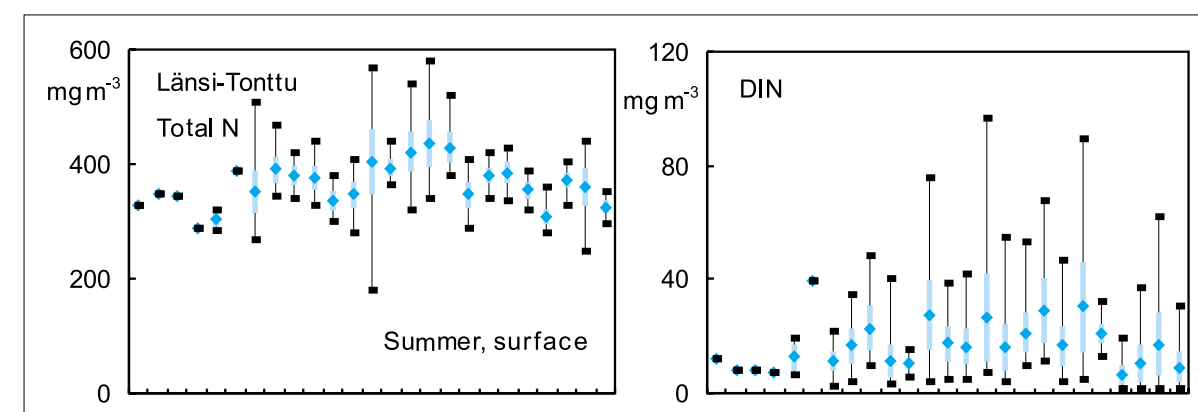

Fig. 5. I 2a. Surface values for total $N$, inorganic $N(D / N)$, total $P$, inorganic $P$ (DIP), salinity and oxygen at LänsiTonttu off the coast of Helsinki in summers 1979-1998.
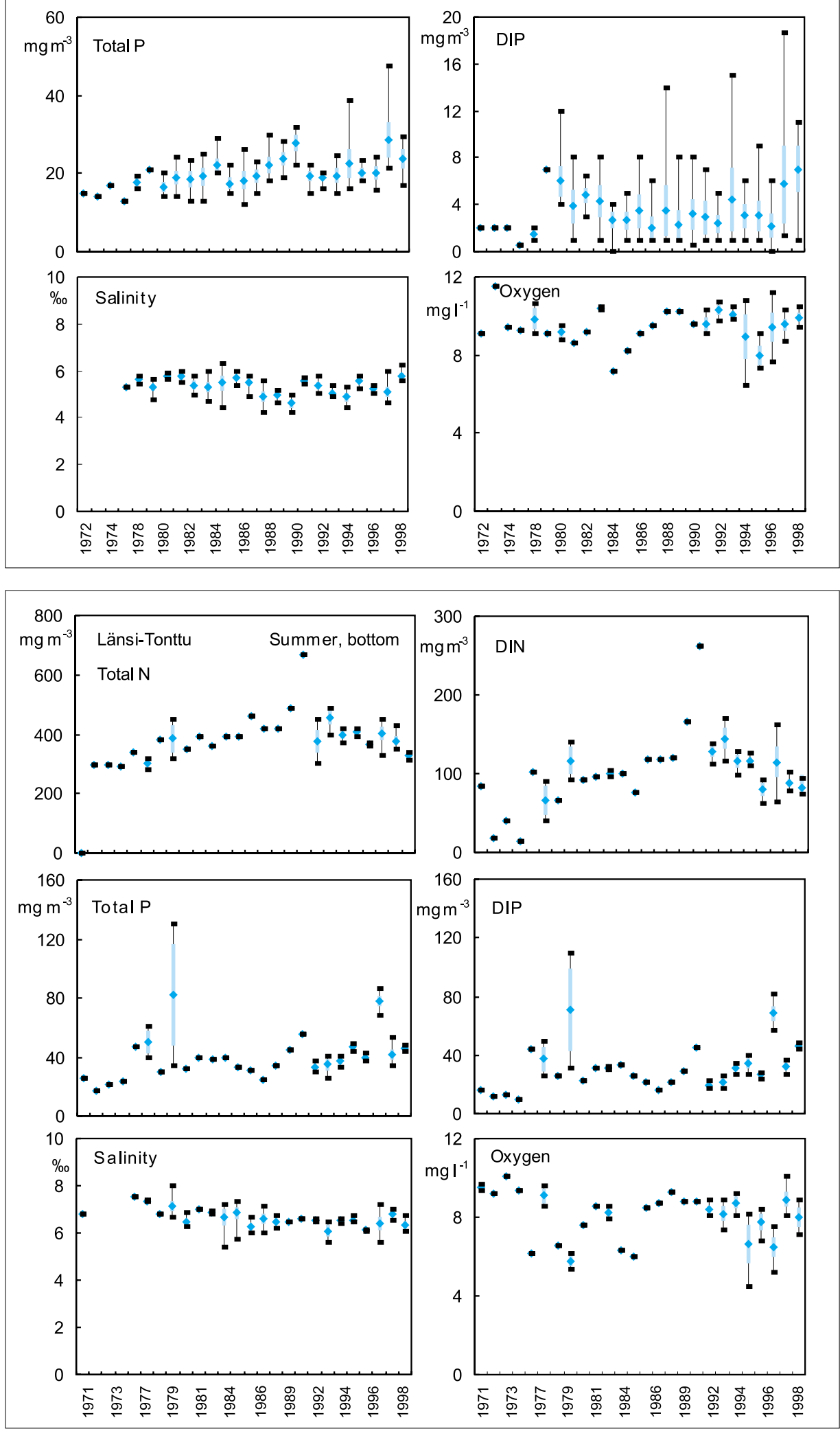

Fig. 5. I 2b. Bottom values for total $N$, inorganic $N(D I N)$, total $P$, inorganic $P$ (DIP), salinity and oxygen at LänsiTonttu off the coast of Helsinki in summers 1979-1998. 
Fig. 5. I3a. Surface values for total $N$, inorganic $N(D I N)$, total $P$, inorganic $P$ (DIP), salinity and oxygen at Seili in the Archipelago Sea in winter 1979-1998. See Fig. I.I for the location of the station.

Fig. 5. I 3b. Bottom values for total $N$, inorganic $N(D I N)$, total $P$, inorganic $P(D I P)$, salinity and oxygen at Seili in the Archipelago Sea in winter 1979-1998.
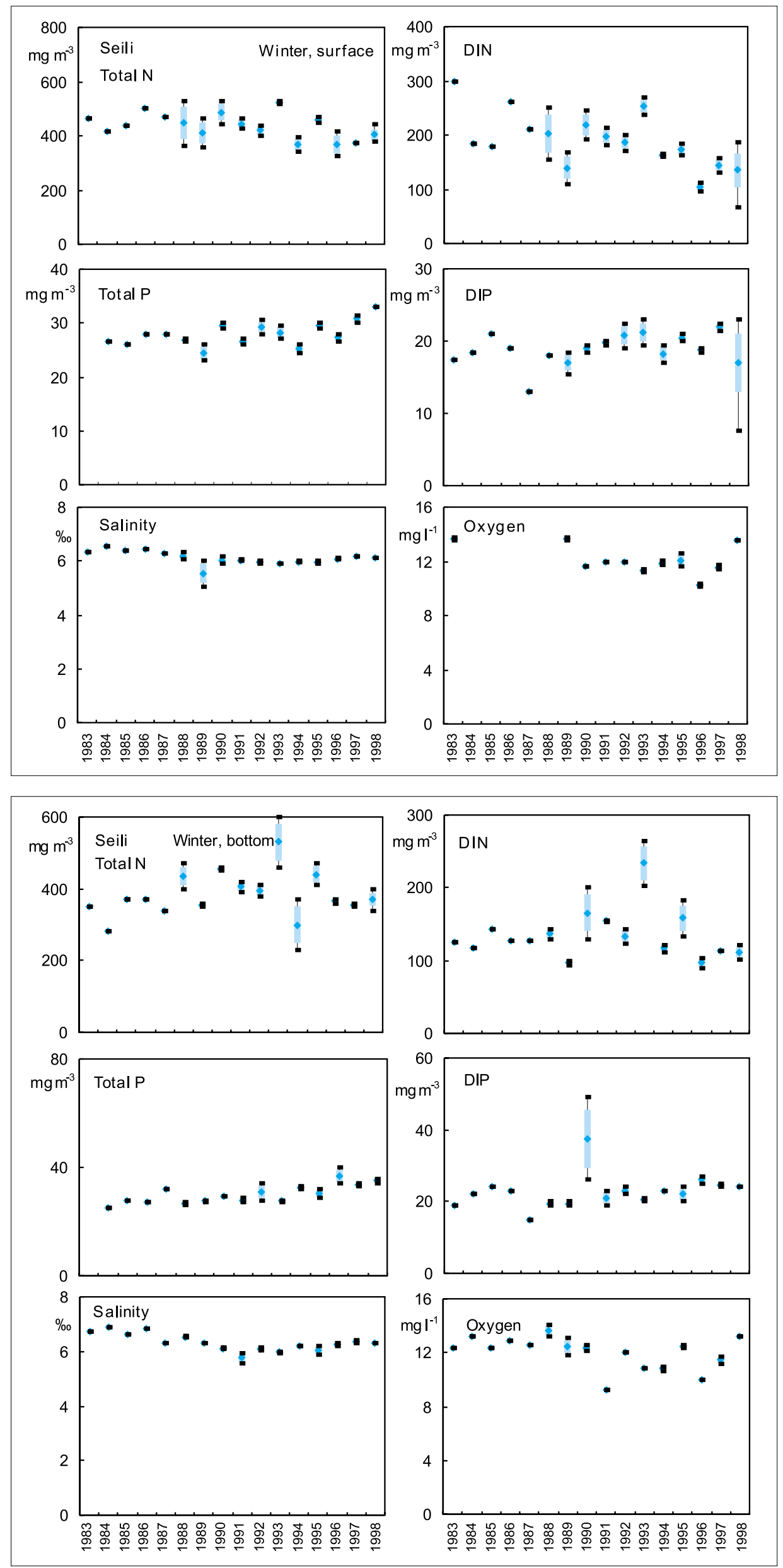


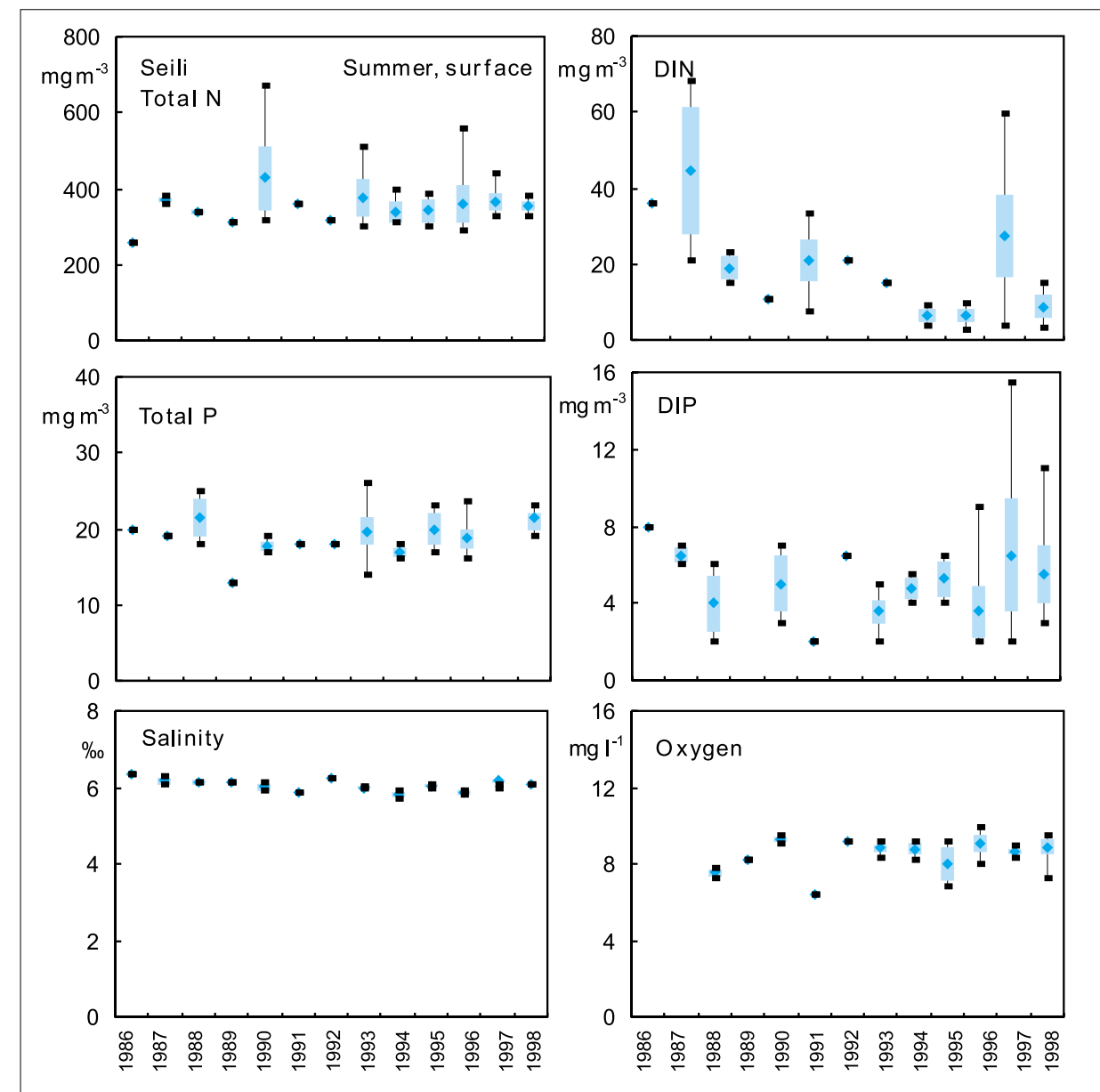

Fig. 5. I3c. Surface values for total $N$, inorganic $N(D I N)$, total $P$, inorganic $P$ (DIP), salinity and oxygen at Seili in the Archipelago Sea in summer 1979-1998.

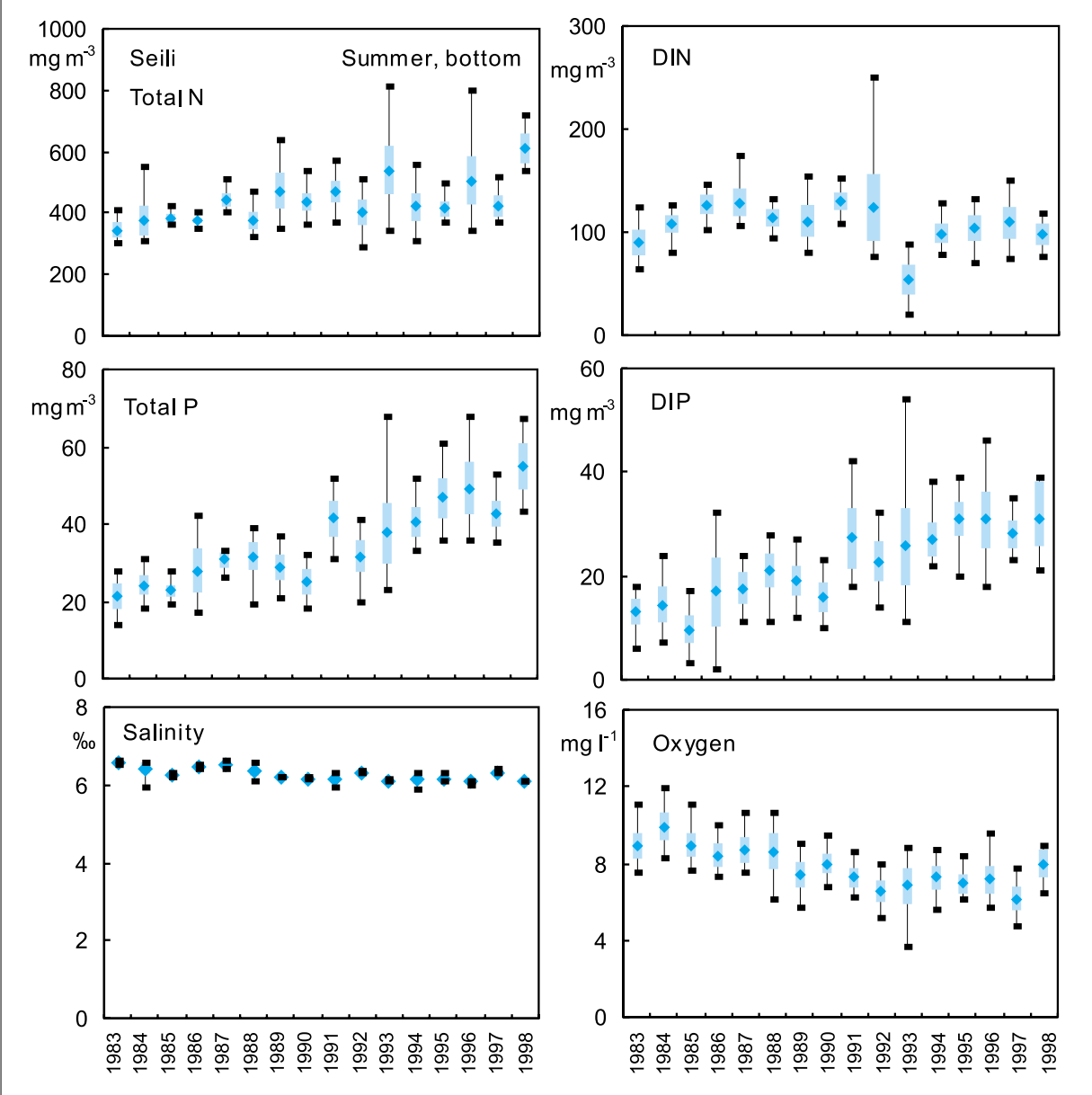

Fig. 5. I3d. Bottom values for total $N$, inorganic $N(D I N)$, total $P$, inorganic $P(D I P)$, salinity and oxygen at Seili in the Archipelago Sea in summer 1979-1998. 


\subsubsection{The Bothnian Sea and the Bothnian Bay}

In general, less clear changes can be found in the rest of the Gulf of Bothnia compared with the Archipelago Sea. A decreasing trend in the wintertime DIN appears possible during the 1990s in the coastal waters of both sea areas (Figs. 5.14, 5.15a). The open Gulf values also support similar conclusion when the present data is compared to that of the early 1980s (Pitkänen et al. 1987). The trend may be connected with the decrease in the river loads of $\mathrm{N}$ in the 1990s mainly due to the decreased runoff (see chapter 3 ). There may also have been changes in the limitation balance between $\mathrm{N}$ and $\mathrm{P}$, due to the increased $\mathrm{P}$ concentrations in the open Bothnian Sea, possibly caused by the decreased vertical stability (cf. Sanden et al. 1996).
In the NE Bothnian Bay, the clear decreases in both $\mathrm{N}$ and $\mathrm{P}$ concentrations since the late 1980s (Figs. 5.15b,c) were most probably attributed to the improvements in sewage treatment techniques and to smaller river runoff in the 1990s (indicated locally also by the decreased salinities). The trend was more pronounced for $\mathrm{P}$ than for $\mathrm{N}$. The decrease of total $\mathrm{P}$ by 4 to $5 \mathrm{mg} \mathrm{m}^{-3}$ during this period is in accordance with the reduction of the load of $\mathrm{P}$ from local point sources by about $50 \%$ (see chapter 3).
Fig. 5. 14. Surface values for total $N$, inorganic $N(D I N)$, total $P$, inorganic $P(D I P)$, salinity and oxygen at Bergö in the Northern Bothnian Sea in winter 1979-1998. See Fig. I.I for the location of the station.

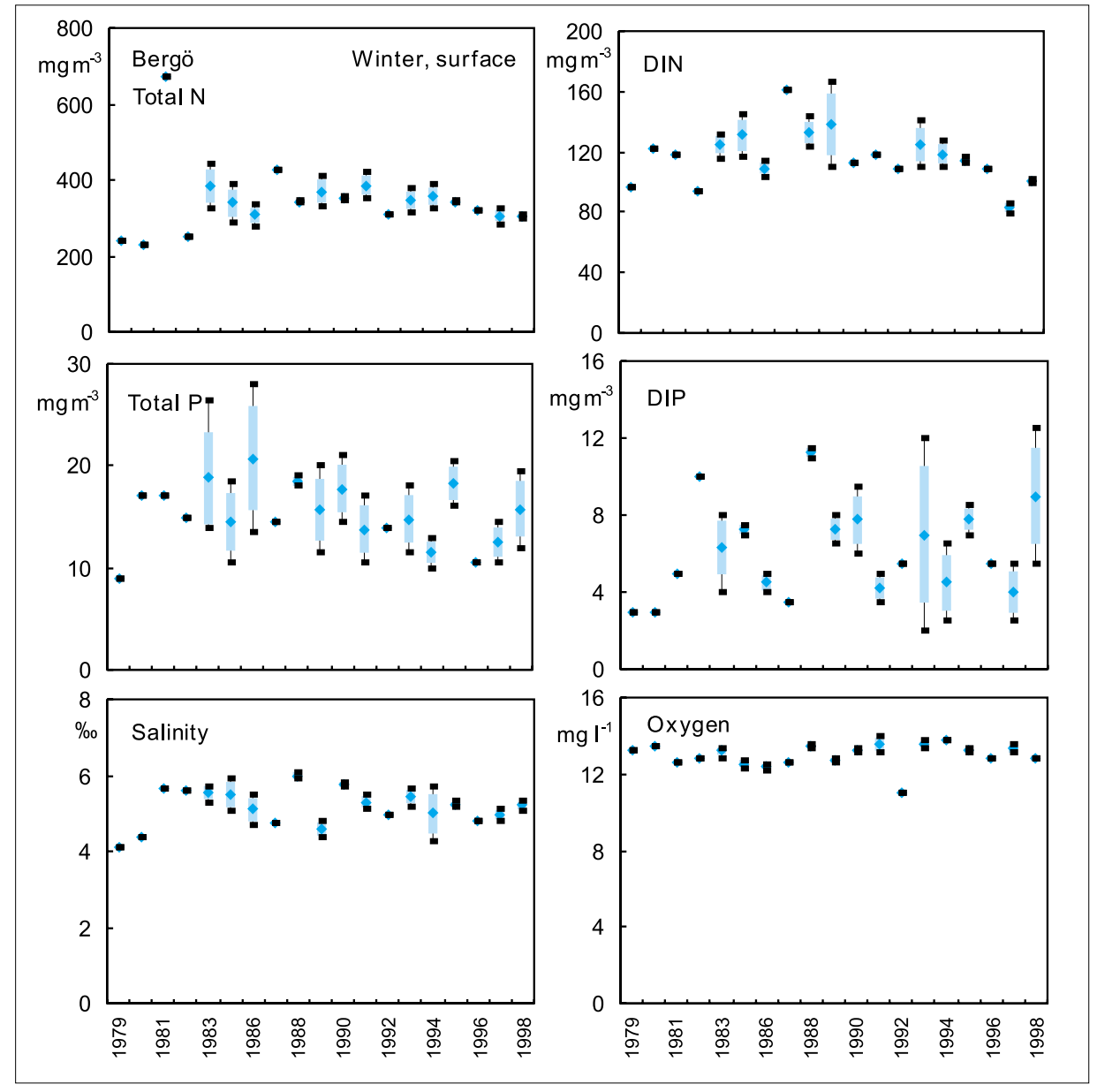




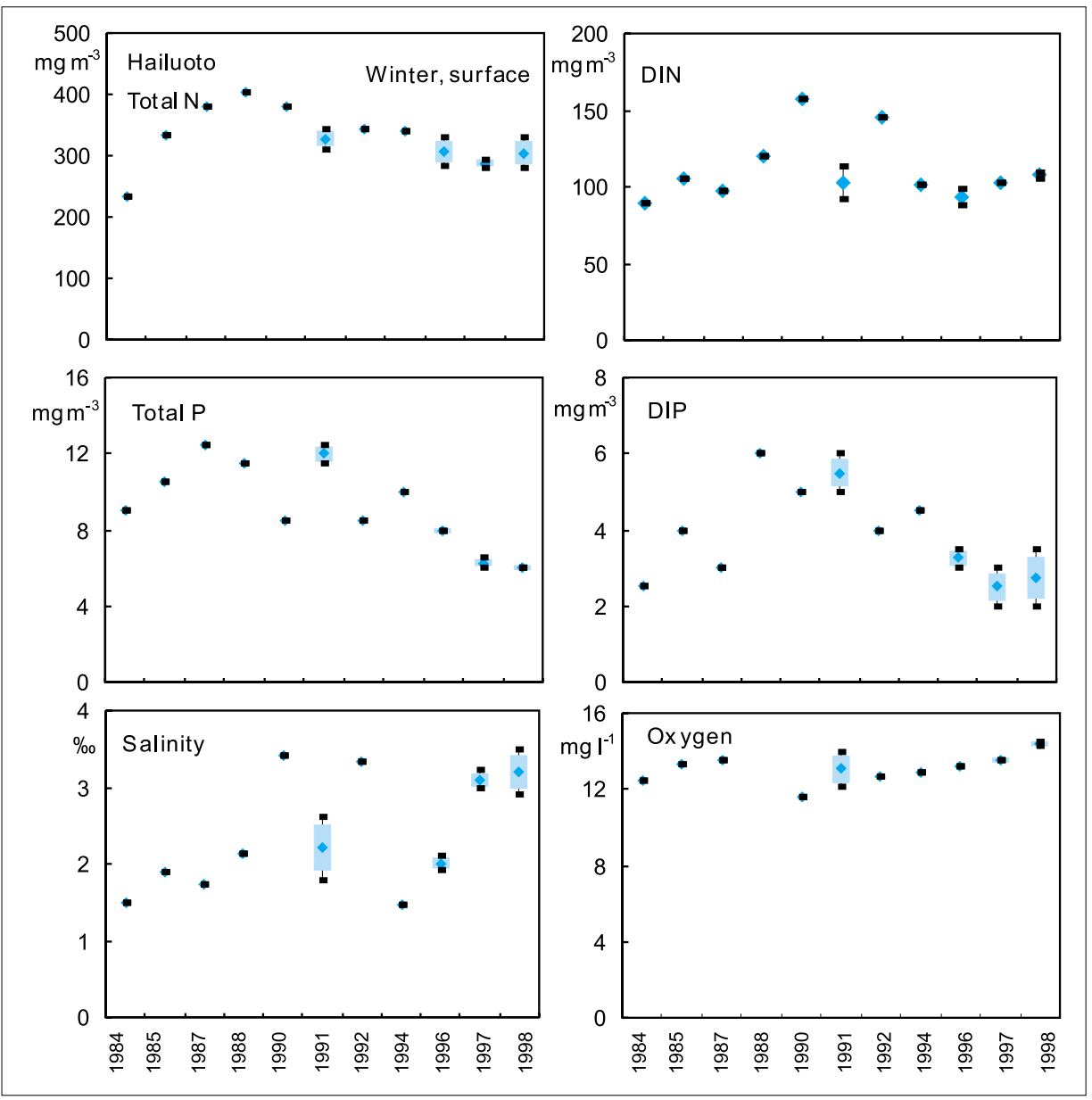

Fig. 5. 15a. Surface values for total $N$, inorganic $N(D I N)$, total $P$, inorganic $P(D I P)$, salinity and oxygen at Hailuoto in the northern Bothnian Bay in winter 1979-1998. See Fig. I.I for the location of the station.
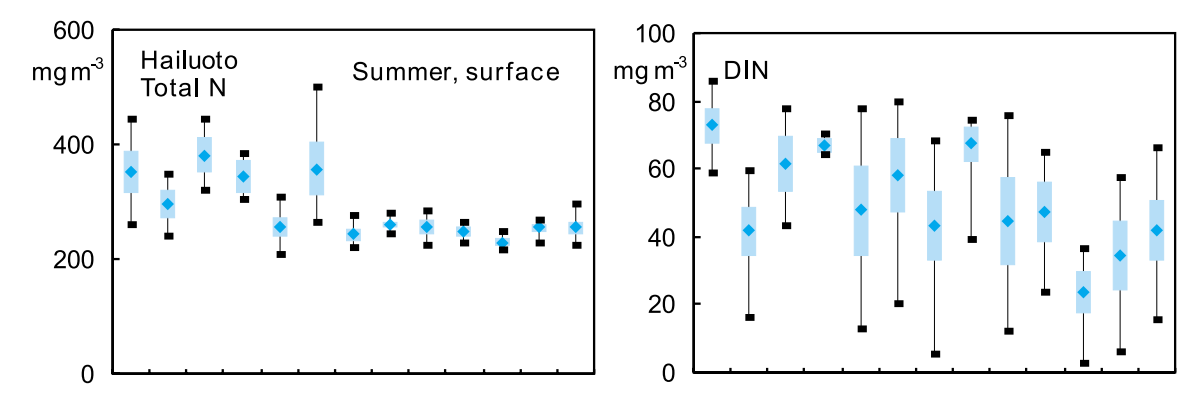

Fig. 5. I5b. Surface values for total $N$, inorganic $N(D I N)$, total $P$, inorganic $P(D I P)$, salinity and oxygen at Hailuoto in the northern Bothnian Bay in summer 1979-1998.
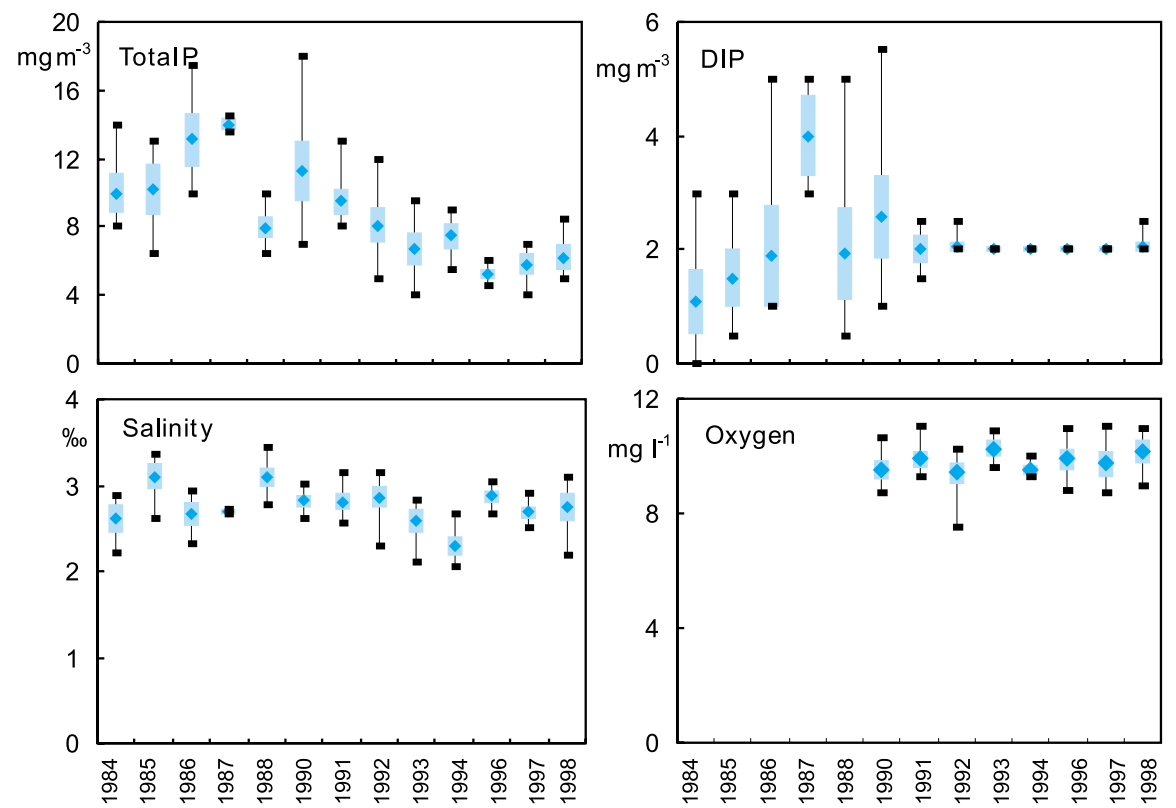
Fig. 5.15c. Bottom values for total $N$, inorganic $N(D I N)$, total $P$, inorganic $P(D I P)$, salinity and oxygen at Hailuoto in the northern Bothnian Bay in winter 1979-1998.

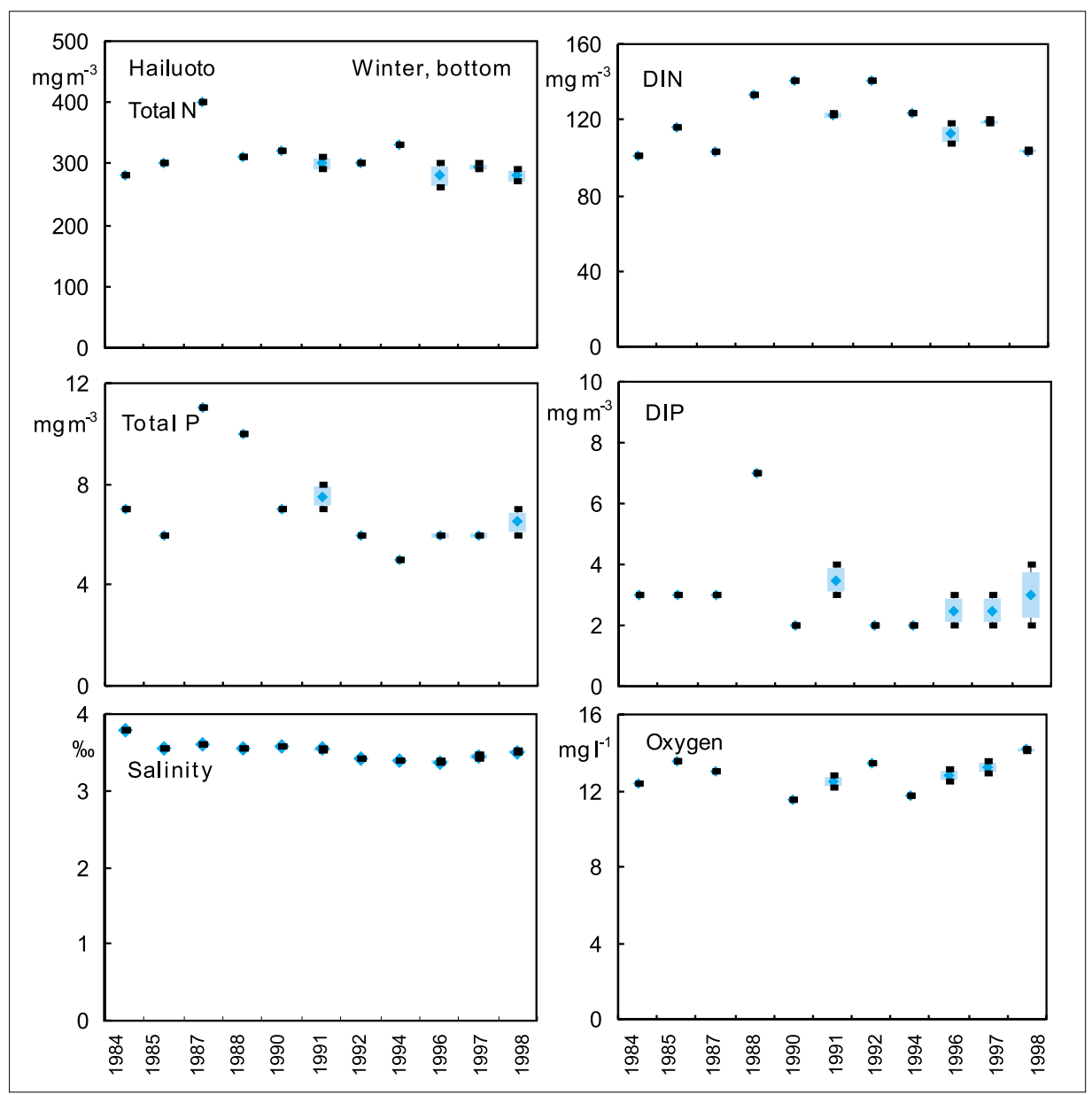




\section{I Areal distribution of phytoplankton chlorophyll a}

A typical feature of summertime concentrations of phytoplankton chlorophyll $a$, commonly used as a measurement of eutrophication, is an increase from the open sea towards the coast and from the northern Bothnian Bay towards the eastern Gulf of Finland (e.g. Pitkänen et al. 1987, Kauppila et al. 1995, HELCOM 1996, Fig 6.1). In the open Gulf of Finland, the slightly eutrophic area ( 3 to $5 \mathrm{mg} \mathrm{chl} a \mathrm{~m}^{-3}$ ) from the Kotka archipelago westwards covered the whole open Gulf in the 1990s, whereas in the 1980s the level of chlorophyll $a$ at the entrance to the Gulf was still below $3 \mathrm{mg} \mathrm{m}^{-3}$ (Pitkänen et al. 1987). This was in accordance with the increasing trend of chlorophyll $a$ identified in the western Gulf in the 1980s (Grönlund and Leppänen 1990). The westward movement of the border of the slightly eutrophied area during the 1980 s can be explained by the weakening of vertical stability and by an increase in $\mathrm{N}$ concentrations (Perttilä et al. 1996). The increased trophic status in the eastern Finnish archipelago was mainly due to the deep water or sediment nutrient reserves, which because of rather unstable physical stratification, could reach the productive layer during mixing events and storms (Pitkänen 1991, Pitkänen et al. 1993).

In the coastal waters of the Gulf of Finland, strongly affected by nutrient inputs from local sources, the eutrophied area ( 5 to $10 \mathrm{mg} \mathrm{chl} a \mathrm{~m}^{-3}$ ) in the 1990s extended as far as 5 to $15 \mathrm{~km}$ from the coast. However, in the inner bays off Helsinki, the concentrations of chlorophyll $a$ decreased in the late 1980s. This was a result of starting to lead purified waste waters to the outer archipelago. As a consequence, the strongly eutrophied area (10 to $15 \mathrm{mg}$ chl $\left.a \mathrm{~m}^{-3}\right)$ in the bays decreased in extent (Pesonen et al. 1995). At the same time, a decrease in the concentrations of $P$ resulted in an increase in the inorganic N:P ratio, which favoured the non- $\mathrm{N}_{2}$-fixing blue-green algae (Pesonen et al. 1995, Räisänen \& Viljamaa 1998). Simultaneously with the clear decrease of nutrient loading, the bluegreen alga Planktothrix agardhii, which is considered to indicate eutrophication in brackish waters (Niemi 1973, Hällfors et al. 1981), lost its dominance in the inner bays.

In the outer Archipelago Sea, the level of chlorophyll $a$ (below $3 \mathrm{mg} \mathrm{m}^{-3}$ ) equalled the level observed in the open sea. In the middle Archipelago Sea, the border of the slightly eutrophied area ( 3 to $5 \mathrm{mg} \mathrm{chl} a \mathrm{~m}^{-3}$ ) moved $20 \mathrm{~km}$ westwards to the outer archipelago during the 1980s, coinciding with the increase in the level of P (see also Kirkkala 1998). Increased trophic status in the 1980s has partly been explained by intensified fish farming and by possibly intensified upwellings. On the other hand, anoxia in semi-enclosed basins in the late 1990s may be a consequence of internal loading (cf. Pitkänen and Välipakka 1997) and net fluxes of nutrients from the western Gulf of Finland (Helminen et al. 1998).

In the open Gulf of Bothnia, the level of chlorophyll $a$ was below $3 \mathrm{mg} \mathrm{m}^{-3}$. In the coastal waters, the eutrophied area was limited to the archipelago off 
Chlorophyll a

summer, surface
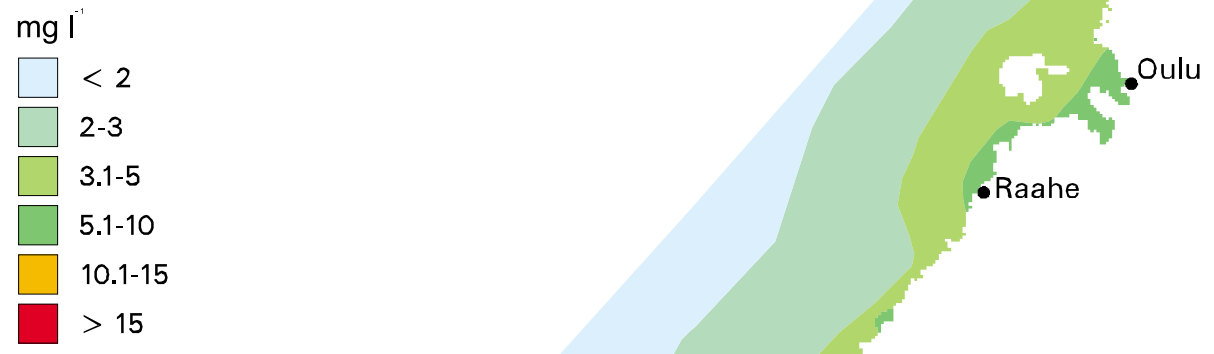

-Raahe

.1-10

$>15$

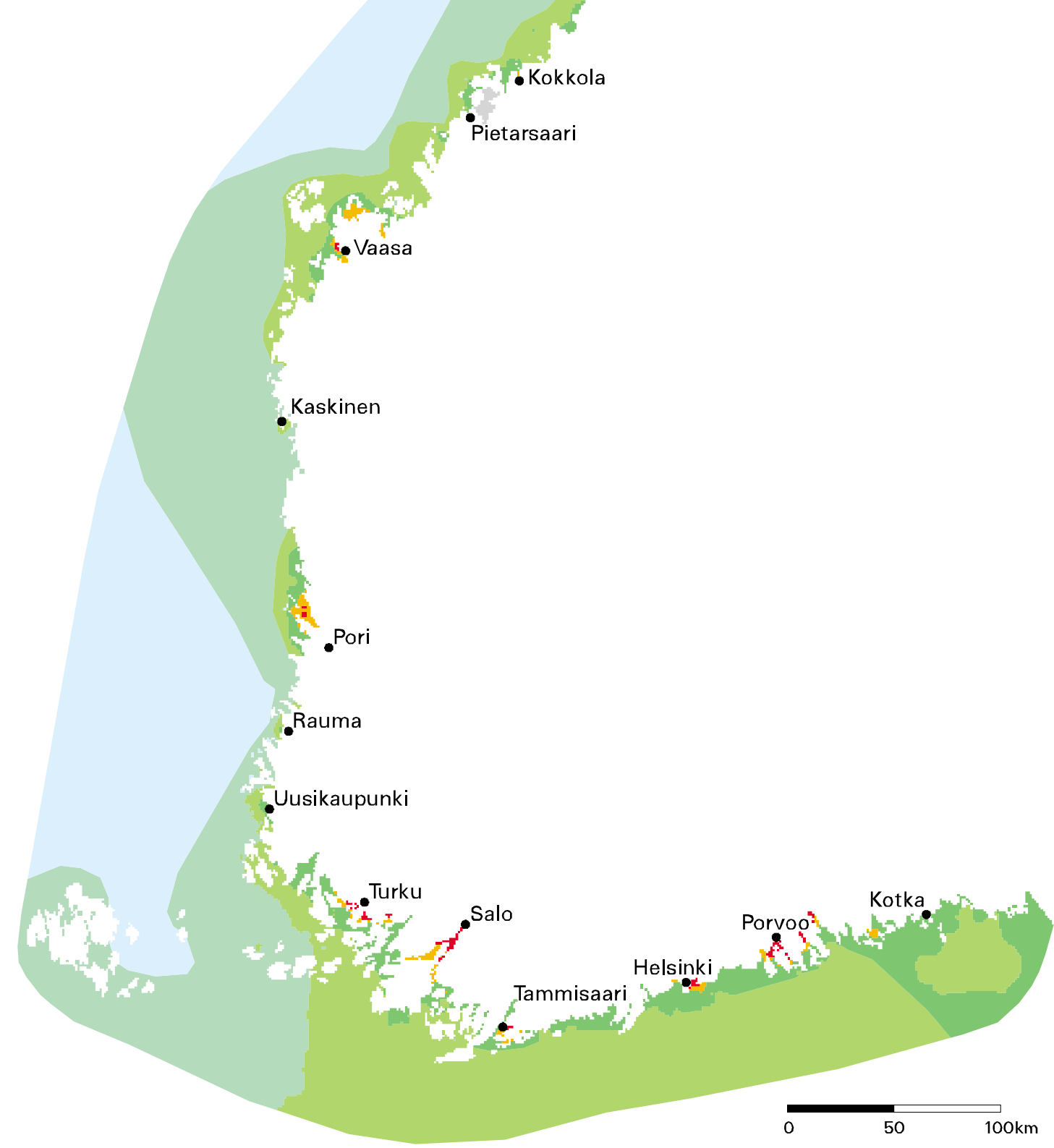

Fig. 6. I. Mean surface values of chlorophyll a in summers 199I-1996. 


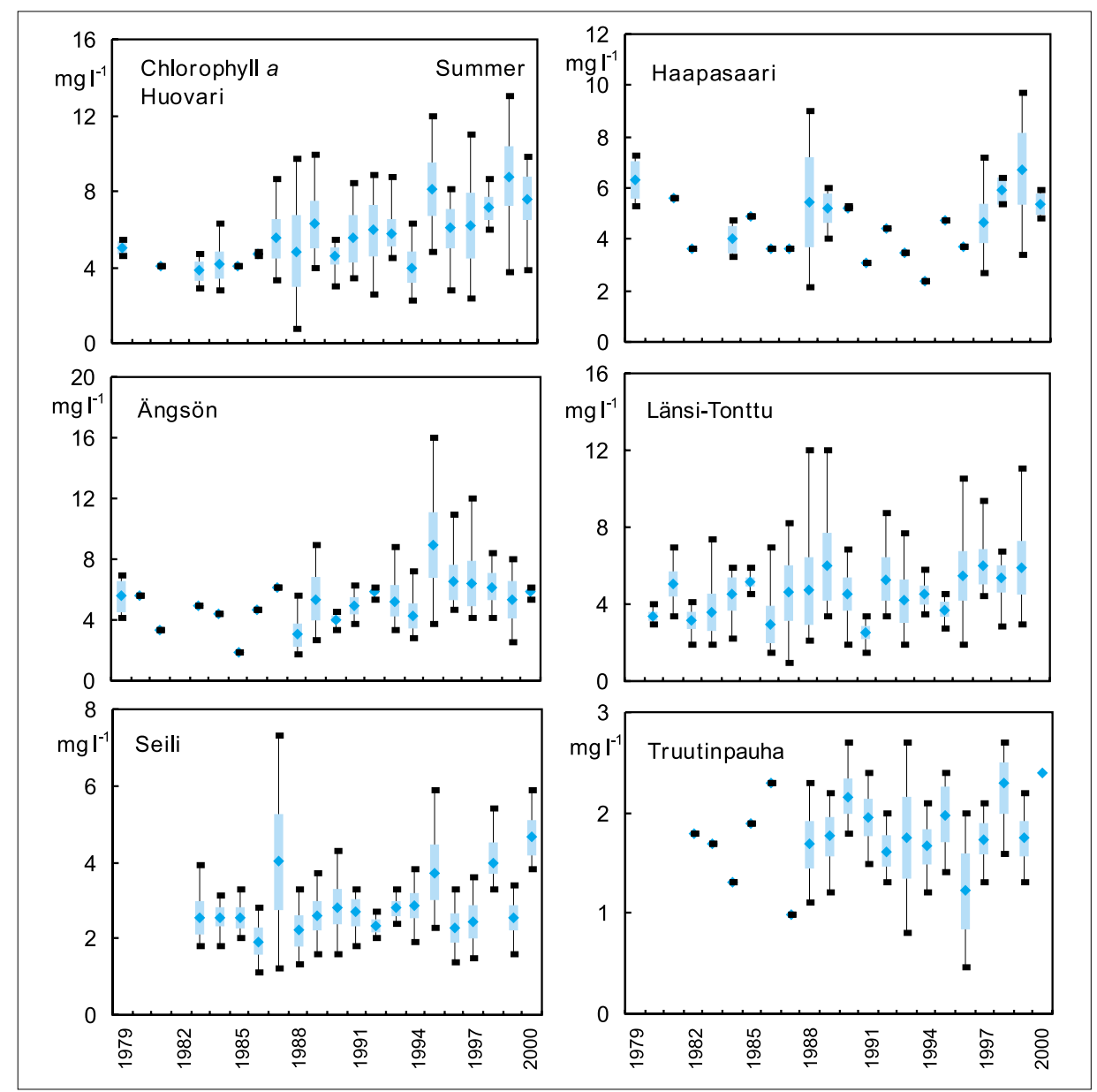

Fig. 6.2. Concentrations of chlorophyll a at the stations of a) Huovari, b) Haapasaari c) Ängsön d) Länsi-Tonttu, e) Seili and f) Truutinpauha in late summers 19792000. See Fig. I.I for the location of the station.
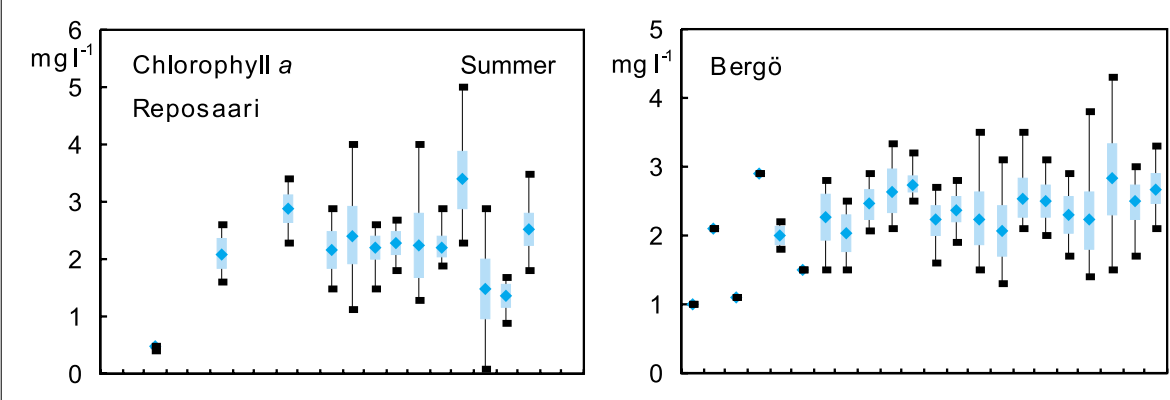

Fig. 6.3. Concentrations of chlorophyll a at the stations of a) Reposaari, b) Bergö,

c) Storbådan, d) Repskär, e) Hailuoto and f) Pohjantähti in late summers 1979-2000.
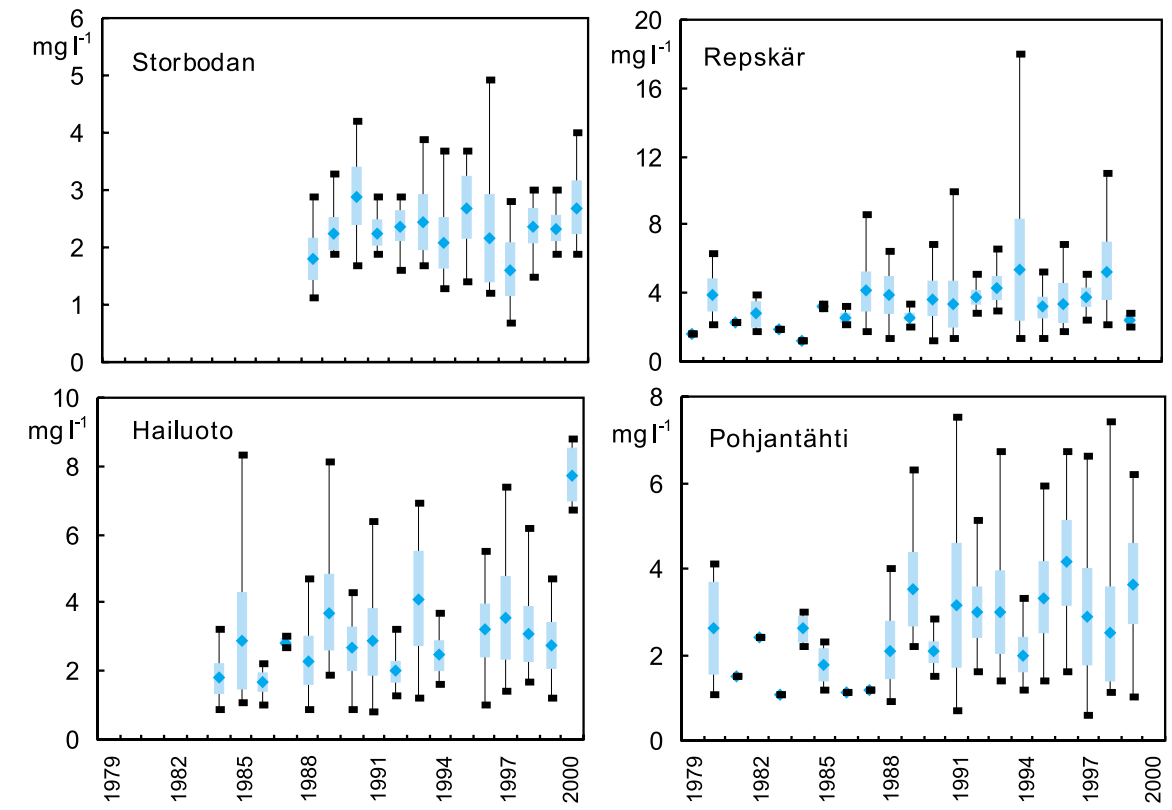
Uusikaupunki, the river Kokemäenjoki estuary, the Quark archipelago, the archipelagos off Kokkola and Pietarsaari and the NE Bothnian Bay from Raahe to Tornio. In the Kokemäenjoki estuary and in the archipelagos off Kokkola, Pietarsaari and Oulu the border of the slightly eutrophied area moved westwards during the 1980s and 1990s despite reduction in the anthropogenic loads of nutrients. The change in the trophic status may thus be related to the general eutrophication of the open sea. The increasing trends of $\mathrm{P}$ in the open Bothnian Sea and that of $\mathrm{N}$ in the whole open Gulf have been explained by weakening of vertical stability, resulting from decrease in salinity in the deep water (Sanden et al. 1996).

Consequently, the higher trophic status was clear especially in the Gulf of Finland and in the Archipelago Sea during the 1980s. However, this trend levelled out in both areas in the mid 1990s (Fig. 6.2). However, in the eastern Gulf of Finland and in the middle Archipelago Sea the concentrations of Chl started to increase again in the late 1990s. In the Gulf of Bothnia, Chl has usually been below $3 \mathrm{mg} \mathrm{m}^{-3}$ (Fig. 6.3).

\subsection{Seasonal variations of phytoplankton}

The spring bloom maximum of phytoplankton in the northern Baltic Sea reveals a normal brackish-water community, dominated by diatoms (Achnanthes taeniata, Diatoma tenuis) and dinoflagellates (Peridiniella catenata, Scrippsiella hangoei, Glenodinium spp., Fig 6.4). The peak time and the species composition of the spring bloom may vary from year to year. The peak of the spring biomass is not always detected during routine monitoring programme sampling. Furthermore, development of the spring bloom occurs later in the north. In Hailuoto, the spring bloom develops in late May, whereas at Längden in SW Finland peak normally occurs in late April. After a decline of phytoplankton in mid June, bluegreen algae start to increase and eventually dominate the phytoplankton communities in the eastern Gulf of Finland and they are abundant in the Archipelago Sea and occasionally in the Gulf of Bothnia. The blue-green algal community is generally dominated by $\mathrm{N}_{2}$-fixing Nostocales.

In mid May 1998, at Huovari in the eastern Gulf of Finland phytoplankton biomass was as high as $16.9 \mathrm{~g} \mathrm{~m}^{-3}$. Diatoms dominated the phytoplankton community. The most abundant species was small sized Achnanthes taeniata, comprising $67 \%$ of the total biomass. The second main group was dinoflagellates, mainly Scrippsiella hangoei with $32 \%$ of the biomass. However, by June the dinoflagellate Peridiniella catena was a dominating species. In July, bluegreen algae succeeded the diatoms. From the beginning of July to late August the $\mathrm{N}_{2}$-fixing Nostocales such as Nodularia sp. and Aphanizomenon sp., dominated the biomass and the biomass portion of Aphanizomenon sp. was ca. $40 \%$. In September the proportion of the non- $\mathrm{N}_{2}$-fixing blue-green algae, such as Snowella lacustris (Chroococcales) and Planktothrix agardhii (Oscillatoriales), increased approximately to $30 \%$ of the total biomass and Nostocales decreased to ca. $10 \%$.

At Längden in the western Gulf of Finland the spring maximum biomass value was $28.0 \mathrm{~g} \mathrm{~m}^{-3}$, observed at the end of April. This maximum was produced solely by the dinoflagellate Scrippsiella hangoei (97\%). In mid May, dinoflagellates were succeeded by diatoms. Skeletonema costatum, Chaetoceras spp. and Achnanthes taeniata dominated. Summer phytoplankton was dominated by the dinoflagellate Heterocapsa triquetra but blue-green algae were scarce during the summer.

In the Archipelago Sea the spring maximum biomass value of $7.9 \mathrm{~g} \mathrm{~m}^{-3}$ was produced by diatoms (95\%), such as Chaetoceras wighami and Achnanthes taeniata in mid April 1998. By the mid May the total biomass was decreased to $3.4 \mathrm{~g} \mathrm{~m}^{-3}$ and dominated by dinoflagel- 


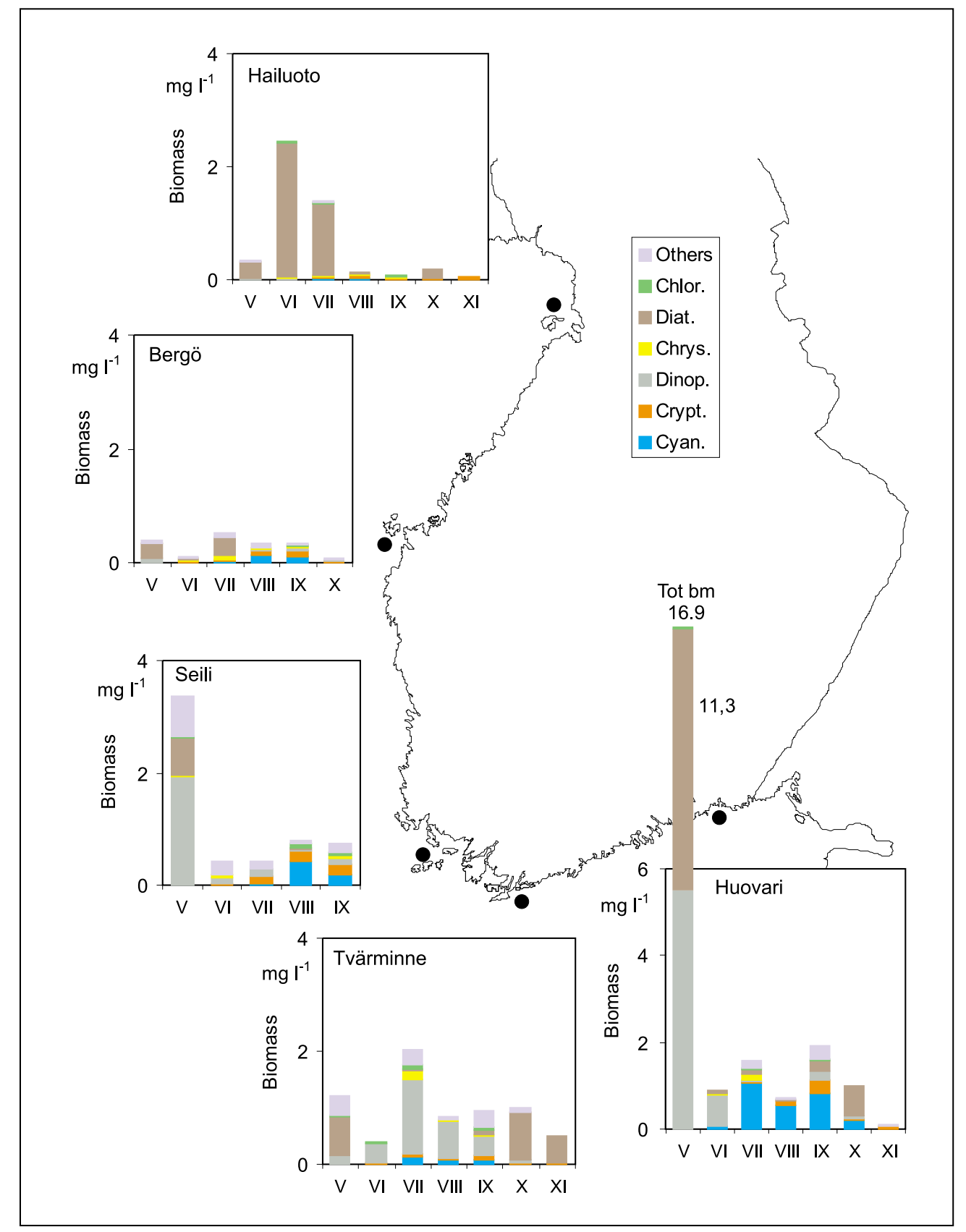

Fig. 6.4. Seasonal variation of phytoplankton biomasses in the eastern Gulf of Finland (at Huovari), the western Gulf of Finland (at Längden), the Archipelago Sea (at Seili), the northern Bothnian Sea (at Bergö) and the northern Bothnian Bay (at Hailuoto) in 1998.

lates (58\%), such as Peri-diniella catena. In August blue-green algae, mainly $\mathrm{N}_{2}$ fixing Aphanizomenon sp., increased to $52 \%$ of the total biomass. Still in September this taxa contributed $30 \%$ of the total phytoplankton biomass.

In the Gulf of Bothnia no clear spring maximum was observed. Phytoplankton biomass was low varying from $0.1 \mathrm{~g} \mathrm{~m}^{-3}$ in June to $0.5 \mathrm{~g} \mathrm{~m}^{-3}$ in July 1998. The diatoms Achnanthes taeniata and Chaetoceras spp. dominated in May and Thalassiosira baltica in July. Cryptomonads and Chrysomonads were abundant in July. In August-September $\mathrm{N}_{2}$-fixing blue-green algae increased, mainly Nodularia sp. and Aphanizomenon sp. 
In the northernmost part of the Baltic Sea, in Hailuoto, phytoplankton started to increase in early June. The maximum total biomass, $2.4 \mathrm{~g} \mathrm{~m}^{-3}$, observed in early June, was formed by diatoms (97\%), mainly Diatoma tenuis. This species dominated the phytoplankton community still in mid July. Cryptomonads and Chrysomonads became abundant at the end of the summer.

\subsection{Long term changes in phytoplankton}

Changes in the phytoplankton total biomasses and species composition are affected by several factors, revealing variations both in nutrient concentrations and hydrographical conditions. Nutrient concentrations are affected both by external loading (e.g. from river water) and internal loading (e.g. from sediment). Hydrodynamics include, e.g. mixing conditions in water, which affect not only nutrient concentrations but also the possibility for phytoplankton to persist and grow in the productive surface layer.

Eutrophication in the outer archipelago of the Gulf of Finland and in

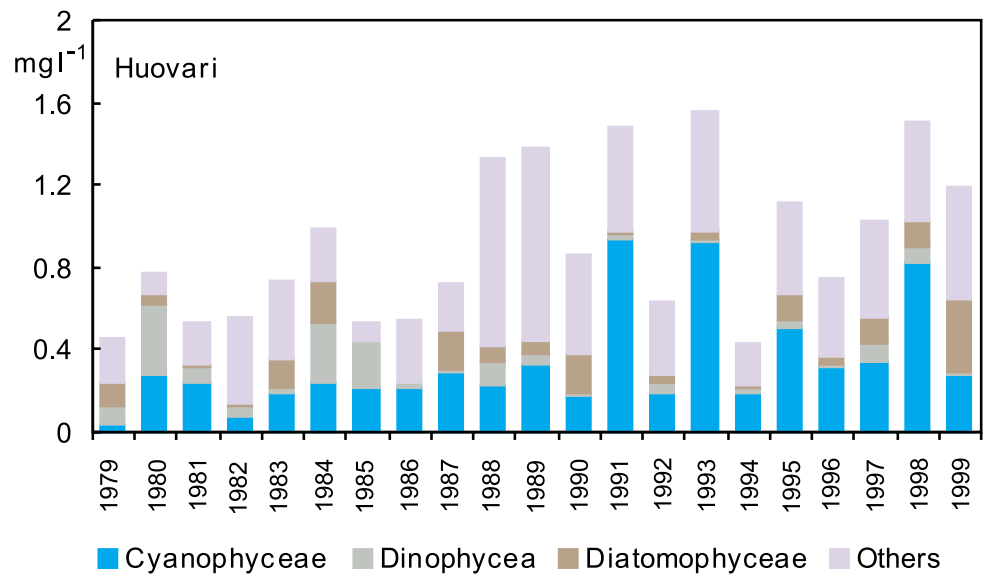

Fig. 6.5. Late summer phytoplankton species composition and biomasses at Huovari in the eastern Gulf of Finland in 1979-1999.

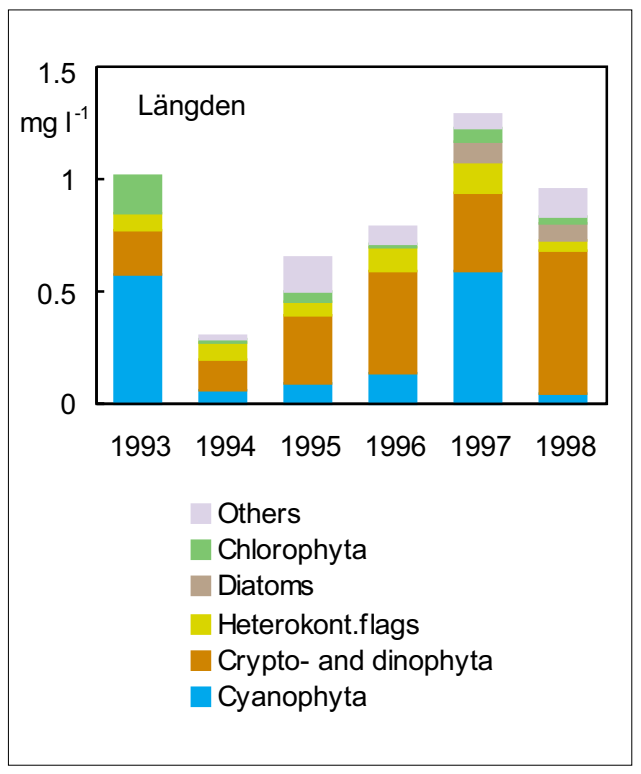

Fig. 6.6. Late summer phytoplankton species composition and biomasses at Längden in the western Gulf of Finland in 19931998.

the Archipelago Sea during the 1980s and 1990s can be seen as an increase in phytoplankton total biomasses in late summers (Figs. 6.2, 6.5-6.7). In the eastern Gulf of Finland, the considerable increase in phytoplankton biomasses in the late 1980s coincided with the general increase in nutrient concentrations. The phytoplankton biomasses were generally high during the 1990s, excluding a decrease in the middle of the decade (Fig. 6.5). Blue-green algae clearly dominated phytoplankton in 1991, 1993 and 1998. The release of phosphorus from sediment during the extensive oxygen deficit in the late 1990s was observed as elevated phytoplankton total biomasses and high chlorophyll a values (Figs. 6.2, 6.5). Strong surface accumulations of bluegreen algae were recorded throughout the whole archipelago area in 1996 and 1997 (Pitkänen and Välipakka 1997, Kauppila and Lepistö 1997, 1998).

In the outer archipelago off Helsinki, phytoplankton total biomasses did not appear to increase despite of the increase in nutrient concentrations 
in the area. This is due to the fact that waste waters have been conducted to the outer archipelago since the late 1980s (Pesonen et al. 1995). In fact, in the innermost bays biomasses clearly decreased after the closing of sewage treatment plants. In the western Gulf of Finland, phytoplankton total biomass had an increasing trend in the 1990s (Fig. 6.6). Only in 1994 was the average biomass exceptionally low. Blue-green algae were abundant in 1993 and 1997, when dense surface accumulations also occurred. In general dinoflagellates dominated.

In the outer Archipelago Sea, total phytoplankton biomasses have slightly increased since the mid 1990s (Fig. 6.2, 6.7). The increase of phytoplankton biomasses in the innermost archipelago in the 1980s and 1990s was in accordance with the trend of phosphorus level, which started to increase since the middle 1980s (Hänninen et al. 1997). Blue-green algae occurred abundantly in 1997 and 1998.

Changes in environmental conditions in the Gulf of Finland and in the Archipelago Sea were reflected not only as an increase in total biomasses but also in changes in the phytoplankton species composition and in the relationships of the dominating phytoplankton taxa. In the eastern Gulf of Finland cryptophytes and dinoflagellates, mainly Dinophysis acuminata, dominated the late summer plankton community in the 1980s (Fig. 6.5). The dominance of these plankton taxa was succeeded by blue-green algae, mainly Aphanizomenon sp. and Planktothrix agardhii. Those two taxa contributed most to phytoplankton total biomasses in the late 1980s and 1990s. The nutrient ratios and hydrodynamic conditions determined which one of the two blue-green algae achieved dominance. The nearly optimal inorganic N/P ratio for phytoplankton growth in the late 1980s probably favoured more the $\mathrm{N}_{2}$ fixing (heterocystic) Aphanizomenon than the non- $\mathrm{N}_{2}$-fixing $P$. agardhii. On contrary, the dominance of $P$. agardhii

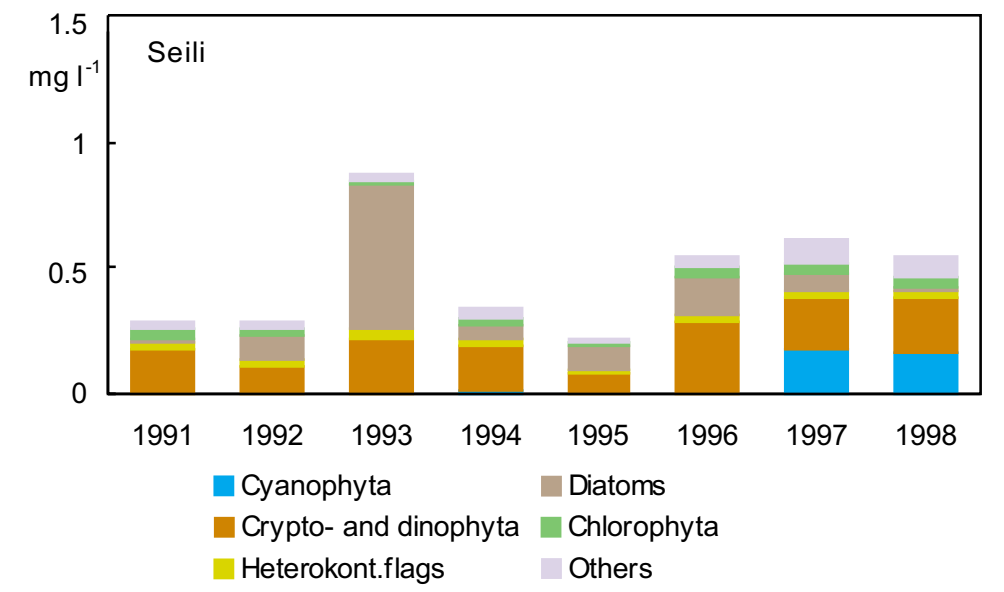

Fig. 6.7. Late summer phytoplankton species composition and biomasses at Seili in the middle Archipelago Sea in 1991-1998.

coincided with the large outflow of Nrich and oligohaline water of the River Neva in 1991 and 1993 (Kauppila et al. 1995). This episode occurred during a period of southwesterly winds at a time when the mixed surface layer was thin. The dominance of $P$. agardhii in the late summer of 1995 after rather similar summer conditions can also imply the possible effect of River Neva waters, because in September the salinity was as low as 3.3-3.5 psu and strong SW winds $\left(8.3 \mathrm{~m} \mathrm{~s}^{-1}\right)$ were prevailed. In the summer of 1998 the biomass of blue-green algae was also high, with the dominance of Aphanizomenon sp., but the hydrographical conditions did not differ from normal, e.g. the salinity was as high as 3.9-4.8 psu.

In the central Gulf of Finland, changes in species composition occurred mainly in the group of bluegreen algae. The increase in the inorganic N:P ratio was caused by waste waters originating from the HelsinkiEspoo area. This favoured flourishing of the blue-green algal order Chroococcales at the expense of $A$. flos-aquae, which is capable of nitrogen fixation (Pesonen et al. 1995, Räisänen \& Viljamaa 1998). Similar changes in nutri- 
ent ratios and species composition also occurred in the inner bays after closing of the wastewater treatment plants in Helsinki.

In the outer Archipelago Sea, dominant phytoplankton species in the summers of the early 1990s consisted mainly of diatoms (Coscinodiscus granii), cryptomonads (Plagioselmis prolonga, Teleaulax spp.) and dinoflagellates (Dinophysis acuminata, Katodinium rotundatum, Fig. 6.7). Additionally, blue- green algae (e.g. Anabaena lemmermannii) and green algae (e.g. Pyramimonas virginica) were also common. The high phytoplankton biomass in 1993 was mainly produced by the large diatom C. granii. The dominance of blue-green algae in the late1990s obviously indicates the effect of eutrophication on the phytoplankton community. The accumulations of blue-green algae also seemed to become stronger in the 1990s (Kirkkala 1998). One explanation for the dominance of blue-green algae as a response to increased P levels in the outer Archipelago Sea may be anoxia.

\subsection{Nuisance algal blooms}

Surface accumulations of filamentous blue-green algae in late summers are a regular phenomenon in the Baltic Sea (e.g. Kahru et al. 1994). The first records of such events date back to the mid 19th century (Pouchet and de Guerne 1885). However, in recent years the extent and intensity of the accumulations have been an increasing environmental concern because of anthropogenic eutrophication. The dominance of certain blue-green algae in phytoplankton communities in late summers is based on their ability to fix dissolved molecular $\mathrm{N}_{2}$ and to use phosphorus stored in their cells in the period when the growth of other algae is usually limited by nutrients. During calm and warm weathers blue-green algae tend to form surface accumulations with the aid of their gas vacuoles. Furthermore, bluegreen algae are the only toxic phytoplankton group in the Baltic, which forms extensive surface accumulations.

In the northern Baltic Sea, surface accumulations of blue-green algae in late summer occur most abundantly in the Gulf of Finland and in the Archipelago Sea. In the Gulf of Finland, the accumulations usually consist of the blue-green algae Aphanizomenon sp., Nodularia spumigena and Anabaena lemmermannii. In the western Gulf, disappearance of the accumulations in the late 1980s was associated with the increased $\mathrm{N} / \mathrm{P}$ ratio and the subsequent loss of competitive advantage provided by nitrogen fixation (Kononen 1992). Although abundant in the water column, P. agardhii does not often form surface accumulations (Lindholm 1992). In the early 1990s the reappearance of accumulations of blue-green algae in the western Gulf was explained by increased phosphorus concentration in the near bottom layers during the latest stagnation period in 1977-1992 (Nehring and Matthäus 1991, Kahru et al. 1994).

The accumulations of blue-green algae in the Gulf of Finland are often enhanced by upwellings of near-bottom waters carrying phosphorus abundantly up to the productive surface layer. Exceptional hydrographical conditions can also favour transportation of blue-green algae near to coast, such as in October 1987 when Microcystis aeruginosa formed a massive bloom in the south-eastern Finnish archipelago (Niemi 1988, Pitkänen et al. 1990). In summer 1997, the accumulations in the whole Gulf of Finland were most extensive and prolonged ever recorded (Rantajärvi 1998). The level of P concentration was elevated in the productive surface layer due to the release of $\mathrm{P}$ from sediment during extensive oxygen deficit in summer 1996 (Pitkänen and Välipakka 1997). The calm and warm weather conditions in summer 1997 also favoured the accumulation of blue-green algae. 
In the Archipelago Sea, surface accumulations of blue-green algae, mainly formed by the nitrogen-fixing species Aphanizomenon spp., Nodularia spumigena and Anabaena sp., are most common in July and August (Häkkilä 1998). The accumulations usually occur most abundantly in the outer archipelago and open sea, partly due to the lower ratio of inorganic $\mathrm{N} / \mathrm{P}$, which favours heterocystic blue-green algal species (Fig. 6.8). The occurence of cyanobacterial accumulations in the outer Archipelago Sea is also affected by the directions of prevailing winds. In summers 1998-2000, accumulations were also recorded in the inner Archipelago Sea (Häkkilä, pers. com), which is mainly due to the increase of $\mathrm{N} \mathrm{lim}$ itation in the whole sea area (cf. Kirkkala et al. 2000). The excess $P$ in the innermost coastal areas is most probably derived from internal loading.

In the Gulf of Bothnia, surface accumulations of blue-green algae are usually restricted by the low concentration of inorganic phosphorus and generally lower water temperatures than in the more southern areas of the Baltic Sea. However, in most recent years accumulations of blue green algae Anabaena spp. have been recorded in some inner coastal areas (Kauppila \& Lepistö 1998).

Surface accumulation of bluegreen algae in exceptional seasons seem to have intensified in the 1980s and 1990s. This can be considered as a sign of eutrophication. As mentionend earlier a fresh water species Microcystis aeruginosa formed a massive bloom in the eastern Gulf of Finland in October 1987 (Niemi 1998, Pitkänen et al. 1990). In January 1998 accumulations of Aphanizomenon $\mathrm{sp}$. were observed in the south-eastern coast of the Archipelago Sea which was ice free during a prolonged period of calm and mild weather in January.

Algal nuisances have taken the form of e.g. liming of bottom layers and fishing nets, dirty beaches, spoiled

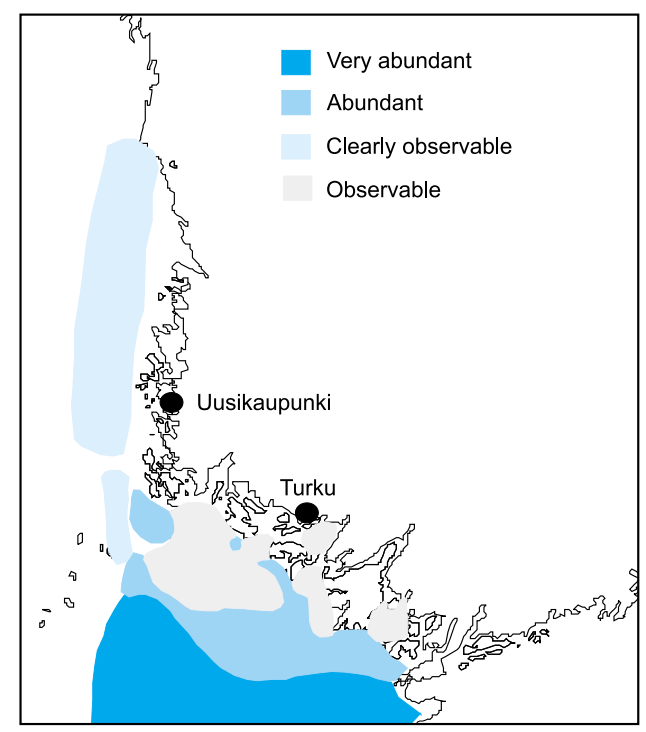

Fig.6.8. Harmful algal blooms registered in the Archipelago Sea in the 1990s.

taste of fish and poisonous phytoplankton stocks. The toxic flagellate Prymnisium parvum caused fish kills in June 1990 in Dragsfjärd, SW Finland (Lindholm and Virtanen 1992). The mass mortality of birds in the eastern Gulf of Finland in spring 1992 was probably caused by toxic diatoms (Kauppi 1993).

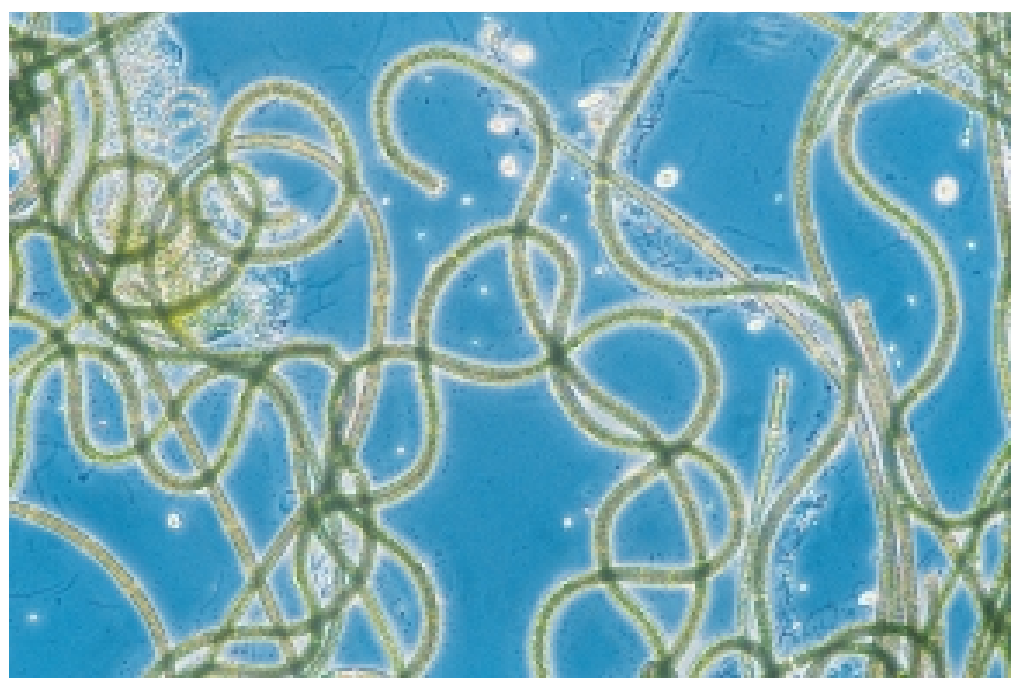

Microscopic view of blue-green alga Nodularia spumigena. Photo P. Kokkonen 


\section{Blue-green algae and $\mathrm{N}_{2}$-fixation}

Blue-green algae have bacteria-like structure and they have been classified as cyanobacteria. However, they differ from bacteria as they function like plants (autotrophs with oxygen production). Several species in Order Nostocales are able to fix nitrogen.

Some of blue-green algae, e.g. the genera Anabaena, Aphanizomenon and Nodularia in the order Nostocales have heterocysts which are quite large in size and they do not contain chlorophyll. Heterocysts are specialized for aerobic $\mathrm{N}_{2}$-fixation $\left(\mathrm{N}_{2}\right.$ gas fixation directly into organic $\mathrm{N}$ ). The blue-greens that are able to fix nitrogen may be abundant when there is a high concentration of phosphorus in water and nitrogen concetration is low. Anabaena and Aphanizomenon are very common in fresh waters. Especially the genus Anabaena includes toxic strains. Aphanizomenon is abundant in late summer and still in winter and is never observed to be toxic in brackish waters. However, mass occurrences of Nodularia, living in brackish waters, are always toxic.

Non $\mathrm{N}_{2}$-fixing blue-green algae are those without any special cell forms, i.e. all cells are uniform. For example Planktothrix agardhii (Order Oscillatoriales) is very abundant in eutrophic brackish waters with high concentrations of nitrogen. This species can typically exist in deep waters as it is able to survive in conditions of low light. The genus Microcystis (Order Chroococcales) is occasionally observed as mass occurrences in the Baltic Sea, although it is typical for highly eutrophic fresh waters.

\section{Phytoplankton communities and biomass}

Dinoflagellates are a very diverse group and very important members of phytoplankton assemblages in marine and brackish waters. The more or less oval medium-sized (ca. $30 \mu \mathrm{m}$ ) flagellated Scripsiella hangoei is often the dominating dinoflagellate species in vernal mass occurrences, together with diatoms such as Achnanthes taeniata. Scripsiella hangoei is a typical cold-water form, and is favoured by high nutrient concentrations in spring, i.e. it is an indicator of eutrophication. Simultaneously with the decrease in nutrients, the plankton community starts to change and Scripsiella cysts are formed and they sink to the bottom.

Diatoms are the other important phytoplankton group in brackish waters. The moderately small sized (ca. $5 \times 25 \mu \mathrm{m}$ ) diatom Achnanthes taeniata is a cold water diatom and thus very common during spring. Due to the intensive cell division cells are often small, only $4 \times 10 \mu \mathrm{m}$ which prevents them in the productive layer.

In brackish waters, the vernal phytoplankton biomasses are generally higher than biomasses in late summer. However, phytoplankton total biomass and its seasonal variation reflects nutrient concentrations, mainly phosphorus, in the environment. In oligotrophic waters, phytoplankton biomass values are low even during spring. The variation of total phytoplankton biomass is low, from $0.4 \mathrm{~g} \mathrm{~m}^{-3}$ to $0.6 \mathrm{~g} \mathrm{~m}^{-3}$ in late summer. In mesotrophic waters, the variation is still moderately low, from ca. $0.5 \mathrm{~g} \mathrm{~m}^{-3}$ in spring to $1.0 \mathrm{~g} \mathrm{~m}^{-3}$ in late summer.

In eutrophic nutrient-rich waters, the spring maximum is a drastic event and biomass may increase to ca. $30 \mathrm{~g} \mathrm{~m}^{-3}$ in April to May, which is thirty times higher than the average summer biomass. On average vernal biomass is ca. $7.3 \mathrm{~g} \mathrm{~m}^{-3}$. Summer phytoplankton assemblages are dominated by blue-green algae, the average total biomass being ca. $1 \mathrm{~g} \mathrm{~m}^{-3}$. 


\section{Saara Bäck, Annamaija Lehvo, Jouko Rissanen and Pentti Kangas}

Coastal ecosystem diversity is richest on the border of land and sea. The mosaics of the islands and skerries are the most typical feature of the Finnish coastline. The phytobenthic zone is defined here as the plant and animal communities of the photic zone. It offers enormously different kinds of habitats supporting different types of vegetation with associated fauna. The distribution of plants on the sea bed depends on several environmental factors. The vertical distribution is governed by light conditions, and the horizontal distribution is influenced mainly by salinity.

Rocky bottoms are often dominated by macroalgae. A typical zonation of macroalgae is usually found on exposed rocky shores. Filamentous algae dominate close to the water level, brown algae (Fucus vesiculosus) in the shallow sublittoral, and red algae at the greatest depths. Sandy bottoms are rare along most of the Finnish and Swedish coasts, where rocky bottoms and softer sediments are the prevailing bottom types (Rantataro 1992). Sandy and muddy bottoms are characterised by phanerogams. The bottom vegetation in shallow bays may also be dominated by charophyte meadows. Small, shallow and sheltered flads and gloes are clearly delimited water bodies, either still connected with the sea or cut off from the sea by land uplift.

The main threats to phytobenthos are considered to be increasing eutrophication and physical habitat de- struction. Eutrophication is related either to local point sources or to longdistance pollution sources. When eutrophication increases, sedimentation and species favouring eutrophication occupy a larger area. Physical habitat destruction includes losses of habitats by e.g. building activities. The factors threatening the phytobenthos in the Baltic Sea are likely to become more severe, in many areas, in the future. Some of these phytobentic changes have been so drastic that great concern and awareness of the phytobenthos zone has developed. Long-term studies on littoral changes in the Baltic Sea are rare. The following information was gathered from various reports and scientific articles.

\section{I Species composition of macroalgae}

Studies in coastal areas from all over the Baltic Sea region have shown negative changes in the macroalgal vegetation. Along the Finnish coast, changes such as decreased occurrence of perennial red and brown algae (Haahtela and Lehto 1982, Kangas et al. 1982), increased occurrence of fast-growing filamentous algae (Mäkinen et al.1994) and drifting algal mats causing anoxia has occurred (Norkko and Bonsdorff 1996). Furthermore, the upward movement of the algal belts due to increased 
sedimentation, overgrowth by epiphytic algae and increased shading by plankton have been widely documented (Mäkinen et al. 1984).

In the outer archipelago of the eastern Gulf of Finland, the upper filamentous algal zone is dominated by Cladophora glomerata, the intermediate zone by Fucus vesiculosus (1-5 m depth) and the deep water filamentous algal zone by Cladophora rupestris (Bäck et al. 1993b, Valovirta \& Porkka 1996). However, according to Valovirta \& Porkka (1996) the filamentous algal zone has become sparse or has disappeared altogether even at semi-exposed sites. They have found that in semi-exposed localities the Hildenbrandia zone can start immediately below the Fucus zone at a depth of about 4 metres. They also suggested that a thick cover of the polyp Cordylophora caspia is a sign of eutrophication.

In the South coast of Finland, Kukk \& Viitasalo (1997) reported that the previously extensive Enteromorpha spp. belt in the inner archipelago off the city of Helsinki decreased and gave way to a Cladophora glomerata belt during the period 1978-1995, after loading with local wastewater was finished in 1978. Phanerogams and filamentous brown algae appeared Fucus did not become established even if suitable rock surfaces were present. The changes reflect the advances in wastewater treatment of the city of Helsinki. The recovery of the phytobenthos is also due to resiting of the discharge points of the adjacent urban areas away from innermost bays to the open fringe of the archipelago waters.

Along the SW coast of Finland investigators have recorded a shift from Fucus vesiculosus -dominated bottoms towards dominance of the filamentous Pilayella littoralis. In some places F. vesiculosus has been replaced by phanerogams, mainly by Potamogeton spp. and Zannichellia palustris. The bottom quality change was explained by heavy sedimentation due to e.g. in- creased primary production. In $1991 \mathrm{~F}$. vesiculosus was still lacking but the amount of filamentous algae had decreased. In the inner and middle archipelago F. vesiculosus was replaced by filamentous brown and red algae (Mäkinen et al. 1994). F. vesiculosus produces gametes in May and June (Bäck 1993) when sediment cover is high, and $P$. littoralis in October-December (Kiirikki and Lehvo 1997) when the sediment cover is minimal. It seems possible that increase in summertime sediment cover could cause changes in the composition of the macroalgal vegetation by favouring species which release their spores in autumn and winter, when storms clean the rock surfaces of loose sediment (Kiirikki \& Lehvo 1997).

In the Åland archipelago, changes in the littoral zone follow those of the Gulf of Finland and the Archipelago Sea. In the Lågskär area of the Åland Sea, Rönnberg and Mathiesen (1997) studied macroalgal vegetation in the 1990s and compared the results to those of the 1950s, when a total of 26 species were identified. The most diverse vegetation, 18 species, was recorded at a depth of 4-7 m. Comparisons with the results from 1956 indicated that the total number of macroalgal species had decreased by six. Species showing a strong decrease included Sphacelaria arctica, Cladophora rupestris, Stictyosiphon tortilis and Polysiphonia fucoides. Species exhibiting a clear increase were the filamentous Pilayella littoralis and Ectocarpus siliculosus, Fucus vesiculosus and the red alga Rhodomela confervoides.

\subsection{Fucus vesiculosus recovery}

Fucus vesiculosus is the only large perennial seaweed which is widespread in the brackish Baltic Sea, and as such it forms the habitat for e.g. the hardbottom macrofauna. Fucus vesiculosus is widely distributed throughout the 
Finnish coast (Björkquist and Bergsröm 1997, Bäck and Ruuskanen 2000). The geographical distribution of Fucus vesiculosus along the Finnish side of the Baltic coast has not dimished since the old records of herbarium and literature. The distribution area of F. vesiculosus reaches north up in the Gulf of Bothnia to the Quark and the northernmost localities are in Valassaaret and Rönnskär. In the Gulf of Finland in the viciny of Virolahti, F. vesiculosus thrives well and its distribution extends into the Gulf of Vyborg (Lehvo and Bäck 2000a). F. vesiculosus thrives in several habitat types which can provide solid substrate. Most vigorous Fucus belts were found on solid homogenous rock surfaces in open shore areas. In sheltered shores it was found to grow on stones and could be restricted by soft sediments.

General deterioration of the $F$. vesiculosus belt is of great concern because it is a key species in the Baltic Sea ecosystem. An extensive decline of F. vesiculosus stands occurred in the southern and SW coast of Finland during the late 1970s (Kangas et al. 1982, Haahtela 1984, Hällfors et al. 1984, Kangas and Niemi 1985). Especially the F. vesiculosus belt disappeared almost completely from open archipelago shores and the abundance of $F$. $v e$ siculosus also decreased drastically along the open shores. The first signs of recovery were observed in the early 1980s in the SW coast of Finland e.g. Tvärminne archipelago. In the Archipelago Sea, F. vesiculosus had also completely vanished from many localities in the early 1980s (Mäkinen et al. 1984, Rönnberg et al. 1985). By the late 1980s (Rönnberg 1991) and the early 1990s (Bäck et al. 1993b) it had partly recolonised its former habitats, but the decline had continued in some parts of the archipelago.

A survey of F. vesiculosus along the southern coast of Finland showed that recovery of the species had occurred only on the upper part of the littoral. The most vigorous growth occurred at a depth of $0.5-2 \mathrm{~m}$ in sheltered and at $0.5-3 \mathrm{~m}$ in open shores. Below five metres the light intensity is near the photosynthesis compensation point of $F$. vesiculosus and can restrict its growth (Bäck and Ruuskanen 2000). Earlier, F. vesiculosus was recorded to grow at a depth of $10 \mathrm{~m}$ in the Tvärminne archipelago (Purasjoki 1935). In the Archipelago Sea, the continuous belt of $F$. vesiculosus nowadays reaches only from depth of 1.0 to 4.0 metres, although individual plants may be found down to a depth of 7-8 metres (Mäkinen et al. 1994).

However, in some places Fucus vesiculosus was reported to grow to great depths in the 1990s. In the northern Quark Fucus has a total distribution of 0.6-8.4 meters, with low biomass in comparison to that recorded in other parts of the Baltic Sea (Bergström and Björkvist 1997). In some places in the Alland Archipelago it thrives depth of even 9 m (Ruuskanen and Bäck 1999).

\subsection{Soft bottom vegetation}

Zostera marina is the only phanerogam species of marine origin in Finland. In these cold water it grows at its limit of distribution, but is an important key species as it creates small meadows with a rich fauna (Lappalainen et al. 1977, Boström and Bonsdorff 1997, Boström and Mattila 1999). The structure (shoot density and biomass) of Zostera meadows in the Tvärminne area appears to be rather stable in the longterm (25 yrs), but the vegetation mosaic changes spatially through vegetative growth (rhizome elongation) (Boström 1996, Boström et al 1997). Flowering and fruit-bearing specimens have been observed in the Alland Islands, but Zostera in the northern Baltic relies mainly on asexual (vegetative) reproduction (Boström 1995). 
The bottom vegetation in shallow areas can be dominated by Charophytes. Most Charophyte species occurring in brackish water are rare and are included in threatened species. In many areas with dominance of Charophytes there are high abundances of filamentous algae covering the bottom. Chara baltica is possibly decreased during the 1990s (Marja Koistinen, pers. comm.).

Flads and gloes are common along Finnish coasts and in the archipelagos. They are shallow and sheltered, clearly delimited water bodies, either still connected with the sea or cut off from it by land. They are often characterized by a well developed reed zone and luxuriant submerged vegetation. The species composition includes e.g. Fucus vesiculosus, Myriophyllum spp. and Potamogeton spp. With increasing isolation and decreasing salinity species such as Chara tomentosa, Najas marina and Ruppia maritima become common (Munsterhjelm 1996). Due to isolation the flads are subject to various threats. Mainly they are threatened by construction on the shore, boating and dredging.

\subsection{Mass occurrences of macroalgae}

Drifting macroalgae have been encountered in the 1990s in the Archipelago Sea and the Åland Sea and also in smaller amounts from the eastern Gulf of Finland to the sea area off Pori city. When the filamentous macroalgae are detached from the rocky shores they are transported to the sublittoral, where they can form loose-lying drift mats (Fig 7.1). As a result, the natural littoral vegetation can be replaced and the bottom fauna can be altered by an algal mat covering the available substrata. It has been shown that with increasing eutrophication drifting algal mats increase, affecting the entire coastal food web. At present these algal mats are probably the main factor inducing hypoxia above the halocline in the archipelago area in the northern Baltic Sea (Norkko and Bonsdorff 1996).

In the NW archipelago of the Åland Islands drift algae were found in many localities studied in 1995 (Holmström et al. 1997). The biomass increased drastically during the summer. The maximum biomass was $287 \mathrm{~g}$

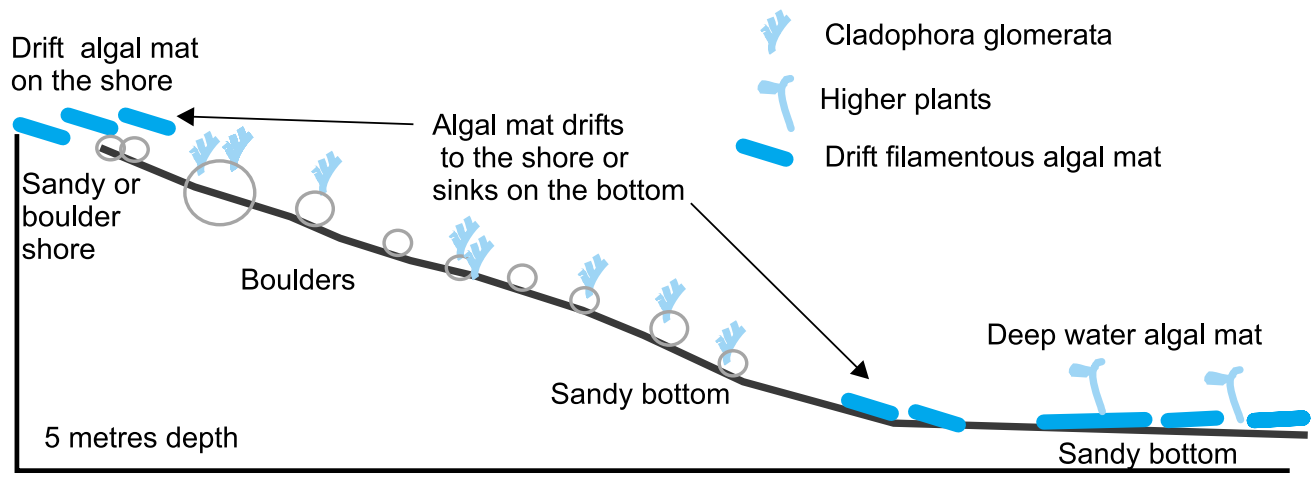

Fig. 7.I. Schematic presentation of the formation of the macroalgal mats. Part of the detached filamentous algae floats on the shore and the major part sinks on the bottom. 
$\mathrm{dw} / \mathrm{m}^{2}$ in August. The dominating species was Pilayella littoralis. Another study (Bonsdorff 1992) revealed that mats was dominated by the genera Stictyosiphon, Polysiphonia, Rhodomela, Sphacelaria, Pilayella, Furcellaria, Ceramium, Cladophora and fragments of Fucus.

Loose-lying macroalgal mats with high biomasses of the species Enteromorpha sp. have been reported along the Finnish coastline (Koistinen 1987, Bäck et al. 1993a). In the archipelago off Rauma a free-lying flake form of Enteromorpha occupied a sheltered coastal area of the mouth of the River Eurajoki. A similar phenomenon of loose lying Enteromorpha has been recorded in the 1990s in the archipelago of Uusikaupunki (Lampolahti 1997). Enteromorpha was able to survive under the ice and exhibited vigorous growth as soon as the ice melted (Bäck et al. 1993a). On the northern side of the Hanko peninsula a large sandy area was covered by the Enteromorpha sp. in the inner archipelago. After reduction of waste water input, nearly all the Enteromorpha sp. was replaced first by Chara aspera and then by Cladophora glomerata in the early 1990s (Kautsky 1982).

Mass occurrences of macroalgae can also be found outside obviously eutrophic estuaries. Ectocarpus siliculosus blooms in the SW coast of Finland have been suggested to be of wind-induced upwelling origin, exploiting short nutrient pulses (Kiirikki and Blomster 1996).

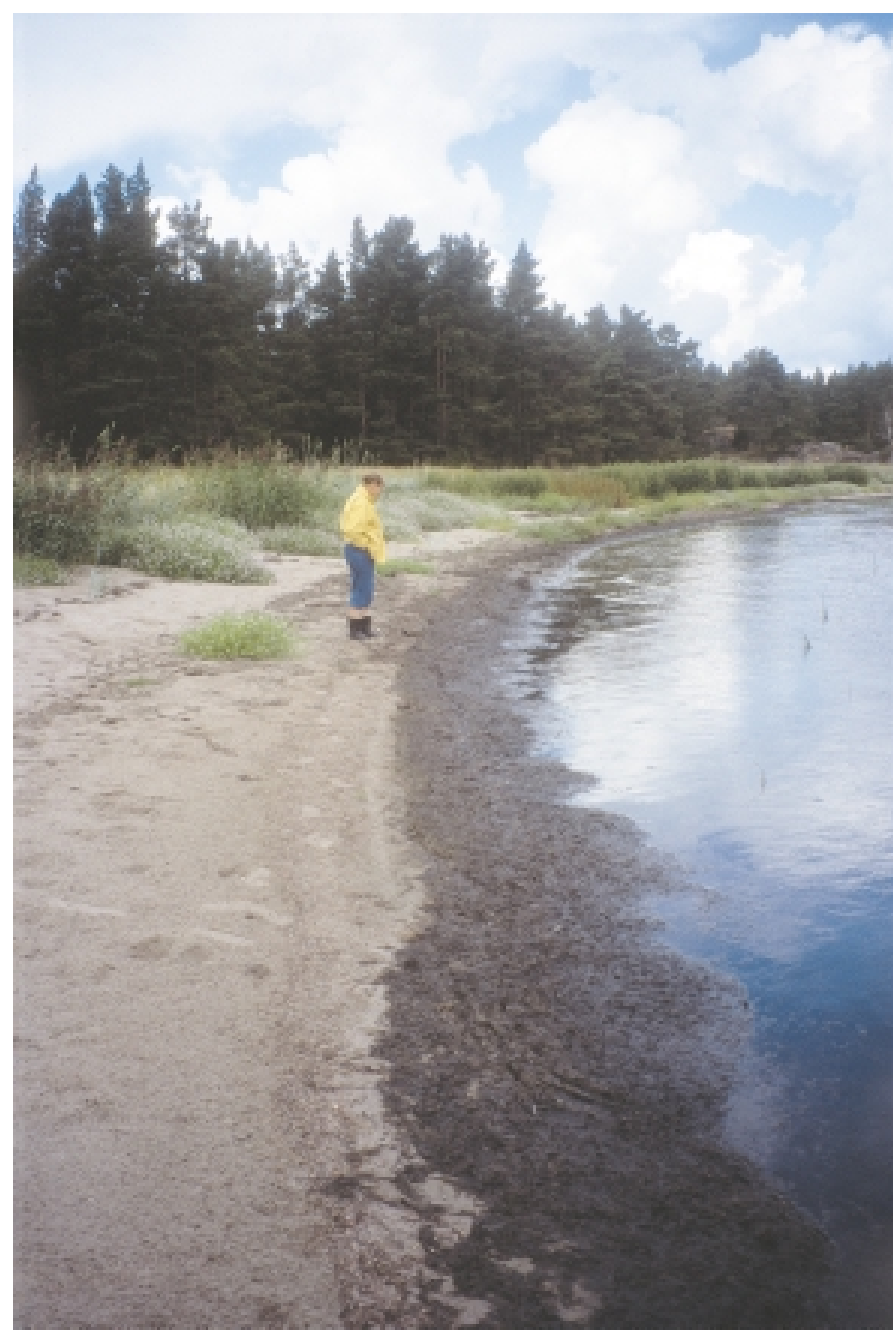

Dense accumulation of macroalgal mats on the sandy seashore can affect the recreational use of the shore. Photo S. Bäck 


\section{Drifting macroalgal mats: A CASE STUDY in 1996}

Lehvo, A.and Bäck, S. (2001)

In summer 1996 the macroalgal mats of the south-eastern Finnish coastal area from Helsinki to Virolahti were mapped for the first time. The project was carried out by the Finnish Environment Institute and the South-east and Southern Finland Regional Environment Centers.

Macroalgal mats of drifting algae were found in 26 places of the 89 studied (Fig. 7.2). The study revealed that mats normally occupy rather shallow and sheltered archipelago areas, or comparatively sheltered bays in exposed areas. The mats were found in areas of different types of bottoms, mostly sandy and silty. The mats were found in water depths of 1 down to 10 meters, with an optimum of 2-4 meters.

The occurrence of drifting algae forming mats was often patchy. The sizes of patches varied from several $\mathrm{cm}^{2}$ to approximately 10 square meters. The thickness of the mats varied from 1 to $20 \mathrm{~cm}$. Inside the macroalgal mats some loosephanerogams were found, such as Zannichellia sp. and Ruppia sp. Under the mat, anoxic conditions with a small amount of black sediments and decaying filamentous algae were found in 4 places.

Several species of filamentous algae were to form the mats. Macroalgae forming single-species mats included Vaucheria spp., Cladophora glomerata, Fucus vesiculosus, filamentous brown algae (Ectocarpus siliculosus together with Pilayella littoralis), and Enteromorpha. The following species were also found in mixed-species mats: Cladophora glomerata, Fucus vesiculosus, filamentous brown algae and Enteromorpha sp. Mixedspecies mats were found in 7 places. The main species was Cladophora glomerata, only once filamentous brown algae were dominant. Ceramium gobii was found in a mat always in association with other species.

Species in mats occurring more towards the west were Cladophora glomerata and $\mathrm{Ce}$ ramium gobii. Species that occurred more towards the east were Fucus vesiculosus, Vaucheria and filamentous brown algae. Vaucheria spp. mats were found in an inner archipelago, in sheltered muddy shores. $\mathrm{Ce}$ ramium gobii was found in mats only in an outer archipelago, on rather exposed shores.

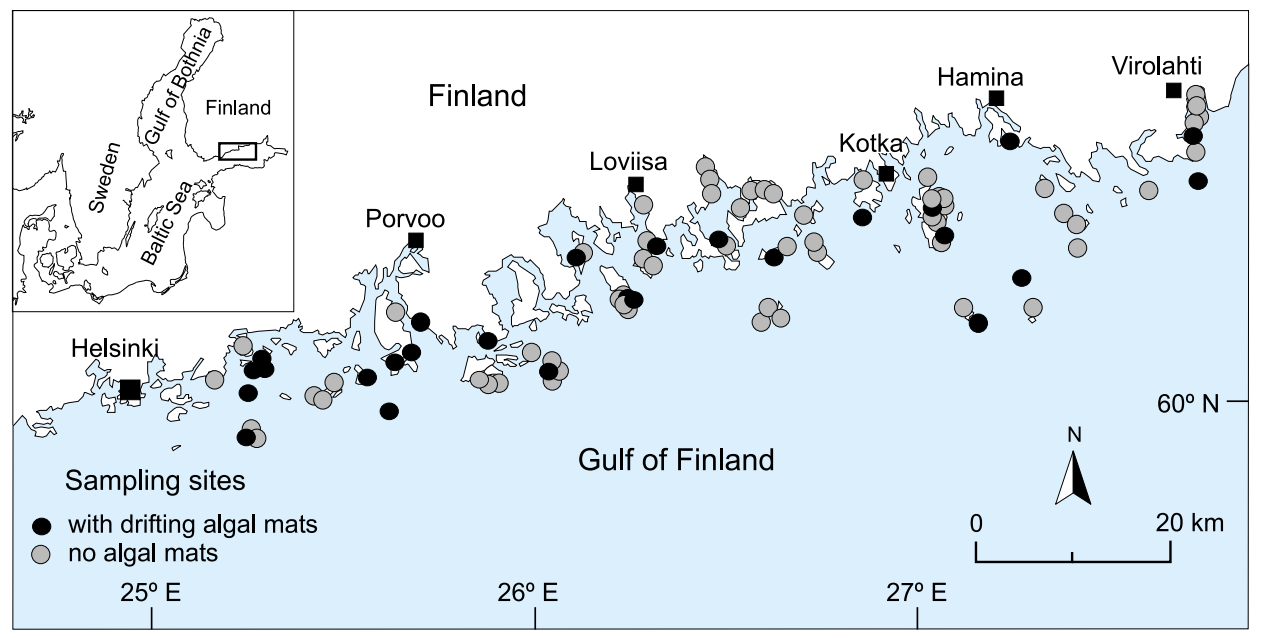

Fig. 7.2. Study area and sampling points in the Gulf of Finland in 1996. 


\subsection{Littoral fauna}

The littoral fauna communities of the Tvärminne area have exhibited remarkable long-term temporal changes in species composition when comparing two large unpublished data sets from studies made in the early 1970s and 1980s. Four main changes were observed. The amount and biomass of filter feeders, such as Balanus improvisus and Electra crustulenta, increased, both in relation to a certain area unit and in relation to the Fucus vesiculosus biomass to which they were attached. Some species of marine origin, such as Idotea granulosa and Gammarus locusta, benefited from the higher salinity. Some deposition feeders and species feeding on filamentous alga also benefited, e.g. chironomids. Limnic species, such as Asellus aquaticus and Lymnea peregra, declined due to slightly more saline water. However, in the middle of the 1980s, the species composition recovered towards the situation that prevailed in the early 1970s, and observations made in the early 1990s support this finding.

In the late 1990s the number of fouling species, such as Balanus improvisus and Electra crustulenta increased temporarily, especially in the very hot summer 1997 (Ari Ruuskanen, pers. comm.). This was also the case with Cordylophora caspia in the summer 1998.

In the Tvärminne area comparisons of Zostera marina-associated fauna from 1968-71 to 1993 indicated an increased abundance and biomass of the fauna, but a decreasing trend in species diversity. The total abundance of zoobenthos has increased significantly in areas with sparse Z. marina cover, and was more than three times higher in areas with a dense vegetation cover. The zoobenthic biomass doubled in the dense meadows, while no significant difference in terms of biomass was detected in the sparcely vegetated areas (Boström et al. 1997).

\subsection{Decline of Mytilus edulis}

The blue mussel, Mytilus edulis is one of the dominant animal species on sublittoral rocky bottoms from the western Gulf of Finland to the southern Bothnian Sea. Decreases in populations of M. edulis have been reported in many areas of the Baltic Sea (Kautsky 1995). Changes in blue mussel populations along the Finnish coast have been reported in 1990s, but virtually nothing is known about the long-term population dynamics of M. edulis. The findings of Littorin and Gilek (1999) indicate that the recolonisation of disturbed patches by M. edulis in the Swedish east coast is a relatively slow process.

On the SW coast of Finland, $M$. edulis biomass per area was about 5 times higher than in the outer the archipelago off Porkkala, on the south coast of Finland in 1996 (Hario et al. 1999). Studies of M. edulis in the 1990s in the Tvärminne archipelago and west of Hanko city demonstrated a consistent trend towards decreasing mussel size; the proportion of larger mussels in the population has decreased significantly since the 1970s (Sunila 1981, Öst and Kilpi 1997).

A decrease in salinity during recent decades may be the ultimate reason for the observed changes, as salinity affects growth, maximum size and reproduction success of mussels. Selective predation on larger mussels by eiders (Somateria mollissima) may be of local importance in this process (Öst and Kilpi 1997, Westerbom 1999). Roach (and flounder) also feeds extensively on M. edulis. (Rask 1989)

Antsulevich et al. (1999) studied the condition of the M. edulis population in the Seili area of the south-eastern Archipelago Sea in 1996. They found out that the Mytilus population is quite stable and dense. In the S-part of the Archipelago Sea (Utö, Hitis), blue 
mussel populations are stable and biomasses per unit area are substantially higher than east of the Hanko peninsula (Westerbom 1999).

\subsection{Newcomers}

The zebra mussel, Dreissena polymorpha was first recorded in the eastern parts of the Gulf of Finland in 1995 (Valovirta and Porkka 1996). In contrast to the main distribution areas of D. polymorpha, it has not been recorded in fresh water areas in Finland. In other countries $D$. polymorpha has caused severe problems in fresh water, e.g. in power plants by strong settlement in the cooling water systems. The zebra mussel is now distributed along the northern coast of the Gulf of Finland from the St. Petersburg region in the east to the Pellinki archipelago in the west (Valovirta and Porkka 1996, Välipakka et al. 1997). The abundance of $D$. polymorpha decreases strongly westwards (Välipakka et al. 1997). Hitherto, D. polymorpha has not been found to co-occur with Mytilus edulis in the Finnish coast, and as a hard bottom filter-feeding bivalve it seems to have occupied an open niche at least in the eastern part of the Gulf of Finland. In many sites in the Russian part of the Gulf of Finland D. polymorpha has become the dominant species on the hard bottom (Välipakka et al. 1997).

A mysid, Hemimysis anomala, orginating from the Caspian Sea, was found in 1992 in the coastal waters of SW Finland (Salemaa and Hietalahti 1993). It is uncertain when the species was introduced to this area, since it lives in crevices of rocks and boulders and can only be observed by SCUBA divers. Originally, the species was found in the Tvärminne-Tammisaari archipelago and near Dragsfjärd, but not from the western parts of the Archipelago Sea, nor from the HelsinkiPorkkala area (Salemaa and Hietalahti 1993). More recently, $H$. anomala has been reported at several sites in the western Gulf of Finland and the Archipelago Sea (Juha Flinkman, Mikko Kiirikki, Ilppo Vuorinen, pers. comm.). During recent years the $H$. anomala population has been increasing drastically in these areas.

The origin of the Cladoceran Cercopagis pengoi is in the Caspian and Black Seas. It also lives in Lake Aral and in estuaries of nearby big rivers such as the Donau, Volga and Don. It is suggested that Cercopagis spread to the Baltic Sea with the ballast waters of boats travelling along the canals and rivers from Russia. The first observations of Cercopagis are from the Gulf of Riga in Pärnu Bay in 1992. In September 1995 mass occurrences of Cercopagis were observed in the eastern part of the Gulf of Finland. They were first recorded by fishermen who noticed that their fishing gear and nets were full of Cercopagis. The species can reproduce rapidly and when the water temperature decreases Cercopagis forms resting eggs which hibernate in the bottom sediments. The distribution area extends from the eastern part of the Gulf of Finland to the Hanko peninsula. It is thought that Cercopagis thrives well along the south coast of Finland and forms stable populations. 


\section{Ghanges in zoobenthic communities}

\section{Pentti Kangas, Leena Byholm and Johanna Stigzelius}

The following presentation on the state and changes of zoobenthic communities in Finnish coastal waters is based on the results of pollution control studies carried out every 3rd to 5th year in the 14 main loaded areas along the coast, and on results of a long-term monitoring in one relatively clean area, the Tvärminne archipelago, $W$ of the Hanko peninsula.

\section{I The Bothnian Bay}

Tornio. The industrial input of nitrogen into the relatively open water area off Tornio increased during 1986-1996, whereas the input of nickel, zinc and cyanide decreased compared to the late 1980s (Rantala 1997a). The bottom fauna of the area consists of Monoporeia affinis, pisidiums, oligochaets and chironomid larvae, but no clear gradient can be seen from the sewers outwards. In 1990, the total abundance of fauna was at its highest during the 20 years of the survey. In particular M. affinis has become more abundant in the whole area, as well as the oligochaets. Larvae of Chironomus plumosus- type indicating eutrophication, present in the early 1990s, were not found in later investigations (Kauppinen 1997). The harmful effects of metals cannot be observed in the bottom fauna off Tornio. The abundances of fauna have not reached the level which would indicate eutrophication, nor have there been significant changes in the species composition during the 1990s (Kauppinen 1995).

Kemi. The organic loading $\left(\mathrm{BOD}_{7}\right)$ is discharged into the open areas and loading in the shallow sea area has decreased markedly since the early 1970s, and that of phosphorus and nitrogen since the late 1980s (Haasala and Kauppinen 1995). The bottom fauna communities in the innermost archipelago areas indicated that slight eutrophication is still continuing. However, the annual fluctuation of the faunal abundances has decreased, which could suggest decreasing effects of waste waters in the inner archipelago area. In the outer archipelago the increasing abundances of especially oligochaets and chironomid larvae, as well as the appearance of C. plumosustype larvae indicate eutrophication. However, the abundance of $M$. affinis has not decreased, and thus the effects of eutrophication changes do not yet seem to be harmful.

Oulu. The direct discharge of particularly $\mathrm{BOD}_{7}$, but also of phosphorus and nitrogen into the open sea area off Oulu has decreased from the early 1980s to the early 1990s (Hökkä and Rantala 1991). There are only four zoobenthos surveys available from the Oulu area between the 1960s and 1991, but the results indicate eutrophication in both inner and outer areas (Kauppinen 1991). Near the sewers the bottom fauna consisted mainly of oligochaets and chironomid larvae in 1991, whereas $M$. affinis occurred only in areas not receiving direct waste water load. A strong increase of faunal abundances, especially in the inner areas, has been reported as a result of diminishing toxic effects of waste waters.

Raahe. The direct discharges of $\mathrm{BOD}_{7}$, phosphorus, suspended solids, iron and oil into the relatively open sea 
area have decreased significantly since the early 1970s. The nitrogen input increased slightly during the 1980s but has remained relatively stable since the late 1980s (Kauppinen 1994). The abundance of zoobenthos increased during 1978-1993. This was mainly due to the increase of oligochaets and C. plumosus-type larvae, whereas the abundance of $M$. affinis decreased dramatically. These changes reflect increased eutrophication.

Kokkola. During 1990-1994 the industrial loading of metals except for arsenic and cadmium decreased. There were no clear changes in the discharges of organic matter and nutrients during that period (Kalliolinna and Aaltonen 1995). The bottom fauna is very poor off Kokkola, partly due to the relatively small number of sedimentation bottoms. In 1994 the bottom fauna was dominated by oligochaets, whereas while $M$. affinis occurred at only one moderately clean station. The decreasing abundance of this species and the occurrence of C. plumosus-type larvae indicate deterioration of the bottom fauna near the sewers during the early 1990s. However, dead bottoms were not found. The great annual fluctuations of bottom fauna communities near the sewers indicated that the area was already polluted in the late 1980s (Aaltonen and Kalliolinna 1990).

\subsection{The Bothnian Sea}

Kaskinen. The water area off Kaskinen is mainly open except for two bays separated by sills. The main source of loading is a pulp and paper plant which discharges its effluents to a semi-enclosed bay with no sills. The industrial and municipal inputs of $\mathrm{BOD}_{7}$ to the area increased during 1993-1995, whereas the loading of phosphorus and suspended solids decreased (Langi and Paavilainen 1996). In 1995, the soft bottom fauna near the sewer indicated eutrophication. The bottom fauna was dominated by oligochaets, chironomid larvae and $\mathrm{Ma}$ - coma balthica, whereas Monoporeia affinis was scarce. Further away from the sewer the bottom fauna consisted mainly of Gammarus, Monoporeia and mysids. During 1990-1995 no essential changes in the state of the bottoms were reported.

Pori. During the early 1990s the river loading of $\mathrm{BOD}_{7}$ and phosphorus into the sea area decreased to one fourth compared to the late 1970s. The industrial loading of ferrosulfate and sulfuric acid also decreased markedly from the mean level of the 1980s (Oravainen 1996). According to a quality classification in 1994, badly polluted bottoms extended several kilometres from the factory sewer (Fig. 8.1a). Only a few species occurred in this area and even the shells of Macoma were badly corroded. Part of the bottom of the inner area was organically polluted (Kärkkäinen 1995). Healthy bottoms occurred only in the open sea area, over $10 \mathrm{~km}$ from the sewers. The changes in the state of bottoms depend on the area. Some improvement in the state of the bottoms of the inner area occurred during 1991-1996, especially near the factory sewer (Vahteri 1997) and in the river Kokemäenjoki estuary (Mankki 1996). However, some organically polluted bottoms further deteriorated during that time (Vahteri 1997). In the outer part of the middle archipelago, the area of healthy and semi-healthy bottoms slightly increased during the early 1990s. The biomasses decreased, mainly due to the succesful rejuvenation of M. balthica. Populations of $M$. affinis have also strongly increased. Thus the development in the sea area off Pori is very different to that in the Bothnian Bay, where the state of bottoms in the inner areas improved and those in the outer areas deteriorated.

Rauma. Direct loading to the archipelago area off Rauma has decreased markedly since the pulp factory closed down in 1991. The loads of $\mathrm{BOD}_{7}$, phosphorus, suspended solids and nitrogen have been lower in the 1990s compared to the 1980s (Jumppanen and Räisänen 1996). According 

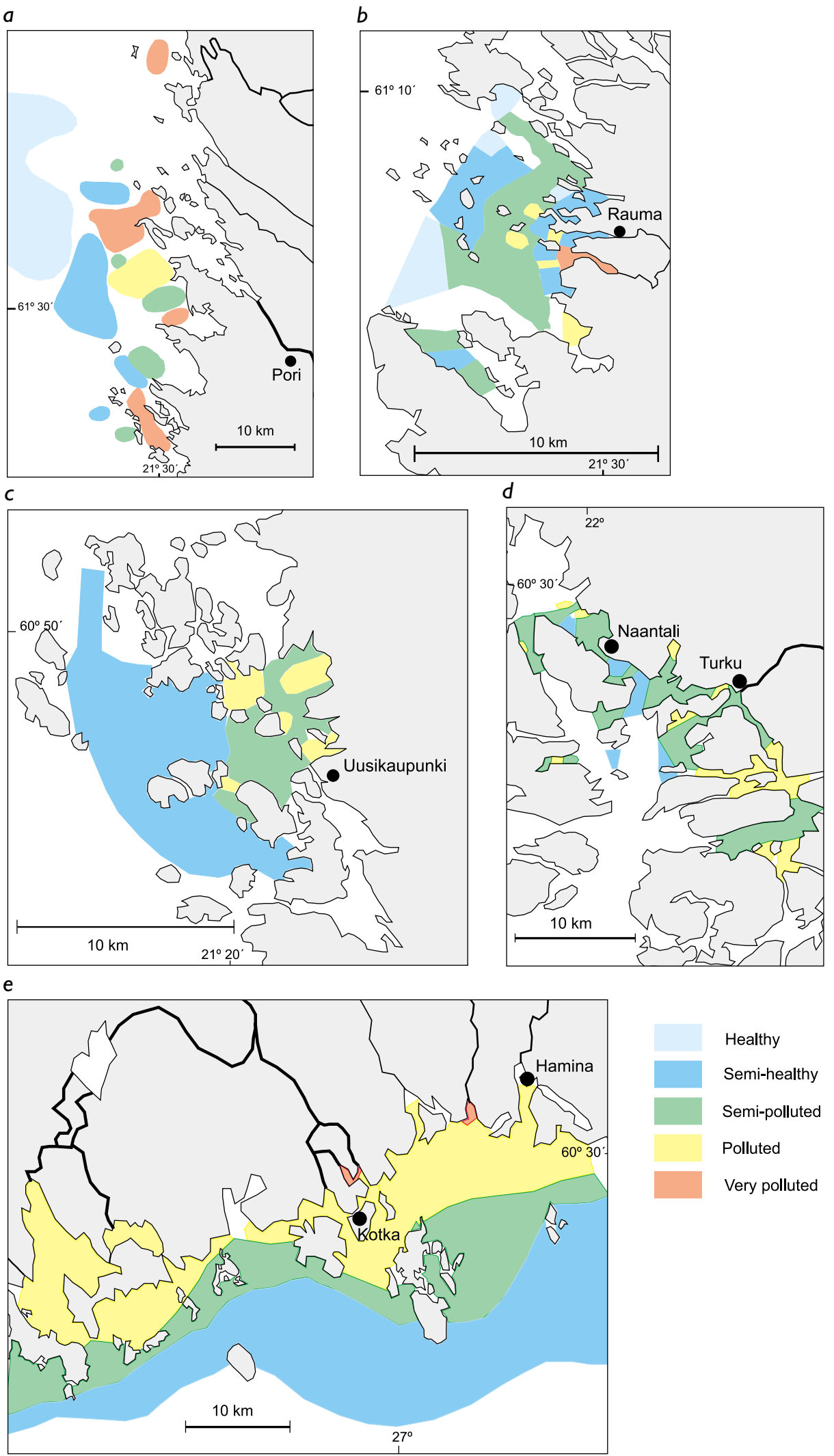

Healthy

Semi-healthy

Semi-polluted

Polluted

Very polluted

Fig. 8. I. Bottom quality classification at the sea areas off five coastal loaded areas, obtained by applying the system of Leppäkoski (1975) based on zoobenthos species composition and biomass. The figures are modified from Kärkkäinen 1994 (in Fig. a, Pori); Jumppanen and Räisänen 1996 (b, Rauma); Jumppanen 1997 (c, Uusikaupunki); Jumppanen and Räisänen 1997 (d, Turku); and Partanen 1993 (e, Kotka-Hamina. Quality classes: I, healthy; II, semi-healthy; III, semi-polluted; IV, polluted; and V, very polluted. 
to the quality classification, the bottoms near the sewers were badly polluted in 1994 (Fig. 8.1b). Abundances were low and the fauna consisted of only a few species. M. balthica dominated the whole sea area and $M$. affinis was absent. The trends in bottom fauna and seem to reflect the intensity of loading. From 1990 to 1994, the state of the bottom communities somewhat improved in the inner archipelago areas and the area of strongly polluted bottoms decreased. In 1990 the state of bottoms in the outer archipelago had deteriorated (Jumppanen and Mattila 1991), and the area of healthy bottoms decreased. However, in 1994 no further significant changes were observed.

Uusikaupunki. The archipelago area off Uusikaupunki is relatively shallow and receives loads from a fertilizer plant, a municipal sewer the and river Sirppujoki, which discharges into the area via a regulated freshwater ba$\sin$. The industrial phosphorus loading has decreased markedly since 1993. However, the background loading has evidently increased at the same time (Jumppanen 1997a). According to quality classification, polluted or semi-polluted bottoms were located near the outlets in 1996 (Fig. 8.1c). Benthic communities on these bottoms consisted typically of Macoma balthica, polychaets (Nereis, Marenzelleria), oligochaets and chironomids. The semi-healthy zone extended 8-10 km from the fertilizer plant and was densely inhabited by Marenzelleria, a newcomer to the area. Healthy bottoms were found only at one station in the outer archipelago (Jumppanen 1997b). The state of the bottoms in the innermost area and in the inner archipelago somewhat improved during the 1990s. Totally dead bottoms were not recorded in the 1990s and the zone of polluted bottoms decreased in the areas where the phosphorus contents and primary production had been highest. Species indicating healthy bottoms, such as M. affinis, almost disappeared even from the outer parts of the investigated area dur- ing the late 1980s. Meanwhile oligochaets and chironomid larvae, indicating polluted bottoms, became more abundant in the whole area. Although the state of the inner archipelago improved during the 1990s, there was no improvement in the state of the outer archipelago, despite the decreased phosphorous load. This reflects the general eutrofication of the sea area, particularly in the outer archipelago (Jumppanen 1997b).

\subsection{The Turku area in the Archipelago Sea}

In that part of the sea area off Turku from where pollution control studies are available, the exchange of water is limited by the wide and dense archipelago. The area receives loads from municipal and industrial waste waters and from the river Aurajoki. The direct phosphorus load was lower in the 1990s than in the 1980s (Räisänen and Jumppanen 1996). The phosphorus load from extensive fish farming is twofold that from sewage waters, and it is focused just on the production season.

Bottom quality classifications have been carried out every fourth year since 1956 (Räisänen 1997). Based on the quality classification in 1995 (Fig. 8.1d), the bottoms between Naantali and Parainen can be divided into three zones on the basis of dominant species. Chironomus plumosus-type larvae, indicating polluted bottoms, were dominant mostly in the sheltered areas. Macoma balthica, an indicator of slightly eutroficated bottoms, dominated bottoms in the more open bays and sound areas. In the outer archipelago the dominating species was Monoporeia affinis. The effects of waste waters extended at most ca. $7 \mathrm{~km}$ from the sewers in 1995. Dead bottoms were not observed in 1995, although signs of oxygen depletion were observed especially in deep areas. 
There were no essential changes in the general state of the benthic fauna during 1983-1995, although some local changes were found. The state of the bottoms in the inner archipelago seems to have slightly improved from 1991 to1995, while the state of bottoms in parts of the outer archipelago deteriorated in 1995. The abundances of species typical for clean waters, such as $M$. affinis, decreased. A new species to the Turku region, Marenzelleria viridis, was found only in 1995.

No clear trend in the status of the bottom existed between the different sub-areas. According to Räisänen (1997), an improvement in the state of bottoms of the Turku sea area in the near future is unlikely because of diffuse loading from land areas and from the Baltic Sea. It is more likely that the quality of bottoms will decline in areas now classified as healthy or semihealthy.

\subsection{The Gulf of Finland}

Helsinki-Espoo sea area. In waters off Helsinki and Espoo the load imposed by municipal sewage clearly exceeds that received from the river Vantaanjoki. The mixing conditions are rather good, except in two semi-enclosed bays into which a large part of the municipal waste waters were earlier discharged. Since 1987 most, and since 1994 all, municipal waste waters of Helsinki have been discharged through a tunnel to the outer archipelago $7 \mathrm{~km}$ from the coast. The waste waters of the neighbouring town of Espoo have been discharged to the outer archipelago since 1974. During 1987-1994 the direct load of phosphorus received by the Helsinki sea area decreased markedly and the $\mathrm{BOD}_{7}$ load slightly (Pesonen et al. 1995). According to annual sampling of selected stations (Norha 1998), the bottom fauna of the inner bays consisted mainly of oligochaets and chironomid larvae. Macoma balthica was found only the inner archipelago are-

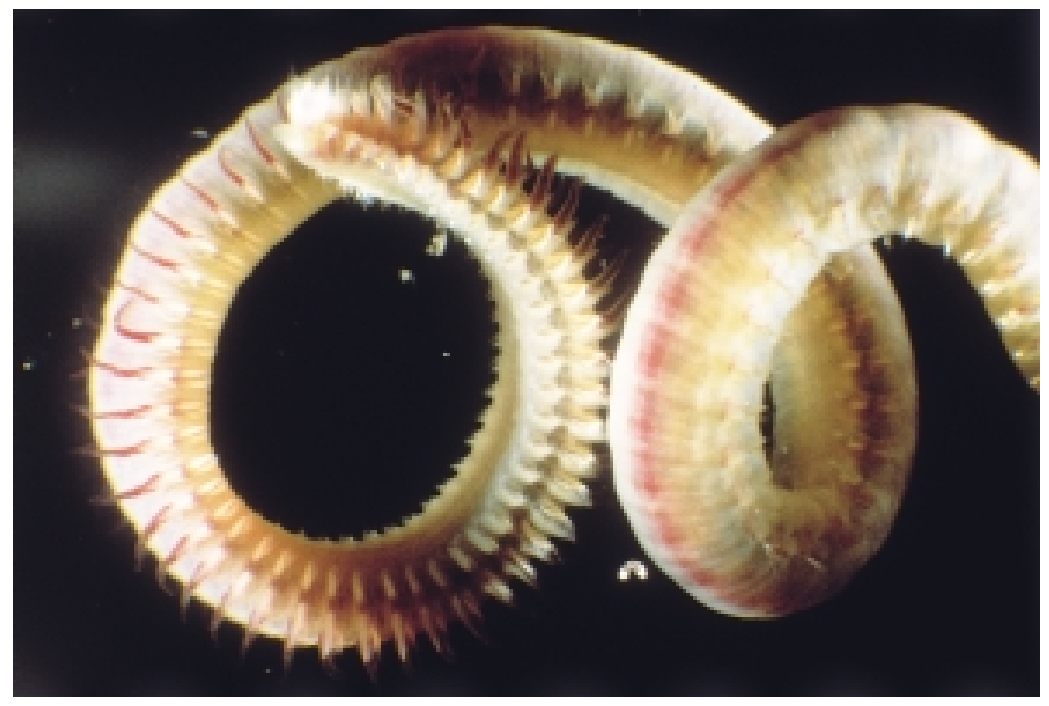

Polychaete worm Marenzelleria viridis was recorded first time in 1990 in Finnish waters. Presently its distribution extends in the coastal waters from eastern Gulf of Finland to the Quark area. Photo J. Stigzelius

as. The state of the bottoms of the bays has slowly improved since the 1960s due to decreasing loading to these areas. No marked changes in zoobenthos occurred from the 1980s to 1997, although abundances in most areas were highest in the early 1990s. In the outer archipelago the dominating taxa are also oligochaets and chironomids, but $M$. balthica became more abundant in the 1990s, while the numbers of $\mathrm{Mo}$ noporeia remained low. The abundances and biomasses were highest in the early 1990s, but decreased thereafter, to be replaced mainly by oligochaets (Norha 1998). The fluctuations in fauna during past last ten years cannot be explained by changes in direct loading into the area, but more probably reflect the general state of the Baltic Sea.

Porvoo. In addition to the waters of two eutrophicated rivers, Porvoonjoki and Mäntsälänjoki, the Porvoo sea area is a recipient for municipal and industrial waste waters. The municipal waste waters are discharged into a semi-enclosed inner bay and the industrial waste waters into the more outer archipelago areas. The direct loads of 
$\mathrm{BOD}_{7}$ and phosphorus have decreased since the 1980s, while those from the rivers have remained stable (Erkkilä and Vaajakorpi 1993). Benthic communities on polluted bottoms of the Porvoo archipelago consisted mainly of $C$. plumosus-type larvae, oligochaets and a few M. balthica individuals in 1992. Tubificids, indicating polluted bottoms, were particularly abundant in 1992. Their increase suggests increased eutrophication in the whole area. The bottoms in the outer area, Svartbäckinselkä, have been in very poor condition since the 1980s. At the shallower stations, the above-mentioned species somewhat increased during the 1990s. At the deepest station, suffering sporadically from oxygen depletion, an extremely scarce fauna was found in 1998 (Erkkilä and Vaajakorpi 1999). M. affinis very strongly decreased throughout the whole outer area during the 1990s andwas not longer recorded in 1998.

Loviisa. Information is available from the middle archipelago, which receives domestic and process waste waters from a nuclear power plant. The total loading from the plant is rather low. The area is also influenced by a long fjord-like bay, and the discharges of waste waters from the town of Loviisa. The $\mathrm{BOD}_{7}$ and nitrogen loads decreased during the 1990s, whereas phosphorus loading slightly increased (Raita and Silvonen 1997). The diversity of the bottom fauna is low. Near the power plant, the dominant taxa were the oligochaet Potamothrix hammoniensis and the chironomid larvae in 1996. M. balthica was found in a few areas. In all deeper and outer parts of the investigated area the bottom fauna was scarce or missing. Mainly chironomids and Marenzelleria viridis have been found occasionally on these bottoms in the 1990s. M. affinis communities already disappeared in the late 1980s (Ilus 1997) and have been absent in the 1990s. The bottom fauna off Loviisa was already found to be scarce in the past 1960s, but during the latest 20 years the abundance and biomass of the bottom fauna have further decreased. The explanation seems to be that, due to the general eutrophication of the Gulf of Finland, the increase of organic matter in the sediments made the oxygen conditions of the bottoms unsuitable for most benthic animals. The most significant change during the 1990 s on the species level was the strong increase of Marenzelleria particularly near the cooling water outlet (Ilus 1997).

The Pyhtää-Kotka-Hamina region. The coastal area covered by control studies is more than $40 \mathrm{~km}$ in width. The River Kymijoki discharges into the sea as five bifurcations. In addition to the river loads, the sea area off Kotka, having limited water exchange conditions, receives discharges from municipal sewers and from wood processing industries. The sea area off Hamina, to the east, receives discharges from wood processing industries, municipal sewers and from the rivers Summajoki and Vehkajoki. This area is also shallow and the bottom consists of mud, thus being eutrophicated by natural causes. Based on the quality classification, most of the bottom near the coast from Pyhtää to Hamina was eutrophicated in 1992 (Partanen 1993, Fig. 8.1e). The fauna on these bottoms consisted of oligochaets (Potamothrix hammoniensis) and chironomid larvae (C. plumosus and Procladius spp). Toxic bottoms occurred near the industrial sewers. The abundance of oligochaets has increased in the eutrophicated zone since 1984, which suggests increasing eutrophication in the inner archipelago. The effects of waste waters extended to the outer parts of the archipelago, where sedimentation of organic matter causes oxygen deficiency in some places. Due to poor oxygen conditions the Monoporeia-Saduria communities in deep bottoms have become less frequent. The state of the outer archipelago deteriorated in the late 1980s (Mankki 1990), but no further changes were reported in 1992. In the latter survey 
the network station had been extended outwards. Preliminary results (Kymijoen vesiensuojeluyhdistys ry) from the next survey with a wide station network in 1997 reveal deterioration of bottoms. At eleven areas, mostly the outermost ones, the bottoms were dead, and most stations situated somewhat inwards from these had only a very scarce bottom fauna. The reason of deterioration for these coastal depressions is most probably connected with over-eutrophication of the whole sea area, with an increase of sedimentation and oxygen consumption on the bottoms. By contrast, the state of the bottoms of some inner areas has improved since the pollution load decreased during the 1990s.

\subsection{Zoobenthos trends in a reference area in Tvärminne}

Long-term zoobenthos data is available from only one relatively non-polluted coastal area. Two sampling stations, situated at Tvärminne Storfjärd at the entrance of the Gulf of Finland, have been monitored since 1964. The same stations were sampled already in the 1920s (Stigzelius et al. in prep.). The study area is situated in the outer archipelago zone in a water body with good water exchange with the Gulf of Finland through a deep furrow. There has been no notable loading from local point sources in the area, but the trophic status has increased during recent decades due to general eutrophication of the Gulf of Finland.

As is characteristic for the northern Baltic Sea, the number of benthic species found was low, 5 to 10 true benthos taxa per sampling occasion. The species composition was rather similar throughout the study period. The bottom communities were dominated by Monoporeia affinis and Macoma balthica at the $20 \mathrm{~m}$ station and by $M$. affinis and Pontoporeia femorata at the 35 $\mathrm{m}$ station. A new species, Marenzelleria viridis, was first observed in 1990. It still has low abundances, but appears to have become a permanent member of the benthic communities.

Species composition, abundance and biomass have changed considerably from the 1960s to 1997 (Fig 8.2.). The populations of $M$. affinis showed a slight tendency to fluctuate with a 6-7 year cycle. Similar fluctuations are also

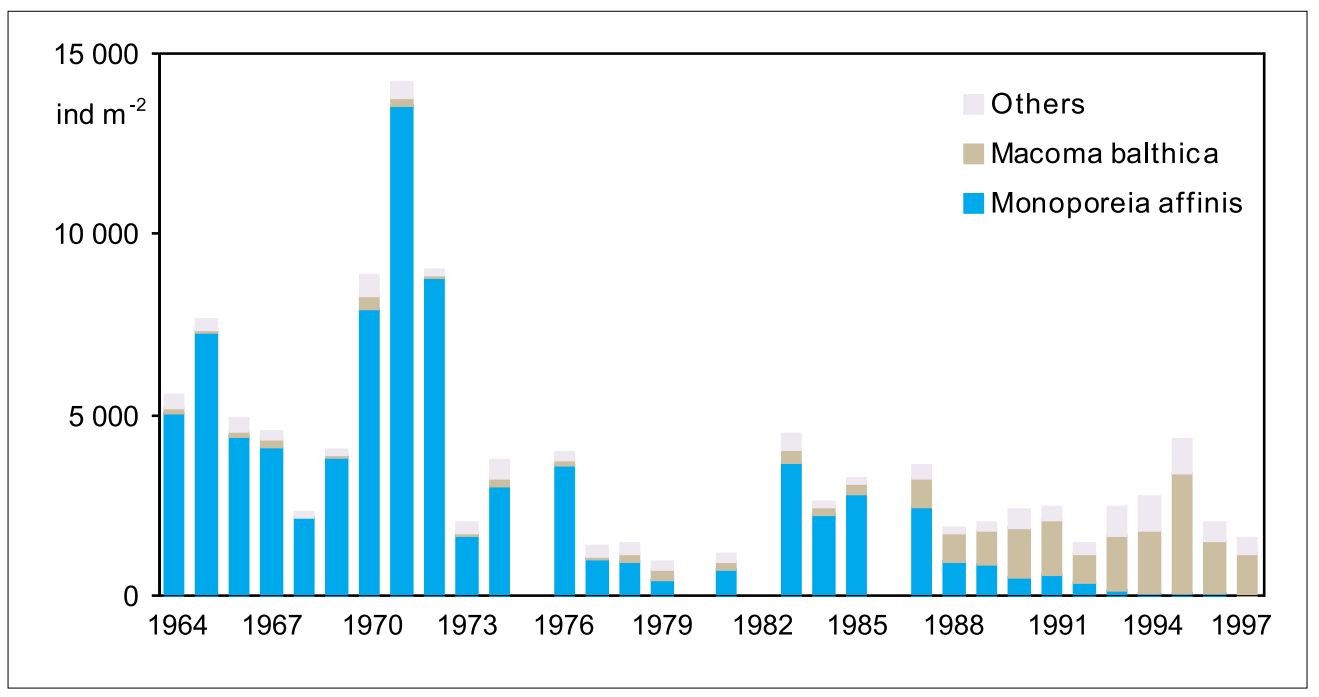

Fig. 8.2. Total abundance of zoobenthos and the dominant species at $20 \mathrm{~m}$ depth in Trärminne from 1964 to 1997. Redrawn from Stigzelius et al. (in prep). 
found in the open sea populations of the Gulf of Bothnia. The crustacea populations were strong until the 1970s, but have strongly decreased thereafter, and were nearly absent in the late 1990s. However, the numbers of $M$. balthica and Halicryptus spinulosus, especially the numbers of young individuals, have increased at the $20 \mathrm{~m}$ station during the 1980s. Macoma became the dominating species, especially for biomass, at the shallower station in the 1990s. The change was similar, but weaker at the $35 \mathrm{~m}$ station. The density of oligochaets at the $20 \mathrm{~m}$ station has decreased since the 1970s, whereas chironomid larvae have increased in abundance in the 1990s. Densities of other species such as Pontoporeia femorata, Harmothoe sarsi and Saduria entomon have not significantly changed during the study period.

The changes in the macrobenthic communities in the Tvärminne area probably resulted from the combined effects of natural events such as intraand interspecific regulation, and eutrophication. The cyclic fluctuations in the population of Monoporeia affinis were probably caused by intraspecific competition, whereas the decreasing trend of density is possibly a consequence of eutrophication. Results from the 1920s and 1930s, however, indicate that eutrophication is not likely to be the main factor causing the decrease, since the populations were occasionally very low in abundance even at that time. Decreasing densities of M. affinis have reduced predatory pressure on Macoma balthica and Halicryptus spinulosus, allowing them to increase in number.

\subsection{General zoobenthos trends in the Finnish coastal waters}

Pollution control studies are planned to assess the effects of waste waters on the state of receiving local areas, and they are widely used for decisions when planning water protection measures. Thus, the studies have not been planned to create a generalized picture of the state of coastal bottoms throughout the Finnish coastal area. Some uncertainties therefore remain when summarising the results for this purpose. This is mainly because less records available from reference areas and the frequency of sampling in most areas is only every 3 rd to 5 th year. However, it is possible to draw some conclusions.

There is no clear overall trend in the state of the loaded bottoms along the Finnish coast. The effects of waste waters on bottoms are clear in areas near the waste water outlets in all the loaded areas, but the extent of effects depends largely on both the amount and the character of loading and physical features of the area, such as the shape of the coast, quality of bottom material and water exchange conditions. The areas with effects of waste waters on bottom fauna are particularly extensive in waters off Raahe, Pori, Rauma, Turku and the Helsinki and Kotka regions.

A considerable change, especially in coastal areas of the Gulf of Finland, is the decrease of populations of Monoporoeia affinis at outermost sites of the control programmes. The species strongly decreased or totally disappeared from all studied bottoms in the1990s or late 1980s. It is worthy of note that the development was similar in the Tvärminne area, which receives very low loading and is generally con- 
sidered as a moderately clean area. This change becomes much weaker through the Archipelago Sea towards the Gulf of Bothnia. Changes in these areas are generally weak, and in the northernmost Bothnian Bay, off Tornio, M. affinis has even increased in the 1990s.

Another important feature in the species composition of the coastal waters of Finland is the introduction of a new species, the polychaet Marenzelleria viridis. The species was first detected in 1990, and it has in places become abundant during the early 1990s. It seems to favour slightly eutrophicated bottoms and, as an expansive species, it may displace weaker species (Stigzelius et al. 1997, Ilus 1997). However, the actual effects of this polychaet on other species are not yet known.

In order to illustrate the possible general trend in the state of Finnish coastal zoobenthic communities, a compilation based on conclusions drawn by the authors of the pollution control reports was made. Because the frequency and intensity of studies vary between the individual areas, the result (Table 8.1) is not very accurate and it should be considered mainly as indicative. Developments in the quality of bottom fauna have been quite different in different loaded areas during the past 20 years.

In the inner archipelago areas near the loading sources the development is most diverse. The direct load of particularly $\mathrm{BOD}_{7}$ and phosphorus decreased in most of the controlled areas during the 1980s and early 1990s. Off Kemi, Rauma, Uusikaupunki, Turku and Helsinki there has been clearest improvement in the state of the most loaded inner areas. This appears e.g. as a decrease in the zone of polluted bottom, and as an increase of other animal groups than oligochaets and chironomids. Off Porvoo and Loviisa the bottoms have deteriorated despite the decrease in direct loading. Some deterioration also occurred off Raahe, Kokkola and Kotka, whereas no clear changes were reported in sea areas off Tornio, Oulu, Kaskinen and Pori.

In the outer archipelago the development was more consistent. In most areas there were changes towards poorer quality during the early 1990s and often already in the late 1980s. Most of the changes were interpreted to be rather weak. A typical sign of this was the decrease of Monoporeia affinis, which indicates clean waters, while the abundances of oligochaets and chironomid larvae increased. This development has been strongest in the Gulf of Finland. Signs of improvement in the state of the outer archipelago around the Finnish coasts were detected only off Pori.

When the state of bottoms in the inner archipelago has improved coincidently with decrease in the point source loading, this decrease does not seem to be able to account for the improvement recorded in the state of bottoms in the outer archipelago more distant from the sewers. As shown above, the state of the bottom fauna in these areas has become poorer, and therefore must be due to some other reason than the effects of waste water loading. There are no signs that harmful substances have such wide effects on the fauna, but rather eutrophication of the Baltic Sea, manifesting as increased production, sedimentation and oxygen consumption on the bottoms, is seen as the most obvious reason for deterioration of the fauna in the outer coastal areas. Decline in species diversity and abundance in these bottoms is strongest in those coastal areas which have the highest degree of trophy (see Chapters 5 and 6), especially in the Gulf of Finland. 
Table 8.I. Changes in state of zoobenthos near the loading sources in the inner archipelago and in the outer archipelago of fourteen loaded coastal areas in the 1980s and 1990s. The conclusions are based on reports of corresponding control study programmes.

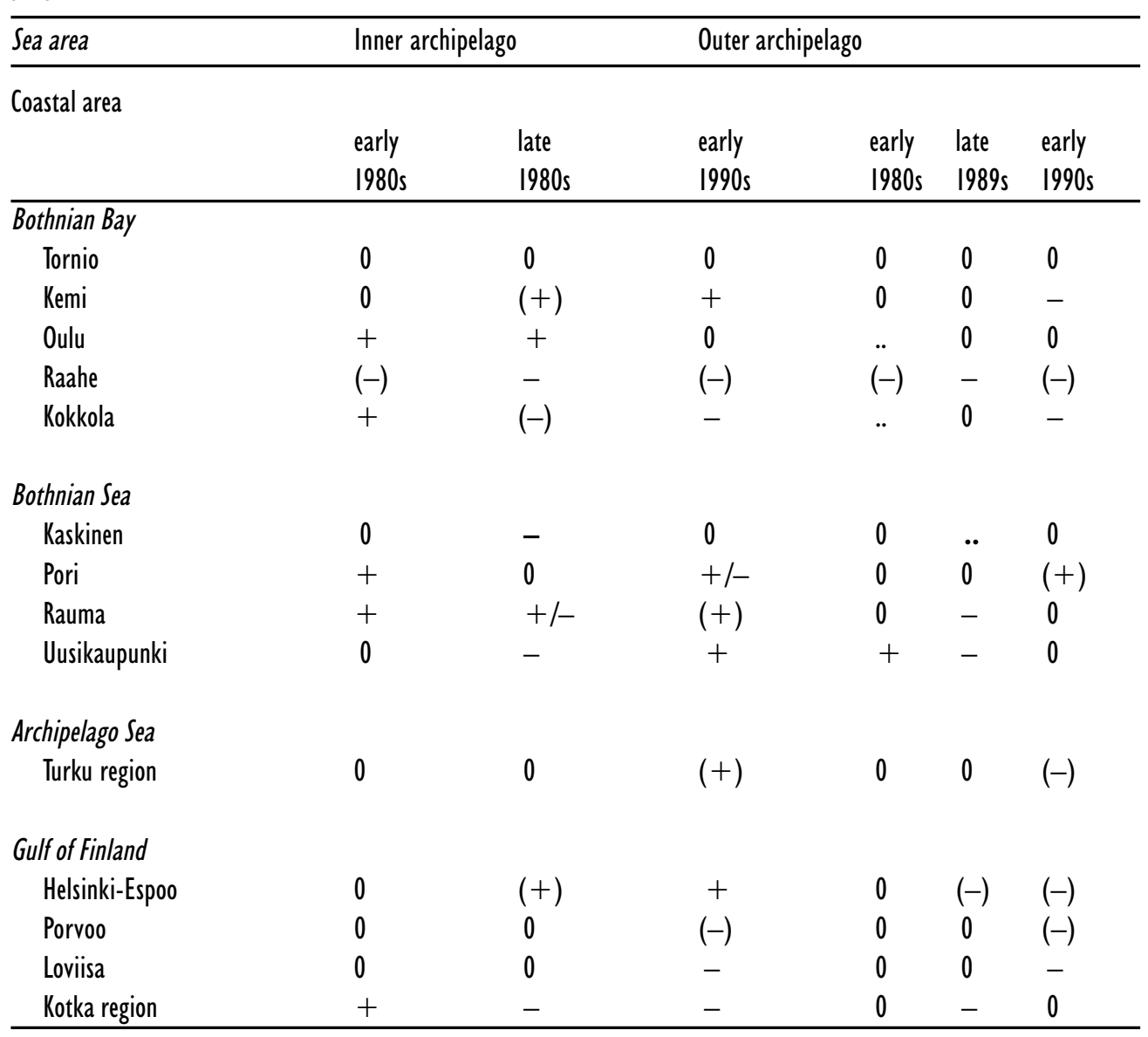

The symbols indicate:

$\begin{array}{ll}+ & \text { improving bottom state } \\ - & \text { deteriorating bottom state } \\ +/- & \text { partly improving, partly deteriorating } \\ 0 & \text { no significant changes detected } \\ () & \text { the development is unclear or weak } \\ . . & \text { the development of the state of the bottom is not stated in the report, } \\ & \text { or the investigation has not been done. }\end{array}$


Antti Lappalainen \& Martti Rask, Finnish Game and Fisheries Research Institute

The number of regularly occurring fish species in Finnish coastal waters is approximately 60 excluding the introduced species. However, the majority of fish species are small-sized or scarcely occurring species and therefore not important for the fisheries. As a consequence, there is very little information about the stocks of these species, although they may be important components of the coastal ecosystems. The status and changes in the stocks are generally better known for the 10-20 species important for fisheries. Coastal fish species are usually classified as migratory, limnic or marine species according to their original adaptation to salinity. This classification is also useful when considering the connection between coastal water quality and fish stocks. Deterioration in coastal water quality may also have direct effects on fisheries as discussed in section 9.4 .

\section{I Migratory species}

The stocks of migratory species, such as salmon (Salmo salar), trout (Salmo trutta) and migrating whitefish (Coregonus lavaretus), were strongly affected by the damming and pollution of most spawning rivers in the first half of the twentieth century. There is no evidence that the state of the coastal area itself has had any major effects on these stocks, which are now depent on stocking programs. At present, reared fish account for $80-90 \%$ of the Finnish salmon and migratory brown trout catches, and $65 \%$ of the migratory whitefish catch in the Baltic Sea. The wild salmon stocks of the Bothnian Sea are further threatened by the M-74 syndrome affecting the survival of yolksac fry. The mean mortalities of salmon yolk-sac fry hatched from eggs collected from the females ascending rivers after feeding migration in the Baltic Sea have varied from 50 to over $90 \%$ in recent years. The cause of this syndrome is still unknown. The toxicants or changes in the food webs in the feeding area of salmon (the Baltic proper) have been proposed as potential causes (Vuorinen et al. 1997).

In addition to salmonids, some cyprinids are also present only as migratory species in our coastal waters. It is evident that the deterioration of the spawnig rivers and brooks has negatively affected the stocks of vimba (Vimba vimba) (see Saulamo and Lehtonen 1998) and the commercial cathes of ide (Leuciscus idus) from the beginning of 1980s. The decrease of ide stocks in the Helsinki region (Anttila 1973) could be partly explained by the same cause.

\subsection{Limnic species}

The effects of eutrophication and pollution of coastal waters on fish stocks are most clearly seen among the limnic species, which permanently live and spawn near the coast and in the archipelago zone. There are a few observations of increased abundance of cyprinids, especially roach (Rutilus rutilus). Paavilainen et al. (1985) carried out test fishings in the eastern Gulf of Finland and found highest proportions of cyprinids and ruffe (Gymnocephalus cernuus) in 


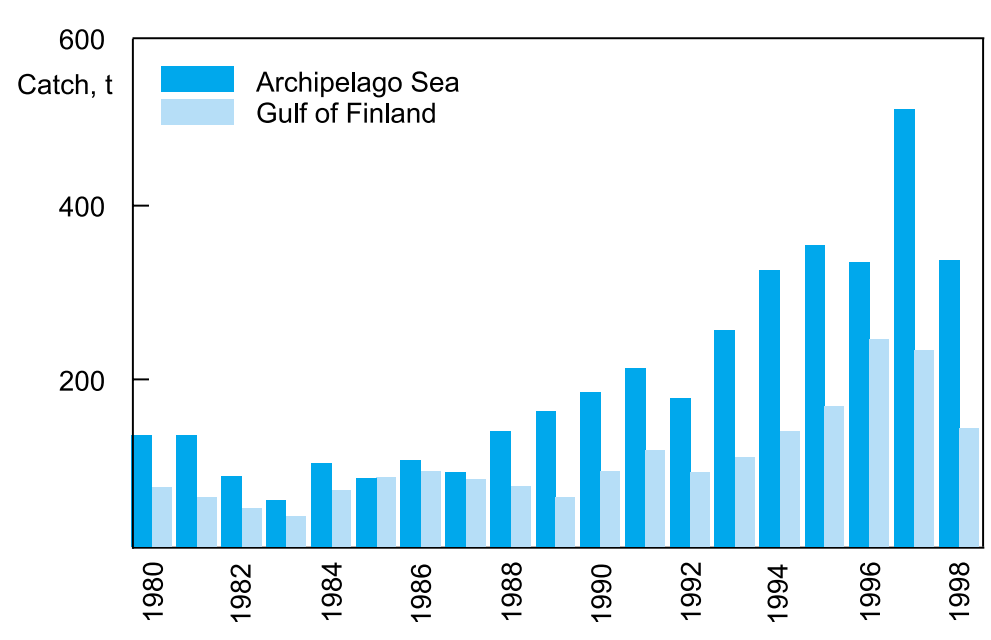

Fig. 9. I. The commercial catches of pikeperch (Stizostedion lucioperca) in the Archipelago Sea and in the Gulf of Finland during 1980-1998.

the most polluted areas. Bonsdorff et al. (1997a) monitored the fish community structure of an inshore area of the Åland Archiplago during 1975-1994. They showed that roach has increased from below 15 to ca. $45 \%$ of the total biomass, reflecting the ongoing eutrophication. In the Tvärminne region, western Gulf of Finland, a strong increase in roach stocks occurred place during the past 25 years. In 1975, roach was abundant only in the innermost areas of the local archipelago. In 1997, however, roach was the most abundat species in the innermost areas but also in the outer archipelago of Tvärminne. The growth rate of roach has decreased, indicating increased competition for food (Lappalainen et al. manuscript a). A gill net survey conducted in summer 1998 revealed that roach is abundant in the intermediate and outer archipelago throughout the whole northetn coast of the Gulf of Finland from Hanko to St Petersburg (Lappalainen et al. manuscript $b$ ). At present, slow increase in roach abundance appears to be occurring in the southern Archipelago Sea. The warm water fish community structure in Brunskär in the southern Archipelago Sea has been monitored since 1992 with gill nets. Roach was rare in the beginning of the period, but has become increasingly more common. (Ådjers et al. 1997). Unfortunately, general trends in roach catches are not available as roach is not accurately recorded in the commercial catches.

The sea area close to Helsinki city has been one of the most polluted along the Finnish coast, especially during the late 1960s and early 1970s when the wastewater load on the adjacent bay areas of Helsinki was at its maximum. The deterioration in water quality was clearly reflected in local fish communities. Anttila (1973) reported that the local whitefish, burbot (Lota lota) and pike (Esox lucius) populations had decreased or disappeared, and specially roach (Rutilus rutilus), ruffe (Gymnocephalus cernuus) and white bream (Blicca bjoerkna) populations had increased. Pike-perch (Stizostedion lucioperca) and bream (Abramis brama) populations also withstood pollution rather well. Later, during the past 20 years, the water quality in the bay areas of Helsinki has improved considerably but Lappalainen and Pesonen (1998) showed that the recovery in local fish communities in the bay area west of Helsinki has been very slow. Cyprinids and ruffe still accounted for about $80 \%$ of summer test fishing catches in 1997. It is evident that white bream is the cyprinid which withstands or even benefits most from extremely eutrophic conditions (Lappalainen and Pesonen 1998). It was earlier the dominant species in the test fishing catches from the most polluted part of the bay area west of Helsinki but more recently its proportion has decreased.

Lehtonen (1985) suggested that the pike-perch stocks have even increased in the southern coast of Finland due to eutrophication. The annual commercial catches of pike-perch from the southern coast have at least doubled during the past 20 years (Fig. 9.1) but the fishing effort has simultaneously also increased. However, summer 
temperature is an important factor detemining the year-class strength of pike-perch and perch (Perca fluviatilis) in our coastal areas (Wiik and Kuikka 1998, Böhling and Ådjers 1998). Strong year classes of pike-perch developed in 1988, 1991 and 1994. The peak in commercial catches of pike-perch was in 1997 as the year class of 1988 was still abundant whereas the year class of 1991 was recruited to fisheries (Wiik 1999). In the gill net survey conducted in 1998, the mean perch catches were approximately threefold higher near the western coast of the Gulf of Finland than in the eastern parts of the gulf (Lappalainen et al. manuscript b). The higher turbidity and resulting vertical narrowness of the littoral and the lack of a bladderwrack (Fucus vesiculosus) belt in the eastern gulf might restrict the food supply and abundance of some species such as perch. Koli et al. (1988) showed that macrocrustaceans were the most important food for perch $(10-20 \mathrm{~cm})$ in the western Gulf of Finland. The bladderwrack belt is important for macrocrustaceans and small fish, as it offers them both food and shelter. However, the general decline in bladderwrack in the southern coastal waters of Finland (Kangas et al. 1982) and the raise of the lower limit of the bladderwrack dominant zone (Kautsky et al. 1986, Bäck and Ruuskanen 2000) might have affected the fish populations. These changes on bladderwrack have been attributed to increased nutrient concentrations and subsequent changes in ecosystems.

Koivisto and Blomqvist (1988) studied the effects of fish farming on local fish communities in the Archipelago Sea. They showed that fish farming can cause changes in species composition towards a greater number of cyprinids, especially roach and white bream, in the immediate vicinity of the farms. Henriksson (1991) showed that ruffe and perch also occurred in large numbers close to the farms. In certain areas of the west coast, soil-induced acidification of rivers and estuaries has caused damage to local fish stocks. In the estuary of the river Kyrönjoki, for example, this has resulted in irregular fluctuations and decreases of burbot and perch stocks (Kjellman et al. 1994, Hudd et al. 1996).

\subsection{Marine species}

Baltic herring (Clupea harengus) is the most important marine species for Finnish commercial fisheries as it accounts over $80 \%$ of the weight of the annual total catch. During the 1990s the herring stocks have been on a normal level as measured by numbers of individuals. However, the growth of Baltic herring has decreased dramatically (Pönni 1998a). Weight-at-age of the Baltic herring was high in the beginning of the 1980s, but has since decreased, being now less than half of the earlier level (Fig. 9. 2). The biomass of the spawning stock has also decreased. Flinkman et al. (1998) showed that the biomass proportion of larger zooplankton preferred by herring has declined in the northern Baltic Sea due to slight

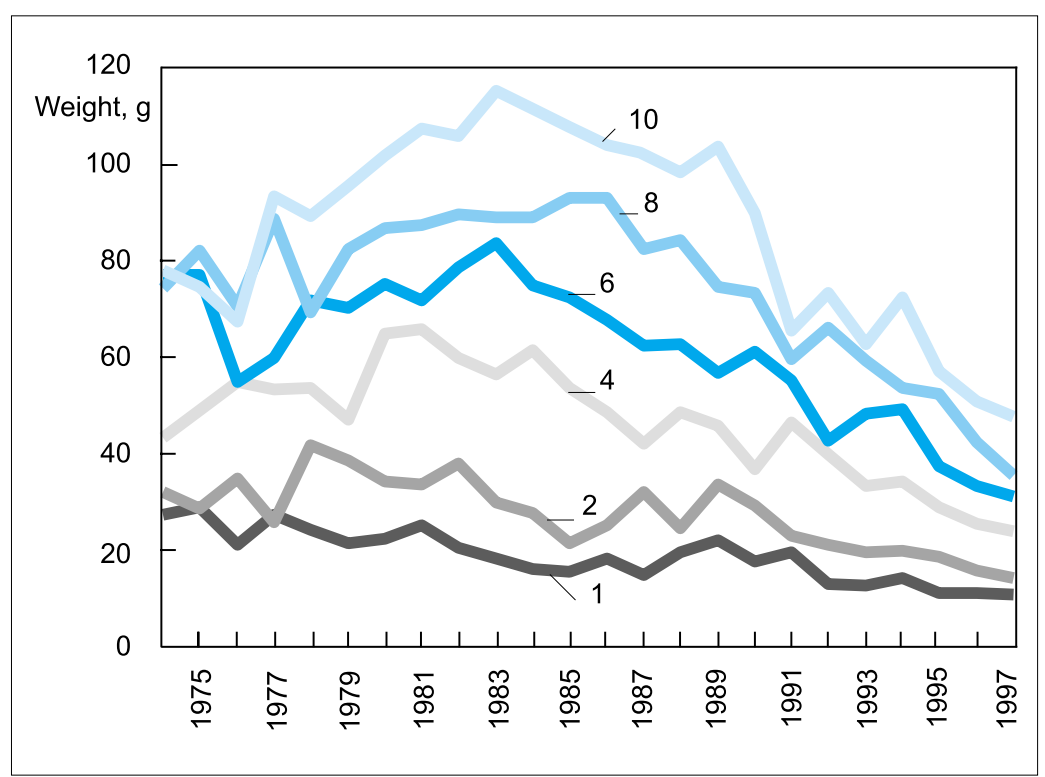

Fig. 9.2. The mean weight of herring at ages $1,2,4,6,8$ and 10 years in the Baltic Proper, Archipelago Sea and Gulf of Finland during 19741997 (Pönni 1998a). 
decrease in salinity, which is one reason for the recent decline in herring growth. The changes in water quality might have some local effects on the reproduction of herring, as the most important spawning grounds are located in the archipelago zone. Anttila (1973) reported that the spawning grounds of herring moved outwards from the shore due to increased pollution in the Helsinki region during the 1960s. Kääriä et al. (1988) showed that the eutrophication has had adverse effects on the spawning grounds of herring and on herring fisheries in the inner parts of the Archipelago Sea. However, Parmanne (1999) found no general changes in the spawning areas of herring in the Finnish coastal zone during the period 1974-1989. Normally, egg mortality of herring is considered to be less than $10 \%$. Rajasilta et al. (1989) observed far higher mortalities in situ in the inner Archipelago Sea, in some spawning substrates even exceeding 90\%. However, the potential consequences of the changes in spawning grounds and nursery areas on the stock level are unknown.

Flounder (Platichtys flesus) and turbot (Psetta maxima) are also marine species spawning in the archipelago zone. Aarnio and Bonsdorff (1997) reported that the increasing eutrophication of the coastal waters of the Baltic Sea favours prey species (e.g. Ostracoda, Hydrobia spp.) that are non-digestable for juvenile flounder. Furthermore, roach feed mainly on molluscs in the southern coastal waters of Finland (Rask 1989, Lappalainen et al. manuscript a) and thus the increased roach stocks utilize the same food resources than flounder. At the end of 1990s the stocks of cod (Gadus morhua) in our coastal waters were very weak (Aro 1998) and, on the other hand, the stocks of sprat (Sprattus sparttus) were abundant (Pönni 1998b). The main spawning areas of these two marine species are situated in the southern
Baltic Sea and the state of the stocks is largely determined by the conditions in the spawning areas. The recruitment of these species is mainly affected by large-scale changes, such as salinity, oxygen conditions (Aro 1998) and possibly the general eutrophication of the Baltic Sea. The fishing pressure on the cod stocks in the southern Baltic is too high as compared to the current status of the stocks (Aro 1998).

\subsection{Direct harmful effects on fisheries}

Eutrophication and pollution of coastal water has caused some direct harmful effects on fisheries. Strong fouling or sliming of passive gear - especially gill nets - is the most prominent problem in recreational fisher caused by eutrophication. Strong fouling or sliming of gear was experienced by $67-86 \%$ of all recreational fishermen in a mail survey conducted in three study areas in the Gulf of Finland (Lappalainen and Pönni 1996). This is also a wellknown problem e.g. in commercial salmon trap fisheries. It causes extra work for fishermen and can decrease the efficiency of gear. The water currents and waves carry loose filamentous macroalgae and loose brown algae (Fucus vesiculosus) to passive gear, especially to those set on the bottom. The filamentous green alga, (Cladophora glomerata), is the dominant littoral macroalgae in the northern Baltic Sea, and the growth of it has increased due to eutrophication of coastal areas. The increased production of filamentous algae has even led to a strong increase in benthic drifting algal mats, covering large areas of intermediate depths (Bonsdorff et al. 1997b). The increased primary production of small algae causes further sliming of gill nets and traps, and in the Gulf of Finland mass occurrences of the alien predaceous 
cladoceran (Cercopagis pengoi) during the late 1990s have also had similar effects on passive gear.

Off-flavours or -odours in fish have been a common problem in some severely polluted areas (Fig. 9.3). For example, Paavilainen et al. (1985) showed that off-flavours in bream and pike were common in some of the most polluted areas close to Kotka, the eastern Gulf of Finland, but they associated these mainly with the effects of pulp and paper mill effluents. In the Helsinki region, off-flavours in fish were obviously more common over 20 years ago when the municipal waste waters were discharged into inner bays around Helsinki. According to a local questionnaire carried out in 1969, as many as every third recreational fisherman had noted clear off-flavours in bream, perch, pike-perch or roach caught in the Helsinki region (Anttila 1973). In a survey conducted in 1994 only $5-10 \%$ of recreational fishermen reported off-flavours or -odours in fish

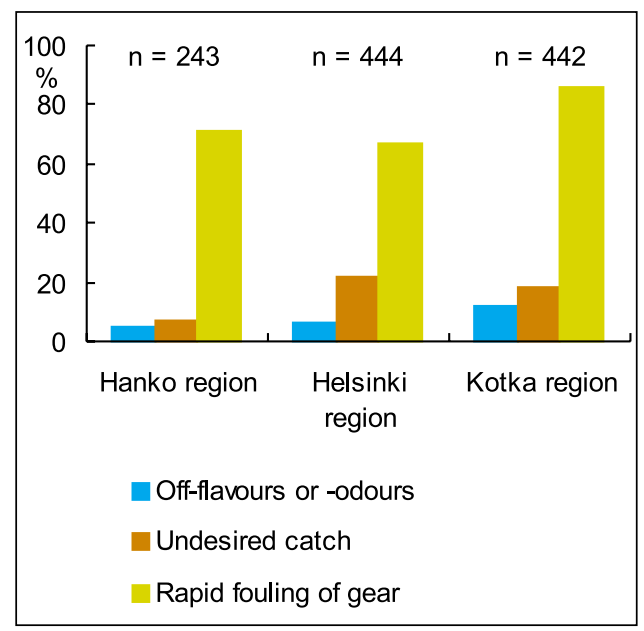

Fig. 9.3. Harmful environmental effects.

caught from three study areas in the Gulf of Finland (Lappalainen and Pönni 1996) and 5-20\% indicated a high abundance of less wanted species, such as cyprinids, ruffe and smelt (Osmerus eperlanus) in gill net catches.

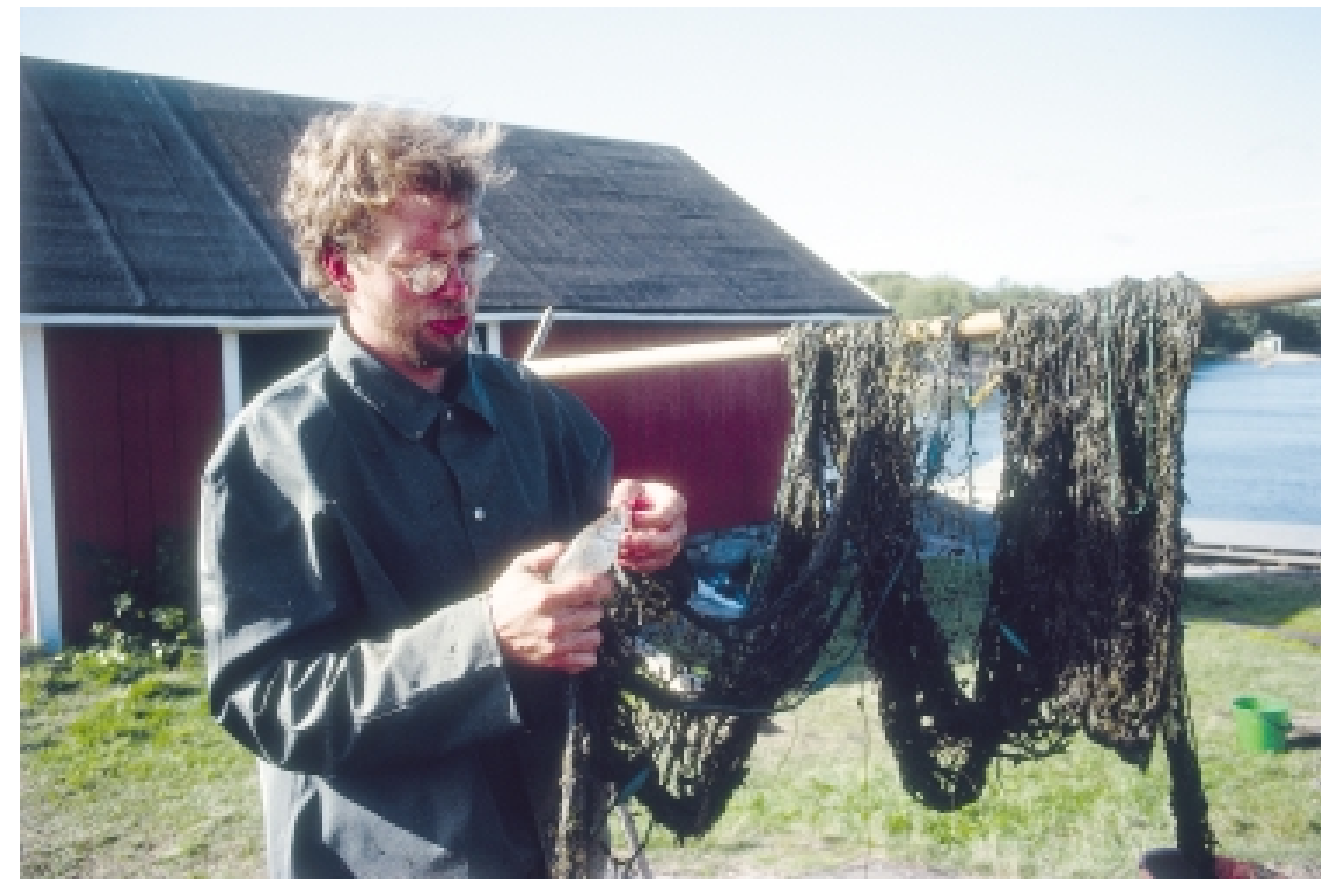

Fouling of gear is caused either by drifting filamentous macroalgae or plankton.

Photo R. Yrjölä 


\section{Harmful substances}

Markku Korhonen, Matti Verta, Viveka Backström

\section{I0.I Heavy metals}

\section{IO.I.I Sediment}

There are considerable variations and regional differences in the concentrations of heavy metals in the surface sediments of the Gulf of Finland and the Gulf of Bothnia (e.g. Leivuori 1998). The distributions of three non-essential and toxic metals $(\mathrm{Pb}, \mathrm{Cd}, \mathrm{Hg})$ show a decreasing trend from north to south in the Gulf of Bothnia, and from east to west in the Gulf of Finland. The mean concentrations of lead in the surface sediment were $50 \mathrm{mg} \mathrm{kg}^{-1}$ dry weight (dw) in the Gulf of Finland, 79 $\mathrm{mg} \mathrm{kg}^{-1}$ in the Bothnian Bay and $42 \mathrm{mg}$ $\mathrm{kg}^{-1}$ in the Bothnian Sea. Mean concentrations for cadmium were 1.1, 0.9 and $0.4 \mathrm{mg} \mathrm{kg}^{-1} \mathrm{dw}$ and for mercury $0.1,0.3$ and $0.1 \mathrm{mg} \mathrm{kg}^{-1} \mathrm{dw}$.
The concentrations of mercury are highest in the Bothnian Bay and of cadmium in the Gulf of Finland. Lead and mercury concentrations are lower in the Baltic Proper than in the Gulf of Finland and the Gulf of Bothnia (Leivuori 1998). The mean concentrations in the open sea area are within the range typically measured in the Baltic Sea and clearly higher compared with the pre-industrial level for all these three metals (Table 10.1).

Several industrial plants are located in the coastal area of Finland. This is usually reflected as elevated metal concentrations in the sediment in areas close to their effluent sources. The individual maximum metal concentrations in the surface sediments are shown in Table 10.1 (Finnish maximum values in 1990s). Clearly higher concentrations than "typical" are measured for each metal on some occasions.

Table 10.I. Examples of trace metal concentrations in sediments of the Baltic Sea ( $\mathrm{mg} \mathrm{kg}^{-1} \mathrm{dry}$ weight), modified from Sternbeck et al.(1999). Present extremes represent Finnish data from surface sediments during the 1990s.

\begin{tabular}{lrrrr}
\hline Metal & Preindustrial & Typical & $\begin{array}{r}\text { Baltic } \\
\text { extreme }\end{array}$ & $\begin{array}{r}\text { Present } \\
\text { extreme }\end{array}$ \\
\hline $\mathrm{Cd}$ & $0.2-0.8$ & $0.3-5$ & 100 & 8.2 \\
$\mathrm{Cr}$ & $20-50$ & $20-200$ & $800, \mathrm{II000}$ & 128 \\
$\mathrm{Cu}$ & $30-50$ & $30-80$ & 1200 & 450 \\
$\mathrm{Hg}$ & $0.02-0.04$ & $0.05-0.8$ & 100 & 13.6 \\
$\mathrm{~Pb}$ & $4-30$ & $40-200$ & 25000 & 240 \\
$\mathrm{Zn}$ & $70-150$ & $150-500$ & 50000 & 920 \\
\hline
\end{tabular}

Data compiled from Swedish EPA 1991, Holm 1988; Östlund et al. 1998; Borg and Jonsson 1996; Perttilä and Brygman 1992, Leivuori and Niemistö 1995, Lapp and Balzer 1993. Finnish maximum values in 1990s are from Kyröläinen 1995, Piiroinen 1992a, Kalliolinna and Aaltonen 1995, Jumppanen 1993, Pesonen 1988, Varmo and Riiheläinen 199I, Lehtoranta, not published, Partanen 199I, Miettinen et al. 1994. 
However, these are far below the Baltic extreme concentrations.

For mercury notably high mean concentrations can be seen in the river Kokemäenjoki and its estuary, with a maximum of $13.6 \mathrm{mg} \mathrm{kg}^{-1}$ (Piiroinen 1992a). This area has a history of high heavy metal loads from the industry located along the river. Metals have been emitted e.g. from a chlor-alkali plant, a fertilizer plant, a copper smelter and a leather factory. The load of metals has decreased considerably since the 1970s and 1980s. Other regions with elevated mercury concentrations are Oulu (a chlor-alkali plant), Kokkola (Kalliolinna and Aaltonen 1995) with fertilizer and chemical production (see also section 8.2.2) and regions with pulp and paper production (eg. Oulu, Rauma, Kotka). In these locations mercury partly originates from its former use as a fungicide.

Concentrations of cadmium in sediments from all locations are typical for the Baltic Sea, with no extreme values reported. However, elevated cadmium concentrations compared with preindustrial levels can be seen in most locations under monitoring.

The importance of point-source loads of lead from industries is marginal for the total lead flux to the Baltic compared to atmospheric deposition and the loads from rivers (Enckell-Sarkola et al.1989). Elevated concentrations can be seen in the Helsinki region due to traffic emissions (Varmo and Riiheläinen 1991) and near steel plants in Uusikaupunki (Partanen 1991) and Koverhar (Miettinen et al. 1994).

The highest copper concentrations in bottom sediments occur in Rauma, where machinery plants and docks are located (Lounais-Suomen vsy 1995). High copper concentrations are also found in the river Kokemäenjoki sediments and in sediments from the Helsinki area (Piiroinen 1987, 1992a, Pesonen 1988).

Generally, highest concentrations of chromium have been measured near a stainless steel plant in Tornio. The emissions of chromium from the plant have increased in recent years compared to the early 1990s (Finnish Environment Institute). The sediments off Rauma and in the river Kokemäenjoki (leather factory) also have local high chromium concentrations (Piiroinen 1992a, Lounais-Suomen vsy 1995).

The titanium dioxide factory in Pori began operations in 1961. This factory uses sulfuric acid and an iron ore to produce titanium oxide. The discharges of sulfuric acid and metals have decreased as a result of improvements in waste water management. Consequently, concentrations of titanium and vanadium in surface sediments have decreased since the early of the 1990s (Patrikainen 1991).

\section{I0.1.2 Zoobenthos}

Metal emissions from industries are usually reflected in higher concentrations of different metals in zoobenthos dwelling in the contaminated area. Heavy metal concentrations in Baltic mussel (Macoma balthica) have been used for monitoring purposes in the sea areas off Vaasa, Rauma, Koverhar and Pori (Häkkilä 1985, Kokemäenjoen vsy 1995, Kyröläinen 1996, Miettinen et. al. 1993). Although, according to these authors, Macoma in the sea area off Vaasa show increased concentrations of chromium $\left(1.8-4.1 \mathrm{mg} \mathrm{kg}^{-1} \mathrm{dw}\right)$ and lead (0.9-1.7 $\mathrm{mg} \mathrm{kg}^{-1} \mathrm{dw}$ ) and Macoma from Koverhar increased concentrations of cadmium (1.3-2.3 mg kg${ }^{1}$ dw, Lounais-Suomen vsy 1995; Kalliolinna and Aaltonen 1995), none of these concentrations can be considered as extremely high. Reference data from the Baltic Sea area is scarce, but comparison with extensive data from blue muscle (Mytilus edulis) from the Arctic indicates that none of these concentrations differ significantly from background variation (data from the Arctic is on a wet weight basis, HELCOM 1996, AMAP 1998). Mercury concentrations in blue mussel from the river 


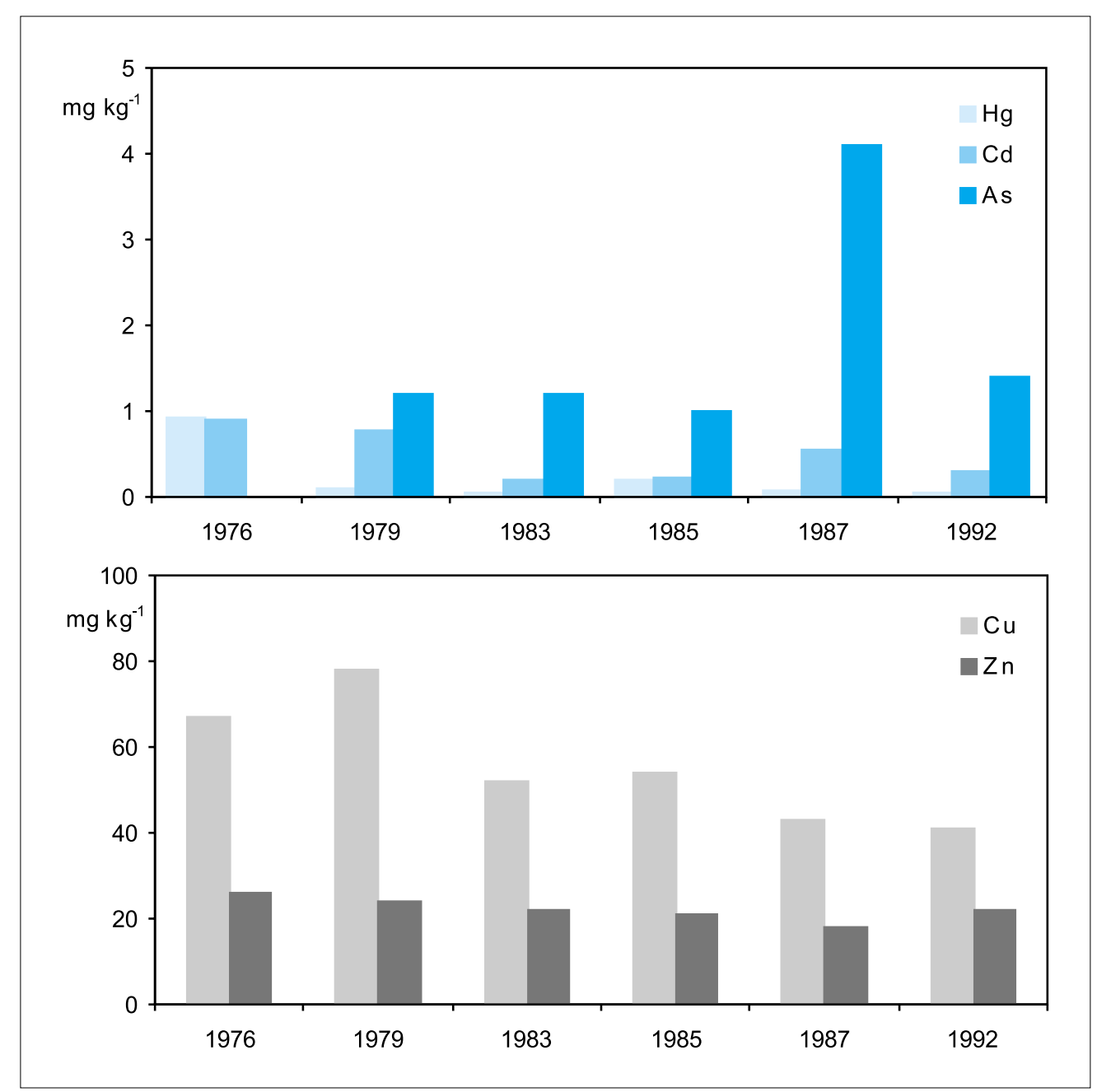

Fig. 10.I. Concentration of some heavy metals in Saduria entomon from the sea area off Kokkola during 1976-1992 (Data from Kalliolinna \& Aaltonen, 1995).

Kokemäenjoki estuary indicate contamination (0.17-1.24 $\mathrm{mg} \mathrm{kg}^{-1} \mathrm{dw}$ ) compared with $\mathrm{Hg}$ in blue mussel in the Arctic $\left(<0.003-0.061 \mathrm{mg} \mathrm{kg}{ }^{-1} \mathrm{ww}\right.$, AMAP 1998) or from the Kattegat Swedish west coast region $(<0.03 \mathrm{mg}$ $\mathrm{kg}^{-1} \mathrm{ww}$, HELCOM 1996).

At certain locations Saduria entomon is used for monitoring of metals in biota. Fig. 10.1 shows a decrease of copper, cadmium and mercury but not of $\mathrm{Zn}$ and As in Saduria caught in the sea area off Kokkola from 1976 to 1992 compared to Saduria from a clean area, Pyhämaa (Kalliolinna and Aaltonen 1995, Figs. 10.1 and 10.2).

\subsection{3 $\mathrm{Hg}$ in fish}

Mercury concentrations in fish in areas with high $\mathrm{Hg}$ pollution during the 1960s and 1970s have decreased considerably. Mercury concentrations in pike muscle have decreased from a level of 1 to $2 \mathrm{mg} \mathrm{kg}^{-1}$ to below $1 \mathrm{mg} \mathrm{kg}^{-1}$, which is the maximum level for human consumption, in all areas under monitoring. At the beginning of the 1990s the mean concentrations of mercury in all polluted coastal areas were $0.63 \mathrm{mg}$ $\mathrm{kg}^{-1} \mathrm{ww}$ (min 0.31, max 1.39), which is only somewhat higher than in reference areas $0.52 \mathrm{mg} \mathrm{kg}^{-1} \mathrm{ww}$ (min 0.17, 


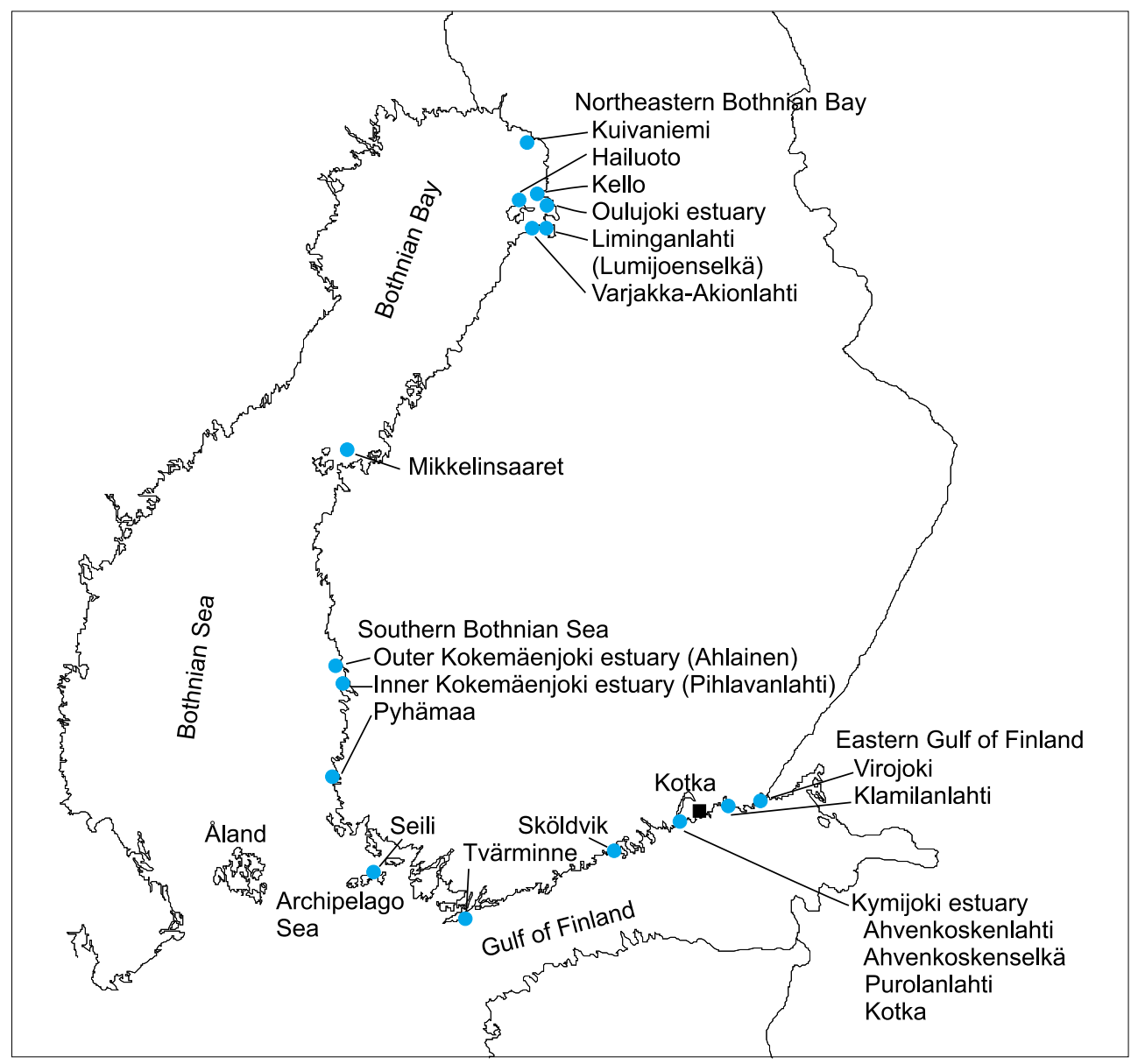

Fig. 10.2. Localities of the sampling sites of harmful substances in this study.

max 0.90). No significant change can be detected during the 1990s in most areas, except for a small decrease at the most contaminated stations (Figs. 10.2, 10.3).

Mercury data for other predatory fish species is rare, but indicates that particularly in burbot (Lota lota) and perch (Perca fluviatilis) the level of 0.5 $\mathrm{mg} \mathrm{kg}^{-1}$ (the maximum level for other species than pike) may be exceeded in older and larger individuals in areas with former $\mathrm{Hg}$ pollution (e.g. Verta et al.1999c).
The mercury concentrations of Baltic herring (Clupea harengus) in Finnish sea areas are below $0.05 \mathrm{mg} \mathrm{kg}^{-1} \mathrm{ww}$ in the Baltic Proper and in the southern area of the Gulf of Finland (HELCOM 1996, Jankovski et al. 1996, Leivuori et al. 1997). For monitoring purposes two-year, non-mature females are used. The highest levels of mercury are found in the eastern part of the Gulf of Finland. 


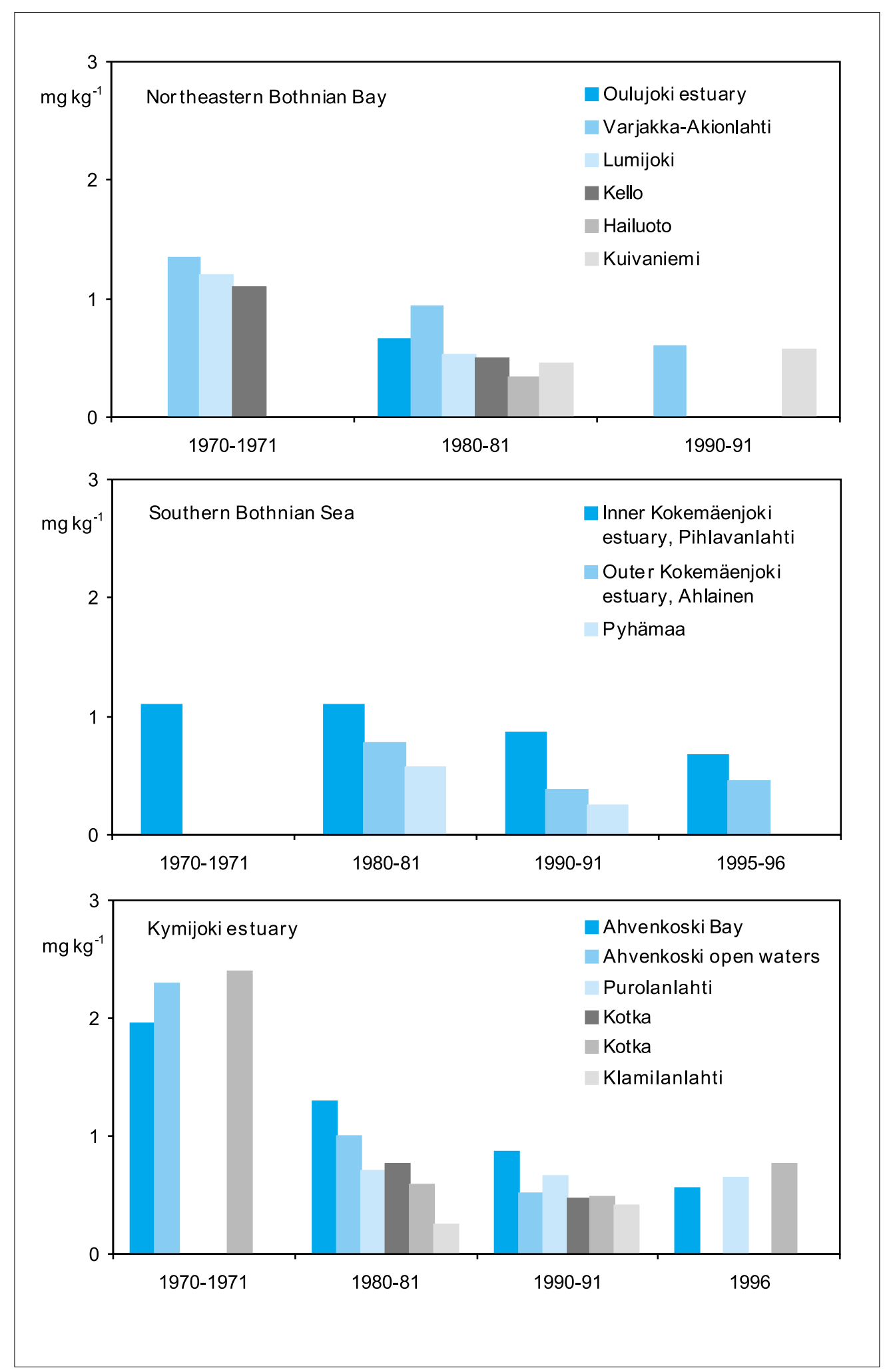

Fig. 10.3. The mercury concentrations in pike in coastal areas. (FEI monitoring data. Piiroinen 1992, Hakaste and Piiroinen 1997) 


\section{0.2 Organic pollutants}

\subsection{Sediment}

The concentrations of polychlorinated dioxins and furanes (PCDD/Fs) varied from 130 to $680 \mathrm{pg} \mathrm{g}^{-1}$ dry weight, (dw) ITEQ in the vicinity of the vinylchloride monomer production plant at Sköldvik on the Gulf of Finland (Vartiainen et al. 1997) and up to $1820 \mathrm{pg} \mathrm{g}^{-1}$ ITEQ in a sediment core (Isosaari et al. 1999). These are the highest reported sediment PCDD/F concentrations in Finnish coastal areas. In the Bothnian Bay about $350 \mathrm{pg} \mathrm{g}^{-1}$ dw ITEQ was reported close to a pulp and paper mill in Pietarsaari.

Up to 6-7 $\mathrm{kg}$ of PCDD/Fs (as ITEQ) has ended up in the Gulf of Finland since 1940 in the estuary of the river Kymijoki, south-eastern Finland, mainly due to production of the wood preservative Ky-5 in the upper region of the river (Verta et al. 1999a,b). This is clearly seen as increased PCDD/Fs concentrations in surface sediments (up to $200 \mathrm{pg} \mathrm{g}^{-1} \mathrm{dw}$ ITEQ). The load of PCDD/Fs to the estuary has decreased only slightly during the past 30 years, as measured from the sediment profile (Verta et al. 1999c). Increased concentrations of polychlorinated phenols (PCPs) and polychlorinated diphenyl ethers were also measured (Verta et al. $1999 a, c)$. As a result of the decreased use of chlorine in bleaching, and other improvements in waste-water management, a greatly decreased discharge of chlorinated organic compounds can be noted.

The decreased discharge of organochlorines from pulp mills is reflected as decreased concentrations of these compounds in sediments close to pollution sources. Palm and Lammi (1995) studied the deposition of AOX and EOX (Extractable Organic Compounds) and different organochlorines specific to bleaching effluents at some stations near a pulp mill in Pietarsaari. The use of chlorine chemicals started in 1976.
Since 1986 effluent has been treated in a secondary activated sludge plant. Presently oxygen and chlorine dioxide are used for bleaching. A clear change in the amount of sedimented chlorinated organic material, measured as EOX or as chlorophenoles, could be seen, reflecting changes in the bleaching processes.

The concentrations of EOX (30$180 \mathrm{mg} \mathrm{Cl} \mathrm{kg}^{-1}$ ) in top sediments from stations close to pulp mills in Kotka, Kemi, Pietarsaari and Rauma in the 1990s (after process changes had been made in the pulp mills) are considerably lower than were reported in the 1980s when chlorine bleaching was generally used. EOX-concentrations of up to $2000 \mathrm{mg} \mathrm{Cl} \mathrm{kg}^{-1}$ were reported for sediments near pulp mills in Sweden (Södergren 1989).

At present, natural organohalogen production appears to be the major source of the EOX in the Gulf of Finland. Specific organochlorine and pulp mill effluents are responsible for only a minor part of the total EOX. EOX is produced predominantly during the spring diatom bloom. As anthropogenic input decreases, the share of natural production in the total EOX budget will increase (Kankaanpää 1997).

\subsubsection{Zoobenthos}

Generally concentrations of PCBs and DDTs in Baltic mussel (Macoma balthica) are higher (2-3 fold) compared with the few available analysis in Macoma sp. in the Arctic area in Kara Sea, Russia (PCB 3.5 and DDT 1.3 ng g $^{-1}$ ww, AMAP 1998). Even higher concentrations have been measured elsewhere in the Baltic; in the Swedish east coast (Tema Nord 1994) and in the southern area of the Gulf of Finland (Roots 1996). According to monitoring data from two stations both PCB and DDT concentrations are somewhat lower in the southern Bothnia Bay (Mikkelinsaaret) than in the western Gulf of Finland (Tvär- 


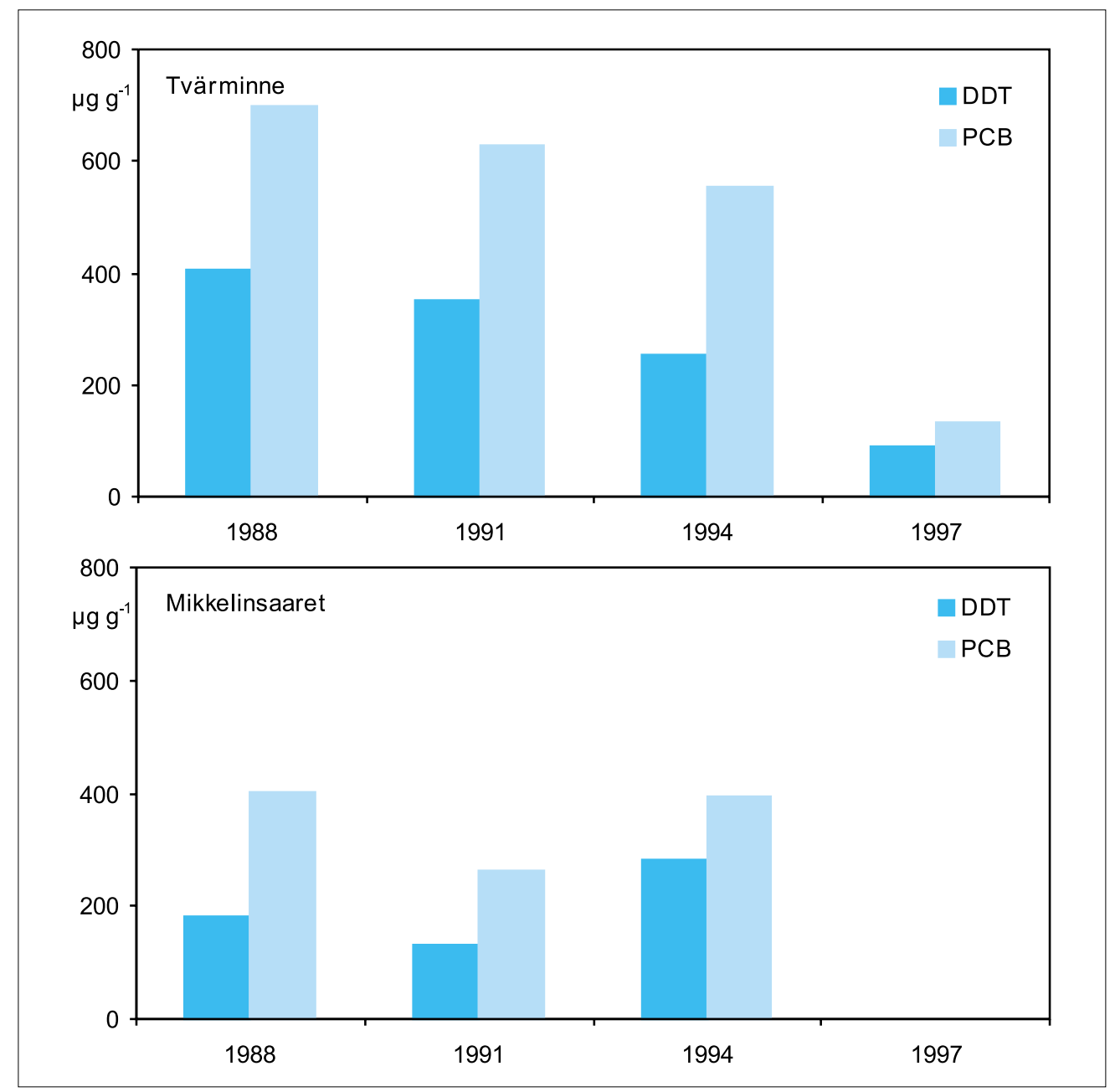

Fig. 10.4. The concentratins of PCB and DDT (ug/g ww) in Macoma balthica from 1988 to 1997 in the coastal areas Tvärminne (Gulf of Finland) and Mikkelinsaaret (Gulf of Bothnia).

minne) (Fig. 10.4). In Tvärminne PCB and DDT concentrations were considerably lower in 1997 than in the early 1990 s and particularly in the late 1980s.

No decreasing trend of PCB and DDT was observed in $M$. balthica in the Mikkelinsaaret area from 1988 to 1994, but further development is uncertain due to lack of data (Figs. 10.2, 10.3). The area is at the limit of distribution of $M$. balthica in the diminishing salinity, and makes interpretation of the monitoring results difficult. The reason for the increase in total DDT from 1988 to 1994 is mainly due to the isomers DDD and DDT. However, the isomer DDE still dominated in mussels from the Gulf of Bothnia in 1994. The dominating PCB congeners have been 153 and 138 (IUPAC).

\subsubsection{Fish}

\section{PCB and DDT}

Annual monitoring of PCB and DDT concentrations in young Baltic herring Clupea harengus (two-year, non-mature females) before their migration to feeding areas has been conducted by the Finnish Marine Research Institute. The PCB and DDT levels have been rather constant and somewhat higher (range 6-15 ng g ${ }^{-1}$ ww for PCB and 2-16 for DDT compared with those in Atlantic herring (Clupea harengus) in the Arctic Sea (Iceland) ( PCB 3.8-11 $\mathrm{ng} \mathrm{g}^{-1} \mathrm{wW}$ and DDT 2.7-8.1 $\mathrm{ng} \mathrm{g}^{-1} \mathrm{ww}$, AMAP 1998). Only slight decreases in concentrations of both PCB and DDT have been observed since the late 1980s (Finnish Marine Research Institute). 


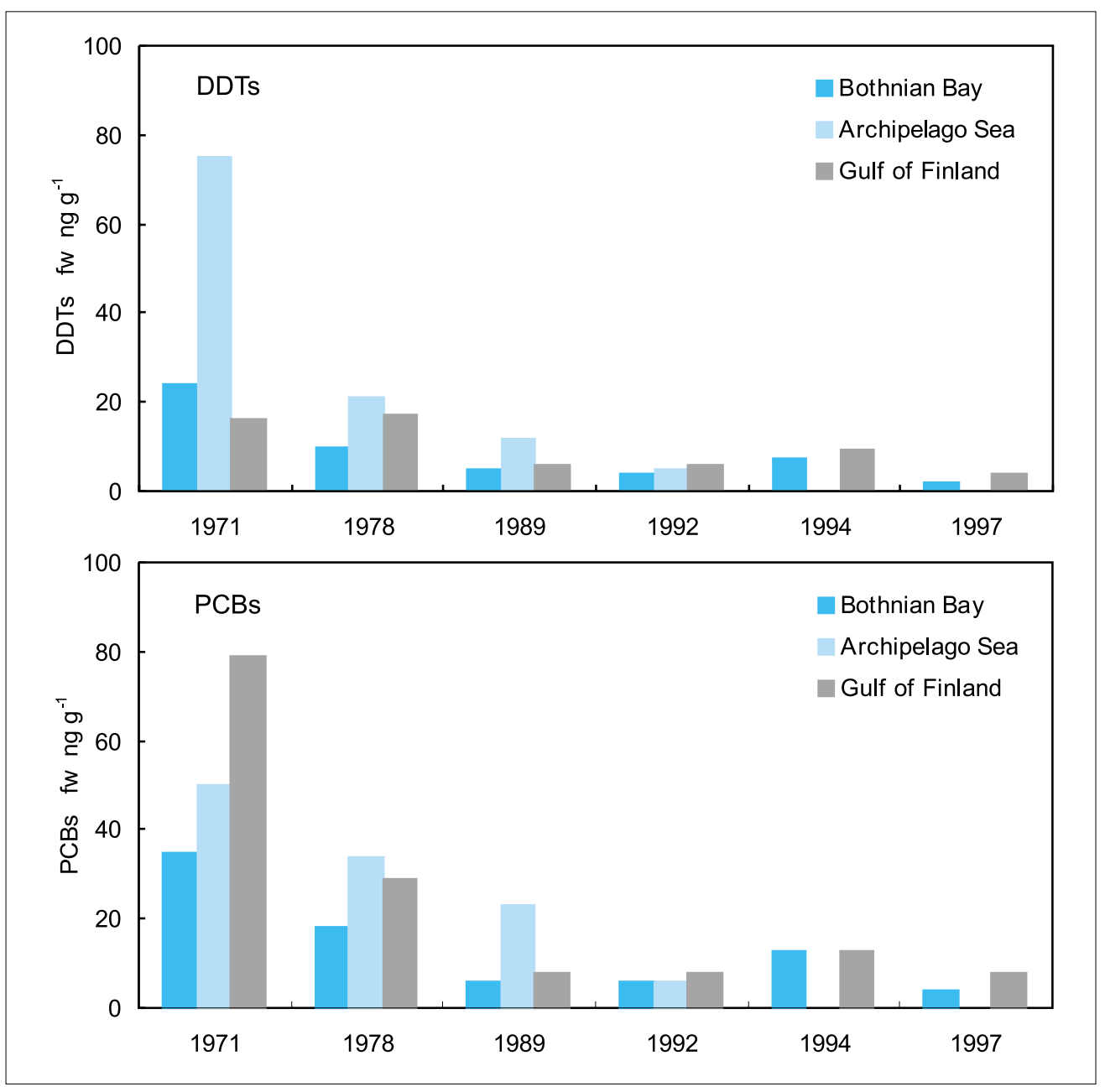

Fig. 10.5. Concentrations of PCB and DDT $\left(\mathrm{ng} \mathrm{g}^{-1} \mathrm{ww}\right)$ in pike in the Bothnian Bay, Archipelago Sea and Gulf of Finland from 197 I to 1997.

Areal differences are small, but indicate higher concentrations in the eastern Gulf of Finland.

The long-term monitoring data by the Finnish Environment Institute show that PCB and DDT concentrations in pike (Esox lucius) in the Bothnian Bay, the Archipelago Sea and the Gulf of Finland were clearly lower in the 1990s compared to the 1970s or the 1980s and at a relatively constant level (PCB less than $15 \mathrm{ng} \mathrm{g}^{-1} \mathrm{ww}$ and DDT less than $10 \mathrm{ng} \mathrm{g}^{-1} \mathrm{ww}$, Fig. 10.5). Significant areal differences were not found either in PCB or in DDT concentrations from different sea areas. Concentrations were only slightly higher in the Gulf of Finland than in the Archipelago Sea or in the Bothnian Bay. The latest results from 1997 show the low- est concentrations. The dominating PCB congeners have been 153 and 138 (IUPAC). The lowest congeners of PCB were the less chlorinated 28, 31 and 51. DDE dominated in the total DDTs. The pike studied were about 5-7 years old and their total weight usually ranged from 800 to $1200 \mathrm{~g}$. A comparison of the PCB and DDT concentrations in pike and Baltic herring on a fat weight basis shows no difference.

\section{Dioxins and furans}

Clearly older (age 4-9 years) Baltic herring was monitored by the Finnish Environment Institute for PCDD and PCDF concentrations in muscle. Concentrations ranged from 0.3 to $3.6 \mathrm{pg} \mathrm{g}^{-1}$ ww calculated as ITEQ (Fig. 10.6). Sim- 


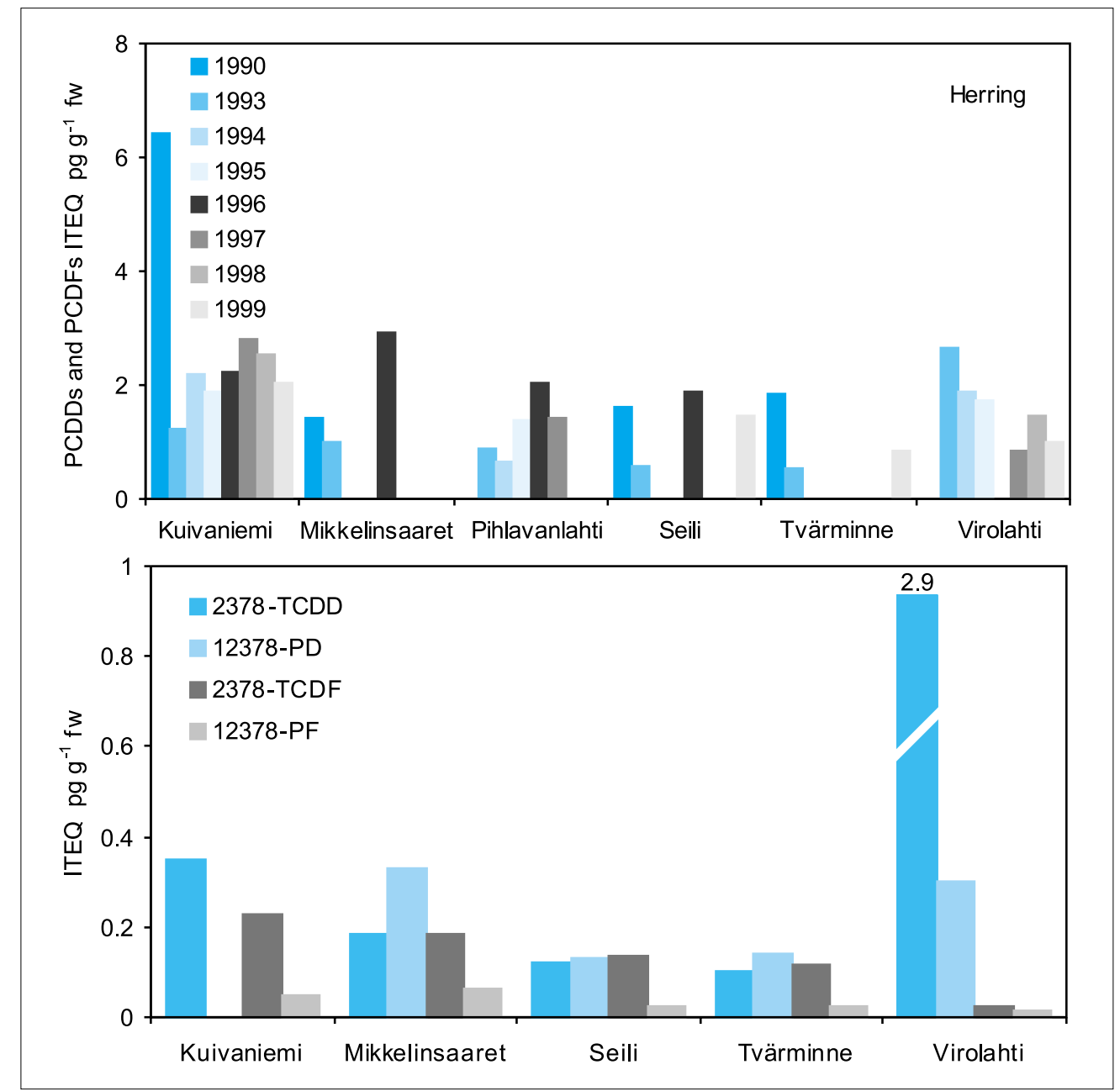

Fig. 10.6. Concentrations polychlorinated dioxins (PCDD) and furans (PCDF) ( $p g g^{-1}$ ITEQ ww) in Baltic herring in eight coastal areas from 1990 to 1999.

ilarly to $\mathrm{PCB}$, concentrations were highest in the eastern Gulf of Finland (Hamina-Virolahti). Generally higher levels were measured in 1993-1996 compared to 1990, and at the Kuivaniemi station in the NW Bothnian Bay with most frequent data a clear increasing trend was observed (Figs. 10.2, 10.6). Concentrations were at the same level as in Baltic herring of similar age in the Baltic Proper (HELCOM 1993).

The concentrations of PCDD/Fs and PCBs tend to increase in the muscle of Baltic herring with age (Vartiainen et al. 1997, HELCOM 1993). Unlike HELCOM monitoring Vartiainen et al. used unskinned fish filet, which gives a notably higher PCDD/F and PCB concentrations enabling a more accurate estimate for human exposure. In the age classes greater than eight years, the increase in both PCDD/F and PCB concentrations is significant. In old fish (12-16 years) PCDD/F concentrations as high as 15-20 ITEQ pg g $^{-1}$ wW and PCB $200 \mathrm{ng} \mathrm{g}^{-1} \mathrm{Ww}$ were measured by Vartiainen et al. (1997). Similarly, Verta et al. (1999c) reported a concentration of $15 \mathrm{pg} \mathrm{g}^{-1}$ ITEQ (ww) in a homogenized Baltic herring sample from the eastern Gulf of Finland in 1996 consisting of age classes 5-10 years.

Korhonen et al. (1999) reported concentrations from 7 to $8 \mathrm{pg} \mathrm{g}^{-1}$ (ww) ITEQ in Baltic salmon (Salmo salar) in the eastern Gulf of Finland. These concentrations are in agreement with those reported by Vuorinen et al. (1993) and 
Vartiainen et al. (1997). The most dominant congeners were 2,3,4,7,8-PCDF and 1,2,3,7,8-PCDD in salmon. In all other species the dominating congener was 2,3,7,8-TCDD.

Perch (Perca fluviatilis), pike, bream (Abramis brama), burbot (Lota lota) and pike-perch (Stizostedion lucioperca) show clearly lower concentrations of $\mathrm{PCDD} / \mathrm{Fs}$ than in Baltic herring; less than 1 pg g $^{-1}$ ww ITEQ, (Korhonen et al. 1999). The concentrations of PCDDs and PCDFs in pike (length $50-60 \mathrm{~cm}$ and age 6-8 years) muscle were less than 0.5 ITEQ $\mathrm{pg} \mathrm{g}^{-1} \mathrm{ww}$ in the beginning of the 1990s. Only in 1992 in Ahvenkoskenlahti Bay did the concentration almost exceed 1 ITEQ $\mathrm{pg} \mathrm{g}^{-1} \mathrm{ww}$. When comparing the concentrations on wet weight basis, the concentrations were about 10 times higher in Baltic herring than in pike. This is due to the lipid content in pike (about $0.4 \%$ ) being about ten times lower than in Baltic herring (about $5 \%$ ), while the concentrations of dioxins in lipid were at the same level.

The Nordic Council of Ministers recommended a Tolerable Daily Intake (TDI) of 35 TEQ pg kg-1 body weight/ week. According to these recommendations an individual weighing $70 \mathrm{~kg}$ could have a daily consumption of about $350 \mathrm{~g}$ fish muscle with a PCDD/F concentration of 1 ITEQ $\mathrm{pg} \mathrm{g}^{-1} \mathrm{ww}$. If old Baltic herring or salmon were used, with PCDD/F concentrations of 10-20 pg g $^{-1}$ (ITEQ) and equal PCB concentrations (ITEQ) the maximum daily consumption should be 40 times lower (less than $10 \mathrm{~g}$ fish muscle) in order to remain below the guideline.

Chlorophenols originating from pulp mill were determined from pike and roach in the sea area off Kotka (Heitto and Anttila-Huhtinen 1995). The concentrations in pike varied from 125 to $205 \mathrm{ng} \mathrm{g}^{-1} \mathrm{fw}$ and in roach from 55 to $70 \mathrm{ng} \mathrm{g}^{-1} \mathrm{ww}$. Concentrations of trichloroguaiachols in the bile of perch were studied in Kemi. These bioaccumulating compounds are specific for bleached pulp effluents and accumulate in the bile. Very low amounts were observed in the fishes studied near Kemi. The levels of 345-TCG $(3,4,6-$ trichloroguaiachol) were $1-6 \mathrm{ng} \mathrm{g}^{-1} \mathrm{fw}$ and of 456-TCG below $1 \mathrm{ng} \mathrm{g}^{-1}$. These concentrations are very low compared with up to much as $50000 \mathrm{ng} \mathrm{g}^{-1} \mathrm{ww}$ 345-TCG found in the bile of perch dwelling $2 \mathrm{~km}$ from Norrsundet, a large mill with conventional chlorine bleaching, in the 1980s (Södergren 1989).

The M74 syndrome appears as yolk-sack mortality and causes high mortalities in salmon returning to Finnish rivers. Yolk-sac mortality in salmon has been about $70 \%$ in the river $\mathrm{Si}$ mojoki and less than $30 \%$ in the river Kymijoki in the 1990s (Vuorinen et al. 1993, 1997). Simultaneously with the mortality increase, the concentrations of PCDD/Fs and expecially coplanar PCBs increased in salmon in the early 1990s as compared to the end of the 1980s. It is not yet clear whether the environmental pollutants or other reasons (carotenoids, thiamine, changes in the abundance of important prey species) are responsible for the yolk-sac mortality of salmon. It has been hypothesized, however, that due to the diminished growth rate of both sprat and herring during the 1990s the salmon has changed its diet to older prey with higher PCDD/F concentrations, which may have precipitated the M74 syndrome outbreak (Keinänen et al. 2000).

Developmental disorders in the gonads of burbot and to a smaller extent in other fish species have been reported along the northern coast of the Bothnian Bay. The fish in this area have been exposed to a large number of chemicals especially from pulp mills. No detailed explanation is available for spawning incapacity and no clear cause/effect relationship between pollution and reproduction disorders has been found (Pulliainen et al. 1999). 


\section{I0.3 Oil and other contaminants from the petrochemical industry}

The sea area off Porvoo is loaded by effluents from an industrial complex outside Sköldvik. The complex consists of an oil refinery and petrochemical plants, the products of which include phthalates, styrene and PVCs. The waste waters are treated by physiochemical and biological methods. The waste waters from the petrochemical industry complex contain oil, sulphides, mercaptans, cyanide, hydrocarbons, phthalates, phenols and heavy metals.

Oil, phenols, chlorinated hydrocarbons and phthalates are monitored in water samples from areas close to the waste water effluent sites. Oil concentrations in water samples have decreased considerably since the 1970s, when concentrations of more than 1000 $\mathrm{mg} \mathrm{l}^{-1}$ were not uncommon. Generally, concentrations in the 1980s and 1990s have been under the detectable limit of $100 \mathrm{mg} \mathrm{l}^{-1}$. DOP concentrations in water have also usually been low $(<2-10$ $\mathrm{mg} \mathrm{l}^{-1}$ ). Vinylchloride has not been detected and dichloroethane was detected in concentrations of $0.05-0.15 \mathrm{mg} \mathrm{l}^{-1}$ in 1987.

\subsection{Sediment}

The accumulation of oil in sediment has been monitored regularly since 1974 in the Porvoo area. The highest oil concentrations were detected outside the cooling water outlet. The oil concentration of the cooling water outlet site has decreased considerably during the past 20 years but is still high. The oil concentration at Illvarden fluctuates considerably (Talsi 1987).

Villa (1989) constructed a map of the areas contaminated with oil in 1987 compared to the situation in 1975. Although the analytical methods for oil are not fully comparable, the area with oil contamination was somewhat larger in 1987 than twelve years earlier. During 1990s no major change in sediment oil concentrations occurred, with clearly (10-100-fold) concentrations near the outlet of the cooling water compared to other stations.

Concentrations of chlorinated hydrocarbons and phthalates in sediments have been measured since 1978. The concentrations of chlorinated hydrocarbons and 1,2-dichloroethane and DOP (dioctylphtalate) have usually been below the detection limits, exept for the sediments closest to the outlet. Clearly highest phthalate concentrations (up to $520 \mathrm{mg} \mathrm{kg}^{-1} \mathrm{dw}$ ) were found at this station, but also occasionally at other nearby stations during recent years. Data from most stations reveal greatly increased concentrations during the late 1990s.

\subsubsection{Fish}

Nakari (1992) studied metabolic changes and accumulation of pollutants in caged and wild fish in the sea area off Sköldvik in 1990 and 1991. The physiological status of two-year-old salmon caged for 2 and 4 weeks near the outlet changed most compared to the control (Pellinki). The pollutants analysed were aliphatic and polyaromatic hydrocarbons, phthalates, volatile chlorinated hydrocarbons, chlorophenols and resin acids. The physiologial changes observed were in the waterand ion regulation of fish, as well as in their enzyme, lipid and hormonal metabolism. Rather high amounts of volatile chlorinated hydrocarbons and phthalates were found in caged fish (18-37 mg g-1 and 1.5-6.3 $\mathrm{mg} \mathrm{g}^{-1}$, respectively) in areas close to the petrochemical factories. In free-living fish (pike), concentrations were not different in areas near the factories compared with the reference areas. 
Deterioration of water quality due to eutrophication, hazardous substances or hygienic bacteria is a common phenomenon both in fresh and brackish waters. For the general characterization of the quality of waters an index is needed, which takes into account these various aspects of water quality. The general classification applied in Finland (National Board of Waters and the Environment 1988, Heinonen and Herve 1987, Vuoristo 1998) divides waters into five classes. Two approaches are in use to produce the general classification. First, the classes are determined by a counting procedure based on three separate classification criteria describing the suitability of waters for water supply, fishing and recreational activities. Second, the concentrations of relevant water quality variables are compared with boundary values which reflect the overall suitability of waters for the above modes of use. These variables include oxygen, turbidity, chlorophyll $a$, total phosphorus, colour, transparency, toxic compounds and algal blooms. In uncertain situations, extra support can be found by examining the criteria of the three more specific classifications. The five classes of the general index also have a verbal description to help in separating them from each other. As brackish coastal waters and sea areas are not used for water supply, their general index is decided by the second approach.

In Finland, water quality classification has been used for reporting the state of surface waters in national, regional and local levels. In coastal wa- ters, this type of classification has been carried out nationwide in the beginning of the 1980s (National Board of Waters 1983), in the middle of the 1980s (Vuoristo 1991) and in the middle of the 1990s (Antikainen et al. 2000). In addition, classification for some coastal regions has been reported for the beginning of 1990s (e.g. Puomio and Braunschweiler 1993, Ferin-Westerholm 1994). However, comparison of the classifications made for those four periods is difficult, because the criteria have been changed twice. First, in the beginning of the 1980s two crucial variables, chlorophyll $a$ and total phosphorus, were not yet included. Second, the boundary values of these two variables (Table 11.1) were lowered for sea waters compared with fresh waters in the latest classification (Antikainen et al. 2000). The new boundary values are considered to produce results which are in better agreement with the general conception of the state of the Baltic Sea.

The latest nationwide classification of the Finnish surface waters was based on the data from the years 19941997, variables listed in Table 11.1 and verbal descriptions in Table 11.2. According to this study, ca. $88 \%$ of the sea area had excellent or good water quality, whereas only one percent was passable or poor (Fig. 11.1). Eutrophication had caused the quality of sea waters to deteriorate mainly in the Gulf of Finland and in the Archipelago Sea. In general, excellent and good classes were located in the open sea. An exception was the eastern Gulf of Finland, where water quality was classified as only satisfactory. This was main- 


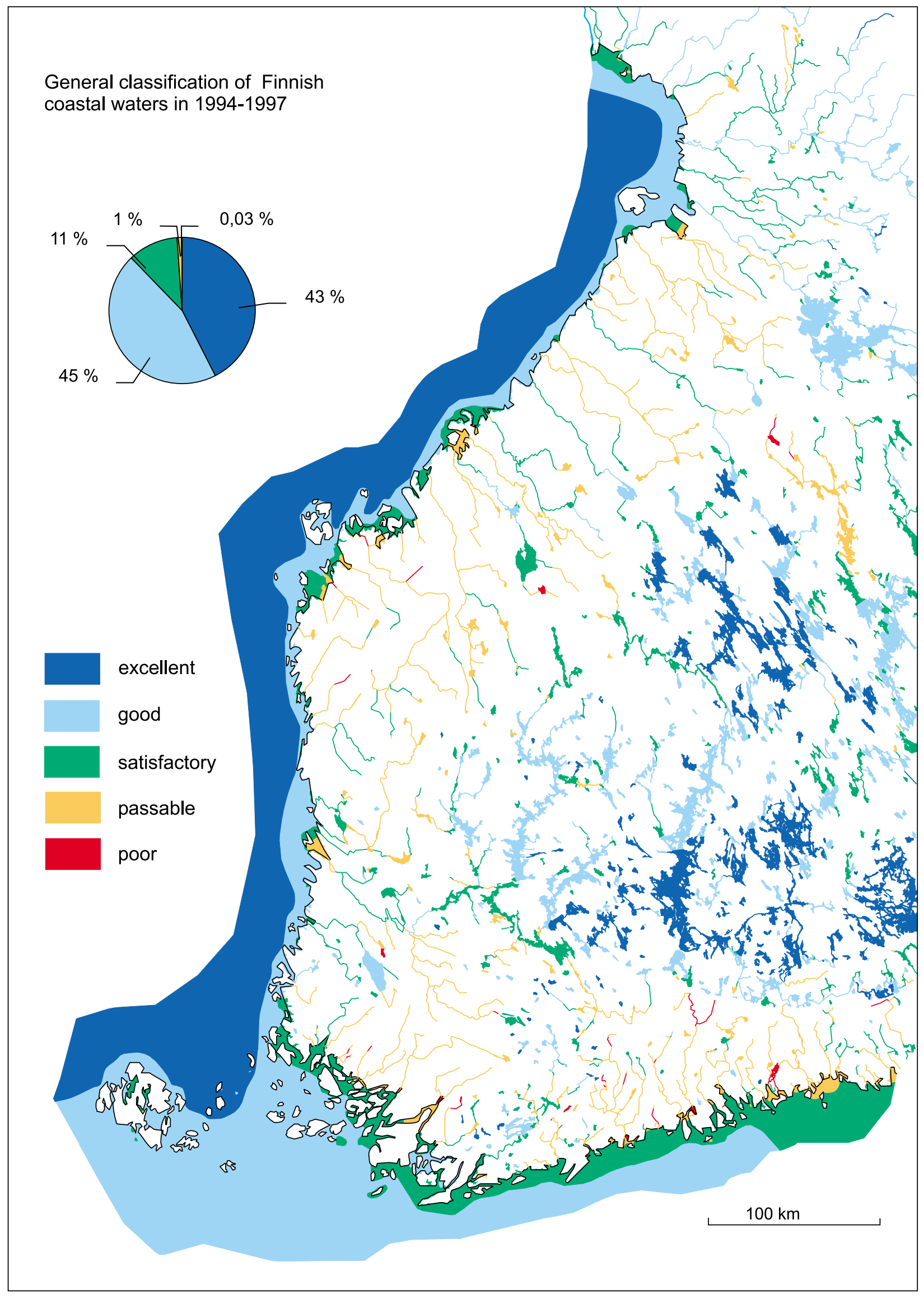

Figure I I. I. General classification of Finnish coastal waters based on water quality data from the years 1994-1997 (Antikainen et al. 2000). 
ly due to eutrophication caused by wastewaters of St. Petersburg (Russia) and loading by the River Neva (Pitkänen 1994, Fig. 6.1). Loading from Finnish rivers, which were mainly classified as passable, also decreased the quality of coastal waters. The effect of direct loading from municipalities and industry could also be seen. Coastal waters were classified as poor or passable off the large municipalities, such as Hamina, Kotka, Porvoo, Helsinki, Turku, Pori, Vaasa, Kokkola, Oulu and Kemi. In the Archipelago Sea, waters around large fish farms were clearly more eutrophic than neighbouring areas, but this could not be seen in the scale of the national map.

Increased numbers of hygienic indicator bacteria were noticed e.g. in the sea area to which wastewaters of Helsinki are conducted (Puomio et al. 1999). Water quality of the rivers in south and southwest Finland is often decreased by high numbers of hygienic indicator bacteria (Niemi et al. 1997) and the effect of this could be seen in some inner bays (e.g. Halikonlahti, Vanhankaupunginselkä). Decreased oxygen content in water worsened the class e.g in the Pohjanpitäjänlahti Bay, off Tammisaari and in the Sipoonlahti Bay (Puomio et al. 1999). Moreover, anoxic sediments and mortality of bottom fauna off Pyhtää-Kotka-Hamina (easternmost Gulf of Finland) affected the assessment of water quality there. Acidity caused fish kills in 1996 especially near the outlet of the Kyrönjoki, a river with a catchment dominated by acid sulphate soils originating from the sediment of the former Littorina Sea.

Mercury concentrations in the muscle of predatory fish, such as pike, were below $1 \mathrm{mg} \mathrm{kg}^{-1}$, which is the maximum level for human consumption (see also section 10.2.3.) and thus did not have an influence on the allocation of class. Classification criteria do not give exact boundary values e.g. to organic chlorine substances. It has been calculated (see section 10.3.3. Dioxins and furans) that when using old Baltic herring or salmon as food, the maximum daily consumption should be less than $10 \mathrm{~g}$ fish muscle in order to remain below the Nordic guideline (Nordisk dioxinriskbedömning 1988). In the classification this could not be taken into account, because the data was sparse. Oil has been detected off an iron smelter near Hanko and this has decreased the usability of water (Puomio et al. 1999).

The general classification of water quality should have more exact boundary limits for harmful substances in water, fish and sediment. In addition, it does not consider the state of the whole aquatic environment, including community structure of organisms. Furthermore, monitoring data especially data on topical harmful substances - should be more numerous in order to provide more accurate classification. Classification criteria are currently being developed under the water framework directive of the European Community (1997/0067/COD). First, coastal waters should be discriminated into different types to ensure that type-specific biological reference conditions can be reliably derived. Second, waters should be divided into five classes by comparing their ecological quality with the reference conditions.

The most remarkable difference between the recent classification and that demanded by the water framework directive will be the crucial role of biological elements, such as phytoplankton, macro algae, benthic invertebrate fauna and fish. The monitoring of these elements should be organized with a frequency of every three years and for phytoplankton every six months. Physical and chemical variables should be monitored at three month intervals and some priority hazardous substances even monthly. These demands for monitoring with emphasis on biological variables would most probably lead to reorganization of the whole coastal monitoring in future. 
Table II.I. Class boundaries of variables used in general classification of water quality (National Board of Waters and the Environment 1988, Vuoristo 1998, Antikainen et al. 2000).

\begin{tabular}{|c|c|c|c|c|c|}
\hline Variable & $\begin{array}{l}\text { I } \\
\text { Excellent }\end{array}$ & $\begin{array}{l}\text { II } \\
\text { Good }\end{array}$ & $\begin{array}{l}\text { III } \\
\text { Satisfactory }\end{array}$ & $\begin{array}{l}\text { IV } \\
\text { Passable }\end{array}$ & $\begin{array}{l}\text { V } \\
\text { Poor }\end{array}$ \\
\hline \multicolumn{6}{|l|}{ Chlorophyll a, mg/l } \\
\hline Fresh water & $<4$ & $<10$ & $<20$ & $20-50$ & $>50$ \\
\hline Baltic Sea & $<2$ & $2-4$ & $4-12$ & $12-30$ & $>30$ \\
\hline \multicolumn{6}{|l|}{ Total P, mg/l } \\
\hline Fresh water & $<12$ & $<30$ & $<50$ & $50-100$ & $>100$ \\
\hline Baltic Sea & $<12$ & $13-20$ & $20-40$ & $40-80$ & $>80$ \\
\hline Transparency, m & $>2.5$ & $\mathrm{I}-2.5$ & $<1$ & & \\
\hline Turbidity, FTU & $<1.5$ & $>1.5$ & & & \\
\hline Colour mg Pt/l & $<50$ & $\begin{array}{l}50-100 \\
(<200)^{*}\end{array}$ & $<150$ & $>150$ & $>150$ \\
\hline $0_{2}, \%$ & $80-110$ & $80-110$ & $70-120$ & $40-150$ & serious problems in surface water \\
\hline Oxygen depletion in hypolimnion & no & no & occasionally & frequently & common \\
\hline $\begin{array}{l}\text { Faecal indicator } \\
\text { bacteria, CFU/100 ml }\end{array}$ & $<10$ & $<50$ & $<100$ & $<1000$ & $>1000$ \\
\hline $\mathrm{Hg}, \mathrm{mg} / \mathrm{kg}$ in carnivorous fish & & & & & $>1$ \\
\hline $\mathrm{As}, \mathrm{Cr}, \mathrm{Pb}, \mathrm{mg} / \mathrm{l}$ & & & & $<50$ & $>50$ \\
\hline $\mathrm{Hg}, \mathrm{mg} / \mathrm{l}$ & & & & $<2$ & $>2$ \\
\hline $\mathrm{Cd}, \mathrm{mg} / \mathrm{l}$ & & & & $<5$ & $>5$ \\
\hline Total cyanide, mg/l & & & & $<50$ & $>50$ \\
\hline Algal blooms & no & occasionally & frequently & common & abundant \\
\hline Off-flavours in fish & & & & common & common \\
\hline
\end{tabular}

* humic waters in their natural state

Table II.2. Criteria for the general water quality classification in Finland (National Board of Waters and the Environment 1988,Vuoristo 1998, Antikainen et al. 2000)

Class I (Excellent) The watercourse is in natural condition, usually oligotrophic, clear or with some humus. No algal blooms preventing the use of water. Highly suitable for all modes of use.

Class II (Good)

Class III (Satisfactory)

Class IV (Passable)

Class V (Poor)
The watercourse is in near-natural condition, slightly eutrophic or with moderate humus content. Local algal blooms might occur occasionally. Water is still suitable for all modes of use.

The watercourse is slightly affected by wastewaters, non-point loading or other changing activity, or it is appreciably eutrophic due to natural causes, or highly coloured with humus. Algal blooms may occur repeatedly. Concentrations of harmful substances in water, sediment and organisms may be slightly increased compared with natural levels.

The watercourse is usually satisfactory for most modes of uses.

The watercourse is strongly affected by waste waters, non-point loading or other changing activity. Algal blooms are common and may restrict the use of water for long periods. Concentrations of harmful substances in water, sediment and organisms can be clearly higher compared with natural levels. Acidity may occasionally cause fish kills in waters in catchments dominated by acid sulphate soils originating from the sediment of the former Littorina Sea. Water is suitable only for modes of use having few water quality requirements.

The watercourse is extensively polluted by wastewaters, non-point loading or other changing activity. Algal blooms are very common and abundant, restricting the use of water often for long periods. Oxygen condition may also be weak due to eutrophication. Concentrations of harmful substances in water, sediment and organisms may be at level causing a clear risk associated with the use of either water or organisms. Acidity repeatedly causes fish kills in waters on catchments dominated by acid sulphate soils originating from the sediment of the former Littorina Sea. Poorly suited to any form of water use. 
The aim of this report is to assess the state of Finnish coastal waters and changes in it during the 1990s. Loading and concentrations of nutrients and harmful substances have been reviewed in different coastal areas. Eutrophication has been described by means of biomass and surface accumulations (blooms) of phytoplankton. The state of the coastal zone has been assessed as changes in phytobenthos and zoobenthos. The report is mainly based on the coastal monitoring data produced by the Finnish Environment Institute. The physical and chemical monitoring data in open sea areas originated from the Finnish Institute of Marine Research. The section on fish catches was delivered by the Finnish Game and Fisheries Research Institute. Numerous scientific arcticles and reports were evaluated to assess the changes in phytobenthos because monitoring data for phytobenthos was not available. Additionally, local pollution control studies were utilized in order to obtain additional information on zoobenthos and harmful substances in polluted water areas.

\section{Loading}

During the 1990s, Finnish coastal waters received annually on average 4090 $\mathrm{t}$ of $\mathrm{P}$ and $74000 \mathrm{t}$ of $\mathrm{N}$ from or via the Finnish territory, corresponding to approximately $10 \%$ of the total loads of nutrients to the Baltic Sea. In the Finnish catchment, agriculture was the main anthropogenic source of $\mathrm{P}$ and $\mathrm{N}$ loading, accounting for one third of the total fluxes of nutrients. The municipal load of $\mathrm{N}$ was the second largest and atmospheric deposition the third largest source of $\mathrm{N}$ load. Regarding the load of $\mathrm{P}$, forestry was the second largest and scattered dwellings the third largest source. The majority of the load of forestry was carried via the large northern rivers to the Bothnian Bay. However, as the loading is expressed as total nutrients, it does not directly describe the biologically available and eutrophying share of the load.

The load of phosphorus has decreased by ca. $16 \%$ and the load of nitrogen ca. 10\% from the level in the late 1980s. In particular, the reduction in the municipal and industrial load of $P$ was significant. By contrast, changes in diffuce loading were slight. The decline in the total load of $\mathrm{N}$ since the late 1980s was explained by the smaller water flow in the 1990s because the point-source loading of $\mathrm{N}$ actually slightly increased during that period. The decline in the load of $P$ was mainly due to water protection measures in industry and municipalities.

Targets set in the Ministrial Declaration of Baltic countries in 1988 for decreasing industrial and municipal loading of $\mathrm{P}$ to the Baltic Sea were achieved in the 1990s. On the other hand, the load of $\mathrm{N}$ from agriculture, municipalities and industry did not significantly decrease. A new national target has been set to decrease the load of nutrients by about 50\% from all sources of nutrient loading by the year 2005 compared to the level of 19901995. The decrease in the point-source load of organic matter $\left(\mathrm{BOD}_{7}\right)$ by more than $70 \%$ since the mid 1980 s was due to improved purification of waste waters in the wood-processing industy.

In addition to eutrophication, contamination by metals and other harmful substances is also a matter of concern in many coastal water areas. The load of heavy metals carried via rivers to the coastal waters spans several orders of magnitude compared to pointsource loading due to natural leaching from soil. Therefore, the effects of water protection measures on the total load of heavy metals remain relatively small. In local scale the reduction in the 
industrial and municipal loads of heavy metals are important as they have a contribution to the state of the biota. Nevertheless, the point-source loads of metals have considerably decreased since the 1970s and 1980s. Additionally, the hot spots specified by HELCOM in the Helsinki Convention in 1992 have decreased throughout the whole Baltic catchment. In Finland, metal industry discharging to the Bothnian Sea via the river Kokemäenjoki is still left in the list due to its considerable load.

\section{Nutrient conditions and trophic status}

Nitrogen and phosphorus are key elements for primary producers (phytoplankton, macroalgae, higher water plants). Additionally, silicate is an important element for diatoms. In the coastal waters of the Gulf of Finland, the Archipelago Sea and the Bothnian Sea, algal production is mainly limited by nitrogen or by both nitrogen and phosphorus. By contrast, production in the Bohnian Bay is clearly phosphorus limited. However, in all environments the availability of phosphorus controls blue-green algae which are cabable of fixing atmospheric nitrogen dissolved in water.

Eutrophication is the main problem in the Gulf of Finland, where the nutrient load per unit water area is $2-3$ times greater than in the whole Baltic Sea. The sensitivity of the Gulf to eutrophication is increased by many factors. The Gulf of Finland is a direct extension of the Baltic Proper, being influenced by the deep water of the Baltic Proper. Additionally, it is affected by considerable nutrient load from land areas, mainly originating from the River Neva and St. Petersburg region. Nutrient supplies become available for phytoplankton through upwellings and strong mixing events in late autumn and winter. In generel, water mixing does not effectively reach the bottom, except in the eastern parts of the Gulf, where nutrient reserves in bottom relatively easily reach the productive surface layer due to the lack of halocline. In the eastern Gulf of Finland, internal loading of nutrients were accelerated in the mid 1990s due to strengthened of stratification and incomplete wintertime mixing.

Nutrient conditions in the Gulf of Bothnia differ considerably from those in the Gulf of Finland. The Gulf of Bothnia is sheltered from the majority of the nutrient-rich deep waters by a ridge, shaped by several underwater thresholds and the Archipelago Sea. Therefore, only small water volumes from the eutrophied Baltic water below the halocline enter to the Gulf of Bothnia. Additionally, due to the smaller external nutrient loading and the lack of areas receiving considerable internal loading, the amount of phytoplankton in the Gulf of Bothnia is clearly smaller than in the Gulf of Finland. In the Archipelago Sea, the general trophic status in summertime is lower than in the western Gulf of Finland.

Most of the Finnish coastal waters are eutrophied compared to open sea areas. The eutrophied zone (more than $5 \mathrm{mg} \mathrm{chl} a \mathrm{~m}^{-3}$ ) along the coast of the Gulf of Finland and the Archipelago Sea is explained by the even distribution of riverine nutrient load directed to the coastal areas. In the Gulf of Bothnia, eutrophied coastal areas were limited to estuaries or archipelagos off greater cities. Regarding the open sea, only the eastern Gulf of Finland is clearly eutrophied due to the considerable load of nutrients from the River Neva and the St. Petersburg region, and also due to its current and mixing conditions.

Changes in trophic status since the 1970s exhibit two opposite directions. The state of some clearly eutrophied areas off greater cities (e.g. the Helsinki-Espoo region and Oulu) show improvement due to the decrease in municipal and industrial nutrient loading. Especially phosphorus concentrations in heavily loaded areas have decreased due to water protection meas- 
ures aimed at reducing point-source loading. However, the total surface area of the coastal waters defined as eutrophied (more than $5 \mathrm{mg} \mathrm{chl} a \mathrm{~m}^{-3}$ ) has increased during the 1980s. The situation in the 1990s has not essentially changed compared to that in the 1980s.

During the 1980s, the border of slightly eutrophied areas moved westwards in the Gulf of Finland, in the outer Archipelago Sea and in the Bothnian Bay. The reason for this are changes in $\mathrm{N}$ loading and changes in nutrient concentrations in the open Baltic Sea. The increase in $\mathrm{N}$ concentrations in the open Gulf of Finland was also observed in the coastal waters during the 1970s and 1980s. $\mathrm{N}$ loading from the coast continuously increased as a result of increased nutrient leaching and use of fertilizers. Additionally, intensified fish-farming contributed to the development of eutrophication in the Archipelago Sea in the late 1980s.

Phosphorus concentrations began to increase strongly in the Gulf of Finland in the middle of the 1990s due to the acceleration of internal loading, especially in the eastern part of the Gulf. Consequently, the decrease in the ratio of inorganic N:P led to mass occurrences of $\mathrm{N}_{2}$-fixing blue-green algae. However, the increase in phosphorus concentrations ceased at the end of the 1990s. The decreasing trend of $\mathrm{N}$ concentrations in the coastal and open Gulf of Finland was possibly due to the decline in the load of $\mathrm{N}$ by $30 \%$ compered to the level in the late 1980s.

\section{Phytoplankton and blue-green algae}

The development of eutrophication in the Gulf of Finland and the Archipelago Sea was manifested as an increase in late summer phytoplankton biomass and as changes in species composition. In the eastern Gulf of Finland, the increasing trend of phytoplankton generally followed the trend of nutrients. However, the increase in phytoplank- ton amounts levelled out in the late 1990s in keeping with phosphorus concentrations, which due to extensive oxygen deficit were elevated in the middle of the decade. The dominance of blue-green algae has increased since the late 1980s. The nutrient ratios and hydrographical conditions determined which of the blue-green algae, Planktothrix agardhii or $\mathrm{N}_{2}$-fixing Aphanizomenon sp., gained dominance. P. agardhii has mainly dominated in summers when nutrient rich waters have extended as far as the easternmost Finnish archipelago.

In the outer archipelago off Helsinki, the increase in nutrient concentrations since purified waste waters started to be conducted to open sea was not reflected in total phytoplankton biomasses. However, the increase in the inorganic N:P ratio favoured flourishing of the blue-green algal order Chroococcales at the expense of Aphanizomenon sp., which in these altered conditions could not take advantage of its $\mathrm{N}_{2}$-fixing capability. Similarily, the decline in phosphorus concentrations in inner bays resulted in the dominance of non- $\mathrm{N}_{2}$-fixing blue-green algae.

In the Archipelago Sea, the increase in total phytoplankton biomasses in the 1990s as a response to the increase in the concentrations of $\mathrm{P}$ can partly be explained by internal loading and nutrient fluxies from the Gulf of Finland. In recent years, the decrease in the $\mathrm{N} / \mathrm{P}$ ratio and the increase in $\mathrm{N}$ limitation has probably contributed to the dominance of blue-green algae.

Eutrophication in the Gulf of Finland and the Archipelago Sea has been reflected as increasing extent and intensity of algal accumulations in late summer. Mass occurrences of bluegreen algae have also occasionally been recorded in late autumn or early winter. The accumulations are rare in the Bothnian Bay. In the accumulations, Aphanizomenon sp. and the occassionally toxic Nodularia spumigena are the most common blue-green algal species, both of which are capable of fixing atmospheric nitrogen. The accumulations are often enhanced by upwellings 
of near-bottom waters, carrying abundant amounts of phosphorus up to the surface layer. In 1997, the accumulations were the most extensive and prolonged ever recorded. This phenomenon was attributed not only to calm and warm weather conditions but also to elevated concentrations of surface phosphorus. In the summers 19982000, accumulations were also recorded in the inner Archipelago Sea. Nitrogen limitation explains why the accumulations of blue-green algae are mainly formed in offshore waters. From there they can be driven to the coast. The blue-green algae Microcystis and Planktothrix, which form accumulations near the coast and in the easternmost Gulf of Finland, also require inorganic $\mathrm{N}$ and suitable weather conditions in addition to phosphorus.

\section{Phytobenthos}

When eutrophication increases, sedimentation and algal species favouring eutrophication occupy a larger area. Along the Finnish coast, changes such as decreased occurrence of perennial red and brown algae, increased occurrence of fast-growing filamentous algae and drifting algal mats causing anoxia have occurred. Furthermore, the upward movement of the algal belts due to increased sedimentation, overgrowth by epiphytic algae and increased shading by plankton have widely been documented.

Drifting macroalgae have been encountered in the 1990s in the Archipelago Sea and the Åland Sea and also in smaller amounts in the eastern Gulf of Finland. When the filamentous macroalgae are detached from the rocky shores they are transported to the sublittoral, where they may form looselying drift mats. As a result, the natural littoral vegetation can be replaced and the bottom fauna can be altered by an algal mat covering the available substrata. It has been shown that with increasing eutrophication drifting algal mats increase, affecting the entire coastal food web. At present these algal mats are probably the main factor inducing hypoxia above the halocline in the archipelago area in the northern Baltic Sea.

Fucus vesiculosus is the only large perennial seaweed which is widespread in the Finnish coastal areas and as such it forms the habitat for e.g. the hardbottom macrofauna. The distribution area of $F$. vesiculosus reaches north up to the Quark and in the eastern part of the Gulf of Finland extends to Virolahti. In sheltered shores it was found to grow on stones and could be restricted by soft sediments. General deterioration of the F. vesiculosus belt is of great concern because it is a key species in the Baltic Sea ecosystem. An extensive decline of F. vesiculosus stands occurred in the southern and SW coasts of Finland during the late 1970s. Especially the $F$. vesiculosus belt disappeared almost completely from open archipelago shores and the abundance of $F$. vesiculosus also decreased drastically along the open shores. The first signs of recovery were observed in the early 1980s in the SW coast of Finland e.g. in the Tvärminne archipelago. In the Archipelago Sea, F. vesiculosus had also completely vanished from many localities in the early 1980s. By the late 1980s and the early 1990s it had partly recolonised its former habitats, but the decline had continued in some parts of the archipelago. Earlier, F. vesiculosus was recorded to grow at a depth of 10 $\mathrm{m}$ in the Tvärminne archipelago but in the 1990s its maximum growth depth was about 5 to 6 metres with an optimum of 2-3 metres. In the Archipelago Sea, the continuous belt of $F$. vesiculosus nowadays colonizes only a zone between depths of 1.0 to 4.0 metres, although individual plants may be found down to a depth of 7-8 metres.

\section{Alien species}

Introduction of alien species was recently recognised as a threat to the Baltic ecosystem. Most of them have entered with ballast water or attached to the hulls of ships. Five alien species 
recorded in Finnish coastal waters in the 1990s have become established. The polychaete Marenzelleria viridis living in bottom sediment, originates from the northern America, whereas the bivalve Dreissena polymorpha, the mysid shrimp Hemimysis anomala and the cladoceran Cercopagis pengoi are of Black Sea and Caspian Sea origin. Cercopagis has formed mass occurrences and caused economic damage by sliming fishing gear and nets. The sensitivity of the Baltic Sea to these newcomers is mainly a consequence of the low number of different species, which is typical to this relatively young brackish water region. There is a potential risk that alien species may change the existing ecosystem and food webs or cause economic harm e.g. by disturbing fishing or by blocking water cooling systems.

\section{Zoobenthos}

Changes in the state of bottom fauna have occurred in many coastal area after the late 1980s. Off the coast of loaded areas these changes exhibited considerable regional differences. The decrease in the loading of organic matter and phosphorus improved the state of bottoms in the innermost parts of several heavily loaded areas. On the other hand, off several other coastal areas, e.g. in the middle Gulf of Finland, the bottoms have deteriorated despite the decrease in point-source loading. These differences between different areas may arise from several factors, due to the fact that waste water effects depend not only on the amount and the character of loading, but also on coastal morphometry, bottom quality and water exchange conditions.

The bottom state of the outer archipelago areas have hardly changed in the Gulf of Bothnia, but have gone deteriorated in the Archipelago Sea, and especially in the Gulf of Finland during the 1990s. This is manifested as e.g. decreasing abundances of Monoporeia affinis and increasing abundances of oligochaets and chironomid larvae. The deterioration of the fauna can be explained by weakening oxygen conditions in bottoms due to increased production of organic matter, and a typical phenomenon to extensive areas of the Gulf of Finland has been anoxic bottoms with no fauna due to both internal and external loading.

Long-term monitoring results of the macrozoobenthos communities of relatively clean sea areas are available only from one area, east of the Hanko Penisula. The most remarkable change on that bottom was the change in dominance of the two main species, Monoporeia affinis and Macoma balthica. The strong dominance of Monoporeia in the 1980s turned to an even stronger dominance of Macoma in the 1990s. This, like changes of some other species as well, could be explained by the general eutrophication of coastal waters. However, the recent species composition resembles that recorded in the area already in the 1920s, indicating that other factors, such as intra- and interspecific regulation, also strongly affect the development of bottom communities.

\section{Fish stocks}

Eutrophication generally affects fish stocks by increasing the abundance and biomass of fish, mainly due to an increase in the supply of their food. It also changes the composition of fish species towards the dominance of roach (Rutilus rutilus), improves the growth of some species, and increases young and small fishs. On the other hand, some species also suffers from eutrophication. For example the disappearance of Fucus communities in extensive bottom areas due to higher turbidity has weakened the living conditions for e.g. perch (Perca fluviatilis). Many fish also avoid waters with low oxygen content. The direct harmful effects of eutrophication on commercial and recreational fisheries are manifested as fouling or sliming of gear and nets, and off-flavours or -odours in fish.

Salinity also affects the composition, abundance and distribution of 
fish species. The salinity of the Baltic Sea has decreased due to the absence of major inflow events via the Danish straits during the 1980s and 1990s, with the exception of the most recent, moderately strong inflow in 1993. The slight decline in salinity in the Gulf of Finland and the Archipelago Sea has indirectly been reflected e.g. in decreased growth of Baltic herring (Clupea harengus) due to the decrease in its food item. Baltic herring is the most important marine species for Finnish commercial fisheries.

\section{Contamination of harmful substances}

Considerable amounts of heavy metals, organic pollutants and other persistent harmful compounds from point- and diffuse sources have discharged into the Finnish coastal waters. This is also evident on the basis of elevated concentrations in sediment and biota. Persistent hazardous compounds can become enriched in the food webs of members of the biota and cause changes in their reproduction, growing and metabolism.

The distributions of the heavy metals $\mathrm{Pb}, \mathrm{Cd}$ and $\mathrm{Hg}$ in sediment showed a decreasing trend from north to south in the Gulf of Bothnia, and from east to west in the Gulf of Finland. Mercury concentrations were highest in the Bothnian Bay and cadmium concentrations in the Gulf of Finland. However, the maximum concentrations were far below the Baltic extremes. High contents of different metals in biota were measured in the vicinity of industrial areas. Metal concentrations in the Baltic mussel (Macoma balthica) did not differ significantly from background variation. Saduria entomon showed a decline in the concentrations of copper, cadmium and mercury. Mercury concentrations in fish in areas with high $\mathrm{Hg}$ pollution decreased considerably during the 1960s and 1970s.

Concentrations of organic pollutants in sediment were elevated in the vicinities of woodprocessing and petrochemical industries. However, emis- sions of these compounds have decreased due to water protection measures. High concentrations were also measured in biota. However, concentrations of PCB and DDT have declined in Baltic biota since the 1970s. In Baltic herring this decline has slowed during the 1990s.

The petrochemical industry is an important source of oil compounds in Finnish coastal waters. In general, concentrations in water have been below the detectation limit during the 1980s and 1990s. The highest oil contents in sediment were detected outside the cooling water outlets. In the vicinity of petrochemical factories concentrations in free-living fish did not differ from normal levels. The harmfulness of oil compounds in biota is based on the fact that in high concentrations they can cause physiological changes.

\section{Classification of coastal water quality}

On the basis of the general classification of coastal water quality, nearly $90 \%$ of the sea area was classified as good or excellent, which shows that watercourses are in natural or near-natural condition. Good and excellent water classes covered open sea areas around Finland and extensive coastal areas in the Gulf of Bothnia. About $10 \%$ of the water area belonged to the satisfactory class, situated along the coasts of the Gulf of Finland, the Archipelago Sea and off loaded coastal areas in the Gulf of Bothnia. Only one percent of the water area was classified as passable. The reason for these lower water classes is mainly europhication, manifested e.g. as elevated concentrations of chlorophyll $a$, frequent algal accumulations or low oxygen concentrations in bottom layers. Additionally, hygienic indicator bacteria weakened water quality in some inner bays, and elevated concentrations of harmful substances such as $\mathrm{Hg}$ and organic chlorine substances off some industrial areas. 
Suomen rannikkovesien tilaraportissa arvioidaan rannikkovesien tilaa ja sen muutoksia 1990-luvulla. Tarkasteluun on otettu ravinnekuormituksen kehitys sekä ravinne- ja rehevyystasot ja niiden muutokset eri rannikkovesialueilla. Rehevöitymistä on kuvattu kasviplanktonin biomassan ja kukintojen avulla. Rantavyöhykkeen tilaa on arvioitu kasvillisuudessa ja pohjaeläimistössä tapahtuneina muutoksina. Suomen ympäristökeskus on koonnut suurimman osan raportin aineistosta. Raportti on laadittu valtakunnallisten seurantaohjelmien, velvoitetarkkailujen sekä rannikkovesien tilaa käsittelevien tutkimusten perusteella. Avomerialueen vedenlaatutiedot on saatu Merentutkimuslaitoksen seuranta-ainestosta. Kaloihin ja kalastukseen liittyvän osuuden on toimittanut Riistaja kalatalouden tutkimuslaitos. Velvoitetarkkailun aineistoa on hyödynnetty arvioitaessa pohjaeläinten tilaa ja haitallisten aineiden pitoisuuksia ja vaikutuksia kuormitetuilla vesialueilla.

\section{Kuormitus}

Suomen rannikkovedet vastaanottivat valuma-alueeltaan keskimäärin noin 4090 tonnia fosforia ja 74000 tonnia typpeä vuodessa, mikä on noin $10 \%$ Itämereen päätyvästä ravinnekuormasta. Maatalous on selvästi suurin yksittäinen typen ja fosforin kuormituslähde. Rannikkovesiin joutuvasta typpikuormasta asutus on toiseksi suurin ja järvialueilta peräisin oleva typpilaskeu-ma kolmanneksi suurin lähde. Fosforikuormittajista metsätalous ja haja-asutus ovat maatalouden jälkeen suurimmat kuormituslähteet. Arviolta $80 \%$ metsätalouden kuormasta kohdistuu Perämereen siihen laskevien suurien jokien välityksellä. Raportissa esitetyt luvut ovat kuitenkin kokonaisravinnekuormia, eivätkä ne siten ku- vaa suoraan rehevöitymisestä aiheuttavaa, biologisesti käyttökelpoista osuutta kuormituksesta.

Fosforin kuormitus on pienentynyt 1980-luvun loppuun verrattuna noin $16 \%$ ja typen kuormitus noin $10 \%$. Erityisesti asutuksen ja teollisuuden fosforikuorma pienentyi merkittävästi. Sen sijaan hajakuormassa muutokset olivat vähäisiä. Typpivirtaamien väheneminen selittyy pääasiassa sadannan ja valumien pienenemisellä, mikä on heijastunut sekä luonnosta että maa- ja metsätaloudesta peräisin oleviin ravinnehuuhtoumiin. Kuitenkin 1990-luvulla myös typen vuotuinen kuorma pienentyi valtakunnallisesti noin 4000 tonnia. Noin puolet tästä vähenemästä johtuu pääkaupunkiseudulla vuonna 1998 aloitetusta tehostetusta typenpoistosta ja toinen puoli teollisuuden päästöjen pienenemisestä. Itämeren valtioiden yhteisen Ministerijulkilausuman vuonna 1988 asettama tavoite teollisuuden ja yhdyskuntien fosforikuormituksen vähentämiseksi onnistui. Sen sijaan maatalouden, asutuksen ja teollisuuden typpikuorma ei ole merkittävästi vähentynyt. Suomen kansallisen vesiensuojelun tavoiteohjelman tavoitteena on kaikkien päästölähteiden ravinnekuormituksen vähentäminen noin $50 \%: 1 l a$ vuosien 1990-1994 tasosta vuoteen 2005 mennessä.

Raskasmetallien ja vahingollisten aineiden aiheuttama saastuminen on rehevöitymisen ohella huolenaihe useilla Suomen rannikkovesialueilla. Luonnonhuuhtouman vuoksi jokien mukanaan kuljettamat raskasmetallimäärät ovat useita kertaluokkia suurempia kuin mitä rannikkovesiin päätyy asutuksesta ja teollisuudesta. Siten vesiensuojelutoimenpiteillä voidaan verrattain vähän vaikuttaa raskasmetallien kokonaispäästöihin. Tästä huolimatta teollisuuden ja yhdyskuntien 
raskasmetallien kuormitusta pienentämällä voidaan parantaa eliöiden elinolosuhteita. Raskasmetallien pistemäinen kuormitus onkin vähentynyt merkittävästi 1970- ja 1980-lukujen aikana. Itämeren suojelukomission Helsinki sopimuksessa vuonna 1992 määrittelemät erityiskohteet (hot spots) ovat vähentyneet koko Itämeren alueelta. Suomen valuma-alueella sijaitsevista haitallisten aineiden kohteista on jäljellä Perämerta Kokemäenjoen kautta kuormittava metalliteollisuus huomattavien raskasmetallipäästöjensä vuoksi.

\section{Ravinne- ja rehevyystila}

Typpi ja fosfori ovat tärkeimmät Itämeren rehevyystilaan vaikuttavat tekijät. Suomenlahden, Saaristomeren ja Selkämeren rannikkovesissä levätuotanto on pääosin joko typpi- tai sekä typpi- että fosforirajoitteista. Perämeri puolestaan on levätuotannoltaan selkeästi fosforirajoitteinen. Ensisijaisesti fosforin saatavuus säätelee kaikkialla niitä sinilevälajeja, jotka kykenevät sitomaan ilmakehästä veteen liuennutta rajatonta typpivarastoa.

Suomea ympäröivillä Itämeren osa-alueilla rehevöityminen on edennyt pisimmälle Suomenlahdella, jonka vesipinta-alaan suhteutettu ravinnekuorma on 2-3-kertainen koko Itämereen verrattuna. Suomenlahden rehevöitymisalttiutta lisää myöskin se, että se on Itämeren pääaltaan kynnyksetön jatke. Tämän vuoksi Itämeren pääaltaan syvänteisiin kertyneet ravinnevarat pääsevät virtaamaan halokliinin alapuolella esteettä Suomenlahdelle. Tuottavaan pintakerrokseen ravinteet joutuvat kumpuamisten sekä erityisesti myöhäissyksyn ja talven voimakkaiden sekoittumisten yhteydessä. Läntisen ja keskisen Suomenlahden syvimmissä osissa sekoittuminen ei koskaan yllä tehokkaana pohjaan saakka. Sen sijaan itäisellä Suomenlahden sekoittumisen estävä suolaisuuden harppauskerros puuttuu ja pohjan ravinnevaroja pääsee tuottavaan pintakerrokseen suhteellisen helposti. Itäisellä Suomen- lahdella ravinteiden sisäinen kuormitus kiihtyi 1990-luvun puolivälissä. Tämä johtui kerrostuneisuuden voimistumisesta ja veden epätäydellisestä sekoittumisesta talvikausina.

Pohjanlahti eroaa ravinneoloiltaan merkittävästi Suomenlahdesta. Sitä suojaa Itämeren ravinteikkaalta syvältä vedeltä Saaristomeren ja vedenalaisten kynnysten muodostama harjanne, joiden vaikutuksesta vain hyvin pieniä määriä Itämeren halokliinin alapuolista, ravinteikasta vettä pääsee Pohjanlahdelle. Merialueen ulkoinen ravinnekuorma on lisäksi pienempi kuin Suomenlahden. Pohjanlahdella ei ole merkittäviä sisäisen kuormituksen alueita, joten avoimen Pohjanlahden keskimääräinen kasviplanktonpitoisuus on kesällä selvästi pienempi kuin Suomenlahdella. Saaristomeri muodostaa vaihettumisvyöhykkeen pohjoisen Itämeren ja Selkämeren välillä, ja siellä yleinen rehevyystaso on kesällä vähän alempi kuin läntisellä Suomenlahdella.

Pääosa Suomen rannikkovesistä on selvästi rehevöitynyt vastaaviin avomerialueisiin verrattuna. Tämä johtuu toisaalta rannikkovesiin joutuvasta ravinnekuormasta ja toisaalta rannikkovesien mataluudesta sekä saarien ja matalikkojen heikentämästä vedenvaihdosta avomeren kanssa. Selvimmin rehevöityminen näkyy Suomenlahden ja Saaristomeren kuormitetuilla saaristoalueilla, joissa yli $5 \mathrm{mg} \mathrm{m}^{-3}$ keskimääräinen kesän $a$-klorofyllin taso vallitsee lähes koko rannikon pituudelta. Yhtenäinen rehevöitynyt vyöhyke selittyy rajoittuneiden sekoittumisolojen ohella jokien tuoman kuorman varsin tasaisella jakautumisella pitkin rannikkoa. Pohjanlahden rannikkovesissä $5 \mathrm{mg} \mathrm{m}^{-3}$ keskimääräinen $a$-klorofyllipitoisuus ylittyy paikoitellen. Avomerialueilla keskimäärin $5 \mathrm{mg} \mathrm{m}^{-3}$ kesäaikainen $a$-klorofyllipitoisuus ylittyy vain itäisellä Suomenlahdella. Syynä rehevöitymiseen ovat Nevan Pietarin mittava ravinnekuorma sekä Suomenlahden virtaus- ja sekoittumisolot. 
Rannikkovesien ravinne- ja rehevyystilassa on 1970-luvulta lähtien vallinnut kaksi vastakkaista suuntaa. Eräiden aikaisemmin hyvin voimakkaasti rehevöityneiden alueiden (esim. Helsinki-Espoo ja Oulu) tila on parantunut, kun asutuksen ja teollisuuden jätevesien puhdistamista on tehostettu. Erityisesti kuormitettujen alueiden fosforipitoisuus on laskenut, sillä pistekuorman fosforin vähentämistoimet ovat olleet tehokkaita. Kuitenkin rehevöityneiden alueiden kokonaispintaalassa tapahtui 1980-luvulla kasvua, jos mittapuuna pidetään alueita, joilla kesäisin ylittyy keskimäärin $5 \mathrm{mg} \mathrm{m}^{-3}$ a-klorofyllipitoisuus. 1990-luvulla tilanne ei ole oleellisesti muuttunut 1980-luvun loppuun verrattuna.

Myös lievästi rehevöityneiden alueiden (3-5 $\mathrm{mg} \mathrm{m}^{-3}$ ) pinta-ala lisääntyi 1980-luvulla sekä läntisellä Suomenlahdella, Saaristomerellä että Perämerellä siten, että alueet ovat paikoitellen levinneet rannikkovesistä avomeren puolelle. Tilamuutosta voidaan selittää sekä avoimen Itämeren ravinnepitoisuusmuutoksilla että muutoksilla typpikuormituksessa. Typen pitoisuuden nousu 1970- ja 1980-luvulla Suomenlahden avomerialueilla heijastui myös Suomenlahden rannikkovesissä, etenkin kun samaan aikaan myös maalta tuleva typpikuormitus jatkuvasti kasvoi mm. valumien ja lannoitteiden käytön lisääntymisen seurauksena. Saaristomerellä rehevöitymiskehitykseen varsin ilmeisesti vaikutti muiden tekijöiden ohella kalankasvatuksen voimakas lisääntyminen 1980luvun lopulla.

Suomenlahden fosforipitoisuus alkoi 1990-luvun puolivälissä kohota varsin voimakkaasti, mikä johtuu erityisesti itäisen Suomenlahden sisäisen kuormituksen kiihtymisestä vuosikymmenen puolivälin tienoilla. Ilmakehän typpeä sitovien sinilevien massaesiintymien intensiteetti lisääntyi Suomenlahdella samaan aikaan, mikä johtui veden epäorgaanisen typpi:fosfori-suhteen pienenemisestä. Planktonin kokonaismäärässä (a-klorofylli) vastaava trendi on todettu itäisellä Suomenlahdella, lievempänä myös avoimella Suomenlahdella. Fosforipitoisuuden kasvu taittui 1990-luvun lopussa ja talvella 2000 Suomenlahden fosforipitoisuus oli palannut lähelle 1990-luvun alkupuolen tasoa. Typen laskeva trendi sekä Suomenlahden rannikkovesissä että avomerialueella 1990-luvulla on mahdollisesti yhteydessä kuormituksen vähentymiseen noin 30\%:1la 1980-lopun tasoon verrattuna.

\section{Kasviplankton ja sinilevät}

Myöhäiskesän kasviplanktonmäärän kasvu ja lajikoostumusmuutokset ilmentävät lisääntyvää rehevöitymistä Suomenlahdella ja Saaristomerellä. Itäisellä Suomenlahdella kasviplanktonin määrän lisääntyminen on ollut samansuuntainen ravinnepitoisuuksien trendin kanssa. Kasviplanktonin määrän kasvu on tasaantunut 1990-luvun jälkipuoliskolla, samoin fosforipitoisuudet, jotka olivat koholla vuosikymmenen puolivälissä laaja-alaisen happikadon seurauksena. Myös sinilevät ovat lisääntyneet 1980-luvun lopulta lähtien. Leväyhteisössä valtalajeina ovat olleet Planktothrix agardhii ja typensitoja Aphanizomenon sp. Mm. epäorgaanisen typen ja fosforin suhde sekä vallitsevat hydrografiset olosuhteet vaikuttavat lajien asemaan leväyhteisössä. P. agardhii on monasti vallinnut silloin, kun Nevan ravinnepitoisia vesiä on poikkeuksellisesti kesällä ulottunut Suomen itäiseen saaristoon asti.

Kasviplanktonin kokonaismäärät eivät ole lisääntyneet Helsingin ulkosaaristossa, vaikka puhdistetut jätevesiä alettiin 1980-luvun lopulla johtaa ulkosaaristoon. Epäorgaanisen typen ja fosforin suhteen kasvu on suosinut Chroococcales -lahkon sinileviä. Aphanizomenon -lajit eivät muuttuneissa olosuhteissa pystyneet hyötymään typensitomiskyvystään. Myös lahtialueilla fosforipitoisuuksien lasku on johtanut siihen, että typen sitomiseen kykenemättömät sinilevälajit ovat saavutta- 
neet valta-aseman kasviplanktonyhteisössä.

Saaristomerellä kasviplanktonin kokonaismäärän lisääntyminen fosforipitoisuuksien kasvu seurauksena selittyy sisäisellä kuormituksella ja läntisen Suomenlahden ravinnevirtauksilla Saaristomerelle. Sisäisen kuormituksen osuutta puolittain suljettujen altaiden hapettomuuteen ei ole selvitetty. Viime vuosina typpi/fosfori -suhteen vähentyminen ja typpirajoitteisuuden lisääntyminen ovat luultavasti myötävaikuttaneet sinilevien valta-aseman voimistumiseen.

Suomenlahdella ja Saaristomerellä myöhäiskesän sinileväkukintojen voimakkuus ja laajuus ovat lisääntyneet. Sinileväkukintoja on satunnaisesti havaittu myöskin myöhäissyksyllä ja varhaistalvella. Perämerellä sinileväkukinnot ovat harvinaisia. Yleisimmät kukintoja muodostavat sinilevälajit ovat Aphanizomenon ja toisinaan myrkyllinen Nodularia spumigena, jotka kumpikin kykenevät sitomaan ilmakehästä veteen liuennutta typpeä.

Sinileväkukintojen muodostuminen kiihtyy usein kumpuamisten yhteydessä, koska pohjalta veden tuottavaan pintakerrokseen kulkeutuu runsaasti fosforia. Kesällä 1997 olosuhteet voimakkaiden sinileväkukintojen muodostumiselle olivat otolliset, koska tyynet ja lämpimät säät vallitsivat ja pinnan fosforipitoisuudet olivat koholla. Vuonna 1998 sinilevien kukintoja havaittiin poikkeuksellisesti Saaristomeren sisäosista, mikä on todennäköisesti yhteydessä typpirajoitteisuuden lisääntymiseen Saaristomeren alueella. Typpirajoitteisuus selittää sen miksi sinileväkukinnot muodostuvat monasti ulappavesillä. Avomereltä levälauttoja voi ajautua myöskin rantaan. Rannikon ja itäisen Suomenlahden Microcystis-ja Planktothrix-kukinnat vaativat fosforin lisäksi myös epäorgaanista typpeä ja sopivia sääoloja.

\section{Kasvillisuuden muutoksia}

Kuormituksen aiheuttaman ravinnepitoisuuksien kasvusta hyötyvät erityisesti rihmamaiset levät. Nopeakasvuisina lajeina ne pystyvät hyödyntämään tehokkaasti nopeat esim. kumpuamisesta johtuvat ravinnepulssit ja lisäävät siten määrällistä osuuttaan leväyhteisöissä. Tämä on johtanut leväyhteisön lajistollisiin muutoksiin; rihmamaiset lajit lisääntyvät ja monivuotiset puna- ja ruskolevät vähenevät ja kokonaislajimäärä pienenee. Myös levien selkeä vyöhykkeisyys esimerkiksi Saaristomerellä on muuttunut yhteisörakenteen muuttuessa. Sisä- ja välisaaristosta ovat rakkoleväyhteisöt kadonneet laajoilta alueilta. Nykyään sen tilalla kasvavat rihmamaiset rusko- ja viherlevät. Lisääntynyt orgaaninen aines on enenevässä määrin sedimentoitunut pohjalle ja muuttanut sen laatua, jolloin putkilokasvien määrä lisääntyy.

Irtonaisina kasvavien rihmalevien massaesiintymisiä (makrolevälauttoja) on havaittu Merenkurkusta Itäiselle Suomenlahdelle saakka. Erityisesti Ahvenanmerellä ja Saaristomerellä on havaittu makrolevämattojen peittävän laajoja alueita sekä Uudenkaupungin saariston ja Eurajoen merialueella esiintyi paljon suolilevän muodostamia irtonaisia kasvustoja. Suomenlahden makrolevälautat eivät ole olleet niin laaja-alaisia ja monilajisia kuin Saaristo- ja Ahvenanmeren levälautat. Levien massakasvustojen vaikutukset ovat kielteisiä, sillä ne aiheuttavat virkistys- ja taloudellista haittaa. Patjamaisiksi kasvustoiksi muodostuneet rihmalevät vaikeuttavat pohjaeläinyhteisöjä ja patjan alle muodostuvat hapettomat olosuhteet lisäävät pohjasedimentistä vapautuvan fosforin määrää.

Veden samentumisen seurauksena levien kasvusyvyydet ovat pienentyneet. Nykyisin kasvillisuutta tavataan Suomenlahden avoimilla rannoil- 
la 10 metrin syvyyteen. Rakkolevä on monivuotinen, isokokoinen ruskolevä, jonka tarjoama elinympäristö on tärkeä monien eliölajien säilymiselle rantavyöhykkeessä. Rakkolevän Suomen puoleinen levinneisyysalue on Merenkurkusta aina Itäiselle Suomenlahdelle, Virolahdelle saakka. 1970-luvun lopussa havaittiin rakkolevän kadonneen monilta saaristoalueilta, mutta 1980-luvulla rakkoleväkasvustot toipuivat monilla alueilla Saaristomerellä ja Suomenlahdella. Tästä huolimatta rakkolevä ei enää kasva yhtä syvällä kuin aikaisemmin. Rakkolevä kasvoi Tvärminnen ulkosaaristossa 1930- ja 1960-luvulla vielä noin 10 metrin syvyydessä, mutta 1990 luvulla rakkolevä kasvoi 5-6 metrissä optimisyvyyden ollessa 2-3 metrissä. Saarisomerellä rakkolevä kasvaa noin 1-4 metrin syvyydessä, vaikka muutamia yksittäisiä yksilöitä on tavattu 7-8 metrin syvyydessä.

\section{Vieraslajit}

Suurin osa lajeista on saapunut laivojen painovesilastin mukana tai runkoon kiinnittyneinä. Suomen rannikkovesialueelta havaitut uudet tulokaslajit ovat vakiintuneet 1990-luvulla alueelle. Pohjois-Amerikkalaista alkuperää on pohjille asettunut monisukamato Marenzelleria viridis, MustanmerenKaspianmeren alueelta ovat peräisin vaeltajasimpukka Dreissena polymorpha, halkoisjalkainen Hemimysis anomala ja petovesikirppu Cercopagis pengoi. Näistä etenkin viimeksi mainittu on muodostanut massaesiintymiä ja aiheuttanut taloudellista vahinkoa limoittamalla kalastajien pyydyksiä ja verkkoja. Itämeren herkkyys näille tulokaslajeille johtuu siitä, että Itämeri on verrattain nuori, vähälajinen ekosysteemi. Tulokaslajit saattavat muuttaa ekosysteemin ravintoketjuja ja aiheuttaa taloudellista vahinkoa kalastukselle tai tukkia vedenottojärjestelmiä.

\section{Pohjaeläimet}

Rannikkovesien pohjien tilassa on 1980-luvun jälkeen tapahtunut huomattavia muutoksia. Kuormitetuilla alueilla muutossuunnat ovat kuitenkin varsin vaihtelevia. Useilla voimakkaasti kuormitetuilla alueilla sisimmän saariston likaantuneeksi luokiteltu alue on nykyään kaventunut, kun orgaanisen aineen ja fosforin kuormitus on alentunut. Suomenlahden keskiosan rannikoilla, näiden pohjien tila on heikentynyt voimakkaasti, vaikka pistemäinen kuormitus onkin vähentynyt. Selvät alueelliset erot sisäsaariston pohjien tilan kehityssuunnissa johtuvat jätevesikuormituksen muutosten lisäksi myös rannikkovesien morfologiasta, pohjasedimentin laadusta ja veden sekoittumisoloista sekä läheisen avomeren tilasta.

Ulommassa saaristossa pohjaeläinyhteisöjen tila on Pohjanlahdella muuttunut varsin vähän, mutta heikentynyt Saaristomerellä ja erityisesti Suomenlahdella 1990-luvulla. Selvimmät merkit tästä ovat puhtaita vesiä indikoivan valkokatkan vähentyminen sekä harvasukasmatojen ja surviaissääsken toukkien määrän lisääntyminen. Syynä on mm. pohjan happiolojen heikkeneminen orgaanisen aineksen tuotannon lisääntymisen seurauksena. Hapettomat, kuolleet pohjat ovatkin olleet yleisiä laajoilla Suomenlahden alueilla 1990-luvun loppupuolella, mikä johtuu huomattavan suuresta niin sisäisestä kuin ulkoisestakin ravinnekuormituksesta.

Rannikkovesien puhtaammilta alueilta pohjaeläimistön seurantatuloksia on käytettävissä ainoastaan Hankoniemen länsipuolelta. Huomattavin muutos on siellä se, että kahden valtalajin, valkokatkan ja liejusimpukan määräsuhteet ovat pitkän seurantajakson aikana muuttuneet, ja jopa kääntyneet 1990-luvulla päinvastaisiksi edelliseen vuosikymmeneen verrattuna. Tämä, 
samoin kuin joidenkin muiden lajien määrämuutokset sopivat yhteen rannikkovesillä jatkuvan yleisen rehevöitymiskehityksen kanssa, mutta on kuitenkin huomattava, että nykyisenkaltainen valtalajikoostumus vallitsi alueella jo 1920-luvulla, joten muutoksiin täytyy olla muitakin syitä kuin vain veden rehevöityminen, kuten esimerkiksi lajien välinen ja lajien sisäinen kilpailu.

\section{Kalat ja kalastus}

Rehevöityminen vaikuttaa yleensä kalakantoihin siten, että kalojen määrä kasvaa lisääntyneiden ravintovarojen seurauksena. Rehevöityminen muuttaa kalakantojen rakennetta särkivaltaisemmaksi, parantaa joidenkin lajien kasvua ja lisää poikasten ja pienten kalojen tuotantoa. Muutamat kalalajit kärsivät rehevöitymisestä. Ruskoleväyhdyskuntien katoaminen sameuden vuoksi laajoilta pohja-aloilta on heikentänyt mm. ahvenen ja hauen elinolosuhteita. Monet kalalajit välttävät vähähappisia vesiä. Rehevöitymisen haitalliset vaikutukset kaupalliseen ja virkistyskalastukseen ilmenee kalastajien pyydysten ja verkkojen tuhriintumisina ja limoittumisina sekä kalojen haju- ja makuhaittoina.

Suolaisuus vaikuttaa myöskin kalakantojen rakenteeseen sekä kalojen määrään ja esiintymiseen rannikolla. Itämeren suolaisuus on alentunut, koska Itämereen ei ole Tanskan salmien kautta tullut voimakkaita suolapulsseja 1980- ja 1990-lukujen aikana, lukuun ottamatta vuoden 1993 kohtalaisen voimakasta suolapulssia. Vähäinen suolapitoisuuden lasku Suomenlahdella ja Saaristomerellä on epäsuorasti heijastunut silakan kasvun pienentymisenä, mikä johtuu silakan ravintokohteiden määrän vähentymisenä. Tällä on taloudellista merkitystä, sillä silakka on tärkein kauppakala Suomessa.

\section{Haitalliset aineet}

Suuret määrät raskasmetalleja, orgaanisia yhdisteitä ym. haitallisia aineita on joutunut piste- ja hajakuormituksen seurauksena Suomen rannikkovesiin. Tämä ilmenee pohjasedimentin ja eliöstön kohonneina pitoisuuksina. Eliöstöön kertyvät haitalliset aineet voivat rikastua ravintoverkossa tai aiheuttaa muutoksia lisääntymisessä, kasvussa ja aineenvaihdunnassa.

Raskasmetallien, erityisesti lyijyn, kadmiumin ja elohopean, pitoisuudet sedimentissä jakautuvat alueellisesti siten, että ne laskevat Pohjanlahdella pohjoisesta etelään päin ja Suomenlahdella idästä länteen päin. Sedimentin elohopeapitoisuudet olivat korkeita Pohjanlahdella kun taas kadmiumpitoisuudet Suomenlahdella. Suomen rannikkovesien alueella raskasmetallien maksimipitoisuudet olivat selvästi alle Itämeren huippuarvojen. Korkeita pitoisuuksia eliöstöstä on mitattu teollisuusalueiden lähivesillä. Kilkin metallipitoisuudet eivät poikenneet taustatasosta. Liejusimpukan kupari-, kadmium- ja elohopeapitoisuudet olivat laskussa. Kalojen elohopeapitoisuudet ovat myöskin vähentyneet selvästi teollisuuden kuormittamilla vesialueilla 1960ja 1970-lukujen aikana.

Haitallisten orgaanisten yhdisteiden pitoisuudet sedimentissä olivat korkeita mm. sellu- ja petrokemian teollisuuden läheisyydessä. Vesiensuojelutoimenpiteiden ansiosta näiden yhdisteiden pitoisuudet sedimentissä ovat vähentyneet. Korkeita orgaanisten yhdisteiden pitoisuuksia on mitattu myös eliöstöstä. PCB:n ja DDT:n pitoisuudet ovat yleisesti laskeneet Itämeren eliöstössä 1970-luvulta lähtien. Silakassa pitoisuuksien pieneneminen on hidastunut 1990-luvulla.

Petrokemian teollisuus on merkittävä öljyperäisten yhdisteiden lähde. Pitoisuudet vedessä ovat yleensä olleet 
määritysrajojen alapuolella 1980- ja 1990-lukujen aikana. Suurimmat öljypitoisuudet sedimentissä mitattiin teollisuuden lauhdevesiputkien ulkopuolella. Petrokemian teollisuuden läheisyydessä kaloissa ei ole todettu normaalia korkeampia pitoisuuksia. Öljyperäisten yhdisteiden haitallisuus perustuu siihen, että suurina pitoisuuksina ne voivat aiheuttaa fysiologisia muutoksia eliöstössä.

\section{Rannikkovesien käyttökelpoisuusluokitus}

Yleisen käyttökelpoisuusluokituksen mukaan lähes 90 \% Suomen rannikkovesistä kuului hyvään tai erinomaiseen laatuluokkaan, mikä on osoitus siitä että vesialueet ovat luonnontilaisia tai lähes luonnontilaisia. Hyvään ja erinomaiseen luokkaan kuuluvat alueet kattoivat avomeren ja suuren osan Pohjanlahden rannikkoa. Noin 10 \% merialueesta kuului tyydyttävään luokkaan. Alue sijaitsee Suomenlahden ja Saaristomeren rannikolla sekä Pohjanlahden kuormitetuilla alueilla. Ainoastaan yksi prosentti merialueesta kuului tyydyttävään luokkaan. Rehevöityminen oli tärkein syy veden laadun heikkenemiseen, mikä ilmeni mm. korkeina a-klorofyllin pitoisuuksina, toistuvina leväkukintoina tai pohjan happikatoina. Hygieniset indikaattoribakteerit heikensivät veden laatua muutamissa sisälahdissa ja haitallisten aineiden kuten elohopean ja orgaanisten klooriyhdisteiden korkeat pitoisuudet joidenkin teollisuusalueiden edustoilla. 
Aaltonen, E.K. \& Kalliolinna, M. 1990. Kokkolan edustan merialueen tila 1986-1989. Vaasan läänin vesiensuojeluyhdistys. 71 p. + app.

Aarnio, K. \& Bonsdorff, E. 1997. Passing the gut of juvenile flounder, Patichtys flesus: differential survival of zoobenthic prey species. Marine Biology 129: 11-14.

Alasaarela, E. 1980. Phytoplankton and environmental conditions in the northern part of the Bothnian Bay. Acta Universitatis Ouluensis. Series A, no. 90, 23 p.

AMAP, 1998. Arctic Monitoring and Assessment Programme, Oslo, 1998.

Andersson, L. \& Lepistö, L. 1998. Links between runoff generation, climate and nitrate-N leaching from forested catchments. Water, Air and Soil pollution 105: 227-237.

Antikainen, S., Joukola, M. \& Vuoristo, H. 2000. Water quality in Finland in the mid 1990s. Vesitalous Vol. 41, No. 2/ 2000. Helsinki.

Antsulevich, A., Maximovich, N. \& Vuorinen, I. 1999. Population structure, growth and reproduction of the common mussel (Mytilus edulis L.) off the Island of Seili (SW Fnland). Bor. Envir. Res. 4: 367-375.

Anttila, R.1973. Effect of sewage on the fish fauna in the Helsinki area. Oikos 15: 226-229.

Aro, E. 1998. Turska (Cod). Official Statistics of Finland, SVT Environment 1998:13: 10-13 (in Finnish).

Barret, K. \& Berge, E. (eds) 1996. Transboundary air pollution in Europe. EMEP, MSC-W Report 1/96, Part 2. Norwegian Meteorological Institute Research Report 32, Oslo.

Bartnicki, J., Barrett, K., Tsyro, S., Erdman, L., Gusev, A., Dutchak, S., Pekar, M., Lükewille, A. \& Krognes, T. 1998. Atmospheric supply of nitrogen, lead, cadmium, mercury and lindane to the Baltic Sea. EMEP/MSC-W Note 3/98.

Bergström, U. \& Björkqvist, L. 1997. Fucus vesiculosus communities in the northern Quark, northern Baltic Sea. - Abstracts of the BMB 15 and ECSA 27 Symposium, Mariehamn, Finland, 9-13 June 1997. p.34.

Bonsdorff, E. 1992. Drifting algae and zoobenthos-effect on settling and community structure. Netherlands J. Sea Res. 30:57-62.

Bonsdorff, E., Blomqvist, E.M., Mattila, J. \& Norkko, A. 1997a. Long-term changes and coastal eutrophication. Examples from the Åland Islands and the Archipelago Sea, Northern Baltic Sea. Oceanologica Acta 20: 319-329.

Bonsdorff, E., Blomqvist, E.M., Mattila, J. \& Norkko, A. 1997b. Coastal Eutro-phication: Causes, consequences and perspectives in the Archipelago Areas of the Northern Baltic Sea. Estuarine, Coastal and Shelf Science 44: 63-72.

Borg, H. \& Jonsson, P. 1996. Large-scale metal distribution in Baltic Sea sediments. Mar. Poll. Bull. 32: 8-21.

Boström, C. 1995. Flowering and fruit-bearing Zostera marina in Åland, Northern Baltic Sea. Mem. Soc. Fauna Flora Fenn. 71: 7-9.

Boström, C. 1996. Evertebratfaunans samhällsstruktur i Zostera marina (L.) ängar - en analys i tid och rum. Pro gradu-avhandling, Inst för biol. Åbo Akademi. 87 p.

Boström, C. \& Bonsdorff, E. 1997. Community structure and spatial variation of benthic invertebrates associated with Zostera marina (L.) beds in SW Finland. J. Sea Res. 37: 153-166.

Boström, C. \& Mattila, M. 1999. The relative importance of food and shelterfor seagrass associated invertebrates - a latitudinal com-parison of habitat choice by isopod grazers. Oecologia 120: 162-170.

Boström, C., Bonsdorff, E., Kangas, P. \& Norkko, A. 1997. Long-term changes in an eelgrass (Zostera marina L.) community in the northern Baltic Sea. - Abstracts of the BMB 15 and ECSA 27 Symposium, Mariehamn, Finland, 9-13 June 1997. p.35.

Bäck, S., Collins, J.C.C. \& Russell, G. 1991. Aspects of the reproductive biology of Fucus vesiculosus from the coast of SW Finland. Ophelia 34: 129-141. 
Bäck, S., Lehvo, A. \& Kiirikki, M. 1993a. The occurrence of macroalgal mass blooms on the Finnish Baltic coast. -In: Rijsteinbil, J.W. \& Haritonidis, S. (eds). Macroalgae, eutrophication and trace metals cycling in estuaries and lagoons. Proc. of the COST48 Symposium of Sub Group III. 24-26 September 1993. Bridge. Commision of the European Communities.

Bäck, S., Mäkinen, A., Rissanen, J. \& Rönnberg, O. 1993b. Phytobenthos monitoring. Two case studies from the Finnish Baltic coast in summer 1993. Ministry of the Environment. Finland. Memorandum 1993: 1-24.

Bäck, S. \& Ruuskanen, A. 2000. Distribution and maximum growth depth of Fucus vesiculosus along the Gulf of Finland. Mar. Biol. 136: 303-307.

Bäck, S., Lehvo, A. \& Blomster, J. 2000. Mass occurrence of unattached Enteromorpha intestinalis on the Finnish Baltic coast. Annales Bot. Fennici 37: 155-161.

Böhling, P. \& Ådjers, K. 1998. Merialueen ahven (Perch in coastal waters). Official Statistics of Finland, SVT Environment 1998:13: 46-49 (in Finnish).

Enckell-Sarkola, E., Pitkänen, H. \& Wrådhe, H. 1989. The metal load on the Gulf of Bothnia. Vesi- ja Ympäristöhallituksen monistesarja 291. 44 p.

Erkkilä, H. \& Vaajakorpi, H. 1993. Porvoon edustan merialueen tarkkailu vuonna 1992. Vesihydro Oy. 53 p. + app.

Erkkilä, H. \& Vaajakorpi, H. 1999. Porvoon edustan merialueen tarkkailu vuonna 1998. Laaja vuosiyhteenveto 31.5.1999. Vesihydro Oy. 40 p. + app.

Ferin-Westerholm, P. (ed.) 1994. Ympäristön tila Pohjois-Pohjanmaalla ja Kainuussa.. Vesija ympäristöhallitus, Ympäristötietokeskus, alueelliset tilaraportit 2, Helsinki.

Finnish statistical yearbook of forestry. (in Finnish): Metsätilastollinen vuosikirja 1997. Suomen virallinen tilasto. Maa- ja metsätalous 1997:4. Helsinki 1997.

Flinkman, J., Aro, E., Vuorinen, I. \& Viitasalo, M. 1998. Changes in northern Baltic zooplankton and herring nutrition from 1980s to 1990s: top-down and bottom-up processes at work. Mar. Ecol. Prog. Ser. 165: 127-136.

Forsberg, C., Ryding, S.-O., Claesson, A. \& Forsberg, Å. 1978. Water chemical analyses and/or algal assay? Sewage effluent and polluted lake water studies. Mitt. int. Verein. Limnol. 21: 352-363.

Grönlund, L. \& Leppänen, J.-M. 1990. Long-term changes in the nutrient reserves and pelagic production in the western Gulf of Finland. Finnish Mar. Res. 257: 15-27.

Haahtela, I. 1984. A hypothesis of the decline of the bladderwrack (Fucus vesiculosus L.) in SW Finland in 1975-1981. Limnologica 15: 345-350.

Haahtela, I. \& Lehto, J. 1982. The occurrence of bladder wrack (Fucus vesiculosus) in 19751980 in the Seili area, Archipelago Sea. Mem. Soc. Fauna Flora Fennica 58:1-5.

Haasala, K. \& Kauppinen, V. 1995. Kemin edustan merialueen biologinen seuranta v. 1994. Pohjois-Suomen vesitutkimustoimisto. 25 p. + app.

Hario, M., Hollmen, T., Kilpi, M., Lehtonen, J.T., Mustonen, O., Westerbom, M. \& Öst, M. 1999: Riittääkö haahkalle ravintoa Suomenlahdella? Suomen Riista 45:34-45.

Heinonen P. \& Herve S. 1987. Water quality classification of inland waters in Finland. Aqua Fennica 17,2:147-156.

Heitto, L. \& Anttila-Huhtinen, M. 1995. Haitalliset aineet Kymijoella ja sen edustan merialueella. Raportti vuoden 1994 velvoitetarkkailutuloksista. Kymijoen Vesiensuojeluyhdistys. Käsikirjoitus.

HELCOM 1993. First assessment of the state of the coastal waters of the Baltic Sea. Baltic Sea Env. Proc. 54: 1-155.

HELCOM 1996. Third periodic assessment of the state of the marine environment of the Baltic Sea, 1989- 93; Background document. Baltic Sea Env. Proc. 64 B: 1-252.

HELCOM 1998. The third Baltic Sea pollution load compilation (PLC-3). Baltic Sea Env. Proc. 70: 1-133.

Helminen, H., Juntura, E., Koponen, J., Laihonen, P. \& Ylinen, H. 1998. Itämereltä saaristomereen tulevan fosfori- ja typpikuormituksen arviointi kolmiulotteisen virtausmallin avulla. Vesitalous 2: 27-30.

Heiskanen 1998. Factors governing sedimentation and pelagic nutrient cycles in the northern Baltic Sea. Doc. thesis. Helsinki 1998, 80 p. 
Henriksson S.-H. 1991. Effects of fish farming on natural Baltic fish communities. In: Mäkinen, T. (ed.). Marine aquaculture and environment. Nordic Council of Ministers. Nord 22: 85-104.

Holm, N.G. 1988. Arsenic regeneration from estuarine sediments of the Bothnian Bay, Sweden. Chem. Geol. 68: 89-98.

Holmström, A., Norkko, A. \& Bonsdorff, E. 1997. Drift algal mats - field and laboratory studies of occurrence, biomass, species composition and decomposition. - Abstracts of the BMB 15 and ECSA 27 Symposium, Mariehamn, Finland, 9-13 June 1997. p. 43

Hudd, R., Kjellman, J. \& Urho, L. 1996. The increase of coincidence in relative year-class strengths of coastal perch (Perca fluviatilis L.) stocks in the Baltic Sea. Ann. Zool. Fennici 33: 383-387.

Häkkilä, K. 1984. Pohjasedimentin ja simpukoiden raskasmetallipitoisuuksia Selkämeren eteläosan rannikolla. Vesihallituksen monistesarja 303: 1-33.

Häkkilä, K. 1985. Pohjasedimentin ja simpukoiden raskasmetallipitoisuuksista Selkämeren eteläosan rannikolla. Vesihallituksen monistesarja 380: 38 p.

Häkkilä, K. 1998. Leväkukinnat Lounais-Suomen ympäristökeskuksen alueella. In: Rantajärvi, E. (ed.) Leväkukintatilanne Suomen merialueilla ja varsinaisella Itämerellä vuonna 1997. Meri 36: 1- 32.

Hällfors, G., Niemi, Å., Ackefors, H., Lassig, J. \& Leppäkoski, E. 1981. Chapter 5, Biological Oceanography. In: Voipio, A. (ed.). The Baltic Sea. Elsevier Oceanography Series, 30. 418 pp.

Hällfors, G., Kangas, P. \& Niemi, Å. 1984. Recent changes in the phytal at the southern coast of Finland. Ophelia 3:51-59.

Hänninen, J., Kirkkala, T. \& Lehtilä, K. 1997. Fosfori- ja typpipitoisuuksien pitkäaikaismuutoksista Saaristomerellä. Vesitalous 5: 17-22.

Hökkä, M. \& Rantala, L. 1992. Oulun edusta. Velvoitetarkkailun yhteenveto v. 1988-1991. Pohjois-Suomen vesitutkimustoimisto. 55 p. + app.

Ilus, E. 1997. Loviisan ydinvoimalaitosta ympäröivän merialueen biologinen tarkkailu vuonna 1996. Säteilyturvakeskus. 31 p. + app.

Isosaari, P., Kiviranta, H., Kohonen, T., Salonen, V.-P., Tuomisto, J. \& Vartiainen, T. 1999. Environmental distribution of PCDD/Fs from vinylchloride monomer production: a case study. Organohalogen Compounds 41: 417-420.

Jankovski, H., Simm, M. \& Roots, O. 1996. Harmful substances in the ecosystem of the Gulf of Finland. Estonian Marine Institute. EMI reports series, No 4. Tallinn. 1996.

Jumppanen, K. 1993. Uudenkaupungin merialueen kuormitus ja tila vuonna 1992. Lounais-Suomen vesiensuojeluyhdistys 82: $38 \mathrm{p}$.

Jumppanen, K. 1997a. Uudenkaupungin merialueen kuormitus ja tila vuonna 1996. Lounais-Suomen vesiensuojeluyhdistys. 48 p. + app.

Jumppanen, K. 1997b. Uudenkaupungin merialueen pohjaeläintutkimus vuonna 1996. Lounais-Suomen vesiensuojeluyhdistys. Tutkimusselosteita 128. 30 p. + app.

Järvinen, O. \& Vänni, T. 1997. Sadeveden pitoisuus- ja laskeuma-arvot Suomessa vuonna 1995. Suomen ympäristökeskuksen moniste 78. Helsinki, 68 pp.

Kahru, M., Horstmann, U. \& Rud, O. 1994. Satellite detection of increased cyanobacteria blooms in the Baltic Sea: Natural fluctuations or ecosystem change? Ambio 23: 469472.

Kalliolinna, M. 1998. Kokkolan edustan yhteistarkkailun tulokset 1997. Pohjanmaan vesiensuojeluyhdisty ry. Pietarsaari 1998, 27 p. + 8 app.

Kalliolinna, M. \& Aaltonen, E.-K. 1991. Pietarsaaren edustan velvoitetarkkailun yhteenveto 1990. Vaasan läänin vesiensuojeluyhdistys ry

Kalliolinna, M. \& Aaltonen, E.-K. 1995. Kokkolan edustan merialueen tila 1990-1994. Vaasan läänin vesiensuojeluyhdistys. 85 p. + app.

Kangas, P. \& Niemi, A. 1985. Observations of recolonization by the bladderwrack, Fucus vesiculosus, on the southern coast of Finland. Aqua Fennica 15:133-141.

Kangas, P., Autio, H., Hällfors, G., Luther, H., Niemi, Å. \& Salemaa, H. 1982. A general model of the decline of Fucus vesiculosus at Tvärminne, south coast of Finland in 1977-81. Acta Bot. Fenn. 118: 1-27.

Kankaanpää, H. 1997. Sedimentation, distribution, sources and properties of organic halogen material in the Gulf of Finland. Bor. Ecol. Res. Monographs, no 6. 
Kauppi, L. 1979. Phosphorus and nitrogen input from rural population, agriculture and forest fertilization to watercourses. Publication of the Water Research Institute, National Board of Waters, Finland 34: 35-46.

Kauppi, L. (toim.) 1993. Itäisen Suomenlahden lintukuolemat keväällä 1992. Vesi- ja Ympäristöhallitus, Helsinki. Vesi- ja ympäristöhallinnon julkaisuja - sarja A, no 142,46 p.

Kauppila, P., Hällfors, G, Kangas, P., Kokkonen, P. \& Basova, S. 1995. Late summer phytoplankton species composition and biomasses in the eastern Gulf of Finland. Ophelia 42: 179-191.

Kauppila, P. \& Lepistö, L. 1997. Levätilanne Suomen rannikkovesissä. In: Rantajärvi, E. (ed.). Leväkukintatilanne Suomen merialueilla ja varsinaisella Itämerellä vuonna 1996. Meri 29: 11-12.

Kauppila, P. \& Lepistö, L. 1998. Levätilanne Suomen rannikkovesissä. In: Rantajärvi, E. (ed.). Leväkukintatilanne Suomen merialueilla ja varsinaisella Itämerellä vuonna 1997. Meri 36: 13-14.

Kauppinen, V. 1987. Tornion edustan kalataloustutkimukset v. 1986. II Kalataloustarkkailu. Pohjois-Suomen vesitutkimustoimisto. 17 p. + app.

Kauppinen, V. 1991a. Oulun edustan merialueen pohjaeläinselvitys v. 1991. PohjoisSuomen vesitutkimustoimisto. 21 p. + app.

Kauppinen, V. 1991b. Raahen edustan merialueen kalataloudellinen velvoitetarkkailu v. 1990. Pohjois-Suomen vesitutkimustoimisto. 25 p. + app.

Kauppinen, V. 1994. Raahen edustan merialueen kalataloudellinen velvoitetarkkailu v. 1993. Pohjois-Suomen vesitutkimustoimisto. 27 p. + app.

Kauppinen, V. 1995. Tornion edustan merialue. II Kalataloustarkkailu v. 1992-1994. Pohjois-Suomen vesitutkimustoimisto. 29 p. + app.

Kauppinen, V. 1997. Tornion edustan merialue. III Kalat ja kalastus v. 1996. PSV-Maa ja Vesi. 26 p. + app.

Kautsky, H. 1995. Vegetationsklädda bottnar. - Östersjö '94. Årsrapport från den marina miljöövervakning-en juli 1995. Stockholms Marina Forskningscentrum. pp. 23-25.

Kautsky, L.1982. Primary production and uptake kinetics of ammonium and phosphate by Enteromorpha compressa in an ammonium sulphate industry outlet area. Aquatic Botany 12: 23-40.

Kautsky, N., Kautsky,H., Kautsky, U. \& Waern, M. 1986. Decreased depth penetration of Fucus vesiculosus (L.) since 1940s indicates eutrophication of the Baltic Sea. Mar. Ecol. Prog. Ser. 28: 1-8.

Keinänen, M., Tolonen, T., Ikonen, E., Parmanne, R., Tigerstedt, C., Ryti-lahti, J., Soivio, A. \& Vuorinen, P.J. 2000. Itämeren lohen lisääntymishäiriö -M74. Kalatutkimuksia, Fiskundersökningar 165. Riista- ja kalatalouden tutkimuslaitos.

Kenttämies, K. \& Vilhunen, O. 1999. Metsätalouden fosfori- ja typpikuormitus vuosina 1977-1996 ja arvio kuormituksen kehittymisestä vuoteen 2005 erityisesti Oulujärven vesistöalueella. In: Metsätalouden ympäristökuormitus. Seminaari Nurmeksessa 23. - 24.9.1998. Tutkimusohjelman väliraportti. Metsäntutkimuslaitoksen tiedonantoja 745: 115-126.

Kiirikki, M. \& Blomster, J. 1996. Wind induced upwelling as a possible explanation for mass occurrences of epiphytic Ectocarpus siliculosus (Phaeophyta) in the northern Baltic Proper. Mar. Biol. 127: 353-358.

Kiirikki, M. \& Lehvo, A. 1997. Life strategies of filamentous algae in the northern Baltic Proper. Sarsia 82:259-267.

Kirkkala, T. 1998. Miten voit Saaristomeri? Ympäristön tila Lounais-Suomessa 1. LounaisSuomen ympäristökeskus. $70 \mathrm{p}$.

Kirkkala, T., Helminen, H. \& Erkkilä, A. 1998. Variability of nutrient limitation in the Archipelago Sea, SW Finland. Hydrobiologia 363: 117-126.

Kivi, K., Kaitala, S., Kuosa, H., Kuparinen, J., Leskinen, E., Lignell, R., Marcussen, B. \& Tamminen, T. 1993. Nutrient limitation and grazing control of the Baltic plankton communcty during annual succession. Limnol. Oceanogr. 38: 893-905.

Kjellman, J., Hudd, R., Leskelä, A., Salmi, J. \& Lehtonen, H. 1994. Estimation and prognosis of recruitment failures due to episodic acidification on burbot (Lota lota L.) of the River Kyröjoki. Aqua Fennica 24: 51-57. 
Koistinen, M. 1989. Vesikasvillisuus Hankoniemen pohjoispuolen merialueella, teollisuuden ammoniumpäästöjen vaikutuspiirissä v. 1988. Vesi- ja ympäristöhallituksen monistesarja 186: 1-149.

Koivisto, V. M. \& Blomqvist, E. M. 1988. Does fish farming affect natural Baltic fish communities? Kieler Meeresforsch., Sonderh. 6: 301-311.

Kokemäenjoen vesistön vesiensuojeluyhdistys ry. 1995. Kokemäenjoen ja Porin edustan merialueen yhteistarkkailu: sedimentin metallipitoisuudet kokemäenjoessa, Pihlavanlahdella ja Ahlaisten saaristossa vuonna 1995.

Koli, L., Rask, M., Viljanen, M. \& Aro, E. 1988: The diet of perch, Perca fluviatilis L., at Tvärminne, northern Baltic Sea, and a comparison with two lakes. - Aqua Fennica 18: 185-191.

Kononen, K. 1992. Dynamics of the toxic cyanobacterial blooms in the Baltic Sea. Finnish Marine Research 261: 1-36.

Korhonen, M., Verta, M., Lehtoranta, J., Kiviranta, H. \& Vartiainen, T. 1999. The levels of $\mathrm{PCDD} / \mathrm{Fs}$ in fish in river Kymijoki polluted by Ky-5 manufacturing. Organohalogen Compounds 41: 431-433.

Kukk, H. \& Viitasalo, I. 1997. The convalescence of Seurasaari Bay: recovery of macrophyte vegetation took fifteen years after closing the wastewater sewers. Abstracts of the BMB 15 and ECSA 27 Symposium, Mariehamn, Finland, 9-13 June 1997. p.13.

Kyröläinen, H. 1995. Vaasan edustan merialueen yhteistarkkailu. Vuosiyhteenveto 1994. Vaasan kaupunki ympäristölaboratorio.

Kyröläinen, H. 1996.Vaasan edustan merialueen yhteistarkkailu. Vuosiyhteenveto 1995. Vaasan kaupunki ympäristölaboratorio.

Kähäri, J., Mäntylahti, V. \& Rannikko, M. 1987. Soil fertility of Finnish cultivated soils. Viljavuuspalvelu Oy. Helsinki 1987. 105 p.

Kärkkäinen, A. 1995. Kemira Pigments Oy. Porin edustan merialueen pohjaeläimistö 1994. Kokemäenjoen vesistön vesiensuojeluyhdistys. 37 p. + app.

Kääriä, J., Eklund, J., Hallikainen, S., Kääriä, R., Rajasilta, M., Ranta-aho, K. \& Soikkeli, M. 1988. Effects of coastal eutrophication on the spawning grounds of the Baltic herring in the SW archipelago of Finland. Kieler Meeresforsch. 6: 348-356.

Lampolahti, J. 1997. Uudenkaupungin merialueen kasvillisuuden kehitys 1990-1996. Tutkimusraportti Kemira Agro Oy:n Uudenkaupungin tehtaille. 30 p. + 36 figs..

Langi, A. \& Paavilainen, K. 1996. Kaskisten merialueen velvoitetarkkailu vuonna 1995. KCL Ekolab. 18 p. + app.

Lapp, B. \& Baltzer, W. 1993. Early diagenesis of trace metals used as an indicator of past productivity changes in coastal sediments. Geochim. Cosmochim. Acta 57: 46394652.

Lappalainen, A., Rask, M., Koponen, H. \& Vesala, S. 2000a. Relative abundance, diet and growth of perch (Perca fluviatilis) and roach (Rutilus rutilus) at Tvärminne, northern Baltic Sea - comparison between years 1975 and 1997. (submitted manuscript).

Lappalainen, A., Shurukhin, A., Alekseev, G. \& Rinne, J. 2000 b. Coastal fish communities along the northern coast of the Gulf of Finland, Baltic Sea: responses to salinity and eutrophication (submitted in Int. Rev. Hydrobiol.).

Lappalainen, A. \& Pesonen, L. 1998. Veden laadun paranemisesta huolimatta Helsingin ja Espoon lahtialueiden kalasto muuttuu hitaasti. Vesitalous 5/1998, p. 32-35.

Lappalainen, A. \& Pönni, J. 1996. Suomenlahti kalastajien silmin - vesien likaantumien ja kalastus Suomenlahdella. Kalatutkimuksia 107, 44 pp.

Lappalainen, A. \& Pönni, J. 2000. Eutrophication and recreational fishing on the Finnish coast of the Gulf of Finland: mail survey. Fishes, Man and Ecol. 7: 323-335.

Lappalainen, A., Hällfors, G. \& Kangas, P. 1977. Littoral benthos of the Northern Baltic Sea. IV Pattern and dynamics of macrobenthos in a sandy-bottom Zostera marina community in Tvärminne. Int. Rev. Ges. Hydrobiol. 62: 465-503

Lehtonen, H. 1985. Changes in commercially important freah water fish stocks in the Gulf of Finland during recent decades. Finnish Fish. Res. 6: 61-70.

Lehvo, A. \& Bäck, S. 2001: Survey of macroalgal mats on southeastern Baltic coast of Finland. Aquatic Conservation 11:11-18

Lehvo, A. \& Bäck, S. 2000: Notes on sublittoral vegetation in the vicinity of the Vyborg Bay, Russia. Mem. Soc. Fauna Flora Fennici 76: 7-13. 
Leivuori, M. \& Niemistö, L. 1995. Sedimentation of trace metals in the Gulf of Bothnia. Chemosphere 31: 3839-3856.

Leivuori, Mirja; Puhakainen, Tanja; Riikonen, Jere 1997: Heavy metals in Baltic herring. Kemia 97. Kemian Päivät, Helsinki. Abstraktit:39

Leppäkoski, E. 1975. Assessment of degree of pollution on the basis of macrozoobenthos in marine and brackish water environments. Acta Acad. Aboensis B 35.

Lindholm, T. 1992. Ecological role of depth maxima of phytoplankton. Arch. Hydrobiol. Beih. Ergebn. Limnol. 35: 33-45.

Lindholm, T. \& Virtanen, T. 1992. A bloom of Prymnesium parvum Carter in a small coastal inlet in Dragsfjärd, southwestern Finland. Environmental Toxicology and Water Quality. 7 (2): 165-170.

Littorin, B. \& Gilek, M. 1997. A photographic documentation of the recolonisation of cleared patches in a dense population of Mytilus edulis in the northern Baltic proper. Abstracts of the BMB 15 and ECSA 27 Symposium, Mariehamn, Finland, 9-13 June 1997. p.15.

Lounais Suomen Vesiensuojeluyhdistys ry. 1995. Rauman edustan sedimentti- ja pohjaeläintutkimukset.1994

Miettinen, P., Holmberg, R., Jokinen, O., Ranta, E. \& Kuosa, H. 1994. Mustionjoen, Fiskarsinjoen, Pohjanpitäjänlahden ja Tammisaaren merialueen yhteistarkkailun yhteenveto vuodelta 1993. Länsi-Uudenmaan vesi- ja ympäristö, julk no 38a.

Munsterhjelm, R. 1997. The aquatic macrophyte vegetation of flads and gloes, $\mathrm{S}$ coast of Finland. Acta Bot. Fennica 157:1-68.

Mäkinen, A., Haahtela, I., Ilvessalo, H., Lehto, J. \& Rönnberg, O. 1984. Changes in the littoral rocky shore vegetation in the Seili area, SW Archipelago of Finland. Ophelia Supplement 3:157-166.

Mäkinen, A., Hänninen, J. \& Vahteri, P. 1994. Saaristomeren kansallispuiston vedenalaisen luonnon kartoitus ja litoraalin kasvillisuuden seuranta. Saaristomeren tutkimuslaitos, Turun yliopisto. Väliraportti 1994.

Mäkinen, T. (toim.) 1998. Kalankasvatuksen ympäristökuormitustavoitteet ja oikeudellinen ohjaus Saaristomerellä ja Ahvenanmerellä. Suomen ympäristökeskuksen moniste, no 133, $44 \mathrm{~s}$.

Nakari, T. 1992. Porvoon edustan merialueen meriveden vaikutuksista sumputettujen ja luonnonkalojen elintoimintoihin. Vesi- ja Ympäristöhallinnon julkaisuja -sarja A, no $94,175 \mathrm{~s}$.

National Board of Waters 1983. Vesistöjen tila 1980-luvun alussa. Vesiensuojelun tavoiteohjelman osaprojekti n:o 7. National Board of Waters Report No. 194, Helsinki.

National Board of Waters and the Environment 1988. Vesistöjen laadullisen käyttökelpoisuuden luokittaminen. Publications of Water and Environment Administration No. 20, Helsinki.

Nehring, D. \& Matthaus, W. 1991. Current trends in hydrographic and chemical parameters and eutrophication in the Baltic Sea. Int. Revue ges. Hydrobiol. 76: 297316.

Niemi, A. 1973. Ecology of phytoplankton in the Tvärminne area, SW coast of Finland. I. Dynamics of hydrography, nutrients, chlorophyll $a$ and phytoplankton. Acta Bot. Fennica 100: 1-68.

Niemi, Å. 1988. Exceptional mass occurrence of Microcystis aeruginosa (Kützing) Kützing (Chroococcales, Cyanophyceae) in the Gulf of Finland in autumn 1987. Mem. Soc. Fauna Flora Fennica 64: 165-167.

Niemi J.S., Niemi R.M., Malin V. \& Poikolainen M.-L. 1997. Bacteriological quality of Finnish rivers and lakes. Environ. Toxicol Water Qual. 12:15-21.

Niemi, J., Heinonen, P., Mitikka, S. Vuoristo, H., Pietiläinen, O-P., Puupponen, M. \& Rönkä, E. 2000. The Finnish EUROWATERNET: The European agencys monitoring network for Finnish inland waters. The Finnish Environment 445, 62 p.

Norha, T. 1998. Helsingin ja Espoon merialueen pohjaeläimistö vuonna 1997. In: Pesonen, L. (ed.). Helsingin ja Espoon merialueiden velvoitetarkkailu vuonna 1997. Helsingin kaupungin ympäristökeskuksen julkaisuja 4/98. p 71-86. 
Norkko, A. \& Bonsdorff, E. 1996a. Rapid zoobenthic community responses to accumulations of drifting algae. Mar. Ecol. Prog. Ser. 131:143-157.

Norkko, A. \& Bonsdorff, E. 1996b. Rapid zoobenthic community responses to accumulations of drifting algae. Mar. Ecol. Prog. Ser. 131:143-157.

Oravainen, 1996. Vuosiyhteenveto Kokemäenjoen ja Porin edustan merialueen yhteistarkkailusta vuodelta 1995. Kokemäenjoen vesistön vesiensuojeluyhdistys. 36 p. + app.

Orlova, M.I., Anokhina, L.E., Panov, V.E., Nekrasov, A.Y. \& Klimentenok, S.N. 1999. Preliminary environmental state assessment for littoral zone in resort district of St. Petersburg (Eastern Gulf of Finland). BFU (Baltic Floating University) Research Bulletin. 3: 37-42.

Owens, J.W. \& Lehtinen, K-J. 1995. Assessing the potential impacts of pulping and bleaching operations on the aquatic environment-TAPPI book series.

Paavilainen, K., Tana, J., Kovanen, V. \& Pogreboff, S. 1985. OY Metsä-Botnia AB, Kaskinen 1985. Tutkimus jätevesien vaikutuksista merialueen veden laatuun ja kalatalouteen Oy Keskuslaboratorio - Centrallaboratorium Ab.

Paavilainen, K., Langi, A. \& Tana, J. 1985. Effect of pulp and paper mill effluents on a fishery in the Gulf of Finland. Finnish Fish. Res. 6: 81-91.

Palm, H. \& Lammi, R. 1995. Fate of pulp mill organochlorines in the Gulf of Bothnia sediments. Environment Science and Technology. 29: 1722-1727.

Parmanne, R. 1999. The spawning time and composition of spawning shoals according to trapnet fishing of Baltic herring. Kalatutkimuksia 159, 41 pp. (in Finnish with English summary).

Partanen, P. 1993. Pohjaeläintutkimukset Konnivedellä, Kymijoella sekä Pyhtään, Kotkan ja Haminan merialueilla v. 1992. Kymijoen vesiensuojeluyhdistys. 39 p. + app.

Patrikainen, M. 1991. Sedimentin ja pohjaeläimien titaani- ja vanadiinipitoisuudet Porin edustan merialueella 1989-90. - Kokemäenjoen vesistön vesiensuojeluyhdistys ry.

Perttilä, M., Savchuck, O. \& Sphaer, I. 1996. Gulf of Finland, Hydrochemistry. HELCOM, 1996. Third periodic assessment of the state of the marine environment of the Baltic Sea, 1989-1993; Background document. Baltic Sea Environ. Proc. 64B: 48-51.

Perttilä, M. \& Brygman, L. 1992. Review of contaminants on Baltic sediments. ICES Coop. Res. Rep. 180.

Pesonen, L. 1999 (toim.). Helsingin ja Espoon merilaueiden velvoitetarkkailu vuonna 1998. Helsingin kaupungin ympäristökeskuksen monisteita 5/99. 81+ 4 app.

Pesonen, L. 1998 (toim.). Helsingin ja Espoon merialueiden velvoitetarkkailu vuonna 1997. Helsingin kaupungin ympäristökeskuksen julkaisuja 4/98. 101+ 4 app.

Pesonen, L., Norha, T., Rinne, I., Viitasalo, I. \& Viljamaa, H. 1995. Helsingin ja Espoon merialueiden velvoitetarkkailu vuosina 1987-1994. Helsingin kaupungin ympäristökeskuksen monisteita 1. 143 p. + app.

Piiroinen, O. 1987. Kokemäenjoen alajuoksun yhteistarkkailu. Haukien elohopeapitoisuudet ja sedimentin raskasmetallipitoisuudet Kokemäenjoessa ja Pihlavanlahdella. 1985. Kokemäenjoen vesistön Vesiensuojeluyhdistys r.y.

Piiroinen, O. 1992a. Kokemäen alajuoksun yhteistarkkailu. Sedimentin metallipitoisuudet Kokemäenjoessa, Pihlavanlahdella ja Ahlaisten saaristossa 1991. Kokemäenjoen vesistön Vesiensuojeluyhdistys ry.

Piiroinen, O. 1992b. Kokemäen ja sen edustan merialueen kalataloudellinen tarkkailu: Kirjanpitokalastus 1989-90 ja haukien elohopeapitoisuudet 1991. Kokemäenjoen vesistön Vesiensuojeluyhdistys ry julkaisu nro 255.

Piiroinen, O. 1995. Kokemäenjoen ja sen edustan merialueen kalataloudellinen tarkkailu: kirjanpitokalastus 1993-1994 ja haukien elohopeapitoisuudet 1993-1994.

Kokemäenjoen vesistön Vesiensuojeluyhdistys ry.

Pitkänen, H. 1991. Nutrient dynamics and trophic conditions in the eastern Gulf of Finland: The regulatory role of the Neva estuary. Aqua Fennica 21: 105-115.

Pitkänen, H. 1994. Eutrophication of the Finnish coastal waters: Origin, fate and effects of riverine nutrient fluxes. National Board of Waters and the Environment, Finland. Publications of the Water and Environment Research Institute, no. 18:1-44. 
Pitkänen, H., Kangas, P., Miettinen, V. \& Ekholm, P.1987. The state of the Finnish coastal waters in 1979-83. National Board of Waters and the Environment, Finland. Publications of the Water and Environment Administration, no. 8, 167 p.

Pitkänen, H., Kangas, P., Sarkkula, J., Lepistö, L., Hällfors, G. \& Kauppila, P. 1990. Veden laatu ja rehevyys itäisellä Suomenlahdella. Raportti vuosien 1987-88 tutkimuksista. Vesi- ja Ympäristöhallitus, Vesi- ja ympäristöhallinnon julkaisuja - sarja A, no 50, 137 s. (with an English summary)

Pitkänen, H., Tamminen, T., Kangas, P., Huttula, T., Kivi, K., Kuosa, H., Sarkkula, J., Eloheimo, K., Kauppila, P. \& Skakalsky, B. 1993. Late summer trophic conditions in the northeast Gulf of Finland and the River Neva Estuary, Baltic Sea. Estuarine, Coastal and Shelf Sci. 37: 453-474.

Pitkänen, H. \& Tamminen, T. 1995. Nitrogen and phosphorus as production limiting factors in the estuarine waters of the eastern Gulf of Finland. Mar. Ecol. Prog. Ser. 129: 283-294.

Pitkänen, H., Kondratyev, S., Lääne, A., Gran, V., Kauppila, P., Loigu, E., Markovets, I., Pachel, K. \& Rumyantsev, V. 1997. Pollution load on the Gulf of Finland from Estonia, Finland and Russia in 1985-1995. In: J. Sarkkula (ed.). Proceedings of the Final Seminar of the Gulf of Finland Year 1996, March 17-18, 1997 Helsinki. Suomen Ympäristökeskuksen moniste 105: 9-18.

Pitkänen, H. \& Välipakka, P. 1997. Extensive deep water oxygen deficit and bethic phosphorus release in the Eastern Gulf of Finland in late summer 1996. In: J. Sarkkula (ed.). Proceedings of the Final Seminar of the Gulf of Finland Year 1996, March 17-18, 1997 Helsinki. Suomen Ympäristökeskuksen moniste 105: 51-59.

Pouchet, G. \& de Guerne, J. 1885. Sur la faune pélagique de la mer Baltique et du Golfe de Finlande. Comptes rend. des séances de l'Académie des Sciences 100: 919-921.

Pulliainen, E., Korhonen, K. \& Huuskonen, M. 1999. Perämeren mateiden sukurauhasten kehityshäiriöt. Ongelman laajuus ja yhteydet muiden kalojen lisääntymishäiriöihin. Suomen ympäristö No. 322.

Puomio, E.-R. \& Braunschweiler, S. 1993. Uudenmaan ja Etelä-Hämeen vesistöjen tila 1990luvun alussa. National Board of Waters and the Environment Report No. 501, Helsinki.

Puomio E.-R., Soininen J. \& Takalo S. 1999. Uudenmaan ja Itä-Uudenmaan vesistöjen tila 1990-luvun puolivälissä. Regional Environmental Publications 128. Uusimaa Regional Environment Centre, Helsinki.

Purasjoki, K. 1935. Merilevien vertikaalisesta esiintymisestä Tvärminnessä. - Master thesis. Univ. of Helsinki. 118 pp. (In Finnish).

Pönni, J. 1998a. Silakka (Baltic herring). Official Statistics of Finland, SVT Environment 1998:13: 2-6.

Pönni, J. 1998b. Kilohaili (Sprat). Official Statistics of Finland, SVT Environment 1998:13: 7-9.

Raita, A. \& Silvonen, J. 1997. Loviisan voimalaitos. Jäähdytys- ja jätevesien tarkkailuraportti 1996. Imatran voima Oy. 13 p. + app.

Rajasilta, M., Eklund, J., Kääriä, J. \& Ranta-Aho, K. 1989. The deposition and mortality of the eggs of the Baltic herring, Clupea harengus membras L., on different substrates in the south-west archipelago of Finland. J. Fish Biol. 34: 417-427.

Rantajärvi, E. (ed.) 1998. Phytoplankton blooms in the Finnish sea areas and in the Baltic Proper during 1997. Meri - Report Series of the Finnish Institute of Marine Research 36: 5-8.

Rantala, L. 1997a. Tornion tehtaiden velvoitetarkkailu v. 1996. I Kuormitus. PSV-Maa ja Vesi. 9 p. + app.

Rantataro, J. 1992. pääkaupunkiseudun edustan vedenalaisen maa-ainesvarojen kartoitus. Helsingin seutukaavaliiton julkaisuja C31. 84 p. +app.

Rask, M. 1989. A note on the diet of roach, Rutilus rutilus L., and other cyprinids at Tvärminne, northern Baltic Sea. Aqua Fennica 19: 19-27. 
Rekolainen, S. 1989. Phosphorus and nitrogen load from forest and agricultural areas in Finland. Aqua Fennica 19: 95-107.

Rekolainen, S., Pitkänen, H., Bleeker, A. \& Felix, S. 1995. Nitrogen and phosphorus fluxes from Finnish agricultural areas to the Baltic Sea. Nordic Hydrology 26: 55-72.

Roots, O. 1996. Toxic chlororganic compounds in the ecosystem of the Baltic Sea. Eesti Vabariigi Keskonnaministeerium. Tallinn. 1996.

Ruuskanen, A. \& Bäck, S. 1999. Does environmental stress affect fertility and frond regeneration of Fucus vesiculosus? Ann. Bot. Fennici 36: 285-290.

Ryther, J.H. \& Dunstan, W.M. 1971. Nitrogen, Phosphorus and eutrophication in the coastal marine environment. Science 171: 1008-1013.

Räinä, P., Kauppinen, V., Kantola, L. \& Viitanen, P. 1991. Kaskisten edustan merialueen velvoitetarkkailu 1990. Pohjois-Suomen vesitutkimustoimisto. 70 p. + app.

Räisänen, R. 1997. Turun merialueen pohjaeläintutkimus vuonna 1995. Lounais-Suomen vesiensuojeluyhdistys ry. Tutkimusselosteita 119.49 p. + app.

Räisänen, R. \& Jumppanen, K. 1996. Turun ympäristön merialueen tarkkailututkimus vuonna 1995. Vuosiyhteenveto. Lounais-Suomen vesiensuojeluyhdistys. Tutkimusselosteita 117. 66 p. + app.

Räisänen, M., \& Viljamaa, H. 1998. Kasviplanktonin lajisto ja biomassa sekä a-klorofylli. In: L. Pesonen (toim.). Helsingin ja Espoon merialueiden velvoitetarkkailu vuonna 1996. Helsingin kaupungin ympäristökeskuksen julkaisuja 4/98. Helsinki 1998, 101 p.+ 4 app.

Rönnberg \& Mathiesen 1997. Long-term changes in the marine macroalgae of Lågskär, Åland sea (N Baltic). Nord. J. Bot. 18: 379-384.

Rönnberg, O. 1991. Förändringar i bottenvegetationen i åländska skärgårdsvatten. Mem. Soc. Fauna Flora Fennica 67:102-106.

Rönnberg, O., Lehto, J. \& Haahtela, I. 1985. Recent changes in the occurrence of Fucus vesiculosus L. in the archipelago Sea SW Finland. Ann. Bot. Fennici 22:231-244.

Salemaa, H. \& Hietalahti, V. 1993. Hemimysis anomala G.O. Sars (Crustacea: Mysidacea) Immigration of a Pontocaspian mysid into the Baltic Sea. Ann. Zool. Fennici 30: 271-276.

Sanden, P., Pitkänen, H. \& Eloheimo, K. 1996. Gulf of Bothnia, Hydrochemistry. In: HELCOM 1996. Third periodic assessment of the state of the marine environment of the Baltic Sea, 1989-1993; Background document. Baltic Sea Environ. Proc. 64B: 29-38.

Saulamo, K. \& Lehtonen, H. 1998. Vimman biologia ja vimpakantojen tila Suomen rannikoilla. Kala- ja riistaraportteja 130, 29 pp. (in Finnish).

Sternbeck, J., Skei, J., Verta, M. \& Östlund, P. 1999. Mobilisation of sedimentary trace metals following improved oxygen conditions - an assessment of the effects of a lower primary productivity on trace metal cycling in the Baltic Sea. TemaNord 1999;594. Copenhagen, Nordic Council of Ministers.

Stigzelius, J., Kangas, P. \& Andersin, A.-B. 1998. Long-term changes in soft bottom macrofauna in the Tvärminne area, Northern Baltic Sea. In prep.

Stigzelius, J., Laine, A., Rissanen, J., Andersin, A.-B. \& Ilus, E. 1997. The introduction of Marenzelleria viridis (Polychaeta, Spionidae) into the Gulf of Finland and the Gulf of Bothnia (northern Baltic Sea). Ann. Zool. Fennici 34:205-212.

Sunila, I. 1981. Reproduction of Mytilus edulis L. (Bivalvia) in a brackish water area, the Gulf of Finland. Ann. Zool. Fennici 18:121-128.

Swedish EPA. 1991. Metaller i Svenska Havsområden. Swedish Environmental Protection Agency, report 3696. (In Swedish).

Södergren, A. 1989. Biological effects of bleached pulp mill effluents. Final report from the Environment/ Cellulose I Project., National Swedish Environmental Protection Board. REPORT 3558.

Talsi, T. 1987. Porvoon edustan merialueen tila ja sen kehitys vuosina 1965-1984. Vesi- ja Ympäristöhallinnon julkaisuja no 5,172 p.

Tamminen, T. 1990. Eutrophication and the Baltic Sea: Studies on phytoplankton, bacterioplankton, and pelagic nutrient cycles. Academic disertation. Helsingfors. 22 p.

Tamminen, T. \& Kivi, K. (toim.) 1996. Typpikuormitus, ravinnekierrot ja rannikkovesien rehevöityminen. PELAG III loppuraportti. $76 \mathrm{~s}$. 
Tarrason, L. \& Schaug, J. 1999. Transboundary Acid Deposition in Europe. EMEP Summary Report 1999. EMEP Report 1/99.

Vahteri, P. 1997. Kemira Pigments Oy. Porin edustan merialueen pohjaeläintarkkailu v. 1995 ja 1996. Kokemäenjoen vesistön vesiensuojeluyhdistys. 21 p. + app.

Valovirta,I. \& Porkka, M. 1996. The distribution and abundance of Dreissena polymorpha (Pallas) in the eastern Gulf of Finland. Mem. Soc. Fauna Flora Fennica 72:63-78.

Varmo, R. \& Riiheläinen, T. Pohjaeläimistö ja pohjasedimentti Helsingin ja Espoon merialuilla vuonna 1991. Helsingin kaupungin ympäristökeskuksen julkaisuja $10 / 94$.

Vartiainen, T., Parmanne, R. \& Hallikainen, A. 1997. Ympäristömyrkkyjen kertyminen silakkaan. Ympäristö ja Terveyslehti 7-8/97:18-22.

Verta, M., Korhonen, M., Lehtoranta, J., Salo, S., Vartiainen, T., Kiviranta, H., Kukkonen, J., Hämäläinen, H., Mikkelson, P. \& Palm, H. 1999a. Ecotoxicological and health effects caused by PCP's, PCDE's, PCDD's and PCDF's in river Kymijoki sediments, SouthEastern Finland. Organohalogen Compounds 43:239-242.

Verta, M., Lehtoranta, J., Salo, S., Korhonen, M. \& Kiviranta, H. 1999b. High concentrations of PCDD's and PCDF's in river Kymijoki sediments, South-Eastern Finland, caused by wood preservative Ky-5. Organohalogen Compounds 43: 261264.

Verta, M., Ahtiainen, J., Hämäläinen, H., Jussila, H., Kiviranta, H., Korhonen, M., Kukkonen, J., Lehtoranta, J., Lyytikäinen, M., Malve, O., Mikkelson, P., Moisio, V., Niemi, A., Paasivirta, J., Palm, H., Rantalainen, A-L., Salo, S., Vartiainen, T. \& Vuori, K-M. 1999c. Organoklooriyhdisteet ja raskasmetallit Kymijoen sedimentissä; esiintyminen, kulkeutuminen, vaikutukset ja terveysriskit. Suomen ympäristö 334.

Villa, L. 1989. Sedimentin öljypitoisuus Porvoon edustan merialueella 1987. Helsingin vesi- ja ympäristöpiiri. Raportti. 5 p.

Voipio, A. 1969. On the cycle and balance of phosphorus in the Baltic Sea. Suomen Kemistilehti 42: 48-54.

Vuorinen, P., Paasivirta, J., Vuorinen, M., Peuranen, S. \& Hoikka, J. 1993. Lohen ja meritaimenen ympäristömyrkkypitoisuudet ja lohen alkio- ja poikaskuolleisuus. Kalatutkimuksia 65: 71 p. Riista- ja kalatalouden tutkimuslaitos.

Vuorinen, P.J., Paasivirta, J., Keinänen, M., Koistinen, J., Rantio, T., Hyötyläinen, T. \& Welling, L. 1997. The M74 syndrome of Baltic salmon (Salmo salar) and organochlorine concentrations in the muscle of female salmon. Chemosphere 34, p. 1151-1166.

Vuoristo, H. 1998. Water quality classification of Finnish inland waters. European Water Management Vol. 1, No. 6.

Vuoristo, H. 1991. Pintavesien yleinen käyttökelpoisuus 1980-luvun alussa. National Board of Waters and the Environment Report No. 327, Helsinki.

Välipakka, P., Antsulevich, A., Vaittinen, J. \& Taskinen, J. 1997. The zebra mussel (Dreissena polymorpha) - a new important element in the fauna of Finland. - Abstracts of the BMB 15 and ECSA 27 Symposium, Mariehamn, Finland, 9-13 June 1997. p.76

Westerbom, M. 1999. Populationsstruktur och tillväxthastighet hos sex blåmusslepopulationer i norra Östersjön: ett spatiellt och temporalt perspektiv. Pro-gradu (69s.) Institutionen för ekologi och systematik, Helsingfors Universitet.

Wiik, T. 1999. Merialueen kuha (Pikeperch in coastal waters). Official Statistics of Finland, SVT Agriculture, Forestry and Fishery 1999:4, p. 33-35.

Wiik, T. \& Kuikka, S. 1998. Merialueen kuha (Pikeperch in coastal waters). Official Statistics of Finland, SVT Environment 1998:13, p. 42-45.

Ådjers, K., Böhling, P., Kangur, M. \& Neuman, E. 1997. Monitoring in Baltic Coastal Reference Areas 1996. Composition of Fish Communities. Kala- ja riistaraportteja nro 90, 21 pp.

Öst, M. \& Kilpi, M. 1997. A recent change in size distribution of blue mussels (Mytilus edulis) in the western part of the Gulf of Finland. Ann. Zool. Fennici 34:31-36.

Östlund, P., Sternbeck, J. \& Brorström-Lundén, E. 1998. Metaller, PAH, PCB och totalkolväten i sediment runt Stockholm- flöden och halter. IVL Rapport B 1297. 


\begin{tabular}{|c|c|}
\hline Publisher & Finnish Environment Institute \\
\hline Author(s) & Kauppila, Pirkko and Bäck, Saara (eds) \\
\hline Title of publication & The state of Finnish coastal waters in the $1990 \mathrm{~s}$ \\
\hline $\begin{array}{l}\text { Parts of publication/ } \\
\text { other project } \\
\text { publications }\end{array}$ & $\begin{array}{l}\text { The publication is also available in the internet } \\
\text { http://www.vyh.fi/palvelut/julkaisu/elektro/fe } 472 / \mathrm{fe} 472 . \mathrm{htm}\end{array}$ \\
\hline Abstract & 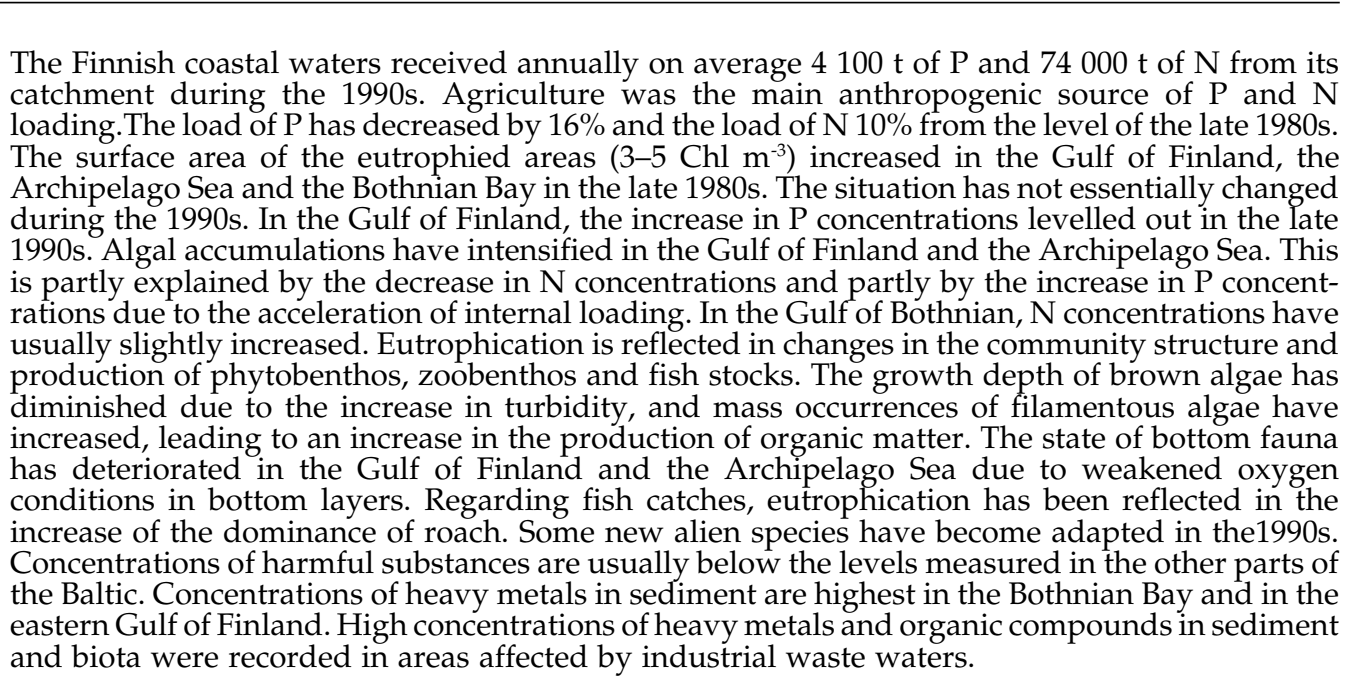 \\
\hline
\end{tabular}

\begin{tabular}{l|l}
\hline Keywords &
\end{tabular}

Baltic Sea, coastal waters, loading, eutrophication, harmful substances, environmental changes

\begin{tabular}{|c|c|c|}
\hline $\begin{array}{l}\text { Publication series } \\
\text { and number }\end{array}$ & The Finnish Environment 472 & \\
\hline Theme of publication & Environmental protection & \\
\hline $\begin{array}{l}\text { Project name and } \\
\text { number, if any }\end{array}$ & & \\
\hline $\begin{array}{l}\text { Financier/ } \\
\text { commissioner }\end{array}$ & Finnish Environment Institute & \\
\hline Project organization & & \\
\hline & ISSN & ISBN \\
\hline & $1238-7312$ & $952-11-0878-9$ \\
\hline & No. of page & Language \\
\hline & 134 & English \\
\hline & Restrictions & Price \\
\hline & For public use & 231 FIM \\
\hline
\end{tabular}

For sale at/

distributor

Edita Ltd, tel. +358 9566 0266, fax +358 95660380

Oy Edita Ab, Asiakaspalvelu, Pl 800, 00043 Edita, Finland

e-mail: asiakaspalvelu@edita.fi

www-server: http://www.edita.fi/netmarket

Financier

of publication

Finnish Environment Institute, P.O. Box 140, FIN-00251 Helsinki, Finland

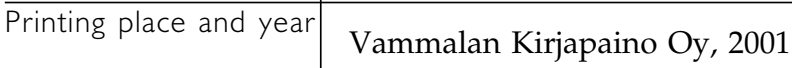




\begin{tabular}{|c|c|}
\hline Julkaisija & $\begin{array}{l}\text { Julkaisuaika } \\
\text { Maaliskuu } 2001\end{array}$ \\
\hline Tekijä(t) & Kauppila, Pirkko ja Bäck, Saara (toim.) \\
\hline Julkaisun nimi & Suomen rannikkovesien tila 1990-luvulla \\
\hline $\begin{array}{l}\text { Julkaisun osat/ } \\
\text { muut saman projektin } \\
\text { tuottamat julkaisut }\end{array}$ & $\begin{array}{l}\text { Julkaisu on saatavana myös internetistä } \\
\text { http://www.vyh.fi/palvelut/julkaisu/elektro/fe472/fe472.htm }\end{array}$ \\
\hline Tiivistelmä & $\begin{array}{l}\text { Suomen rannikkovedet vastaanottivat } 1990-\text { luvulla valuma-alueeltaan keskimäärin } 4100 \text { tonnia } \\
\text { fosforia ja } 74000 \text { tonnia typpeä vuodessa. Maatalous oli suurin yksittäinen typen ja fosforin } \\
\text { kuormituslähde. Fosforin kuormitus on pienentynyt } 1980-l u v u n \text { loppuun verrattuna reilut } 16 \% \\
\text { ja typen kuormitus noin } 10 \% \text {. Rehevöityneiden alueiden (3-5 mg Chl m³) pinta-ala kasvoi } 1980- \\
\text { luvun lopulla Suomenlahdella, Saaristomerellä ja Perämerellä. Tilanne ei ole oleellisesti muuttunut } \\
\text { 1990-luvulla. Eräiden voimakkaasti kuormitettujen alueiden rehevyys on vähentynyt kuormituk- } \\
\text { sen pienentymisen seurauksena. Suomenlahdella fosforipitoisuuksien kasvu taittui vuosikymme- } \\
\text { nen lopulla. Kasviplanktonkukinnot ovat voimistuneet Suomenlahdella ja Saaristomerellä. Tämä } \\
\text { johtuu osittain typpipitoisuuksien vähentymisestä ja osittain fosforipitoisuuksien kasvusta sisäi- } \\
\text { sen kuormituksen kiihtymisen seurauksena. Pohjanlahdella typpipitoisuudet ovat yleensä lievästi } \\
\text { vähentyneet 1990-luvulla. Rehevöityminen näkyy makrolevien ja pohjaeläinten sekä kalakanto- } \\
\text { jen yhdyskuntarakenteen muutoksina. Rakkolevien kasvusyvyys on pienentynyt sameutumisen } \\
\text { vuoksi, ja makroleväyhdyskunnat muuttuneet rihmalevävaltaisiksi. Myös irtonaisina kasvavien } \\
\text { rihmalevien massa-esiintymät ovat lisääntyneet, mikä on nostanut orgaanisen aineksen määrää. } \\
\text { Pohjaneläinten tila on heikentynyt Suomenlahdella ja Saaristomerellä pohjan happiolojen heik- } \\
\text { kenemisen seurauksena. Kalakannoissa rehevöityminen on ilmennyt mm. särkivaltaisuuden } \\
\text { lisääntymisenä. Rannikkovesiimme vakiintui uusia tulokaslajeja 1990-luvulla. Haitallisten ainei- } \\
\text { den pitoisuudet jäivät yleensä Suomen rannikkovesissä Itämerestä mitattujen keskiarvojen ala- } \\
\text { puolelle. Raskasmetallien pitoisuudet sedimentissä olivat korkeimmat Perämerellä ja Suomenlah- } \\
\text { den itäosissa. Korkeita raskasmetallien ja orgaanisten yhdisteiden pitoisuuksia sedimentistä ja } \\
\text { eliöstöstä tavattiin teollisuuden jätevesien vaikutuspiirissä. }\end{array}$ \\
\hline
\end{tabular}

\begin{tabular}{|c|c|}
\hline Asiasanat & Itämeri, rannikkovedet, kuormitus, rehevöityminen, haitalliset aineet, ympäristömuutokset \\
\hline $\begin{array}{l}\text { Julkaisusarjan nimi } \\
\text { ja numero }\end{array}$ & Suomen ympäristö 472 \\
\hline Julkaisun teema & Ympäristönsuojelu \\
\hline $\begin{array}{l}\text { Projektihankkeen nimi } \\
\text { ja projektinumero }\end{array}$ & \\
\hline $\begin{array}{l}\text { Rahoittaja/ } \\
\text { toimeksiantaja }\end{array}$ & Suomen ympäristökeskus \\
\hline & $\begin{array}{ll}\text { ISSN } & \text { ISBN } \\
1238-7312 & 952-11-0878-9 \\
\end{array}$ \\
\hline & $\begin{array}{ll}\text { Sivuja } & \text { Kieli } \\
134 & \text { englanti } \\
\end{array}$ \\
\hline & Luottamuksellisuus \\
\hline & julkinen \\
\hline $\begin{array}{l}\text { Julkaisun myynti/ } \\
\text { jakaja }\end{array}$ & $\begin{array}{l}\text { Oy Edita Ab, Asiakaspalvelu, Pl 800, } 00043 \text { Edita } \\
\text { puh. (09) } 566 \text { 0266, telefax (09) } 566 \text { 0380, sähköpostiosoite: asiakaspalvelu@edita.fi } \\
\text { www-palvelin: http://www.edita.fi/netmarket }\end{array}$ \\
\hline Julkaisun kustantaja & Suomen ympäristökeskus, PL 140, FIN-00251 Helsinki \\
\hline Painopaikka ja -aika & Vammalan Kirjapaino Oy, 2001 \\
\hline
\end{tabular}




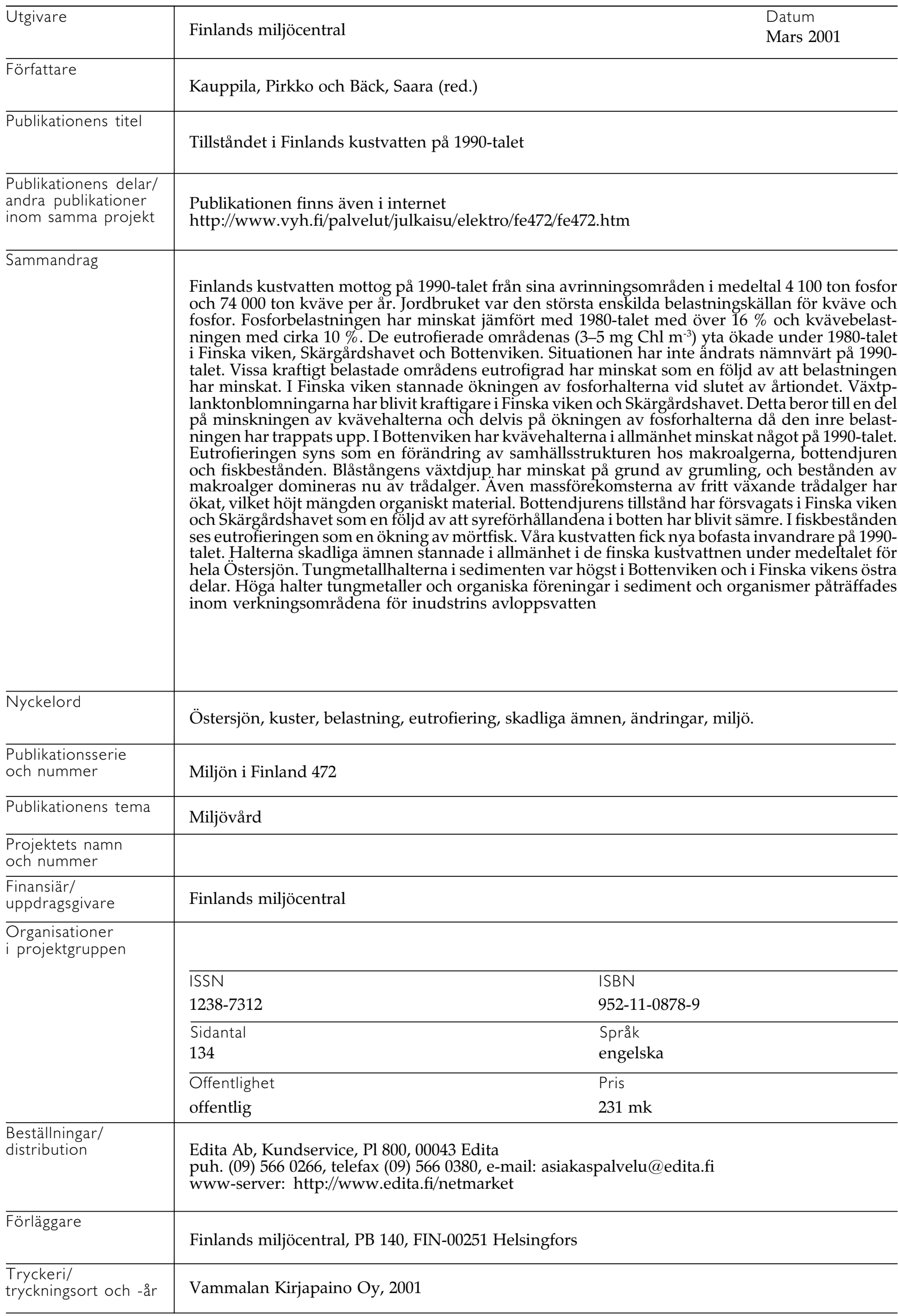




\section{The Finnish Environment}

\section{$-4$ \\ ENVIRONMENTAL PROTECTION}

\section{The state of Finnish coastal waters in the 1990s}

The ecological status of coastal waters still is an important environmental issue. Especially the shallow Finnish coastal zone is in many respects sensitive to pollution and eutrophication. The long term point-source loading of watercourses, especially by nutrients and harmful substances, as well as the indirect effects of increasing demand for different land use e.g agriculture and building activities in catchment areas have had deteriorating effects in many ways.

This report is the second national effort to compile monitoring information on the changes in water quality in Finnish coastal waters. The report is based on the results of different monitoring programmes, loading statistics and studies concerning the state of Finnish coastal water areas. In this report data and information have been collected using the national data bases in which the monitoring data are stored and maintained. In addition to nutrients and harmful substances, monitoring data of phytoplankton and macrozoobenthos are also evaluated. Moreover, the available data on phytobenthos changes originated from separate research projects were evaluated. The report covers the years from the the early 1980s to $1998 / 2000$.

The report cover the following topics

- loading of nutrients and harmful substances originating from different sources

- assessment of the effects of loading on chemical and biological water quality in coastal areas

- assessment of changes in the state of coastal waters during the 1990s and reasons for those

- phytobenthos and macrozoobenthos changes as a measure of the state of coastal waters

- changes in fish populations and fisheries

ISBN 952-11-0878-9

ISSN 1238-7312

EDITA PIC

P.O.Box 800, FIN-00043 EDITA, Finland

Phone + 3582045000

MAIL ORDERS

Phone + 35820450 05, fax + 358204502380

EDITA-BOOKSHOP IN HELSINKI

Annankatu 44, phone 0204502566

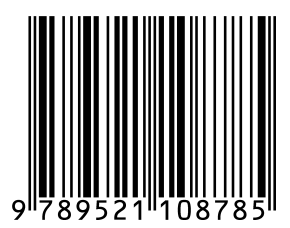

